\title{
THE PROMOTION OF LEARNER AUTONOMY IN THAILAND TERTIARY EDUCATION: \\ LECTURERS' PERSPECTIVES AND PRACTICES
}

BY

PIYAWAN RUNGWARAPHONG

\begin{abstract}
A thesis
submitted to the Victoria University of Wellington

in fulfilment of the requirements for the degree of

Doctor of Philosophy

in Education
\end{abstract}

Victoria University of Wellington

2012 


\begin{abstract}
The study seeks to describe the current state of the promotion of learner autonomy in Thailand, from the perspectives and practices of university language lecturers. The study employed a mixed method approach with emphasis on the qualitative phase. The research was conducted in two sequential phases, a quantitative survey followed by qualitative cases studies. The first phase aimed to investigate the extent to which learner autonomy has been valued by lecturers. The second phase aimed to describe how learner autonomy is currently practiced among Thai lecturers.
\end{abstract}

In the first phase, the survey questionnaire was completed by 297 lecturers who taught foreign languages in universities in Bangkok and the south of Thailand. The survey findings suggest an inconsistency between the lecturers' beliefs and practices. The lecturers reported strong beliefs in learner autonomy, but moderate practices. The lecturers also reported low levels of confidence in their students' ability to be autonomous learners.

Using the survey results, five lecturers were purposely selected to be included in the second, qualitative phase. Data in the second phase were collected through interviews, class observations, follow-up discussions and document analysis. Results show that the lecturers promoted learner autonomy in their class through communication strategies, teaching pedagogy and the learning atmosphere.

The link from Phase 1 to Phase 2 reveals a pathway to the promotion of learner autonomy. The pathway begins with the lecturer beliefs in learner autonomy and ends with the practices of promoting learner autonomy. Along this pathway, the lecturers may experience four main factors that might support or prevent them from promoting learner autonomy. These factors include the lecturer's understanding of the principles of learner autonomy; the organizational climate of their university; student attributes; and the social and educational elements of Thai society.

Finally, the findings of both phases are used to develop a framework for ways to promote learner autonomy in Thailand. This framework includes activities that 
lead to dialogic teaching, shift of responsibility, and power symmetry between lecturers and students. The framework serves as a preliminary guideline for Thai lecturers to promote learner autonomy in their classes. 


\section{Acknowledgements}

I would like to express my great thanks to my mother, who has inspired my love for teaching and provided me with a role model of what a good teacher should be. Her years of teaching children in rural schools in Thailand opened my eyes and my heart to the happiness giving to others can bring. I thank her for all her love and support. Thanks to my father for all the strength and encouragement that he has given to me.

Special thanks to my husband, whose love and support have kept me going through this thesis. I could not have survived the three years that we were forced to be apart without the courage he has been giving to me.

Many thanks from the bottom of my heart to my supervisors, Carolyn Tait and Jeff Sigafoos, for all their hard work. Thanks to Carolyn for taking care of me, not only academically, but also in my personal life. Thanks to Jeff for continuously giving me excellent advice, and guiding me to write in the academic register.

I thank Victoria University of Wellington, who has given me a strong foundation for the rest of my teaching profession.

Thanks to Prince of Songkla University, who gave me the opportunity to pursue this PhD. Without the full funding from PSU I would never have been able to strengthen my professional development.

And finally, many thanks to all my participants, all the Thai lecturers that participated in this study. They have a large share in the success of my thesis. 
Abstract..................................................................................................................ii

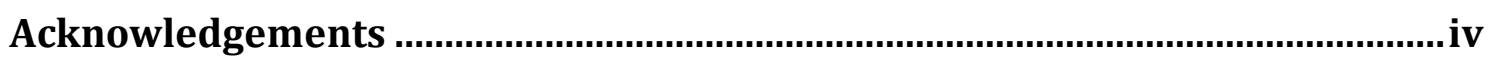

CHAPTER 1: INTRODUCTION ............................................................................... 1

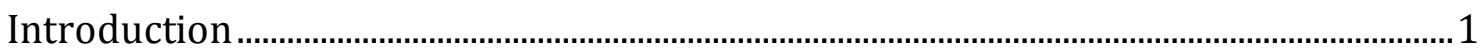

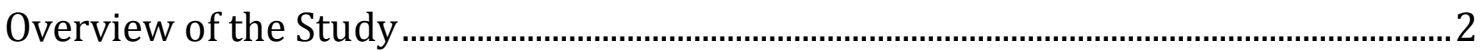

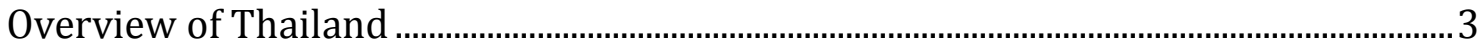

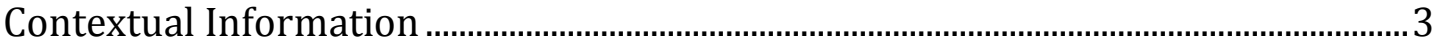

Socio-cultural Perspectives of Thailand ............................................................................... 4

Historical Perspectives of Thai Education........................................................................... 5

The Current Position of Thai Education ........................................................................... 6

Language Education in Thailand..................................................................................

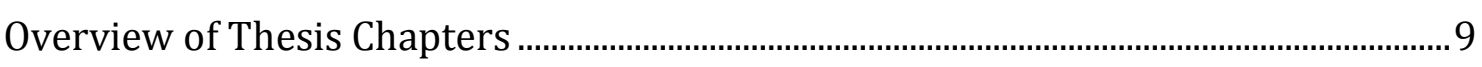

CHAPTER 2: SYSTEMATIC REVIEW OF LITERATURE ..................................... 11

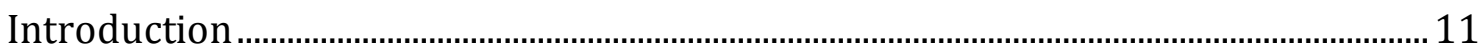

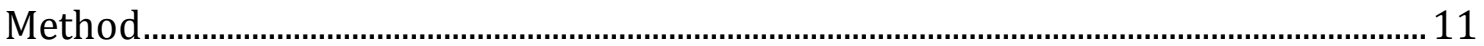

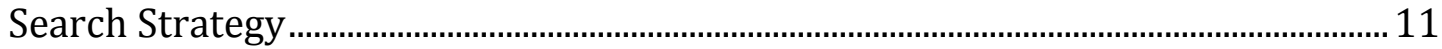

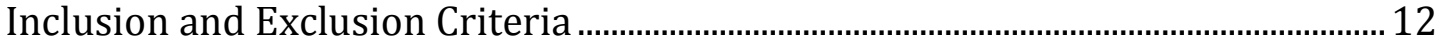

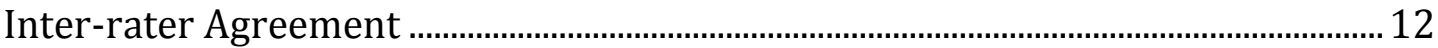

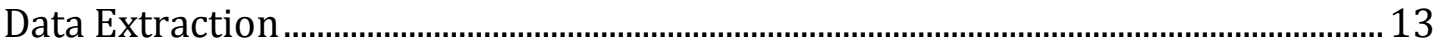

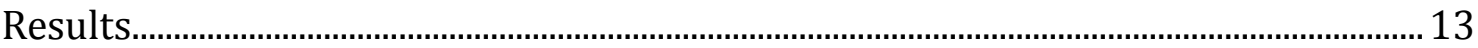

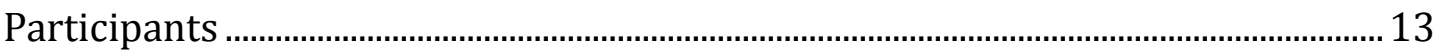

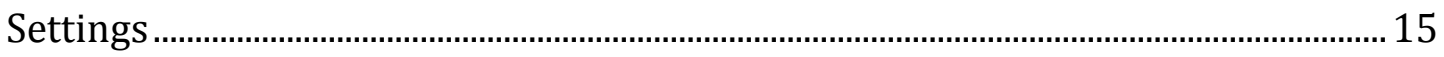

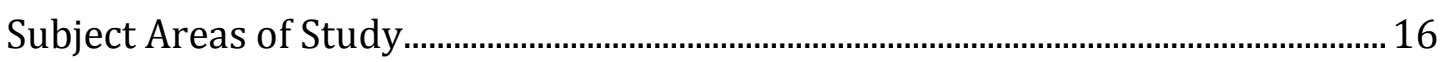

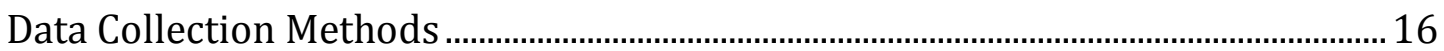

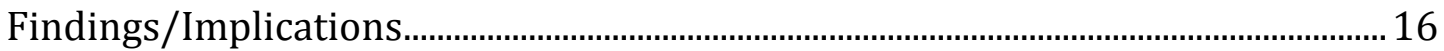

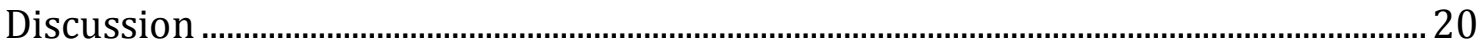

Learners' Beliefs and Perceptions.................................................................................... 21

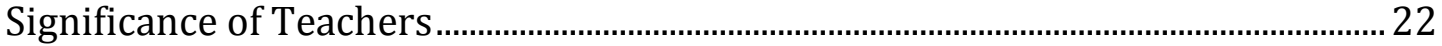

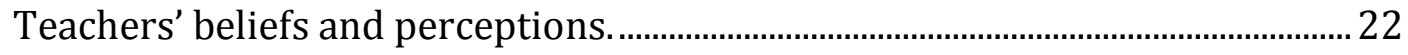

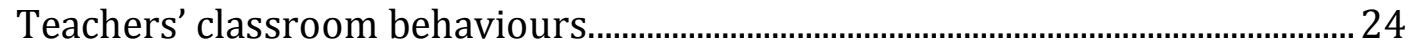

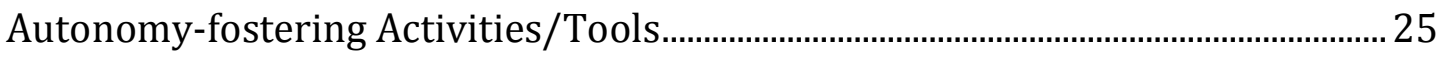

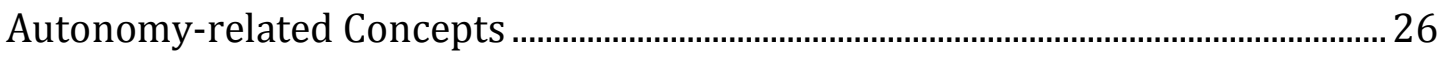

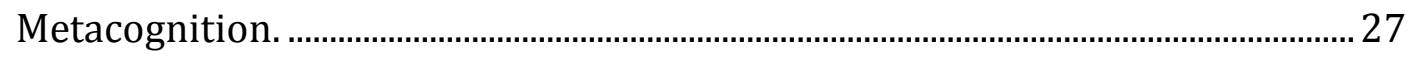

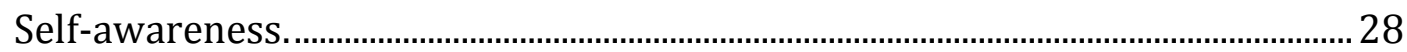

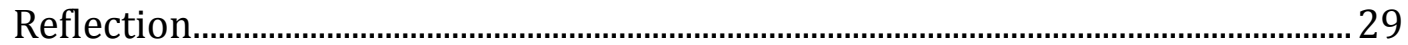

Self-evaluation/assessment. .............................................................................. 30 
CHAPTER 3: THEORITICAL AND METHODOLOGICALFRAMEWORKS

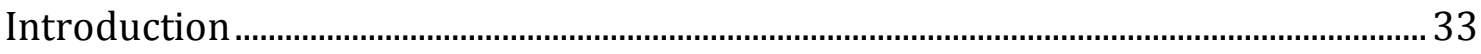

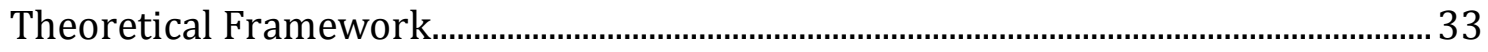

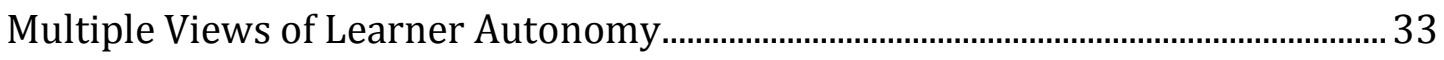

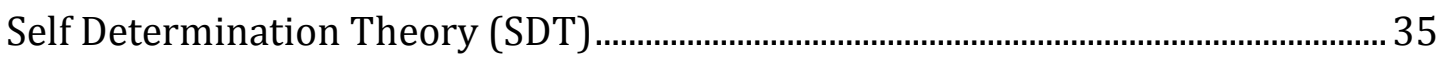

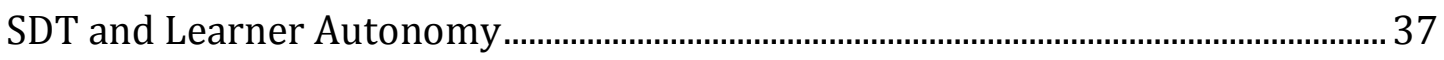

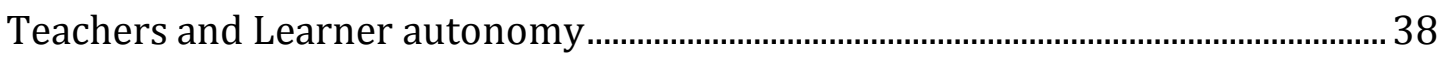

Learner Autonomy in Language Learning.......................................................................... 40

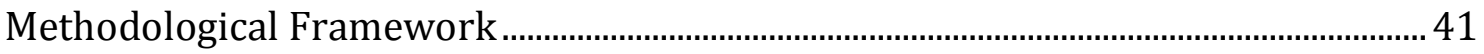

Mixed Methods Research............................................................................................... 41

Justification for the Use of Mixed Methods Research ...................................................... 43

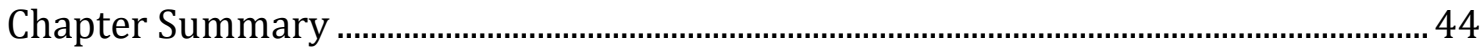

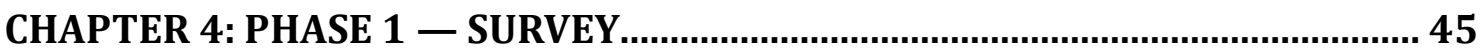

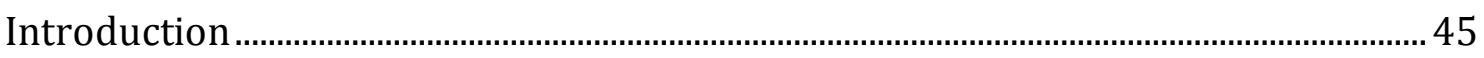

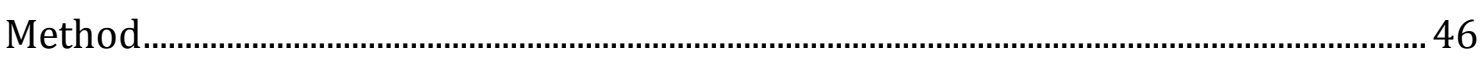

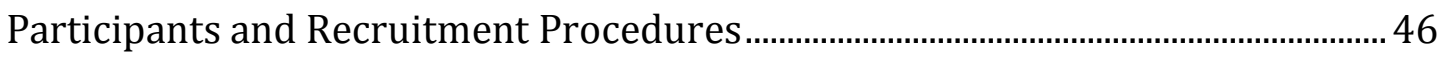

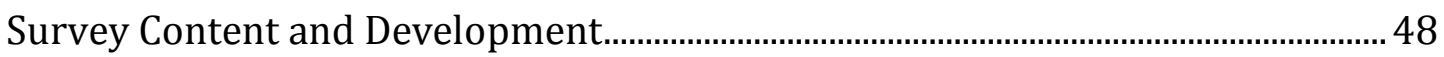

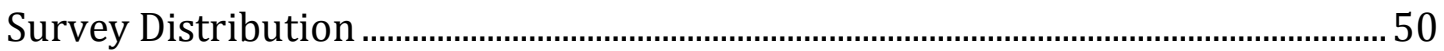

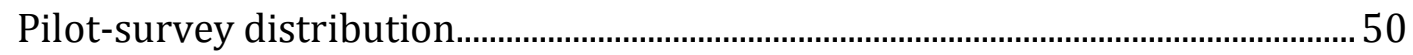

Post-pilot survey distribution. ..................................................................................... 51

Nature of Research in Thai Educational Setting ................................................................ 52

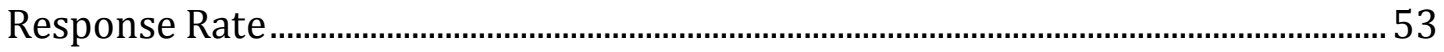

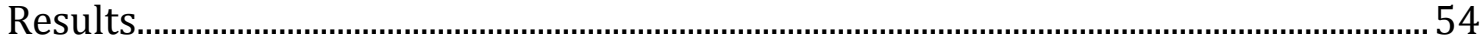

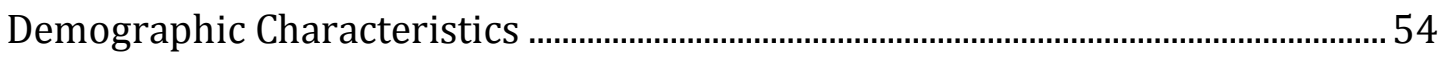

Beliefs about the Nature of Language Learning ……................................................... 57

Perceptions and Practices of Learner Autonomy .......................................................... 58

Beliefs in learner autonomy......................................................................................... 59

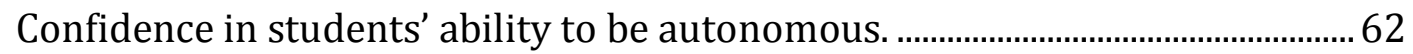

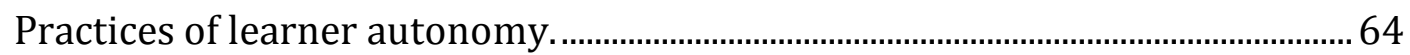

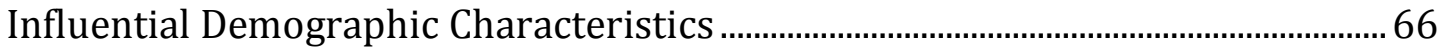

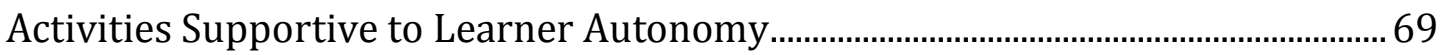

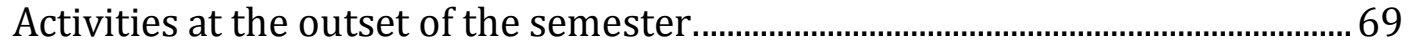

Opportunities for self assessment............................................................................. 71

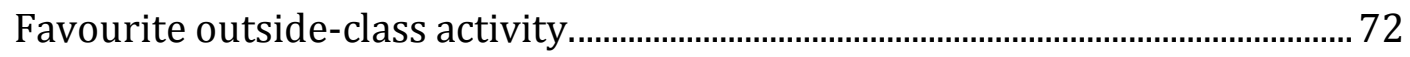

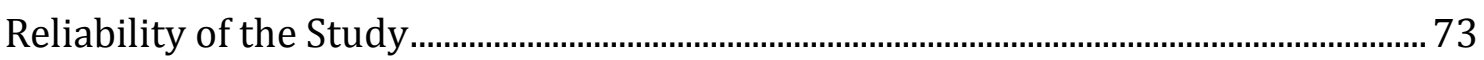




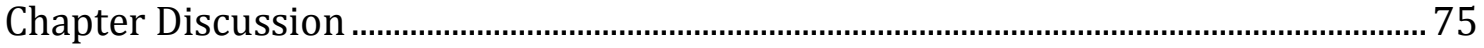

Inconsistency between Beliefs and Practices .................................................................... 75

BA in Education and Beliefs in Learner Autonomy …….................................................. 77

Low Confidence in Students' Abilities ............................................................................ 79

Resistance to Students' Involvement in Decisions about Time and Assessment 80

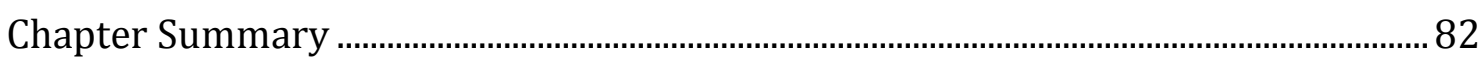

CHAPTER 5: PHASE 2 - CASES STUDIES....................................................... 83

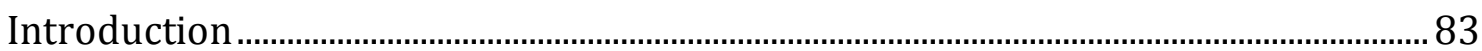

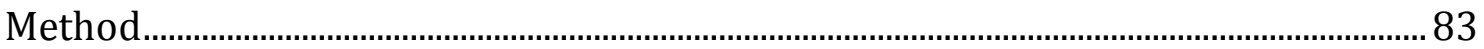

Participants and Selection Procedures ………….............................................................. 84

Explanation of Participant Selection ................................................................................ 86

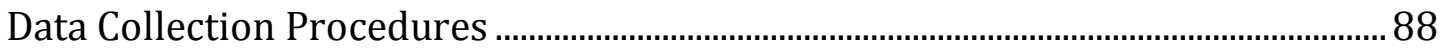

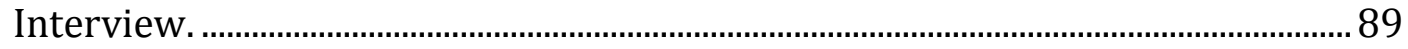

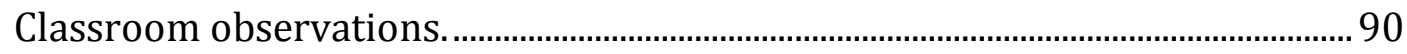

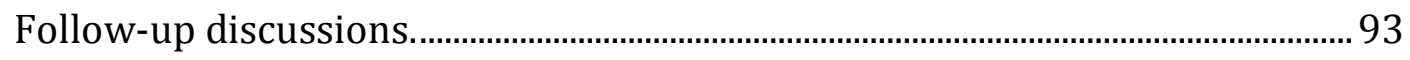

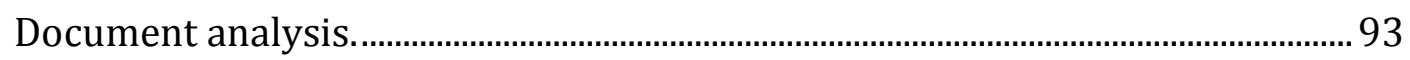

Timeframe for Cases Studies ............................................................................................ 96

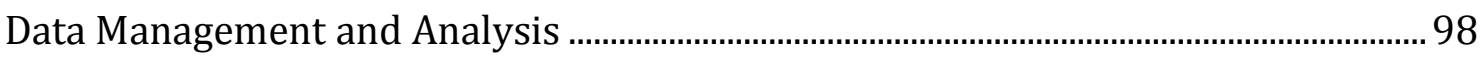

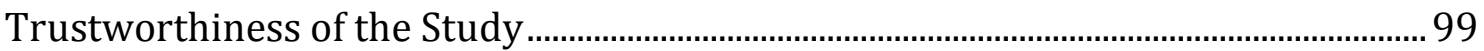

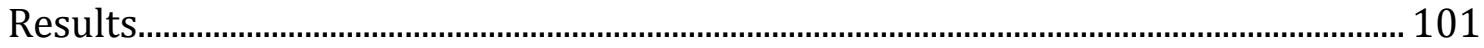

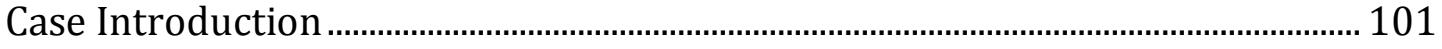

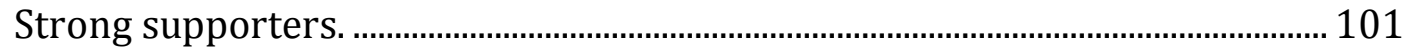

Unconfident supporters. ....................................................................................... 103

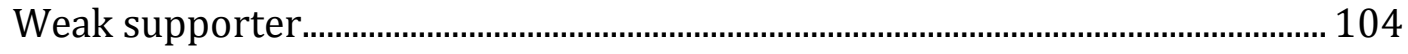

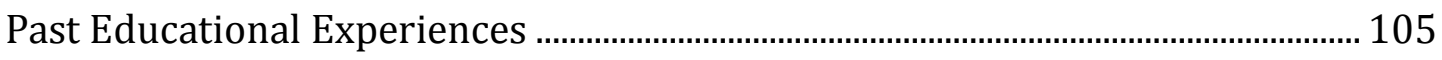

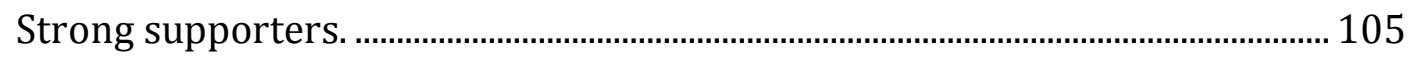

Unconfident supporters. ....................................................................................... 108

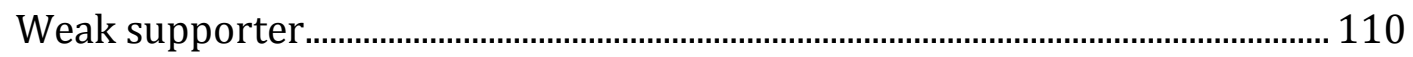

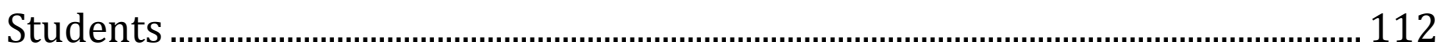

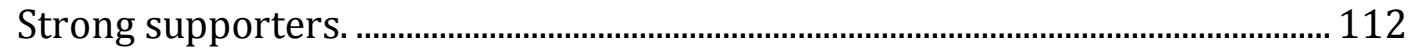

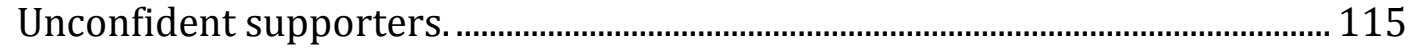

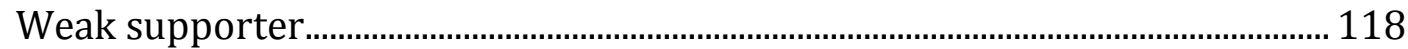

Classroom Physical Environment..................................................................................... 121

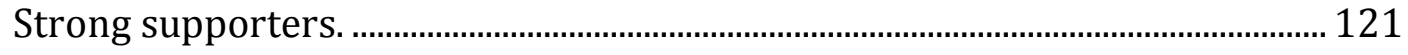

Unconfident supporters. .................................................................................. 124

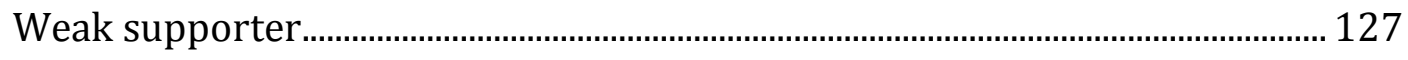


Classroom Practices

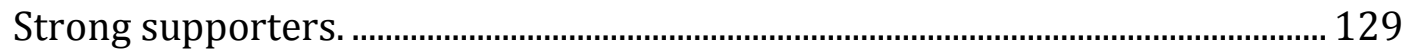

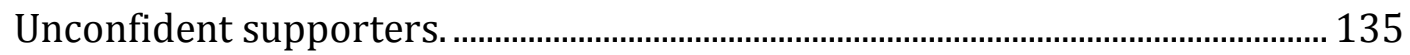

Weak supporter

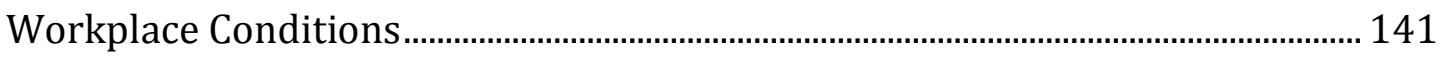

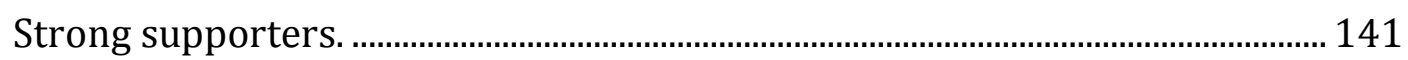

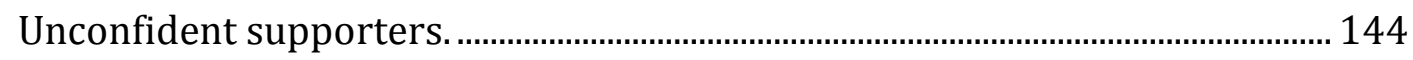

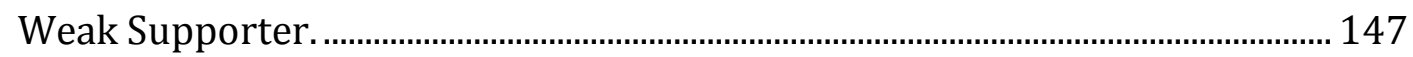

Cultural, Social and Educational Contexts .................................................................... 149

Strong supporters. …............................................................................................ 149

Unconfident supporters. ....................................................................................... 152

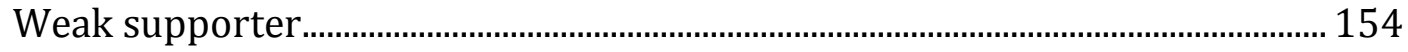

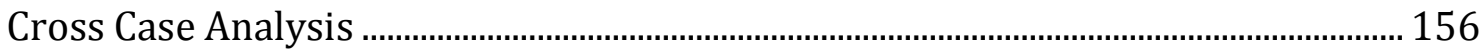

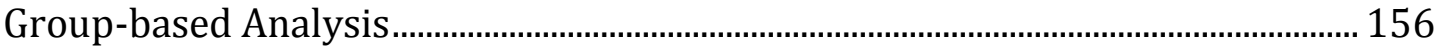

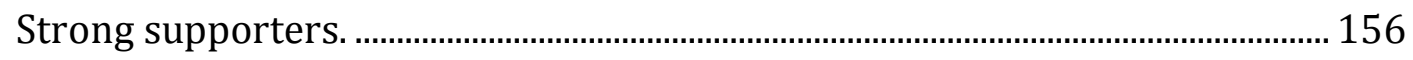

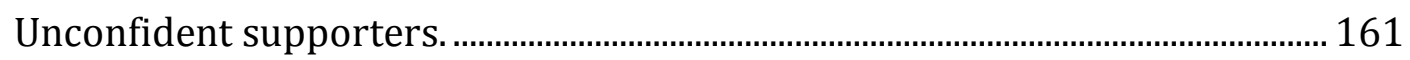

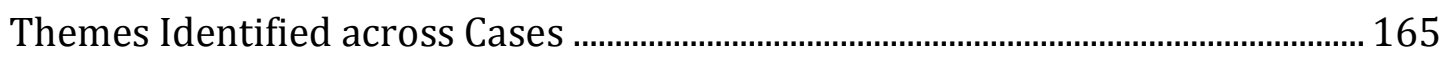

Pedagogic practices. ...................................................................................................... 166

Factors influencing perceptions and practices. ..................................................... 166

Findings from Cross Case Analysis .............................................................................. 168

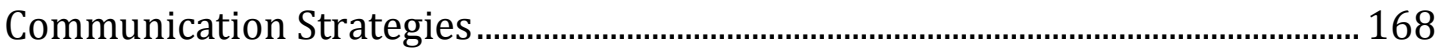

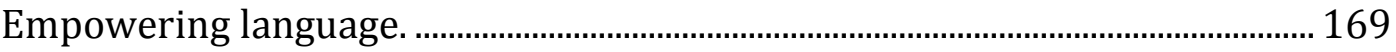

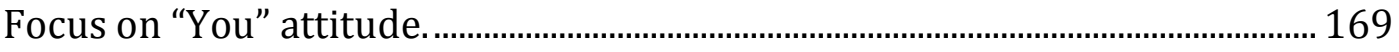

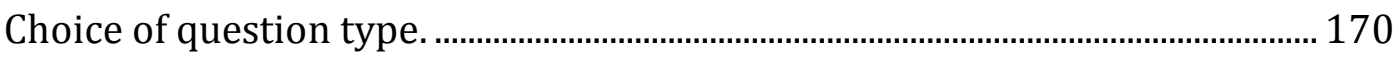

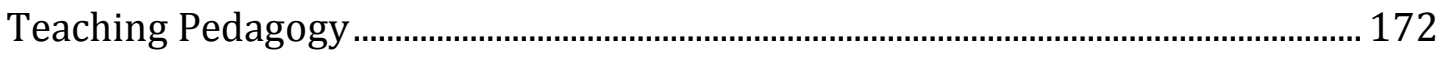

Collaborative learning.......................................................................................... 172

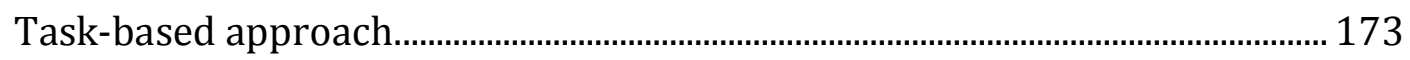

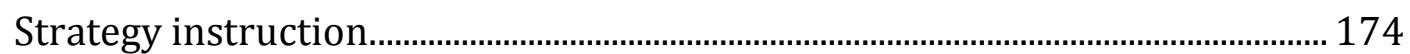

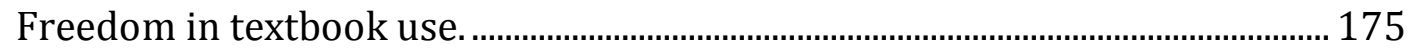

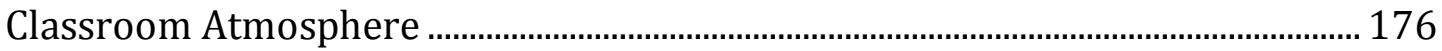

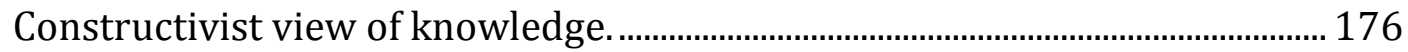

Optimal degree of students' freedom. ..................................................................... 177

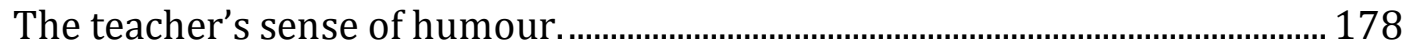

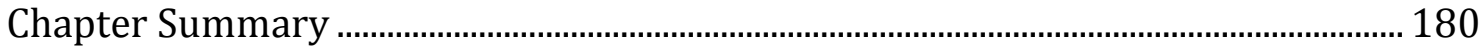

CHAPTER 6: THE CONVERGENCE OF TWO STRANDS.....................................181

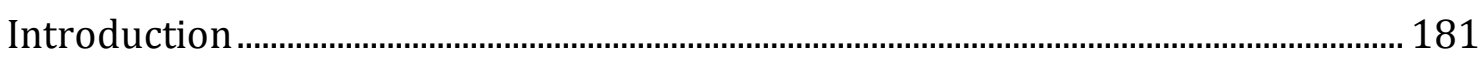


A Pathway to the Promotion of Learner Autonomy …….................................................. 181

Mediators of Lecturers' Beliefs and Practices ...................................................................... 184

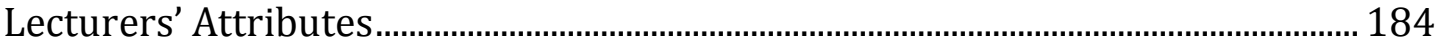

Lecturers' understanding of learner autonomy. ...................................................... 185

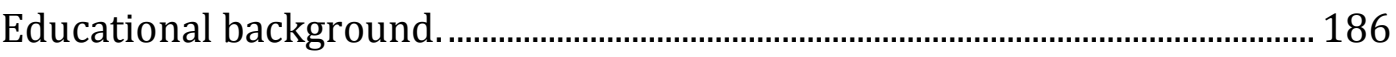

Organizational Climate ................................................................................................. 187

Professional development and level of support..................................................... 187

Career evaluation and work requirements............................................................ 189

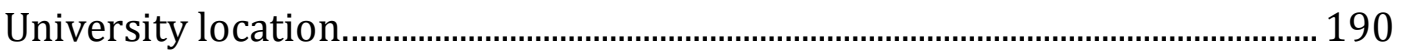

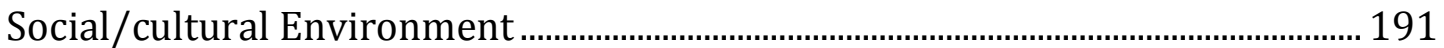

Thai cultural expectations of the role of teachers. .................................................... 192

Thai cultural expectations of the role of students..................................................... 192

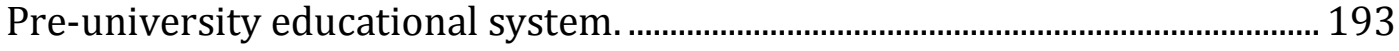

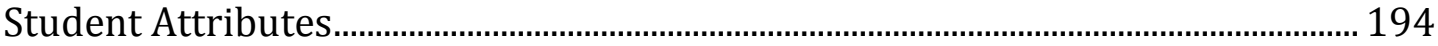

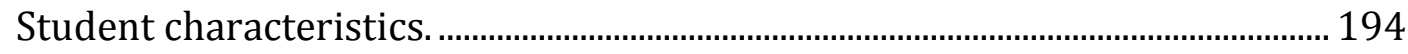

Students' perception and motivation about learning......................................... 195

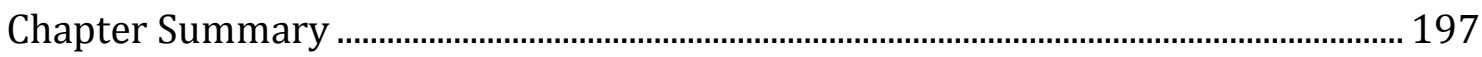

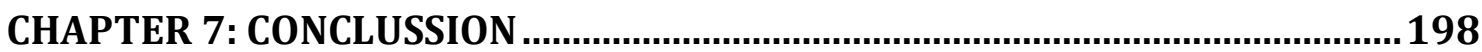

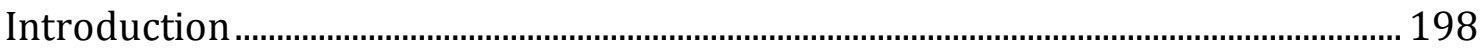

Summary of the Research............................................................................................. 198

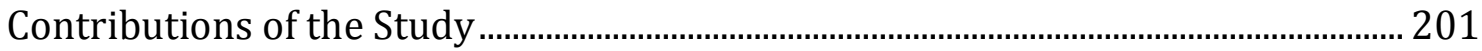

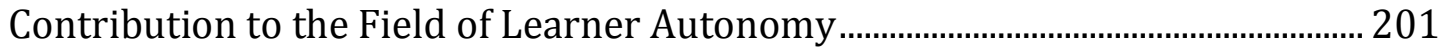

Contribution to Classroom Practices ............................................................................... 204

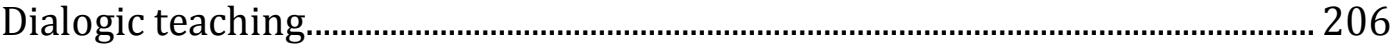

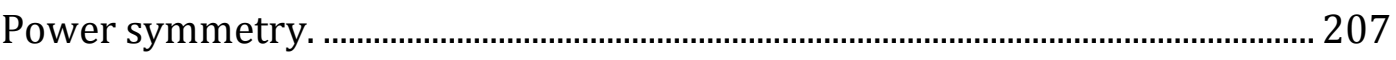

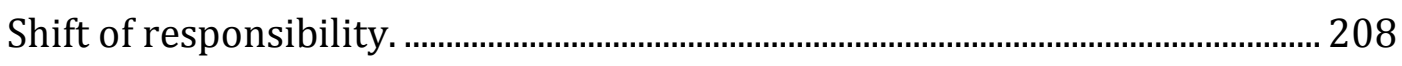

Contribution to the Promotion of Learner Autonomy in Thailand ......................... 209

Managing professional development................................................................... 210

Resolving lecturers' tensions from organizational demands.............................. 211

Increasing students' motivation............................................................................. 213

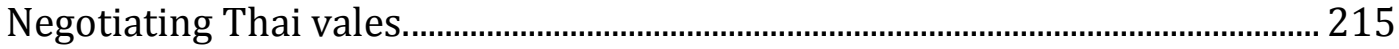

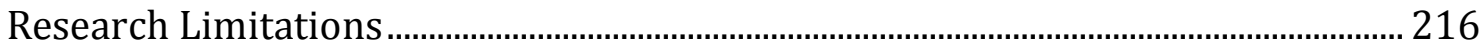

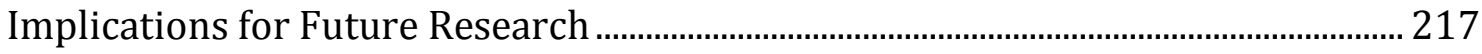

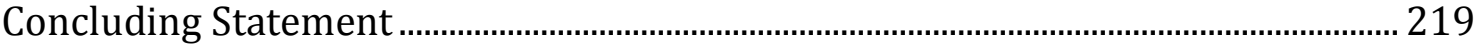

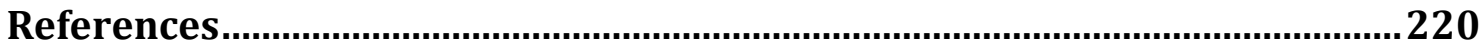

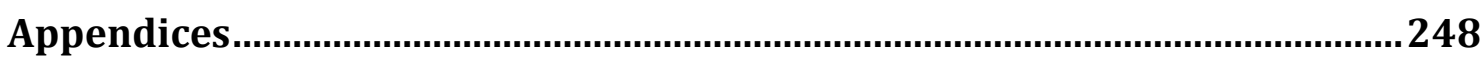


Appendix A: Detailed Data Extraction ......................................................................... 249

Appendix B: Letter Requesting Permission from Deans ................................................ 267

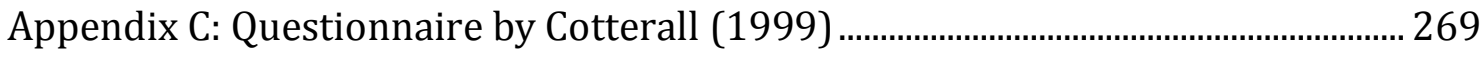

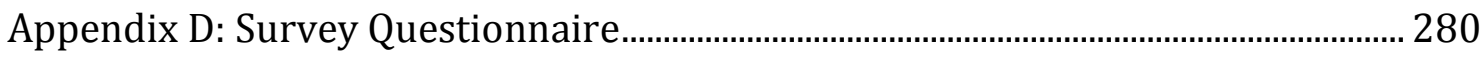

Appendix E: Information Sheet and Consent Form for Survey ………........................ 286

Appendix F: Information Sheet and Consent Form for Cases studies........................ 289

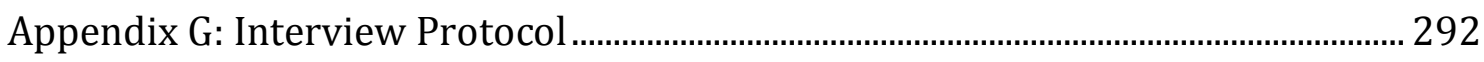

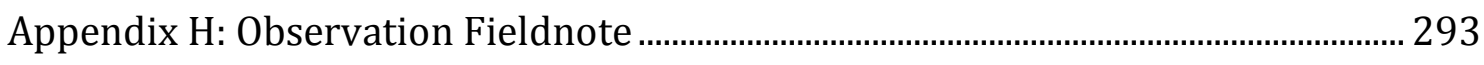

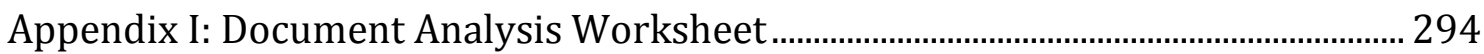




\section{List of Tables}

Table 2.1: Sample Data Sheet for Screening Studies for Inclusion......................12

Table 2.2: Categories of Participants in the Reviewed Studies..............................14

Table 2.3: Settings of the Reviewed Studies..............................................................15

Table 2.4: Subject Areas of the Reviewed Studies...............................................17

Table 2.5: Data Collection Methods of the Reviewed Studies...............................18

Table 2.6: Key Findings/Implications of the Reviewed Studies..........................19

Table 4.1: Learning Dimensions Underlying the Questionnaire.........................49

Table 4.2: Demographic Information of the Participants...................................54

Table 4.3: University's Location and Teaching Experience ...............................55

Table 4.4: University's Location and Lecturers' Qualification..............................56

Table 4.5: Beliefs in the Nature of Language Learning......................................57

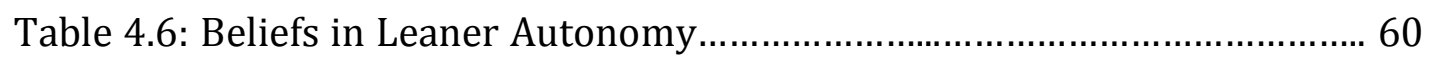

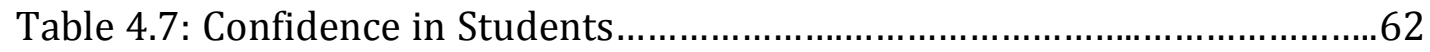

Table 4.8: Practices related to Learner Autonomy............................................64

Table 4.9: Beliefs, Confidence, and Practices with Ages....................................66

Table 4.10: Beliefs, Confidence, and Practices with Teaching Length...................67

Table 4.11: Beliefs, Confidence, and Practices with Bachelor Fields...................67

Table 4.12: Beliefs, Confidence, and Practices with Qualifications.........................68

Table 4.13: Beliefs, Confidence, and Practices with University Locations............68

Table 4.14: Questionnaire Internal Consistency ...............................................73

Table 5.1: Guided Questions for Class Observations.........................................92

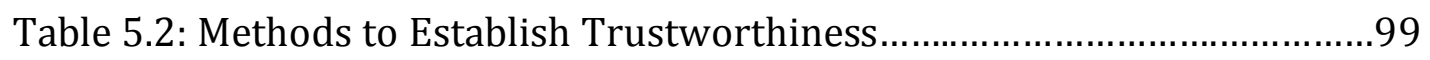

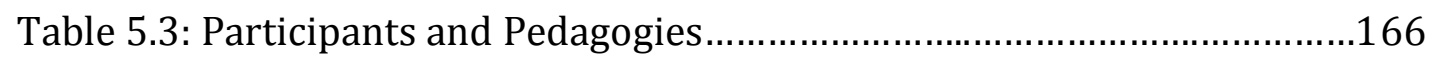

Table 5.4: Factors Influencing Perceptions and Practices...............................167

Table 7.1: Summary of Research Findings.....................................................20 


\section{List of Figures}

Figure 2.1: Categories of participants in the reviewed studies ...................14

Figure 2.2: Settings of the reviewed studies...............................................15

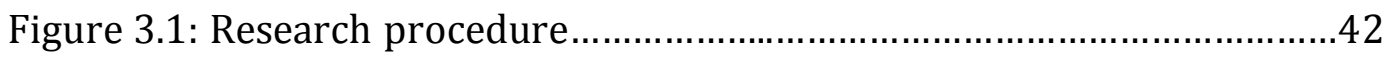

Figure 4.1: Mean scores of beliefs-related items..........................................61

Figure 4.2: Mean scores of confidence-related items...................................62

Figure 4.3: Mean scores of practice-related items.........................................65

Figure 4.4: Activities at the outset of the course..........................................70

Figure 4.5: Frequency of encouraging students for self-assessment................71

Figure 4.6: Favourite outside-class activities................................................72

Figure 4.7: Comparison of beliefs, confidence and practices............................76

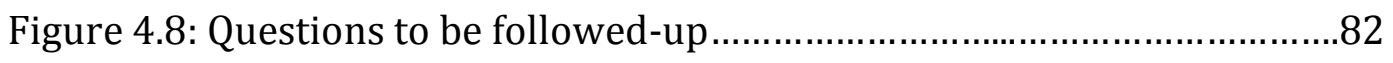

Figure 5.1: Participant selection procedures for phase 2 ..............................85

Figure 5.2: Questionnaire scores of potential participants.............................86

Figure 5.3: Potential participants' beliefs, confidence, and practices..............87

Figure 5.4: Participants in phase 2 and scores.............................................8

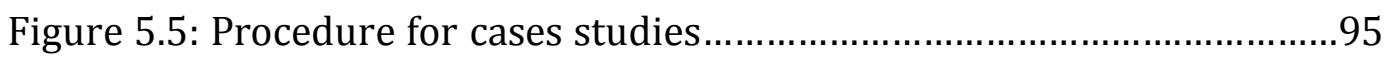

Figure 5.6: Bussaya's and Wipakorn's beliefs, confidence and practice......102

Figure 5.7: Wassamon's and Jensuda's beliefs, confidence and practice.......103

Figure 5.8: Thananya's beliefs, confidence and practices ...........................104

Figure 5.9: Bussaya's classroom seating arrangement...............................121

Figure 5.10: Wipakorn's classroom seating arrangement............................122

Figure 5.11: Wipakorn's classroom seating re-arrangement.......................123

Figure 5.12: Jensuda's classroom seating arrangement .............................125

Figure 5.13: Wassamon's classroom seating arrangement............................126

Figure 5.14: Thananya's classroom seating arrangement...........................127

Figure 5.15: Similarities of strong supporters..........................................157

Figure 5.16: Similarities and differences of unconfident supporters.............161

Figure 5.17: Components of an autonomy-supportive classroom.................168

Figure 6.1: Pathway to the promotion of learner autonomy.........................182

Figure 7.1: Learner autonomy in its wider contexts....................................202 
Figure 7.2: A framework of strategies and concepts underpinning the promotion of learner autonomy. 


\section{CHAPTER 1: INTRODUCTION}

\section{Introduction}

In this thesis, I report on a mixed-method study of the perspectives and practices of learner autonomy among a sample of lecturers in a range of higher education institutions in Thailand. Two research phases were conducted to examine the extent to which learner autonomy has been valued by these lecturers and to discover how the concept of learner autonomy had been operationalized in the university classroom teaching practices of sample of these lecturers.

My decision to undertake research on the topic of learner autonomy was primarily inspired by my beliefs in the benefits of learner autonomy. I believe that learner autonomy can bring better learning outcomes. When learners are autonomous, they become responsible members of the communities in which they live and learn. Particularly in language education, when grown up autonomous learners become autonomous users of the target language in which they have learnt. Before doing the PhD I was a lecturer of English in a branch campus of a well-known university in Thailand for almost six years. Being a lecturer gave me some experience of students' learning habits. In class, most of my students tended to rely almost totally on me and usually waited to be told what to do. They usually were quiet, and did not voice out their opinion or give respond. When assigned homework or assignments, some of these students copied the works of their peers; some came to me and expressed that they could not do it because I did not tell them how to do it. The usage of learning facilities, such as the self-access learning center, the library, in my campus was also low. Together with these learning habits, their English competence was poor even though they had been studying English since they were in Prathom suuk sa 1 or Grade one. In other words, with their 12 years of learning English, the majority of my students were not able to communicate in English.

Significantly, there has been a tremendously flourishing of after-hour private tutorials in Thailand. These are not limited to language learning but also to other subjects areas such as mathematics, chemist, and physics. Most Thai students, particularly from pre-university levels, spend their evening after formal school as 
well as on their weekend and semester breaks in the private tutorials. The aim of attending those private tutorials is to improve their grades, to prepare themselves for school examination and for university-admission examination. Many students tend to focus and put more effort on learning with their private tutors. In this sense, private tutorials have been treated as a substitute to learning in classroom, rather than complementary to classroom education.

I feel strongly that if Thai students were autonomous in their learning, the above phenomena would not have occurred. In addition to my beliefs in learner autonomy, results from my systematic review of the literature (Chapter 2) further inspired my interest in discovering the extent to which autonomy in learning was valued and practiced by university lecturers. The existing literature suggest that, although the concept was introduced in the Thai National Education Act of 1999 and has become a topic for Thai educationalists, there was little research examining how learner autonomy has been perceived, valued, and practiced in Thailand. In addition, investigations of learner autonomy in Thailand have focused more on the perspectives of learners, rather than on the teachers', despite the recognition of the crucial role that teachers play in the development of learner autonomy.

\section{Overview of the Study}

This study was conducted to address the gap identified in the results of the systematic literature review (Chapter 2). The gap was investigated through five research questions:

1. To what extent does the sample of Thai lecturers report that they believe in or value learner autonomy?

2. To what extent does the sample of Thai lecturers report that they are confident in the students' ability to exercise autonomy in their learning?

3. To what extent does the sample of Thai lecturers report that they allow their students to exercise autonomy in their learning?

4. What factors may be associated with the trends identified in the quantitative results? 
5. How has the concept of learner autonomy been operationalized in university language classrooms?

In an attempt to answer the research questions, I adopted a mixed-method approach to my study with an emphasis on qualitative data. The study was designed to consist of two phases; each phase acted as a "mini-study" (Johnson \& Onwuegbuzie, 2004, p.20) and was conducted sequentially. As the study put more emphasis on the second, qualitative phase, the thesis gives more space and indepth analysis to the qualitative results compared to the quantitative statistical results.

\section{Overview of Thailand}

This research project was set within the context of language education in Thailand. Therefore, it is relevant to describe the location, history, culture and religion of the country. This information indicates how the socio-cultural environments influences context in relation to education in Thailand. This suggests the significance of socio-cultural perspectives which were taken into account when my study was conducted. This section also provides information on the history and current state of language education in Thailand. The political and social organization of Thailand underlies the development of an education system that has continued to evolve in order to enable Thai people to participate in a global economy. The current emphasis on learner autonomy in language learning is part of that evolution.

\section{Contextual Information}

Thailand, or Siam, is named as "the land of smiles". It is the only country in Southeast Asian that has never undergone the colonization and has a long history of over 700 years. It borders the Lao People's Democratic Republic and the Kingdom of Cambodia to the East, Malaysia and the Gulf of Thailand to the South, and the Union of Myanmar and the Andaman Sea to the West.

Thailand has a population of 63,396,000 (estimated at midyear 2009) (Mahidol Population Gazette, 2009). The country has 76 provinces, with Bangkok as the capital city. The provinces are geographically grouped into 6 regions: north, north- 
east, west, central, east and south. Within Thailand, there is a considerable diversity in the home languages or dialects spoken. This depends to some extent on the region. According to Smalley (1988), Thailand only has Thai Klang (central Thai) or standard Thai included in the Thai constitution as a national language. Thai Klang is widely spoken in Central Thailand including Bangkok. The majority of Thai people in regional areas may communicate with people within their region with their local dialects or regional languages, with the main differences between these dialects being tone and vocabulary. Some may speak languages of their ethnic origin such as Chinese, Malay and other minority languages. Children from local areas speak their local languages and learn to speak standard Thai in school. Those from educated middle and upper class might learn to speak standard Thai from birth. There can often be an association between fluency in standard Thai and one's level of education and social status.

However, despite the varied local languages spoken within the country, Thailand encounters no rivalry between its language group and is considered to be a country with "linguistic diversity within national unity" (Smalley, 1994, p.70). In order to communicate with foreigners, Thai people usually speak English. Other popular foreign languages include Chinese, Japanese, Korean, French, and German.

Thailand is under a constitutional monarchy, with the king as the leader of state and the Prime Minister as the leader of the government. Although not officially stated, Buddhism is the national religion with approximately $95 \%$ of the population being Buddhist. According to Baker (2008), Buddhism has been the most important source of Thai values and education. Based on Buddhism, Thais value cooperation and avoid confrontation with higher status people.

\section{Socio-cultural Perspectives of Thailand}

Like Hong Kong, Singapore and Malaysia, Thailand is a highly collectivist culture (Dimmock, 2000). Thai individuals tend to view themselves as part of a group. Cohesion, harmony and interests of the group are emphasized more than any individuals' personal accomplishments. Unlike in an individualistic culture, personal freedom is not highly valued in Thai society. Thai children are raised with a great emphasis on loyalty and obedience to community leaders, particularly to 
the King. As group cohesion is highly valued, disagreement, confrontation and anything that might lead to conflicts within the group are likely to be discouraged. The collectivism of the country is also evident in the value of the extended family. Younger members of the family are close with grandparents and are expected to pay respect and be obedient to older members of the family. This suggests that interdependence is valued over independence in young people.

Although regarded as a Buddhist country, Thailand is well-known for its extension of freedom for its people to practice other religions and faiths. Together with a deep love of the King, the respect of Buddhism as the national religion, and general patriotism have become the three fundamental elements of contemporary Thai society that prevail in every aspect of Thai life. This is called "Chat, Sadsana, Pramaha ga sat" or "Nation, Religion and King".

\section{Historical Perspectives of Thai Education}

Historically, Thai education was tightly tied to Buddhism (Baker, 2008). It was mainly offered in the palace and temples (or "Wad"). Delivered by monks, education in Wad was reserved for monks and boys, and aimed at religious-based literacy (Costa, 1997). Education offered in the palace was aimed primarily at producing noblemen into the future leaders of the country (Sinlarat, 2004).

The formal and modernized tertiary education that now exists in Thailand began in the reign of King Rama V, who developed a mandate for the establishment of Chulalongkorn University as the country's first university in 1917. During its initial years, Chulalongkorn University was open only to men and aimed to produce personnel for government agencies (Costa, 1997). The period of King Rama V (late 1800s- early 1900s) is considered as the first and one of the most significant educational reform periods of the country, in which the old system of education which took place in the palace and temples were replaced by the "modern secular system" (Fry, 2002, p.2). The higher education system in this period had a primary aim of producing staff to serve increasing demand from an expanding bureaucracy.

After this period, higher education in the country began to expand. Since the 1960s, the education system has spread throughout the country, with the 
emergence of private and public colleges and universities. According to Baker and Phongpaichit (2005), from the mid-1980s, the number of tertiary institutes in Thailand has increased greatly. The higher education system is moving to mass education. It is no longer designed to serve the demands of an expanding bureaucracy, but to address the increasing demand from other sectors of Thailand's economy.

\section{The Current Position of Thai Education}

Founded upon the reforms put forth in the 1999 National Education Act, the current Thai education system aims to enhance life-long education, and to promote the decentralization of administrative authority. According to the Ministry of Education (2008), the Thai formal educational system is comprised of Early Year Education, Basic Education, Vocational and Technical Education, and Higher Education.

Early Year Education, or "Chan Aa nu barn" is provided for children from 3 to 5 years of age. It aims to prepare young children for higher levels of education, with emphasis on their physical, emotional, social and intellectual readiness. Basic education is mostly provided by the government. It is free and comprises 12 years with 6 years for primary education (Prathom suuk sa 1-6), and 6 years for secondary education (Maad dha yom suuk sa 1-6). According to the Ministry of Education (2008), basic education is based on the National Curriculum. The curriculum requires students to study eight main subject areas: Thai language; foreign language; mathematics; science; social studies; religion and culture; health and physical education; and arts, careers and technology.

After finishing Maad dha yom suuk sa 3, or lower secondary education, Thai students can choose to continue in formal upper education (or Maad dha yom suuk sa 4-6), or pursue vocational or technical education. Individuals eligible for admission to higher education institutes must finish Maad dha yon suuk sa 6 (upper secondary education) or its equivalent. The recent admission to an institution of higher education is based on Grade Point Averages (GPA), the 0-Net examination and a standardized aptitude test. 
At present, there are 89 government institutions and 78 private sector institutions providing higher education (Ministry of Education, 2008). All these tertiary institutions are dispersed evenly throughout almost every province of the country (Kirtikara, 2001). In recent years there has been a significant increase in both higher education opportunities as well as the rates of students attending higher education (Ministry of Education, 2008). The increasing expansion of higher education nationwide is reflected in the setting up of national branch campuses of those institutions. The number of branch campuses reported by the Office of Higher Education, Thailand (2011) is now up to 75. The increasing expansion of both home and branch campuses of higher education institutions in Thailand reflects the impact of globalization in driving the country's economy. To address the increasing demand for higher education, the state of Thai higher education is becoming more competitive and more business-like. Students tend to be regarded as customers, and lecturers as employees of the institutions (Sinlarat, 2007). The teaching methods commonly used expect students to be passive recipients of knowledge, and place emphasis on rote learning and memorizing skills (Richmond, 2007).

\section{Language Education in Thailand}

Languages other than Thai are considered foreign languages. Among these, English has been the most used. Other languages such as Chinese, Japanese, Korean and French have increased both in use and teaching, but are not as popular as English.

Language education in Thailand has a long history. It can be traced back to the Ayuddhaya period, approximately four hundred years ago, when the country first made contact with the West. French was the first foreign language spoken by Thais. However, English began to gain popularity over other languages in the country. English language teaching began in the reign of King Rama III (1824-1851 A.D), and was limited to elite families and members of the Thai royal family (Wongsothorn, 2004). It was during this period that the country increased its contact with other countries, usually for business and political reasons. In this era, western countries were expanding their global influence through colonization. This called for the need to equip members of the royal family with language 
communication skills (Durongphan, Aksornkul, Sawangwong, \& Tiancharoen, 1982).

Many years later, it was felt that English should not be reserved exclusively for certain groups of children; all other children, even though they may not come from elite or royal families, should receive opportunities to study English (Aksornkul, 1980). Thus, in 1890, English was first taught in schools established by American missionaries. This year became the starting point of the expansion of English education to ordinary children.

In 1921, English was assigned as a compulsory subject for students from Prathom suuk sa 5 or the equivalent of fifth grade (Aksornkul, 1980). Since then English education has assumed a significant role in the country's formal education system and has undergone a number of changes and reforms. In 1996, English teaching was made compulsory for students in Prothom suuk sa 1. This revision aimed to provide students with opportunities to continue their English education without interruption and to facilitate lifelong learning (Ministry of Education, 1996). However, Khamkhien (2006) noted that the revision aimed to minimize the gap between the English proficiency of students from private and public schools. Foreign languages other than English are not compulsory. However, they have received increased interest, and thus are selected as study majors by a number of university students.

Thailand's history, geography, religion and social organization underlie both its education system and the role of English and other language teaching at all levels for students. These set the context when examining learner autonomy from the perspective of university lecturers. 


\section{Overview of Thesis Chapters}

This thesis is composed of seven chapters:

Chapter 1 begins with the introduction and an overview of the study. After this, the chapter provides an overview of Thailand including contextual information about the country, its education system, and the state of language education in the country.

In Chapter 2, I present a systematic review of literature. This chapter provides a justification for the research questions. The review was conducted to identify gaps in the literature pertaining to learner autonomy. I begin the chapter by describing the methodology of the systematic review, and then present the results of the analysis of the included studies. The implications from these findings for the research are put forth in the final section of the chapter.

Chapter 3 discusses the theoretical and methodological frameworks of the study. I introduce Self Determination Theory (SDT) (Deci \& Ryan, 1985) and the concept of autonomy from the perspective of this theory. The relationship between teachers and learner autonomy is presented. A discussion of the mixed methodology of the study follows. I end this chapter with a justification for using a mixed method approach in my study of learner autonomy.

Chapter 4 reports on Phase 1, the quantitative phase, and its findings. The focus of this chapter is on describing the existing state of learner autonomy in the country, in particular on the extent to which Thai lecturers believed in learner autonomy and practiced it in their courses. The chapter also discusses issues that arose from the findings that were further studied in Phase 2.

Chapter 5 reports on Phase 2 of the research. The focus of this chapter is on describing how the concept of learner autonomy has been operationalized in university language classrooms. A cross-case analysis in the final sections of the chapter provides insights into factors that contribute to the issues found in Phase 1. 
Chapter 6 links the findings from the two phases of the study together. Through this linkage the promotion of learner autonomy in Thailand is then conceptualized as a pathway, starting from lecturer beliefs and ending with lecturer practices. This pathway delineates factors that might impact on the lecturers' practices of the promotion of learner autonomy. The product of the combination of the two phases of the study also provides explanations for the issues that arose from the first, quantitative phase of the study.

The thesis ends with Chapter 7. This chapter revisits the research questions and summaries the research findings. The chapter then discusses the theoretical and applied contributions of this study. Limitations of the study are explained and directions for future research are recommended. The chapter ends with a concluding statement. 


\section{CHAPTER 2: SYSTEMATIC REVIEW OF LITERATURE}

\section{Introduction}

This chapter presents a systematic review of the literature pertaining to learner autonomy. This review was undertaken to identify gaps in the literature relating to learner autonomy and to broaden my perspectives on learner autonomy. In addition, I used the review to identify suitable methodology and instruments to use in my thesis research. The first section of the chapter describes the method of the systematic review. Next, the results of the analysis of the included studies are presented. The final section concludes with the implications of these findings for the design of the present thesis research.

\section{Method}

\section{Search Strategy}

Systematic searches were conducted in six electronic databases: Educational Resources Information Center (ERIC); PsycINFO; Google Scholar; Linguistics and Language Behavior Abstracts (LLBA); SAGE Journals Online; and ScienceDirect. The library search was conducted at the library of Victoria University of Wellington, New Zealand and libraries at four universities in Thailand, to which I had access (i.e., Chulalongkorn University, Thammasat University, Srinakharinwirot University, and Prince of Songkla University). The search was limited to articles, book chapters, and books published in English or Thai. The years of publication were limited to the years 1994 to 2010 in order to focus the review on contemporary studies. The search and retrieval of articles was completed in waves of searches between April 2009 and September 2010. Search terms were entered into the keywords field and included "learner autonomy", "autonomous learner", "student autonomy", "independent learner", "self-regulated learning", "self-directed learning", and "lifelong learning". The search for studies particularly conducted in Thailand applied either of these terms plus "Thai". Thai terms, i.e. “การเรียนรู้ด้วยตนเอง”, “การเรียนรู้ด้วยการนำตนเอง”, “ผู้เรียนโดยเสีว”, and “ผู้ควบคุมการเรียนรู้ด้วยตนเอง” were also used. 


\section{Inclusion and Exclusion Criteria}

Each identified study was assessed to determine if it met the pre-determined inclusion criteria. To be included in this review, the article had to meet the following criteria:

1. The topic of the article, book chapter, or book was clearly related to learner autonomy or its related concepts, including learner-centered teaching, selfdirected learning, self-directed learner, and self-regulated learning.

2. The article, book chapter, or book had to report original findings from an empirical study.

3. The study had to be conducted in an educational setting.

4. The article, book chapter, or book was published between 1994 and 2010.

\section{Inter-rater Agreement}

From the search procedures, 209 articles were identified as potential candidates for inclusion in the systematic review. I used the criteria checklist (Table 2.1) to screen each of these 209 studies. According to this screening, 122 studies met the inclusion criteria and were included for summary and analysis. A colleague acted an independent rater. Before assessing the pool of 209 studies, the application of the inclusion/exclusion criteria was explained to the independent rater. The same criteria checklist was given to her to facilitate the assessment. Prior to undertaking these independent evaluations, the independent rater worked through five randomly selected studies to ensure a clear understanding of the process. The independent rater's results were compared to my results. As no discrepancies existed, the rater independently assessed each of the remaining studies.

Table 2.1

Sample Data Sheet for Screening Studies for Inclusion

\begin{tabular}{lccccc}
\hline Study & $\begin{array}{c}\text { Related to learner } \\
\text { autonomy (Yes or No) }\end{array}$ & $\begin{array}{c}\text { Research study } \\
\text { (Yes or No) }\end{array}$ & $\begin{array}{c}\text { Educ. Setting } \\
\text { (Yes or No) }\end{array}$ & $\begin{array}{c}\text { 1994- 2010 } \\
\text { (Yes or No) }\end{array}$ & $\begin{array}{c}\text { Eng. /Thai } \\
\text { (Yes or No) }\end{array}$ \\
\hline 1. & & & & \\
\hline 2. & & & & \\
\hline 3. &
\end{tabular}

Agreement between the rater and I as to the inclusion/exclusion was $94.57 \%$ (the results was that I included 122 studies while the independent rater included 129 
studies). To resolve the discrepancies, the rater and I discussed the details of the aim of this systematic search and the inclusion/exclusion criteria again. After that, the rater and I jointly evaluated the seven studies for which there was an initial discrepancy. As a result, the seven studies were excluded.

\section{Data Extraction}

I extracted information on each study's (a) aims, (b) participants, (c) methodology, (d) findings, and (e) implications. With regards to methodology, information about methods of data collection, the study's design, a brief description of instruments, and the methods of data analysis were extracted. Detailed information on the data extraction is presented in Appendix A.

\section{Results}

From 209 potential studies, 122 studies met the criteria and thus were included for summary and analysis. Eighty-seven of these studies were carried out in international contexts and 35 studies were carried out in Thailand. International contexts included studies conducted in New Zealand, Hong Kong, Canada, the United States of America, Singapore, Taiwan, Trinidad and Tobago, Japan, the Netherlands, Mexico, Brazil, the United Kingdom, Norway, China, Turkey, Spain, Australia, Malaysia, Ireland, Italy, Flanders, Jordan, UAE, Greece, India, Ukraine, and Iran.

\section{Participants}

The participants of 122 studies were divided into seven categories as shown in Table 2.2. 
Table 2.2

Categories of Participants of the Reviewed Studies

\begin{tabular}{|c|c|c|}
\hline Participants & Details & $\begin{array}{l}\text { Studies } \\
\end{array}$ \\
\hline Teachers & $\begin{array}{l}\text { Teachers from primary/secondary } \\
\text { schools; lecturers from } \\
\text { tertiary institutes }\end{array}$ & $\begin{array}{l}17 \text { studies }(13.93 \%): \text { Studies } 16- \\
17,28-29,36,44,61,74,79,85 \text {, } \\
88,90,101,105-107 \text { and } 111 .\end{array}$ \\
\hline Students & $\begin{array}{l}\text { Secondary/primary students, } \\
\text { university students (including } \\
\text { undergraduates and } \\
\text { postgraduates), and adult learners }\end{array}$ & $\begin{array}{l}75 \text { studies }(61.48 \%): \text { Studies } 1- \\
13,15,19-24,26-27,31-34,38- \\
40,45-52,55,59,64-66,69,71, \\
73,75-78,80-83,86,92-98,102- \\
104,110,112 \text {, and114-122. }\end{array}$ \\
\hline Teachers and students & $\begin{array}{l}\text { Both teacher and student } \\
\text { participants under the same study }\end{array}$ & $\begin{array}{l}17 \text { studies }(13.93 \%): \text { Studies } 14 \text {, } \\
37,43,53,56,58,63,68,70,72 \text {, } \\
84,87,89,91,100 \text { and } 109\end{array}$ \\
\hline Student teachers & $\begin{array}{l}\text { Pre-service teachers and student } \\
\text { teachers }\end{array}$ & $\begin{array}{l}6 \text { studies }(4.92 \%) \text { : Studies } 30 \text {, } \\
35,41,54,60 \text {, and } 67 \text {. }\end{array}$ \\
\hline Schools/universities & $\begin{array}{l}\text { Cases studies of schools or } \\
\text { universities }\end{array}$ & $\begin{array}{l}3 \text { studies }(2.46 \%) \text { : Studies 25, } \\
108 \text {, and } 113\end{array}$ \\
\hline $\begin{array}{l}\text { Three groups } \\
\text { participants }\end{array}$ & $\begin{array}{l}\text { Involve up to three types of } \\
\text { participants: students, faculty staff } \\
\text { and mentor teachers; and teachers, } \\
\text { students' parents and students }\end{array}$ & $\begin{array}{l}2 \text { studies (1.64\%): Studies } 62 \\
\text { and } 99\end{array}$ \\
\hline No participants & $\begin{array}{l}\text { Study } 18 \& 57 \text { examined materials } \\
\text { and documents related to the } \\
\text { courses }\end{array}$ & $\begin{array}{l}2 \text { studies (1.64\%): Studies } 18 \\
\text { and } 57\end{array}$ \\
\hline
\end{tabular}

Figure 2.1 provides a visual representation of the data presented in Table 2.2.

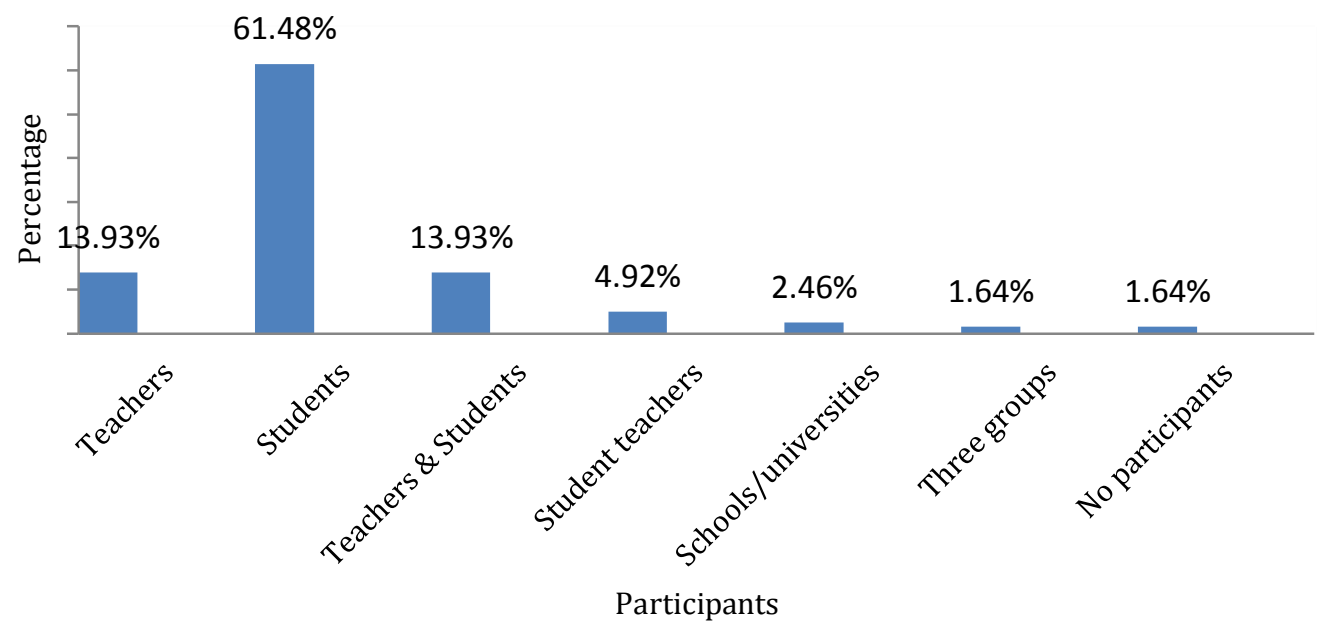

Figure 2.1. Categories of participants of the reviewed studies 


\section{Settings}

All of the studies in this review were carried out in one of five different educational settings, as shown in Table 2.3 and Figure 2.2.

Table 2.3

Settings of the Reviewed Studies

\begin{tabular}{|c|c|c|}
\hline Setting & Details & Studies \\
\hline Primary/secondary level & $\begin{array}{l}\text { Schools in primary or secondary } \\
\text { levels }\end{array}$ & $\begin{array}{l}22 \text { studies (18.03\%): Studies 9, } \\
16,25,29,36,43,58,61,63,74- \\
76,81-87,88,91,101,106-107, \\
109,111 \text { and } 113 \text { (Eight of these } \\
\text { studies were in Thailand) }\end{array}$ \\
\hline Tertiary level & $\begin{array}{l}\text { Undergraduate or postgraduate } \\
\text { level in universities or tertiary } \\
\text { institutes }\end{array}$ & 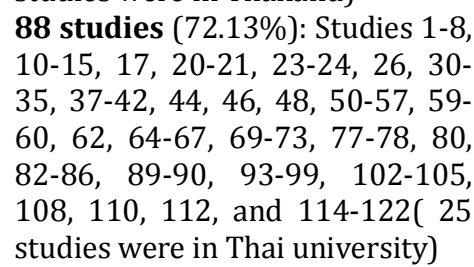 \\
\hline $\begin{array}{l}\text { Secondary and tertiary } \\
\text { levels }\end{array}$ & $\begin{array}{l}\text { Carried out in both secondary and } \\
\text { tertiary education settings }\end{array}$ & 1 study (0.82\%): Study 100 \\
\hline Diploma level & Conducted in diploma institutes & $\begin{array}{l}3 \text { studies (2.46\%): Studies 18, } 27 \\
\text { and } 49\end{array}$ \\
\hline Informal education & $\begin{array}{l}\text { Conducted in learning projects or } \\
\text { language schools }\end{array}$ & $\begin{array}{l}8 \text { studies }(6.56 \%): \text { Studies } 19,22 \text {, } \\
28,45,47,68,79 \text { and } 92\end{array}$ \\
\hline
\end{tabular}

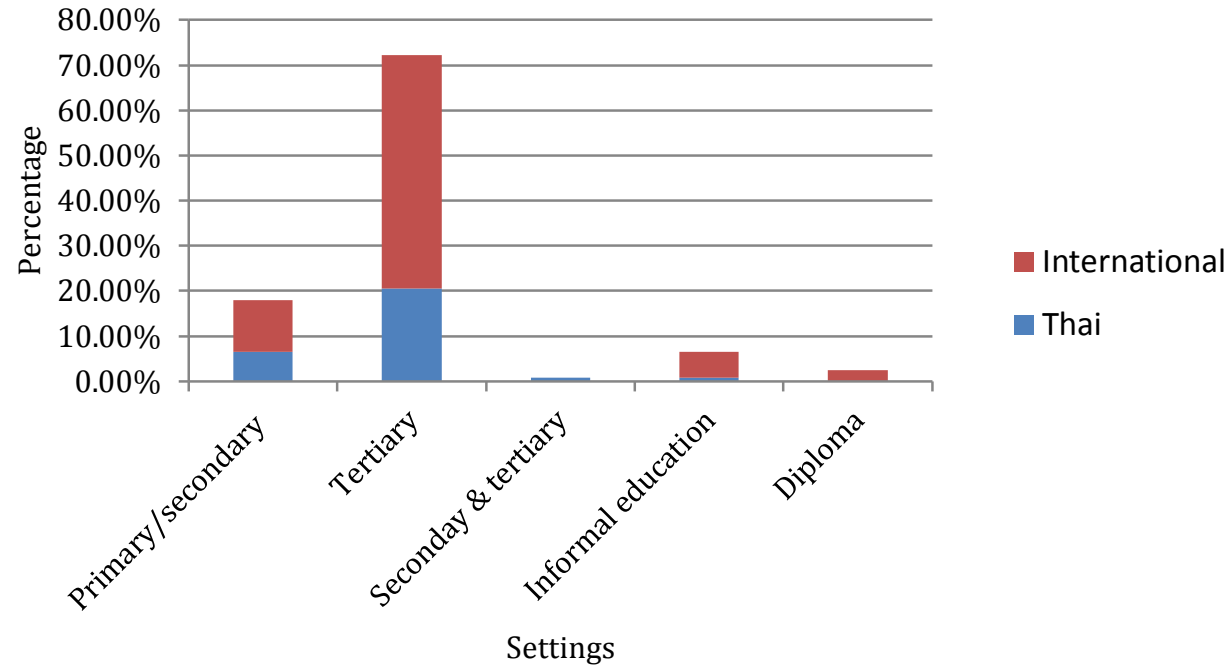

Figure 2.2. Settings of the reviewed studies 


\section{Subject Areas of Study}

Fields of the included studies fell into three main categories: language education, non-language education and unable to classify. The majority of the studies were conducted in language-learning settings with English language learning being the most commonly studied subject. Table 2.4 described the subject areas of the 122 studies.

\section{Data Collection Methods}

The methods employed to collect data across 122 studies were separated into seven main categories (Table 2.5). Most of the studies employed more than one tool to collect data. The most commonly used methods were a questionnaire, interviews, and document analysis.

\section{Findings/Implications}

The included studies yielded an insight into at least one of five areas: teachers' perspectives; learners' perspectives; suggested activities/materials to promote learner autonomy; constraints and supports; and autonomy-related principles (Table 2.6). A study may appear in more than one category. 
Table 2.4

Subject Areas of the Reviewed Studies

\begin{tabular}{|c|c|c|}
\hline Subject area & Details & Studies \\
\hline Language education & $\begin{array}{l}\text { English was the most frequently studied language. } \\
\text { Other languages included French, Spanish, Russian } \\
\text { and Japanese. Three studies were related to more } \\
\text { than one language }\end{array}$ & $\begin{array}{l}73 \text { studies }(59.84 \%) \text { : Studies1-2, 5-8, 10-14, 17-20, } \\
22-24,26-28,31-34,36-39,41-42,43-51,53,56-57, \\
59-60,66,68,70,72,73-74,78,80,83-84,87,89-90, \\
93-94,96-98,100,104,106,109-110,115-117,120 \\
\text { and } 122\end{array}$ \\
\hline Non-language education & $\begin{array}{l}\text { Subjects other than languages. Ranged from medicine, } \\
\text { nursing education, chemistry, teacher education, } \\
\text { Islam education computer science to research } \\
\text { methodology }\end{array}$ & $\begin{array}{l}28 \text { studies }(22.95 \%): \text { Studies } 3-4,9,15,21,30,35 \text {, } \\
40,52,54-55,58,62,64,67,69,71,77,86,95,102- \\
103,105,107,112,114,118 \text { and } 121\end{array}$ \\
\hline Unable to classify & $\begin{array}{l}\text { Studies which were unclear about or did not specify } \\
\text { under what field/subject they were examined; } \\
\text { studies with mixed subjects }\end{array}$ & $\begin{array}{l}21 \text { studies }(17.21 \%): \text { Studies } 16,25,29,61,65,75-76 \text {, } \\
79,81-82,85,88,91-92,99,101,108,111,113 \text { and } \\
119\end{array}$ \\
\hline
\end{tabular}


Table 2.5

Data Collection Methods of the Reviewed Studies

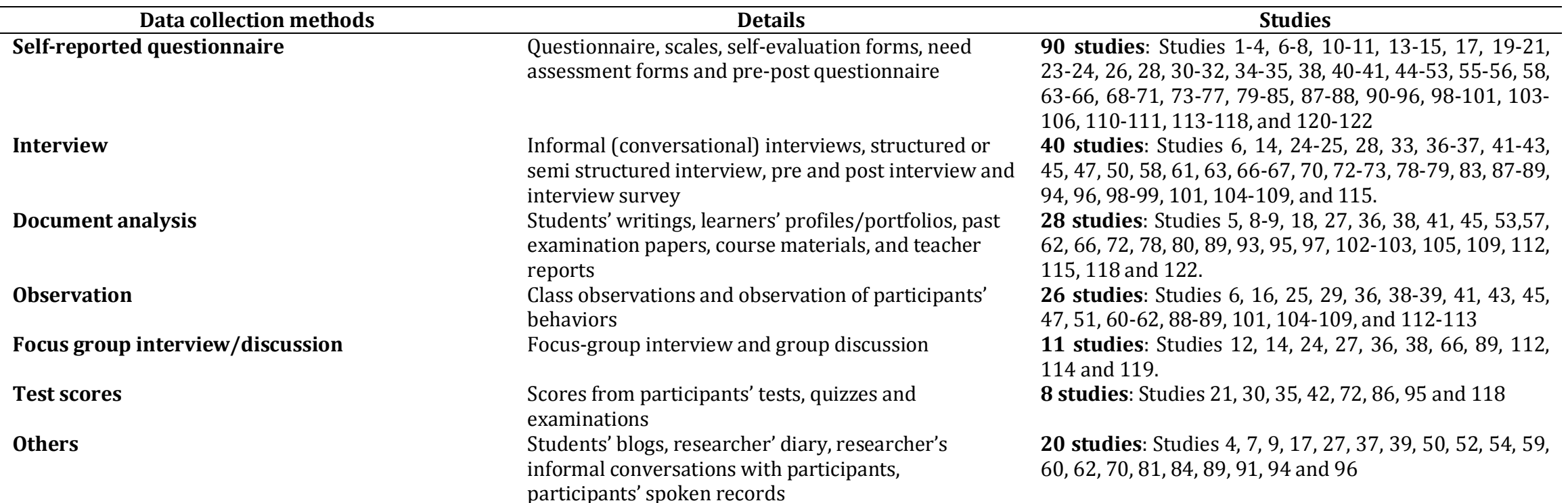
participants' spoken records 
Table 2.6

Key Findings/Implications of the Reviewed Studies

\begin{tabular}{|c|c|c|}
\hline Category & Details & $\begin{array}{l}\text { Studies } \\
\end{array}$ \\
\hline Teachers' perspectives & $\begin{array}{l}\text { Reflecting teachers' beliefs, attitudes, perceptions or } \\
\text { readiness towards, and teachers' influence on, } \\
\text { teaching in general and learner autonomy in } \\
\text { particular ( } 13 \text { studies in total) }\end{array}$ & $\begin{array}{l}\text { - Related to learner autonomy: Studies } 36,43-44,74 \text {, } \\
\& 106-107 \text {; } \\
\text { - Not related to leaner autonomy: Studies } 28,68,72 \text {, } \\
79,99,105, \& 107 \text {. }\end{array}$ \\
\hline Students' perspectives & $\begin{array}{l}\text { Reflecting students' beliefs, attitudes, perceptions or } \\
\text { readiness to teaching in general or learner autonomy } \\
\text { and its related concepts in particular. (34 studies in } \\
\text { total) }\end{array}$ & $\begin{array}{l}\text { - Related to learner autonomy: Studies } 1,10-11,19 \text {, } \\
23-24,31,41,43,48,66,67,69,75-76,83,86,92,94 \text {, } \\
\text { 115-117 and } 121 \text {; } \\
\text { - Not related to leaner autonomy: Studies } 5,26,34 \text {, } \\
68,72-73,97,105,112,118 \text { and } 120 .\end{array}$ \\
\hline Learning activities/materials & $\begin{array}{l}\text { Offering activities or materials to promote learner } \\
\text { autonomy. These included learning diaries, learning } \\
\text { portfolios/ profiles, blogs, journal writing, computer- } \\
\text { mediated learning, cooperative/collaborative } \\
\text { learning, problem-based learning, task-based } \\
\text { learning, and blended learning. ( } 63 \text { studies in total) }\end{array}$ & $\begin{array}{l}\text { Studies } 2-9,13,16,18,21-23,25,27,30,32-33,35 \text {, } \\
37,39-40,42,45-46,49,51-57,59,62-66,68,70,77- \\
78,80-82,84-85,89,91-93,95,97,100,102-104, \\
110,116,120 \text { and } 122 .\end{array}$ \\
\hline Constraints and supports & $\begin{array}{l}\text { Obstacles: examination-oriented learning, } \\
\text { teachers'/students preferences of traditional teaching, } \\
\text { top-down mandated policy and insufficient support } \\
\text { for teachers. } \\
\text { Areas that need immediate support: } \\
\text { trainings/workshops for students and professional } \\
\text { development programs/workshops/training for } \\
\text { teachers. (67 studies in total) }\end{array}$ & $\begin{array}{l}\text { Studies } 1,6,11-13,17,19-20,26-29,31,34,36-44 \text {, } \\
\text { 46-48, 50, 56, 58, 60-64, 69-74, 79, 81, 83, 85, 88, 90, } \\
92-94,96-99,101,105-109,111,113-115,117,119- \\
120 \text {, and } 122 \text {. }\end{array}$ \\
\hline Principles pertaining to learner autonomy & $\begin{array}{l}\text { Principles underlying learner autonomy i.e. self- } \\
\text { awareness, self-evaluation, reflection, self- } \\
\text { metacognition ( } 30 \text { studies in total). }\end{array}$ & $\begin{array}{l}\text { Studies } 1-2,5,7-8,11-13,23-24,42,45,51,57,59 \\
61-63,66-68,77-78,81,84,89,95,102-103 \text {, and } 116 .\end{array}$ \\
\hline
\end{tabular}




\section{Discussion}

The systematic review of the literature provided evidence for the promotion of learner autonomy in countries around the world, including Thailand. Considered together, the results of this review suggest the essential role of learners in the learning process (having the capacity to make their own decisions and take control of their own learning). There is, however, some evidence that the development of autonomy may depend to some extent on the amount of support that learners receive from their teachers. That is, teachers may play an important role in a student's transformation from a less autonomous to a more autonomous learner. Paradoxically, then, to become more autonomous in learning, students may often benefit from receiving specific types of support from teachers (Balcikanli, 2007; Cotterall, 1995, 1999; Cotterall \& Murray; 2009, Yang, 1998).

With regards to Thailand in particular, the results from the review offer little evidence to describe the country's existing state of learner autonomy. Despite the recognition of the need to acknowledge teachers' beliefs and perception, so far this area has been under-researched in the country. In addition, investigations of learner autonomy in Thailand have been focused more on learners, rather than from the teachers' perspectives. How learner autonomy has been viewed and practiced by lecturers in the higher education level has rarely been studied.

This review provides an insight into the concept and the development of learner autonomy in the following areas:

(1) Learners' beliefs and perceptions

(2) Significance of teachers

(3) Autonomy-fostering activities/tools

(4) Autonomy-related concepts 


\section{Learners' Beliefs and Perceptions}

Several studies have shown that a learner's readiness to be autonomous is oftentimes reflected in how they perceive their own roles and what they expect from the teacher (Cotterall, 1995, 1999; Januin, 2007; Sanprasert, 2010; Wei, 2009). Cotterall (1995) indicated the necessity to gauge learners' readiness for changes before any intervention occurs. When she examined the factors underlying students' beliefs, her results suggested that students who viewed their teacher as an authority figure, rather than as a facilitator, were not ready for autonomy. Students' perception of the teacher as an authority figure may hinder the development of learner autonomy, as it inhibits the teachers transferring responsibility for the management of learning to the students. Another of her studies (Cotterall, 1999) confirmed the necessity of acknowledging learner beliefs. That is, students viewed the teacher's ability to show how to learn as more important than the ability to teach. They also realized that they lacked monitoring and evaluation skills. This finding allows teachers to identify areas to focus on if learner autonomy is to be promoted. Items in the questionnaire were partly adapted from her earlier study of learners' beliefs (Cotterall, 1995).

Cotterall's (1995) questionnaire was adapted and used in later studies by Januin (2007), Sanprasert (2010) and Wei (2009) in their investigation of learner perceptions. Results from these studies imply a need to investigate beliefs, attitudes, and perceptions that learners hold prior to the implementation of learner autonomy. Results from these studies reflect the mismatch of students' expectations and teachers' actual instructional practices. Students were positive towards autonomous learning and expected teachers to teach them about how to learn autonomously. However, teachers did not provide knowledge about learning strategies to students and did not give room for students to practice learning strategies. This resulted in students feeling unconfident, doubtful and anxious when taking charge of their own learning. 
The investigation of learners' beliefs by Zhou and Zhang (2005) also supported the possible necessity of knowing learners' beliefs beforehand. The students in this study appeared to be influenced by the examinationoriented system, even though they seemed to realize the ineffectiveness of traditional ways of learning. Hence they were likely to adopt learning methods that focused more on memorizing than thinking, which hindered their high-order thinking skills.

Students' perception of the level to which their teachers support autonomous learning could have a significant impact on their own learning behaviours. Williams and Deci (1996) demonstrated that students who perceived their instructors as being supportive of a student's autonomy were more likely to be more autonomous in their learning. These findings were later confirmed by Black and Deci (2000). The students' degree of self-regulated learning behaviours could be predicted by noting their perceptions of their instructors' support for autonomy. Findings from these two studies emphasize the importance of students' perceptions of course assessments and their teachers' disposition towards their choice of learning behaviours.

\section{Significance of Teachers}

\section{Teachers' beliefs and perceptions.}

The results of this review indicated that teachers' perspectives and practices are under-researched in Thai contexts. So far, this area has been examined by merely two studies. Nonkukhetkhong, Baldauf, Richard and Moni (2006) and Israsena (2007) carried out studies that directly address teachers' perspectives towards learner-centered teaching. Both studies asserted that teachers' strong belief in learner-centred teaching did not translate into practice, because they lack the necessary conceptual and operational knowledge. The studies suggest that a priority for the successful implementation of learner-centred teaching in Thailand is to provide a model program and skill development for teachers. However, these two studies did 
not provide evidence of the existing state of learner autonomy in Thai higher education. In addition, they were perspectives of teachers from preuniversity levels i.e. secondary education and early childhood education respectively.

The findings of the review of the literature suggest the influence that teachers' beliefs and perception might have on their teaching behaviours. Littlewood (2003) claimed that teachers might play a part in students' inability to take charge of their learning. This challenges the commonly held assumptions of Asian and Western learning preferences because the study posited that the apparent passiveness of Asian students resulted from the way they were expected by the teachers to learn traditionally. This made students unable to behave otherwise. Littlewood's study implies a need to address teachers' beliefs and perceptions before implementing educational innovations.

Similarly, traditional teaching as a barrier to learner autonomy has been criticized in a study by Liu (2005). Findings from Liu's study suggest that Chinese students were not ready to be autonomous because of the teacherdominated methodology. However, the root causes of the passive nature of students in Littlewood's (2003) and Liu's (2005) studies were different. Students in Littlewood's study behaved as passive learners because they were expected to and could not behave otherwise. In contrast, the passiveness of students in Liu's study seemed to be rooted in the students' own preferences. They preferred a traditional way of learning and did not want to behave otherwise.

Teachers as one of the causes of students' inability to learn autonomously has been further reported in a number of studies. Sert (2006) indicated that activities that Turkish teachers employed in the classroom did not assist in enabling students to be aware of their needs, goals, strengths and weaknesses. In Nicolaides' (2008) study, academic contexts shaped how 
students viewed teachers. Though students realized the importance of controlling their own learning, the attitude that teachers know best seems to affect their willingness to exercise autonomy. Students felt their freedom to follow their own beliefs and make their own decision was limited within the classroom. Using student teachers as participants, both Sert's (2006) and Nicolaides'(2008) studies imply that these student teachers will probably not adopt tools to promote autonomous learning amongst their future students as they themselves have been shaped by traditional ways of teaching.

\section{Teachers' classroom behaviours.}

A number of studies included in the systematic review demonstrate the significant impact of teachers' teaching behaviours on students' learning behaviours. Reeve, Jang, Carrell, Jeon, and Barch, (2004), for example, revealed that teachers' behaviours that were supportive to learner autonomy increased students' engagement in learning. This autonomy-supportive behaviour is considered as a motivating style that can engage students' learning. In order for teachers to behave in ways that support learner autonomy, the study called for a development program. The program could provide answers to questions related to pedagogical practices that teachers might have. This study shows that professional development workshops seem to provide "concrete answers" (p. 167) to questions of how teachers could support autonomy in their classes.

Findings from a later study by Zhou, Ma and Deci (2009) confirmed that teachers' teaching behaviours influence students' perception of their learning. Findings from this study are consistent with those from a recent study by McLachlan and Hagger (2010), which also studied the influence of teachers' autonomy-supportive teaching behaviours on students' perception towards learning. Findings from McLachlan and Hagger (2010) suggested that teachers could be more supportive of learner autonomy given that they understand more about the principles and benefit of learner autonomy, and receive more knowledge about which teaching behaviours support and 
hinder it. McLachlan and Hagger's (2010) study was similar to an early study conducted by Reeve et al. (2004) that suggested that teachers exposed to an autonomy-based workshop showed an increase in their autonomysupportive behaviours in their classroom practices. The interventions in both studies were focused on giving knowledge about principles of learner autonomy and behaviours that would facilitate development of learner autonomy in classroom pedagogy.

\section{Autonomy-fostering Activities/Tools}

Autonomy is not an innate capacity and skills to learn autonomously do not come naturally; they are "learned skills" (Areglado, Bradley, \& Lane, 1996, p.51). This is the crux of the paradox; learner autonomy suggests the student's capacity to learn independently from the teacher, but in order to do so, they need assistance from the teacher. This paradox confirms what Macaro (1997) stated: "the presence or the absence of the teacher is not the yardstick by which one can judge autonomous learning skills" (p.168). In a classroom and learning contexts that aim to promote learner autonomy, the teacher, therefore, is there to aid learners in the pursuit of their autonomy.

However, the results from the systematic review suggest that there may not be one single best way to promote learner autonomy. An activity that promotes learner autonomy in one setting may fail to do so in other settings. An example of this is evident Bakar's (2007) study, which examined the use of a computer in learning English. Findings from Bakar's study suggested that the use of computers might not be appropriate for all students. A similar study by Walters and Bozkurt (2009) was carried out to examine the use of vocabulary notebooks in higher education in Turkey. Its findings indicated that the use of vocabulary notebooks, which were believed to help facilitate learners in controlling their own education, did not seem workable in the context of Turkey. Findings from these two studies suggested that strategies for developing learner autonomy need to be contextualized and the use of one strategy to enhance learner autonomy might not be enough. 
The finding that any single pedagogy for promoting learner autonomy cannot be prescribed universally is also evident in a later study by Lo (2010). Lo examined the use of reflective portfolios in the contexts of Taiwan. Numerous researchers, particularly those from western countries, have claimed that reflective portfolios are able to enhance student autonomy (e.g. Alexiou \& Paraskeva 2010; González, 2009; Meeus, Van Petegem \& Meijer 2008). However, the Taiwanese students' inability to complete the critical reflection part of the portfolios suggested that this tool might not work in Taiwanese contexts. Using portfolios alone cannot lead to the successful pursuit of learner autonomy. Teachers, as suggested in the study, need to enhance critical thinking skills and change students' perception of evaluations from an "end-product" to one that is "process-oriented" (Lo, 2010, p.90).

Taken together, all those studies indicate that the idea of helping students to become autonomous by the teacher devising a specific framework and strictly following it may not be workable. In Murphey (2003)'s point of view, managing or teaching autonomy is "anti-autonomous" (p.7). Rather than a fixed framework, Murphey proposed what he regards as "autonomy- inviting structures", which should include "possibilities for autonomous action at different developmental stages and offer as many choices as possible" (p.4). One tool that might be workable in some environments might not be so in others, suggesting that the strategies for promoting learner autonomy cannot be rigidly prescribed.

\section{Autonomy-related Concepts}

Although autonomy-inviting structures are not written in stone and cannot guarantee the successful pursuit of learner autonomy (Murphey, 2003), results from the systematic review suggest certain common principles that need to be taken into account when promoting learner autonomy. These include metacognition, self-awareness, reflection, and self-evaluation/ assessment. 


\section{Metacognition.}

In language learning, metacognitive knowledge becomes particularly essential for the purposes of learner autonomy or self-directed learning. This is because it can be used as "the knowledge base" by students when making decisions about their own learning (Cotterall \& Murray, 2009, p.34). Wenden (1998) defined metacognitive knowledge as "knowledge about learning" (p.516). This knowledge consists of three categories of knowledge, which learners bring with them in the process of language learning: person knowledge, task knowledge and strategic knowledge (Flavell, 1979). Victori and Lockhart (1995) highlighted metacognitive knowledge as the knowledge about one's self as the learner as well as knowledge of "factors influencing language learning and about the nature of language learning and teaching" (p.224).

Holme and Chalauisaeng (2006) recommended the use of Participatory Appraisal (PA) as a means of enhancing students' metacognition. Their study found that PA enables students to assess their needs, which in turn helps them to set their learning targets accordingly. This approach offers a "participatory mechanism" (p.416) for students to understand the real purpose of their learning and find out their own way of achieving this purpose. When engaging in PA, students are enabled to exercise their metacognition, as they begin to know more about themselves as a learner, and know more about the task at hand.

The importance of metacognition is also stressed in Murphy's (2008) exploration of course materials in the Open University. In order to enhance the development of learner autonomy, Murphy suggests the course writers expose students to more metacognitive strategies. This also implies the essential role that teachers should play in designing classroom activities and materials, which should facilitate the development of students' metacognition. 


\section{Self-awareness.}

The importance of learners being aware of themselves and their learning has been highlighted in a number of studies (e.g. Cotterall, 1995; Goh, 1997; Liu, 2005; Sert, 2006). Learning will be most meaningful and learners will make the most of it only when they are aware of it (Crabbe, 1993). Therefore, raising learner awareness should be included as the first stage of training for learner autonomy and the environment surrounding learners should stimulate self-awareness (Liu, 2005).

Findings from the literature review suggest that learner awareness embraces both awareness of the language learning process and awareness of the learners themselves. Awareness of language learning signifies the knowledge of factors that affect - either positively or negatively - the language learning process. This awareness is sometimes intertwined with metacognitive awareness. Knowledge of this kind helps learners to foresee problems that might occur along the path of their learning, and to prepare themselves with strategies for overcoming those problems. Thus, learners are less likely to be overwhelmed or discouraged in their real practice. Being forewarned, the learner is "forearmed" (Dickinson, 1996, p.45). The other aspect of awareness is the knowledge about the learners' "self". This knowledge includes knowing their own weaknesses and strengths (Natri, 2007) and their wants, needs and preferred learning style (Breen \& Mann, 1997) so that learners can identify and achieve their own goals.

Raising these kinds of awareness can be carried out during learner training sessions and teachers have many different ways to help learners in doing so. Teeraputon (2003) encouraged the students to record their learning experience in a book. By recording the stages of their learning, the students become aware of their learning. Anderson and Bourke (2007) recommended the explicit incorporation of strategy instruction into the curriculum as a way to enhance students' awareness of their learning. Strategy instruction will 
raise learners' awareness of their own learning, which will enhance their ability to take charge of their learning.

\section{Reflection.}

Reflection is one way to change the direction of learning; it "opens the mind's pathway to improved self-direction" (Areglado et al., 1996, p.27). Reflection enables the learner to evaluate the consequences of the decisions they make. This is a way to let them share the responsibility of their own actions (Scharle \& Szabó, 2000). Accepting shared responsibility entails the capacity of learners to reflect so that the content and process of their learning will be under their "conscious control" (Little, 1995, p.175). A class which is focused more on learning than teaching necessitates the learner to reflect on their situation, goals, roles, assumptions and, of course, learning (Hammond \& Collins, 1991). When students reflect on their own learning, they will have the opportunity to engage in self-monitoring. That is, they will examine themselves and their learning at that moment, which may result in the discovery of more effective learning approaches and strategies.

Though reflection might be a hard-earned skill for some learners, it can be developed by appropriate strategies and "sufficient emphasis" from teachers (Hammond \& Collins, 1991, p. 178). The teacher can help their students to reflect through a variety of activities. Keeping dairies is one way of doing so. Goh (1997) indicated that diaries give students opportunities to discuss their personal needs and learning. Similarly, Porto (2007) postulated that when writing learning diaries students become "solid and robust explorers of language, of their learning, and of themselves" (p.677). In such a sense, the diaries support the development of autonomy by encouraging learners to be reflective and helping them to judge their own learning and events in their classroom. Goh (1997) and Porto (2007) implied that in addition to providing a platform for learners to reflect, diaries become a rich source of information, which teachers can then use as a tool to design tasks and classroom activities. Through this tool, the teachers will be able to better 
understand their students, because diaries will bring to "the surface information related to attitudes, social norms, habits and expectations" of the students (Porto, 2007, p.672).

Apart from diaries, reflection can also be done through other means. González (2009) used portfolios as a tool for promoting learner autonomy. By keeping a record of their learning experiences, the students in the study became aware of their weakness and strengths. Consequently, the students were be able to set their own goal and plan their own learning in a more realistic way, and had a greater sense of ownership of the learning. A more recent study by Alexiou and Paraskeva (2010) demonstrated that the portfolio could also be done electronically. The reflection activity ownership was embedded in a technological tool - an e-portfolio. Students reflected on their own learning, and felt a sense of ownership in their learning while doing portfolios, as they acted as active participants in their own learning process.

\section{Self-evaluation/assessment.}

Evaluation is usually viewed as the most sacred part of the learning/teaching process (Hammond \& Collins, 1991), and hence is to be done by the most authoritarian figure in the process: the teacher. This view is fundamentally conventional because it excludes the learner from the process and neglects the sharing of responsibility between the teacher and the learner. In autonomous learning, this process is supposed to be shared. According to Natri (2007), students will be more responsible for their own learning if they have chance to take part in the evaluation process. In doing so, learners are allowed to "take the first steps toward greater learner responsibility" (p.111).

Carter (2006) regarded self-evaluation as one of the "higher level learning skills" which are essential in higher education (p.7). It facilitates the development of learner autonomy, as it frees learners from a preoccupation 
with examination. When evaluating one's own self, the learner no longer defines his/her achievement according to the examination results. The individual's progress is compared with the goals that they have set themselves. Assessment is then not to be viewed as an "end" product of learning. It, on the other hand, becomes the learners' "diagnosis" tool for their learning progress (Tepsuriwong \& Srisunakrua, 2009, p. 365).

Self-evaluation is also regarded as a type of metacognitive strategy, which should become an alternative or addition to traditional forms of assessment (Hedge, 2000). The process of self-assessment does not exclude the presence of teachers. They still need to be there to support the process by, for instance, establishing evaluation standards or criteria. This self-evaluation skill is particularly essential when learning is taking place beyond the classroom, such as in self-access centers or open learning centers. Successful learning in such places is conditional on the ability of the users to perform selfassessment (Hedge, 2000).

Self-assessment, apart from making learners independent of teachers in terms of feedback, allows the teacher to acknowledge the learning needs of individual learners. It can be used as a source of knowledge, which enables the teacher to know more about his/her students - their learning histories, preferred learning methods, learning goals, difficulties, views and beliefs. By drawing on this knowledge, the teacher can design activities and materials that tailor to particular students' learning style (Natri, 2007). This view supports the roles of the teacher in a self-directed learning classroom proposed by Areglado et al. (1996): the assignments in class should not be the same; rather, they should be assigned according to a learner's "developmental needs" (p.22). 


\section{Chapter Summary}

This chapter indicates that despite differences in studies conducted in Thailand and those conducted elsewhere, there is one thing that the studies all share in common: the essential role teachers play in the development of learner autonomy. The results of the literature review suggest the need to investigate teachers' perceptions before the commencement of any efforts to promote learner autonomy. Investigating teachers' perspectives and practices seems particularly relevant in the context of Thailand, given that the literature review revealed little evidence to describe the perspectives and practices of teachers within the country.

The results of the review suggest that a survey might be suitable to address the gaps in terms of teachers' perspectives. The questionnaire by Cotterall (1999) is a suitable instrument to measure these perspectives. Her questionnaire was adapted from the one she used in her 1995 study (Cotterall, 1995). The 1999 version employed factor analysis to enhance its validity. Some items were based on her review of the literature, which helped identify major variables in second language learning and methodological issues in investigating beliefs.

The other gaps in the literature (i.e. how learner autonomy has been practiced) require an in-depth investigation, in which qualitative cases studies seem to provide the best opportunity to obtain answers. 


\section{CHAPTER 3: THEORITICAL AND METHODOLOGICALFRAMEWORKS}

\section{Introduction}

In addition to the gaps in the literature pertaining to learner autonomy, results of the systematic review of literature presented in Chapter 2 show that learner autonomy has been interpreted in many different ways. Several studies associated learner autonomy with the ability to learn independently (Bakar 2007; Bolhuis \& Voeten, 2001; Clemente 2001; Lee, 1998; Wiriyakarun, 2002). Some studies seemed to suggest a link between learner autonomy and particular modes of learning such as learning in self-access centers, learning in a particular program, and technology-based learning (Erstad, 2003; Charupan, Soranastaporn, \& Suwatttananand 2001; Martin, West \& Bill, 2008; Sanprasert, 2010; Teeraputon, 2003). For the purpose of this thesis, however, learner autonomy is considered within the context of Self Determination Theory (SDT) (Deci \& Ryan, 1985) and conceptualized as part of personal autonomy. In this chapter I therefore present a theoretical framework of the thesis. In presenting the theoretical framework, I discuss the multiple interpretations of learner autonomy and present a concept of learner autonomy from the position of SDT. Learner autonomy in language learning and the relation between teachers and learner autonomy are also discussed in the final section of the theoretical framework. After this, I discuss the methodological framework of the thesis, in which a mixed method approach has been adopted. A justification of the use of this approach in my study is also provided.

\section{Theoretical Framework}

\section{Multiple Views of Learner Autonomy}

The term 'learner autonomy' appears to have been derived from the concept of autonomy in the political discourse of ancient Greece. According to Wall (1998), the term is a combination of two Greek terms: auto, which means self, and nomos, which means law. In a political sense, autonomy is used to refer to a state being self-ruling and self-governing. When applied to an 
individual, autonomy signifies the capacity of the individual to act as an autonomous agent; that is, to be independent and not governed by others. The description of an autonomous person given by Gibbs (1979) implies an analogy with the original political concept of the term autonomy. From Gibbs' point of view, an autonomous person must be free from external authority and "capable of formulating and following a rule, pattern or policy of acting and working" (p. 119).

Gibbs' (1979) analogy of personal autonomy bears a resemblance to Wall's (1998) ideal of self-government. To achieve this ideal, people need:

(a) the capacity to choose projects and sustain commitments, (b) the independence necessary to chart their own course through life and to develop their own understanding of what is valuable and worth doing, (c) the selfconsciousness and vigor to take control of their affairs, and (d) an environment that provides them with a wide range of eligible pursuits to choose from (Wall, 1998, p.132).

In education, Holec (1981) conceptualized learner autonomy as the ability to undertake one's own learning, especially the ability to choose and to make decisions. Holec contended that autonomy occurs when learners are able and willing to take charge of their own learning. This means learners can independently choose goals, materials, tasks and strategies, have choices in carrying out the chosen tasks and evaluate themselves. Another conceptualization of learner autonomy in education was provided by Winch (1999). Winch viewed learner autonomy as an important objective that democratic societies should aim towards through their educational systems. In relation to this view, autonomy might be thought to signify the underlying function of education in its aim towards liberating or freeing people from authority of others (Marshall, 1996). 


\section{Self Determination Theory (SDT)}

Self Determination Theory posits that human beings have innate tendencies for self-development (Ryan \& Deci, 2002). These tendencies are the "fundamental process of human nature" which can be supported or thwarted by social contexts (Ryan \& Deci, 2002, p.5). Self-development and the full functioning of a person occur when their basic psychological needs of competence, autonomy and relatedness are satisfied.

According to SDT, behaviours can be intrinsically or extrinsically motivated. Intrinsic motivation occurs when individuals perform an action because of their interest, enjoyment, and satisfaction in doing so. They expect no separable consequence and require no external contingencies in order to perform that action (Deci, Ryan \& Williams, 1996). Extrinsically motivated people, in contrast, perform an activity for external tangible outcomes, not for the intrinsic reinforcement derived from engaging in the activity itself (Niemiec \& Ryan, 2009). They perform an activity with the expectation of separable consequences such as receiving a reward, avoiding punishment, or gaining acceptance (Deci et al., 1996).

However, SDT contends that intrinsic and extrinsic motivations should not be viewed as antagonistic (Rigby, Deci, Patrick, \& Ryan, 1992). Although intrinsic motivation is the prototype of autonomous action, certain forms of extrinsic motivation can be associated with autonomous actions. Deci and Ryan (1985) classified extrinsic regulation into four types according to its degree of self-determination.

External regulation describes the least autonomous type of extrinsic motivation in which an individual's behaviours are controlled by external prompts from someone else, such as rewards and punishment from the teacher. 
Introjected regulation describes behaviours that do not require prompts or pressures from an external controller. Rather, the control comes from the person who performs those behaviours. Thus, the controlled and the controller are the same person. Prompts in this regulation are related to the sense of self such as the feeling of shame, guilt or self-esteem. These feeling then become internal pressures.

Identified regulation is when people value the outcome of an action and realise that it is necessary to perform a particular action in order to produce the outcome. People accept the regulation as their own. Through this process, the controlled behaviours become more autonomous. The sense of choice increases while inner conflict decreases, and people become more responsible in initiating and maintaining their own action (Black \& Deci, 2000).

Integrated regulation is the most autonomous form of extrinsic motivation and is the endpoint of the continuum (Rigby et al., 1992). Integrated extrinsic motivation is comparable to intrinsic motivation as both represent autonomy and self-determination, except that the former is instrumental while the latter is autotelic, or done for its own sake (Deci \& Ryan, 1985).

In line with the conceptualization of motivation on the continuum, Auerbach (2007) suggested that being autonomous is a state along a continuum, which can be context specific. An individual can be autonomous in one particular situation, but less autonomous in another. Thus, one's degree of autonomy is "fluid, variable, ideologically situated" (Auerbach, 2007, p.84). The view of autonomy as a non-static state suggested in SDT and Auerbach's proposition imply the possibility of individuals to be transformed from less autonomous to more autonomous agents given that the elements of the contexts in which they live are conducive to this. More specifically, as suggested in SDT, when the social contexts are autonomy-supportive, people tend to exercise greater autonomy, whereas a lesser level of autonomy will be exercised in the 
controlling contexts (Deci \& Ryan, 1985; Williams \& Deci, 1996). Taken together, all these signify the significance of contexts that the behaviours are situated.

\section{SDT and Learner Autonomy}

SDT posits that autonomy should not be viewed as the opposite of dependence (Deci \& Ryan, 1985). Rather, it is a "feeling of volition that can accompany any act, whether dependent or independent, collectivist or individualist" (Ryan \& Deci, 2000b, p. 74). The connection between learner autonomy and the absence of the teacher or learning "at home, with a computer, in a self-access center etc." can be regarded as a "misconception" (Smith, 2003, p. 2). Thus, autonomous learners are not expected to be completely independent of the teacher. In line with this conceptualization, Benson's (2008) view of autonomy in learning is in accordance with SDT. His view is grounded in the concept of personal autonomy in which 'individuals must strive to lead autonomous lives and society must strive to respect the freedom such lives require" (p. 18).

SDT defines learning as a natural process, which is facilitated by environments that sustain three basic needs of human beings: autonomy, competence, and relatedness. Learning occurs out of "interest, exploration, and assimilation" and takes place after and beyond classroom contexts (Rigby et al., 1992, pp. 165-166). Learning becomes a life-long process as learning transcends the confinement of formal classroom contexts. As such, it is important that learners develop life-long learning skills and retain them even after their formal education ends (Lee, 1998). This suggests that it is necessary that intrinsic motivation occur in the learning process.

However, many tasks and learning activities that students are required to performed are not intrinsically motivating (Ryan \& Deci, 2000a). It is therefore important for the teacher to understand different types of extrinsic 
motivation and know how to transform a less autonomous type to a more autonomous one.

\section{Teachers and Learner autonomy}

SDT contends that the satisfaction of students' basic psychological needs leads to students' academic achievement and well-being (Niemiec \& Ryan, 2009). It emphasizes the need for teachers to display autonomy-supportive behaviour in classroom, as the perceived autonomy-supportiveness of the teacher results in students becoming more autonomous in their learning (Williams \& Deci, 1996). Autonomy-supportive behaviours that the teacher could adopt include acknowledging students feelings, taking their frame of reference when making decisions, providing them with choice, and avoiding pressure and control (Deci \&Ryan, 1985).

The view of autonomy-supportive teaching behaviours entails certain changes in teachers' roles. Its realization will never be possible if the teacher still embraces the old traditional roles. Areglado et al. (1996) stated that teachers can never change their students as long as they still deliver their instruction in traditional teacher-centred ways. Teachers should no longer be the "purveyors of knowledge" (McDevitt, 1997, p.36). Rather, knowledge can be reshaped and organized by learners. Thus, the teacher sets up "a dialogue in which the learner can reshape his knowledge through interaction with others" (Barnes, 1992, p.144).

Voller (1997) described new roles for a teacher as being facilitator, counselor, and resource. When teachers function as a facilitator, they provide support for learning, either technical or psycho-social. As a technical provider, the teacher helps learners (a) to plan and carry out their independent language learning, (b) to evaluate themselves, and (c) to acquire the skills and knowledge needed to implement above. Psycho-social support refers to (a) being caring, supportive, patient, empathic, open and non-judgmental, (b) 
motivating learners, and (c) raising a learner's awareness of autonomous learning.

Teacher as a counselor places an emphasis on one-to-one interaction. A counselor generally is a person who provides advice to those who need it. According to Riley (1997), when teachers act as counselors, they give students suggestions regarding aspects of learning e.g. materials, methodology, sources, and self-assessment techniques. They become good listeners, by carefully listening to their students and providing assistance. Rather than answering questions, counseling teachers offers alternatives for students to make decisions on their own.

When the teacher acts as a resource, the teacher is seen as a source of knowledge and expertise (Benson \& Voller, 1997). To optimize learning conditions for the development of learner autonomy, the teacher has to raise learners' awareness of a wide range of knowledge materials and learning strategies.

However, the idea of helping students to become autonomous by the teacher devising a specific set of activities and strictly following their plan may jeopardize learner autonomy. Murphey's (2003) point of view is that managing or teaching autonomy is "anti-autonomous" (p. 7). Rather than a fixed set of activities or materials, Murphey suggested the teacher provide students with as many choices and opportunities to exercise their autonomy as possible. According to Cotterall and Murray (2009), the teacher is to provide students with a learning environment conducive to their metacognitive knowledge. In order to do so, the teacher will need to provide not only support, but also opportunities for students to personalize their learning, engage in learning experiences, reflect on their learning process and try out their own goals, materials and strategies. 


\section{Learner Autonomy in Language Learning}

Learner autonomy in language learning has been viewed in many different ways. One way it has been viewed is as a situation in which the learner is "totally responsible" for all the decisions he/she makes for their learning (Dickinson, 1987, p.11). This view signifies full autonomy, which is referred to a situation in which the learner is independent and learns with the absence of the teacher. However, Little's (1990) interpretation of learner autonomy is contradictory to this. For him, learner autonomy should signify neither the teacher taking no responsibility nor the learner working with absolute freedom and in isolation from the teacher and peers. Being completely independent or, in other words, having a total detachment is not an indicator of autonomy.

The development of learner autonomy can be either a means to effective language learning, or the end of language learning itself. It is a means because it requires involvement from the learner in their language study, which in turn leads to the success of their study (Tudor, 1996). Little (1999) considered learner involvement as one of the three factors, in addition to learner reflection and appropriate target language use, of successful language learning. According to SDT, autonomy-supportive teaching is associated with the quality of students' learning. In comparing students' learning from autonomy-supportive and controlling classrooms, Deci, Schwartz, Sheinman and Ryan (1981) found that students in autonomy-supportive classrooms tended to be more curious and independent, and had higher self-esteem than students from controlling classroom.

Alternatively, learner autonomy becomes one of the key goals of a number of projects, courses, and many modes of learning. In this respect, learner autonomy becomes one end of language learning. The notion of autonomy in language learning being potential either a means or an end in itself resonates with the question of the orientation of education. That is, it parallels the question of whether education should be product-oriented, in which the goal 
of education is to produce an autonomous person, or be process-oriented which requires students to act autonomously (Boud, 1981).

Despite the multiple views of learner autonomy, in this thesis learner autonomy is defined by incorporating elements of personal autonomy as posited in SDT. Thus, learner autonomy is the learner's psychological capability to take control of their own learning by making their own decisions and initiating behaviours that lead to the optimal outcomes of their learning. It is essential for educational and social contexts to provide environments that maximize the learner's capability to do so.

No matter what it is used for, autonomy should be viewed neither as a form of teaching or learning, nor the outcome of a particular mode of teaching (Auerbach, 2007). It should not be treated as a way of organizing teaching or learning, because if it is, it becomes a method that can be abandoned when it is judged unsuccessful (Little, 2007).

\section{Methodological Framework}

Self-determination theory considers the impact of varying contexts on an individual's fulfillment of autonomy. Taking this into account, I believe that it is necessary to use a research methodology that takes into account the environment in which the teaching involving the development of autonomy is occurring. In addition to answering my five research questions, a mixed method approach, in which I include cases studies, allowed me to include the contexts in Thailand which might be associated with the current position of learner autonomy in the country.

\section{Mixed Methods Research}

Tashakkori and Teddlie (2003) viewed the mixed methods design as a "separate methodological orientation with its own world view, vocabulary, and techniques..." (p. 679). In line with this view, the mixed method research design can be call the "third research paradigm" (Johnson \& Onwuegbuzie, 
2004, p. 15) in addition to quantitative and qualitative paradigms. Creswell and Plano Clark (2007) called it a methodology and a method. As a methodology, it entails the philosophical stances that direct the researchers to mix both quantitative and qualitative approaches in phases of their research process. As a method, the focus is on collecting, analyzing, and mixing both quantitative and qualitative data in one single study or series of studies.

There are many designs that could be incorporated into a mixed-methods approach. One research design employed in this thesis is an explanatory design with the participant selection model (Creswell \& Plano Clark, 2007) as illustrated in Figure 3.1. The study started with a quantitative survey, which was administered to 297 lecturers who taught language courses across 37 universities in Thailand. The second phase was qualitative case studies of the practices of five university lecturers identified from the survey results.

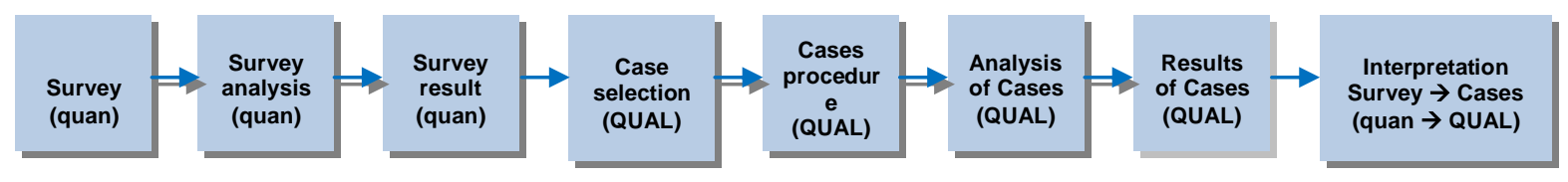

Figure 3.1. Research procedure (adapted from Creswell \& Plano Clark, 2007, p.73)

According to Creswell and Plano Clark (2007), this explanatory design is not complicated to implement as it is clear-cut and does not require a research team. A single researcher conducts quantitative and qualitative methods in a separate phase and collects one type of data at a time. In my study, the qualitative phase was commenced after the quantitative survey was finished. Quantitative information was used to identify and purposefully select participants for the follow-up, in-depth qualitative study. The anticipated outcome was to be able to better explain the results of the quantitative phase by the analysis of the cases, which provided more qualitative data. 


\section{Justification for the Use of Mixed Methods Research}

Johnson and Onwuegbuzie (2004) argued, in their discussion of mixed methods research, that one's epistemological stance does not "dictate what specific data collection and data analytical methods researchers must use" (p.15). As a linkage between the paradigm and methods is not always necessary, the methodology that researchers adopt should not be solely determined by the epistemology.

The methodology that researchers adopt should be guided by their research questions (Johnson \& Onwuegbuzie, 2004). This is because the differences in the questions asked in this study required different types of data i.e. qualitative or qualitative and hence the need for a mixed methods approach (Punch, 2005). In this study the first three research questions were viewed as requiring quantitative data. These quantitative survey results were then used as the purposeful sampling for selecting the sample for the second phase of the study. The fourth and the fifth research questions, in contrast, suggested the need for in-depth, qualitative description from cases studies.

Each methodology, either quantitative or qualitative, has its own strength and weaknesses. The mixing of them is intended to bring a balance in that the weaknesses of each are offset by using both approaches (Punch, 2005). The mixed methods approach is useful here as it is intended to represent a position between solely qualitative and solely quantitative approaches, which can therefore provide for "multiple viewpoints, perspectives, positions and standpoints" (Johnson, Onwuegbuzie, \& Turner 2007, p.113). In conclusion, my selection of mixed methods was based on my research questions. The mixing of both approach helped me to answer questions that can be answered by neither approach alone. 


\section{Chapter Summary}

SDT provides a theoretical framework for this thesis. In this theory, autonomy is one of the basic needs of human beings that need to be satisfied in order to be fully functional. This theory also centres on the positive potential in human beings to learn. It also indicates the essential impact of contexts on autonomy. The essential function of teachers in managing teaching and classroom contexts is recognized within this theory. This prompted the adoption of a mixed methods design in order to investigate learner autonomy and the influence of context. 


\section{CHAPTER 4: PHASE 1 - SURVEY}

\section{Introduction}

This chapter reports on the first phase of the study. This study phase examined the extent to which university lecturers in Thailand valued and promoted learner autonomy in their courses. Specifically, this phase of the study was designed to answer the first three research questions, which were developed from the results of the systematic literature review reported in Chapter 2. These questions were:

1. To what extent does the sample of Thai lecturers report that they believe in or value learner autonomy?

2. To what extent does the sample of Thai lecturers report that they are confident in their students' ability to exercise autonomy in their learning?

3. To what extent does the sample of Thai lecturers report that they allow their students to exercise autonomy in their learning?

In addition to aiming to answer the above questions, the first phase of the study also aimed to identify participants for participation in the more indepth case studies planned for Phase 2. Thus, this initial quantitative survey was used as a "wider net" to "target a specific population of interests" (HesseBiber, 2010, p. 465).

The instrument for this first phase of the research was a survey questionnaire. Wiersma and Jurs (2005) considered this type of questionnaire to be an appropriate instrument when conducting a survey study of the type conducted in this first phase. 


\section{Method}

\section{Participants and Recruitment Procedures}

Because the survey was designed to be completed by a sample of languagestudies lecturers in a sample of Universities in Thailand, recruitment focused on identifying lecturers who taught language courses across a number of universities in Thailand. Language courses were defined as courses focusing on the teaching of languages other than Thai, which were formally offered by the university to its students. These could be any course offered for students of any year, and could be either compulsory or elective. Courses taking the form of a seminar, a project, or a tutoring session were not included, nor were summer courses. In total, 530 lecturers, who were full-time lecturers, were recruited using the following 5-step recruitment and enrollment process:

Step 1: Selecting locations. Universities in the Bangkok region and from the southern provinces of Thailand were targeted. Within the Bangkok region, universities located in six provinces were included. These provinces were Pathum Thani, Nonthaburi, Samut Prakan, Samut Songkhram, Samut Sakhon, and Nakhon Pathom. Southern Thailand consists of 14 provinces, namely: Chumphon, Ranong, Surat Thani, Phang Nga, Phuket, Krabi, Nakhon Si Thammarat, Phattalung, Trang, Song Kla, Pattani, Satun, Yala, and Narathiwat. Only 11 of the 14 provinces were included. Universities in Satun, Yala, and Narathiwat were not included because these three provinces were experiencing considerable violence from separatists' movements at the time that this survey was undertaken.

Step 2 Listing universities. To identify potential universities in the Bangkok region and southern provinces of Thailand, I visited the website of the Office of the Higher Education Commission. This website contains the names and locations of all universities in Thailand. Across Thailand there are a total of 
89 government and 78 private universities. Only universities located in the selected areas were included. In total, 43 universities were identified.

Step 3 Recruiting participants. I visited the website of 36 of the 43 universities to identify lectures involved in language education i.e. lecturers in the faculties of Arts, Liberal Arts, Humanities and Social Sciences, Department of Languages, or the language center/institute(if this existed). Only full-time lecturers of language(s) were selected. Using these criteria, I identified 547 lectures.

For the remaining seven universities, which did not have websites, I obtained the names of lecturers of language(s) by requesting them either from my colleagues or university officers. This process identified a further 100 lecturers, for a total of 647 potential participants.

Step 4: Requesting permission. Prior to sending the questionnaire to the identified participants, I sent a letter, either by mail or in person, to the Dean of the Faculty or the Director of the Language Institute of each university requesting permission to conduct the research and make contact with their lecturers. A copy of this letter is provided in Appendix B. Initially the letter was sent to 43 universities, including state and private universities. However, 6 universities refused to grant permission. Thus a total of 530 potential participants from 37 universities were approached to complete the survey.

Step 5: Coding the recruited participants. Names and contact information for these 530 potential participants were tabulated, including their university, department/faculty, position, room number, office and/or private telephone number(s), email address, and postal address. To ensure their confidentiality, the participants were numerically coded. 


\section{Survey Content and Development}

The questionnaire used was adapted from Cotterall (1999) (Appendix C). Items in Cotterall's questionnaire were partly adapted from an earlier study of learner beliefs (Cotterall, 1995). Some items were based on her survey of the literature, which helped identify major variables in second language learning and methodological issues involved in investigating beliefs.

It is important to note here that the participants of the 1999 questionnaire were ESL students learning in an English-speaking country (New Zealand) The questionnaire used in the present study was adapted and extended to suit the investigation's context of lecturers of foreign language courses in Thailand. That is, the adapted version (Appendix D) measured the extent of lecturers' advocacy of learner autonomy via three subscales - beliefs, confidence in students' abilities, and practice. Each subscale contained 13 items involving dimensions of teaching-learning processes. These 13 items are regarded as essential for teachers in promoting learner autonomy in Cotterall's (1999) study as well as in other literature. These dimensions were strategies-related learning activities; assessment and feedback; and strategic/psychological preparation. They included activities shown in Table 4.1. 
Table 4.1

Learning Dimensions Underlying the Questionnaire

\begin{tabular}{|c|c|}
\hline Teaching-Learning Dimensions & $\begin{array}{l}\text { Related Activities } \\
\end{array}$ \\
\hline Strategies-related activities & $\begin{array}{ll}- & \text { Skills practice } \\
- & \text { Learning goals } \\
- & \text { Learning plans } \\
- & \text { Learning strategies } \\
- & \text { Decisions about time } \\
- & \text { Choices of activities } \\
- & \text { Purpose of doing activities } \\
\text { - } & \text { Outside class activities }\end{array}$ \\
\hline Assessment and feedback & $\begin{array}{ll}\text { - } & \text { Checking work for mistakes } \\
\text { - } & \text { Identifying strengths and weaknesses } \\
\text { - } & \text { Learning from mistakes } \\
\text { - } & \text { Work evaluation } \\
- & \text { Test results as a learning monitor } \\
- & \text { Self-measuring of learning progress } \\
- & \text { Self-assessment }\end{array}$ \\
\hline Strategic/psychological preparation & $\begin{array}{l}\text { - } \quad \text { Training students about learning strategies } \\
\text { - } \quad \text { Giving students orientation about the course } \\
\text { - Holding a workshop for students about how to } \\
\text { learn } \\
\text { - Finding out what students expect from the } \\
\text { course } \\
\text { - Finding out students' attitudes or beliefs related } \\
\text { to language learning } \\
\text { - Analyzing students' needs }\end{array}$ \\
\hline
\end{tabular}

The questionnaire included 56 items in three parts: demographic information, teaching-learning dimensions, and general beliefs about language learning (Appendix D). Both open-ended and closed questions using a 5-point Likert scale were included. Ten items examined demographic information (Items 1-10), 4 items general beliefs about language learning (Items 23, 50, 51 and 53), and 42 items examined learner autonomy, which incorporated constructs from Table 4.1. Items to investigate the participants' beliefs include Items 11, 12, 17, 21, 28, 29, 32, 33, 40, 43, 45, 48, and 49 . Participants' confidence was investigated with Items 14, 16, 18, 20, 22, 24, $25,26,35,37,39,42$, and 46 , while their practices were examined with Items: $13,15,19,27,30,31,34,36,38,41,44,47$, and 52 . Items 54,55 and 
56 were open-ended and related to activities that they hold for psychological preparation, self-assessment and outside-class activities, respectively.

For items scored on the 5-point Likert scale, the participants rated the degree of their agreement to each statement. Scores ratings were as follows:

\section{Rate of agreement}

Strongly disagree

Disagree

Neutral

Agree

Strongly agree

\section{Score}

1

2

3

4

5

\section{Survey Distribution}

\section{Pilot-survey distribution.}

Before the questionnaire was distributed to the participants, a pilot trial of the questionnaire was completed. A pilot trial can reveal deficiencies in the instruments and procedures, which can be addressed before time and resources are spent on the real, larger studies (Cohen, Manion, \& Morrison, 2007). Specifically, 15 people who shared some of the characteristics of the potential participants completed the questionnaire to determine how long it took to complete and to provide feedback on clarity and layout. Eight of the 15 pilot participants were Thai and taught languages (English, French and Japanese) in Thailand; three in junior high schools, two in universities and three in privately-owned language schools. The draft questionnaire was emailed to them and feedback and comments were emailed back to me. By trialing the survey with these Thai teachers and lecturers, I was able to make sure that the questionnaire was understandable and suitable for a Thai setting and a Thai frame of reference. 
The other seven pilot participants were international. One of them was my co-supervisor, who is a native New Zealander. Two were PhD students in Wellington. The remaining four out of seven were lecturers in Thailand who spoke English as their first language. For those who lived in Wellington, I gave them the hard copies of the draft questionnaire. For those in Thailand, the draft questionnaire was emailed to them and feedback and comments were emailed back to me.

\section{Post-pilot survey distribution.}

The data obtained from the pilot trial were used to ensure that the wording of the items was clear. The questionnaire was revised and reworded according to the feedback received. In distribution of the revised post-pilot survey, participants' codes were put on the questionnaire to ensure confidentiality. All the participants were given the information sheet and the consent form (Appendix E) as required by Victoria University of Wellington Human Ethics Committee. The whole process of the administration of the questionnaire took approximately 3 and a half months (October 2009 Middle of January 2010). The questionnaire was distributed to lecturers who had been identified as potential participants in one of the following ways:

By mail. Participants who were not easily accessible in person were mailed the questionnaire with a stamped and addressed envelope enclosed. They were asked to return the filled-in questionnaire by using this enclosed envelop.

Direct by hand. I went in person to the universities that were easily accessible. I left a pack of the addressed questionnaire to the secretary of the participants' department/ faculty/language center. To ensure confidentiality each individual questionnaire was a separate sealed envelope. The secretary then distributed the questionnaire to the lecturers. Those who agreed to participate in the questionnaire returned their completed questionnaire to 
the secretary of their department/faculty/ center. A month later I went back to the secretaries to collect the questionnaires that had been returned.

Through networks of colleagues. I had a network of colleagues in some universities and sent the questionnaire to them. As with the direct by hand method, each individual questionnaire was in a separate sealed envelope to ensure confidentiality. These colleagues distributed the questionnaires to the lecturers according to the names on the envelopes. The participants returned their questionnaire to the colleagues in a sealed envelope. My colleagues then mailed the completed questionnaires to me.

\section{Nature of Research in Thai Educational Setting}

Based on my experience of conducting this first phase of the study, I saw that Thai people are not accustomed to "research". Often, research is viewed as something theoretical and non-practical. Research outcomes are perceived as beneficial to the researcher, not the public. When conducting the questionnaire study, I found it quite difficult to get cooperation from the person I contact initially. As discussed previously, I could not meet the lecturers in person. So I needed to contact the secretary of the Department or School. Usually, I was perceived as an intruder who added a more burden to them. Thus, when conducting the survey, I made sure that I did not add much more burden for them, by not requiring them to do anything more than distributing the packs of addressed questionnaire to the lecturers. All information of how to return the questionnaire was provided in those packs and they did not need to answer further questions from the lecturers. I had to project myself in ways to minimize this perception. In addition, projecting myself not as a researcher, but as a young student who needed their assistance increased their willingness to help, as it suggested the importance of their role in the success of my research. This aspect is reflective of the concept of seniority and power asymmetry between younger and senior people in Thai society. 
The difficulty was reduced when I met the lecturers. This is probably because the lecturers were more accustomed to research and understood the purpose of my research. With the lecturers I still also projected myself as a young student who sought assistance from them, paid respect, and truly appreciated their participation in my study. This increased the likeliness that the lecturers would respond to my questionnaire.

\section{Response Rate}

Questionnaires started coming back two weeks after distribution. As of early December 2009, the return rate was very low (approximately 20\%), I sent a follow-up email to the lecturers who had not returned the questionnaire. I also asked secretaries and colleagues to help follow up in person, by reminding the participants in their faculties or institutes. One month after this first reminder, the rate increased to about $42 \%$. In order to boost the return rate, a reminder was sent three times by email, by letter, and/or through friends or colleagues. Some of my colleagues did a follow-up in person once more with the lecturers who had not yet returned the questionnaire. For participants who were easy to access, I reminded them in person at their workplace. Eventually, around the second week of January 2010, I had received 297 returned questionnaires out of 530, representing a $56.04 \%$ return rate overall, which is considered to be a good return rate according to Monette, Sullivan, and DeJong (2011). 


\section{Results}

The quantitative data were analyzed using SPSS version 17 . The percentages and frequencies were calculated to ascertain the extent of the participants' beliefs in learner autonomy, the extent of their confidence in their students being autonomous learners, and the extent that they reported practicing the promotion of learner autonomy within their own teaching. In addition, a oneway analysis of variances (ANOVAs) was used to measure the relationship between the participants' characteristics and their beliefs in learner autonomy, their confidence in students' ability and their practices of encouraging learner autonomy.

\section{Demographic Characteristics}

The demographic characteristics of the participants that were collected were gender, age, qualifications, areas of bachelor degree, location of bachelor degree, teaching experience, workplace type, workplace location, department, and language taught. Table $4.2-4.4$ provide statistics for the participants' characteristics.

Table 4.2

Demographic Information of the Participants

\begin{tabular}{llc}
\hline \multicolumn{1}{c}{ Characteristics } & & \% Total \\
\hline Gender & Male & 20.2 \\
University type & Female & 79.8 \\
& Government & 78.8 \\
Language taught & Private & 21.2 \\
& English & 94.6 \\
Bachelor field & Others & 5.4 \\
& Arts & 45.6 \\
& Education & 26.7 \\
Location of BA & Humanities & 21.3 \\
& Others & 6.4 \\
& Thailand & 96.3 \\
\hline
\end{tabular}

Table 4.2 shows the participants 'gender, university type, the language they taught, and the field and location of their bachelor degree. The table shows 
that female participants outnumber male participants. The number of female participants is almost four times that of the male participants $(79.8 \%$ female and $20.2 \%$ male). Secondly, over three quarters of the lecturers taking part in the survey worked in government universities (78.8\%) whereas less than one fifth worked in private universities (21.2\%). The table also indicates that almost all of the lecturers surveyed (94.6\%) were lecturers of English whereas 5\% taught other languages ranging from French, German, Chinese, to Japanese, Cambodian, and Malay.

Table 4.2 further indicates that almost half of the surveyed participants (45.6\%) received bachelor degree in Arts. Almost the same number of the participants (26.7\% and 21.3\%) did their bachelor degree in Education and Humanities, respectively. The other $6.4 \%$ of the lecturers taking part in the survey did their bachelor degree in other fields, which were neither relevant to language nor education. These included statistics, business administration, political science, social science, and science. Nearly all of the participants (96.3\%) graduated from universities in Thailand. Only 3.7\% lecturers obtained their bachelors degree from overseas.

Table 4.3

University's Location and Teaching Experience (\%)

\begin{tabular}{lccccc}
\hline \multicolumn{1}{c}{ University location } & $\mathbf{1 - 5}$ years & $\mathbf{6 - 1 0}$ years & $\mathbf{1 1 - 1 5}$ years & $\mathbf{1 6 - 2 0}$ years & 21 years up \\
\hline In Bangkok and its vicinities & 20.0 & 22.4 & 17.6 & 8.5 & 31.5 \\
In a city & 18.8 & 15.8 & 5.0 & 25.7 & 34.7 \\
In a small town & 35.5 & 29.0 & 12.9 & 3.2 & 19.4 \\
Total & 21.2 & 20.9 & 12.8 & 13.8 & 31.3 \\
\hline
\end{tabular}

Table 4.3 shows that the participants had a wide range of teaching experience, from the newly trained to the highly experienced. Approximately one third of the participants (31.3\%) had been teaching for more than 21 years, $26.6 \%$ had been teaching for 11-20 years and 20.9\% had been teaching for 6-10 years. The participants with less than five years of teaching experience totaled $21.2 \%$. 
Table 4.3 also indicates that the majority of lecturers in universities located in small towns were relatively inexperienced (i.e. had less than 5 years experience) compared to lecturers in universities in Bangkok and other cities of the country. This difference is statistically significant $(p=0.000)$.

Table 4.4

University's Location and Lecturers' Qualification (\%)

\begin{tabular}{lccc}
\hline \multicolumn{1}{c}{ University location } & Bachelor's & Master's & Doctoral \\
\hline In Bangkok and its vicinities & 1.2 & 66.7 & 32.1 \\
In a city & 5.9 & 55.4 & 38.6 \\
In a small town & 6.5 & 74.2 & 19.4 \\
Total & 3.4 & 63.6 & 33.0 \\
\hline
\end{tabular}

Table 4.4 indicates that the majority of the lecturers who participated in the survey have a master's degree as their highest education, regardless of where their university is located. Approximately two third of the participants had a master's degree as their highest form of education (63.6\%). One third of the participants had a doctoral qualification (33\%). Less than $5 \%$ of the lecturers had a bachelor's degree as their highest education. Table 4.4 also shows that in small towns the different ratio of lecturers with a master's degree to those with bachelor and doctoral degrees is considerably higher than those in other locations. 


\section{Beliefs about the Nature of Language Learning}

The participants were asked to express their view on the nature of language learning. This included their view on language capability as an inborn ability, the relationship between successful language learning and grammar knowledge, ways of learning, and making mistakes in language learning. Items reflecting beliefs in the nature of language learning were rated on a five-point range, expressing different degree of agreement from 1(strongly disagree) to 5 (strongly agree). The results are presented in Table 4.5.

Table 4.5

Beliefs in the Nature of Language Learning

\begin{tabular}{|c|c|c|c|c|c|c|c|c|}
\hline \multirow[t]{2}{*}{ Items } & \multirow[t]{2}{*}{$\mathbf{N}$} & \multicolumn{5}{|c|}{ Degree of Agreement (\%) } & \multirow[t]{2}{*}{ Mean } & \multirow{2}{*}{$\begin{array}{c}\text { Std. } \\
\text { Deviation }\end{array}$} \\
\hline & & 1 & 2 & 3 & 4 & 5 & & \\
\hline $\begin{array}{l}23 . \text { I believe that successful } \\
\text { language learning is an inborn } \\
\text { ability. }\end{array}$ & 296 & 25.0 & 32.4 & 27.0 & 15.2 & 1.4 & 2.36 & 1.06 \\
\hline $\begin{array}{l}50 \text {. I believe that students need to } \\
\text { know language grammar before } \\
\text { they can communicate in that } \\
\text { language. }\end{array}$ & 296 & 3.7 & 15.2 & 33.8 & 32.8 & 14.5 & 3.39 & 1.03 \\
\hline $\begin{array}{l}\text { 51. I believe that different people } \\
\text { learn language in different ways. }\end{array}$ & 295 & 0 & 0.3 & 3.1 & 31.9 & 64.7 & 4.61 & 0.57 \\
\hline $\begin{array}{l}53 \text {. I believe that making mistake } \\
\text { is a natural part in language } \\
\text { learning. }\end{array}$ & 295 & 0.3 & 1.7 & 3.1 & 31.5 & 63.4 & 4.56 & 0.67 \\
\hline
\end{tabular}

Table 4.5 shows that approximately half of the participants (57.4\%) indicated that they did not believe language learning was an inborn ability while less than one fifth (16\%) of them regarded language competency as an inborn skill. It can be assumed from this finding that many Thai lecturers view linguistic competence as something that can be nurtured and that it depends a lot on what an individual does. This implies that Thai lecturers have a perception of the importance of students' contribution to their learning. This finding supports Holec's (1981) concept of learner autonomy, in which students are to take charge of their own learning. 
Grammar knowledge was regarded as a prerequisite by almost half of the participants (47.3\%), whereas $18.9 \%$ of the participants did not agree that students needed to know the grammar of a language before they could communicate in that language. This finding might reflect the demands of the language education system in Thailand, which may focus on accuracy instead of fluency. It also reflects "the demands of the contexts" (Cotterall 1999., p. 508) in which their learners would be using their second/foreign language after their courses (e.g. in their workplace or in their postgrad education).

Table 4.5 shows that almost all the lecturers who participated (96.6\%) agreed that different people learned languages in different ways, with $64.7 \%$ strongly agreeing. Only one participant did not agree that different people had different ways of learning a language. This finding implies that the lecturers respect the individuality of learners, who come to their classes with differences learning histories, beliefs and values, learning styles and expectations (Natri, 2007).

The final item in this section indicated the participants' attitudes to learners making mistakes. Almost all the participants (94\%) expressed their agreement with the notion that making a mistake is a natural part of learning a language. Only $2 \%$ of the participants did not view making a mistake as a natural part of learning a language. Mistakes in language learning could indicate to both the teacher and the learners the stage that the learners are at. This finding supports Victori and Lockhart's (1995) emphasis on metacognition in the development of learner autonomy, in which learners are required to have knowledge about themselves as learners.

\section{Perceptions and Practices of Learner Autonomy}

The participants' perceptions and practice of learner autonomy were examined through their beliefs, confidence and practices in the classroom (see Survey Content and Development section). This section reports on findings related to these and discusses demographic characteristics of Thai 
lecturers that may have an association with their perceptions and practices of learner autonomy.

\section{Beliefs in learner autonomy.}

The participants were asked to rate the degree of their agreement to 13 statements that were relevant to beliefs about teaching/learning aspects. Table 4.6 summarizes the participants' answers to 13 items related to their beliefs. After this, the mean scores of the 13 items are presented in Figure 4.1.

Table 4.6 and Figure 4.1 show that all aspects of learning, except decisions about time (Item 17), receive mean scores higher than 3.80. This indicates that the participants strongly believed that the responsibility to carry out these aspects of learning should be handed to students. Among these, learning strategies (Item 32), learning plans (Item 33), and learning goals (Item 12) receive the highest mean scores $(4.23,4.22$, and 4.20 respectively). In contrast, participants did not believe that students should make their own decisions about time, as this item (Item 17) receives the lowest mean, 2.92. 
Table 4.6

Beliefs in Leaner Autonomy

\begin{tabular}{|c|c|c|c|c|c|c|c|c|}
\hline \multirow{2}{*}{ Items } & \multirow[t]{2}{*}{$\mathbf{N}$} & \multicolumn{5}{|c|}{ Degree of Agreement (\%) } & \multirow{2}{*}{ Mean } & \multirow{2}{*}{$\begin{array}{c}\text { Std. } \\
\text { Deviation }\end{array}$} \\
\hline & & 1 & 2 & 3 & 4 & 5 & & \\
\hline 11. I believe that students should & 296 & 0.3 & 4.4 & 19.6 & 37.5 & 38.2 & 4.09 & .88 \\
\hline $\begin{array}{l}\text { know how to find their own ways } \\
\text { of practising their language skills. }\end{array}$ & & & & & & & & \\
\hline $\begin{array}{l}\text { 12. I believe students need to set } \\
\text { their own goals for learning } \\
\text { another language. }\end{array}$ & 297 & 0.3 & 2.4 & 17.5 & 36.4 & 43.4 & 4.20 & .83 \\
\hline $\begin{array}{l}\text { 33. I believe that students should } \\
\text { know how to plan their learning. }\end{array}$ & 297 & 0 & 1.7 & 14.1 & 45.1 & 39.1 & 4.22 & .74 \\
\hline $\begin{array}{l}\text { 32. I believe that training about } \\
\text { learning strategies is really helpful } \\
\text { for students. }\end{array}$ & 293 & 0 & 1.4 & 15.4 & 42.3 & 41.0 & 4.23 & .75 \\
\hline $\begin{array}{l}\text { 17. I believe that the length of time } \\
\text { for an activity should be decided } \\
\text { by students. }\end{array}$ & 294 & 5.1 & 26.2 & 44.2 & 21.1 & 3.4 & 2.92 & .90 \\
\hline $\begin{array}{l}\text { 40. I believe that teachers should } \\
\text { provide a choice of activities for } \\
\text { students. }\end{array}$ & 293 & 1.0 & 1.7 & 16.0 & 45.1 & 36.2 & 4.14 & .82 \\
\hline $\begin{array}{l}\text { 49. I believe that students should } \\
\text { identify the purpose of doing } \\
\text { activities. }\end{array}$ & 296 & 0.7 & 3.7 & 19.9 & 52.0 & 23.6 & 3.94 & .80 \\
\hline $\begin{array}{l}\text { 43. I believe students should check } \\
\text { their own work for the mistakes. }\end{array}$ & 296 & 1.7 & 7.4 & 25.7 & 39.5 & 25.7 & 3.80 & .96 \\
\hline $\begin{array}{l}\text { 28. I believe that students should } \\
\text { know how to identify their } \\
\text { strengths and weaknesses as a } \\
\text { language learner. }\end{array}$ & 297 & 0 & 2.4 & 15.2 & 46.8 & 35.7 & 4.16 & .76 \\
\hline $\begin{array}{l}\text { 48. I believe that students can } \\
\text { learn from their own mistakes. }\end{array}$ & 293 & 1.0 & 5.5 & 26.6 & 45.1 & 21.8 & 3.81 & .87 \\
\hline $\begin{array}{l}\text { 29. I believe that students should } \\
\text { evaluate their own work. }\end{array}$ & 296 & 0 & 6.8 & 18.2 & 46.6 & 28.4 & 3.97 & .86 \\
\hline $\begin{array}{l}\text { 21. I believe that test results } \\
\text { should be viewed as a way for } \\
\text { students to monitor their own } \\
\text { learning. }\end{array}$ & 297 & 2.0 & 4.7 & 19.2 & 46.1 & 27.9 & 3.93 & .92 \\
\hline $\begin{array}{l}\text { 45. I believe that students should } \\
\text { know how to measure their } \\
\text { language learning progress. }\end{array}$ & 295 & 1.0 & 8.1 & 20.3 & 47.8 & 22.7 & 3.83 & .91 \\
\hline
\end{tabular}




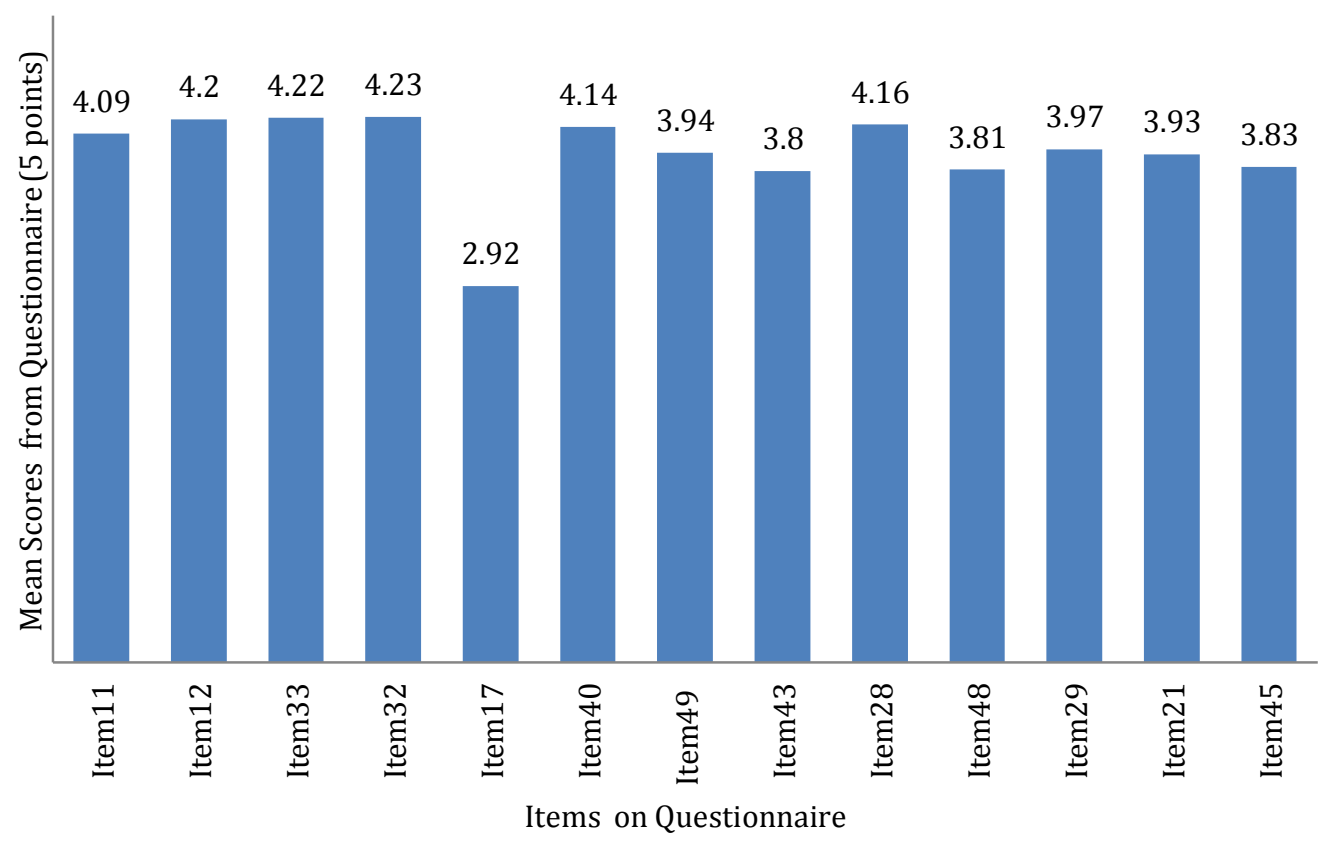

Figure 4.1. Mean scores of beliefs-related items

Thus, it can be assumed that the participants strongly believed in learner autonomy. They believed that students should take charge of their own learning process, except when deciding about the length of time for an activity. 


\section{Confidence in students' ability to be autonomous.}

In the questionnaire, the participants were asked to state the degree to which they were confident in their students' ability to take charge over activities occurring when learning a language. Summary statistics items related to the participants' confidence were listed in Table 4.7 and Figure 4.2.

Table 4.7

\section{Confidence in Students}

\begin{tabular}{|c|c|c|c|c|c|c|c|c|}
\hline \multirow[t]{2}{*}{ Items } & \multirow[t]{2}{*}{$\mathbf{N}$} & \multicolumn{5}{|c|}{ Degree of Agreement (\%) } & \multirow[t]{2}{*}{ Mean } & \multirow{2}{*}{$\begin{array}{c}\text { Std. } \\
\text { Deviation }\end{array}$} \\
\hline & & 1 & 2 & 3 & 4 & 5 & & \\
\hline $\begin{array}{l}\text { 24. I am confident that my } \\
\text { students are able to find out their } \\
\text { own effective ways of practising } \\
\text { their language skills }\end{array}$ & 297 & 4.4 & 19.5 & 46.8 & 24.9 & 4.4 & 3.05 & .89 \\
\hline $\begin{array}{l}\text { 18. I am confident that my } \\
\text { students can set their own goals } \\
\text { for learning another language. }\end{array}$ & 297 & 5.1 & 21.5 & 37.0 & 30.3 & 6.1 & 3.11 & .98 \\
\hline $\begin{array}{l}25 . \text { I am confident that my } \\
\text { students are able to plan their } \\
\text { learning. }\end{array}$ & 295 & 4.1 & 17.6 & 50.8 & 25.8 & 1.7 & 3.03 & .82 \\
\hline $\begin{array}{l}\text { 22. I am confident that my } \\
\text { students can effectively use } \\
\text { learning strategies in their } \\
\text { language learning. }\end{array}$ & 297 & 4.4 & 19.5 & 47.8 & 24.2 & 4.0 & 3.04 & .88 \\
\hline $\begin{array}{l}\text { 39. I am confident that my } \\
\text { students are able to effectively } \\
\text { decide how much they need to } \\
\text { spend on an activity. }\end{array}$ & 297 & 2.0 & 18.5 & 44.8 & 30.0 & 4.7 & 3.17 & .85 \\
\hline $\begin{array}{l}\text { 26. I am confident that my } \\
\text { students can make appropriate } \\
\text { choices to fit their learning needs. }\end{array}$ & 296 & 2.0 & 16.6 & 50.7 & 28.0 & 2.7 & 3.13 & .79 \\
\hline $\begin{array}{l}\text { 16. I am confident that my } \\
\text { students can identify the purpose } \\
\text { of doing activities. }\end{array}$ & 297 & 4.7 & 22.2 & 46.8 & 24.6 & 1.7 & 2.96 & .85 \\
\hline $\begin{array}{l}\text { 46. I am confident that my } \\
\text { students can check their work for } \\
\text { mistakes. }\end{array}$ & 295 & 4.1 & 22.0 & 39.3 & 26.4 & 8.1 & 3.13 & .98 \\
\hline $\begin{array}{l}\text { 20. I am confident that my students } \\
\text { know how to identify their strengths } \\
\text { and weaknesses as a language learner. }\end{array}$ & 297 & 1.7 & 19.9 & 33.0 & 40.1 & 5.4 & 3.28 & .90 \\
\hline $\begin{array}{l}\text { 42. I am confident that my } \\
\text { students can learn from their own } \\
\text { mistakes. }\end{array}$ & 295 & 2.4 & 7.1 & 32.5 & 38.0 & 20.0 & 3.67 & .95 \\
\hline $\begin{array}{l}\text { 14. I am confident that my } \\
\text { students are able to evaluate their } \\
\text { own work. }\end{array}$ & 296 & 3.4 & 26.7 & 43.6 & 22.0 & 4.4 & 2.97 & .89 \\
\hline $\begin{array}{l}\text { 35. I am confident my students } \\
\text { are able to use test results to } \\
\text { monitor their own learning. }\end{array}$ & 297 & 1.0 & 10.8 & 35.0 & 40.4 & 12.8 & 3.53 & .89 \\
\hline $\begin{array}{l}\text { 37. I am confident that my } \\
\text { students are able to effectively } \\
\text { measure their language learning } \\
\text { progress. }\end{array}$ & 297 & 2.4 & 16.5 & 48.5 & 28.3 & 4.4 & 3.16 & .83 \\
\hline
\end{tabular}


Table 4.7 and Figure 4.2 indicate that generally the participants were not very confident in their students' ability to carry out various aspects of learning on their own. Among the 13 aspects of learning that were investigated, learning from mistakes (Item 42) and using test results to monitor learning progress (Item 35) received the highest means (3.67 and 3.53, respectively). Self-evaluation (Item 14) and identification of activities purposes (Item 16) are the areas that the participants are least confident that their students are able to carry out (Means 2.97 and 2.96, respectively).

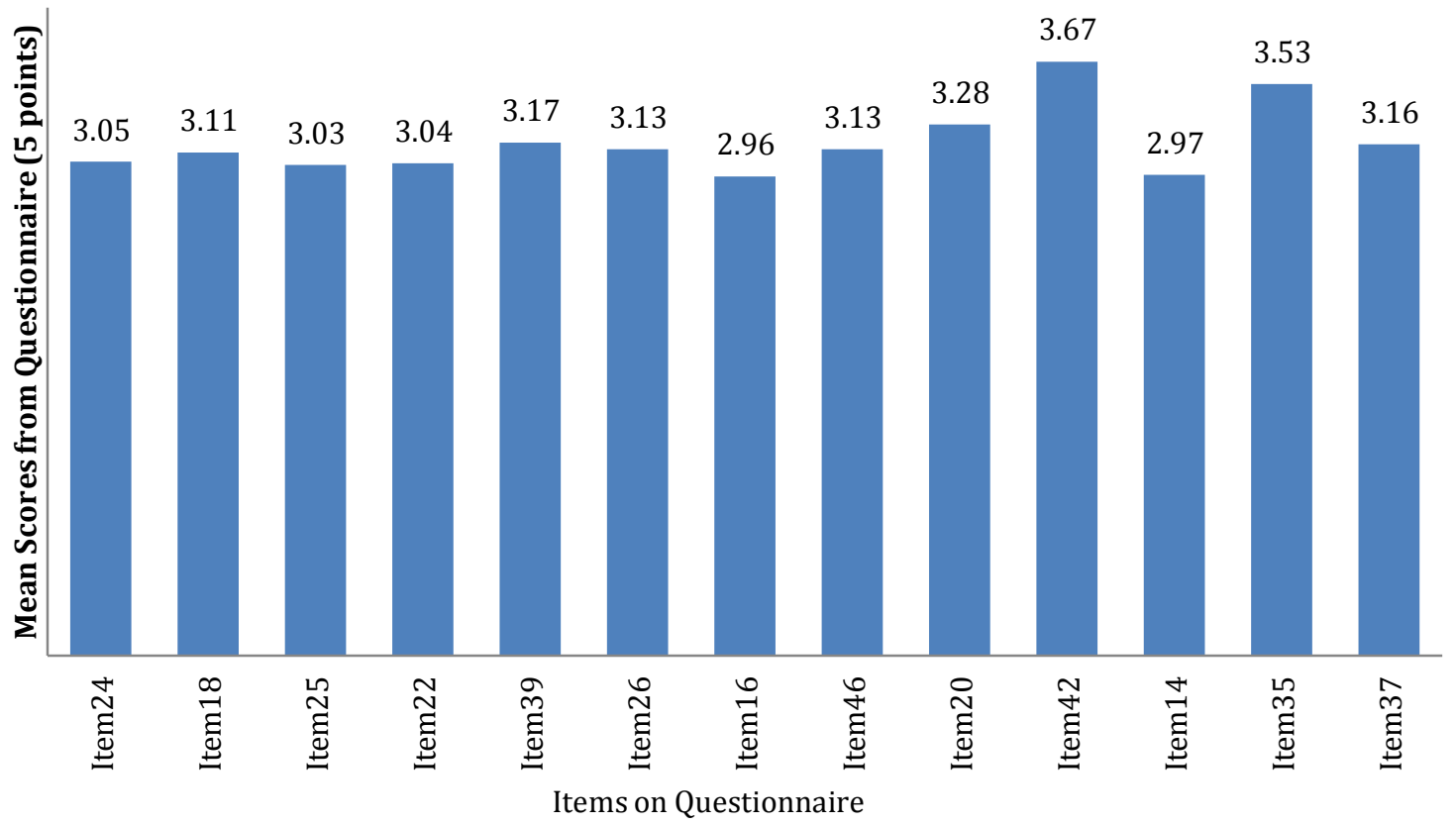

Figure 4.2. Mean scores of confidence-related items

Thus, it can be concluded that the lecturers were not very confident in their students' ability to learn autonomously. 


\section{Practices of learner autonomy.}

Findings from the survey on the practice section indicated that the participants did not give their students opportunities to exercise their autonomy in every area of the learning process. Findings regards practices are presented in Table 4.8 and Figure 4.9.

Table 4.8

Practices related to Learner Autonomy

\begin{tabular}{|c|c|c|c|c|c|c|c|c|}
\hline \multirow{2}{*}{ Items } & \multirow[t]{2}{*}{$\mathbf{N}$} & \multicolumn{5}{|c|}{ Degree of Agreement (\%) } & \multirow{2}{*}{ Mean } & \multirow{2}{*}{$\begin{array}{c}\text { Std. } \\
\text { Deviation }\end{array}$} \\
\hline & & 1 & 2 & 3 & 4 & 5 & & \\
\hline $\begin{array}{l}\text { 27. I give my students } \\
\text { opportunities to find out their own } \\
\text { ways of practicing their language } \\
\text { skills. }\end{array}$ & 297 & 1.0 & 7.1 & 27.9 & 51.2 & 12.8 & 3.68 & .82 \\
\hline $\begin{array}{l}\text { 34. I allow my students to set their } \\
\text { own goals for learning another } \\
\text { language. }\end{array}$ & 295 & 1.7 & 9.2 & 33.2 & 38.6 & 17.3 & 3.61 & .93 \\
\hline $\begin{array}{l}\text { 44. I give my students } \\
\text { opportunities to plan their } \\
\text { learning. }\end{array}$ & 294 & 2.0 & 8.8 & 35.4 & 41.8 & 11.9 & 3.53 & .89 \\
\hline $\begin{array}{l}\text { 41. I give my students } \\
\text { opportunities to use their own } \\
\text { learning strategies in their } \\
\text { language learning. }\end{array}$ & 297 & 1.3 & 6.7 & 27.6 & 43.1 & 21.2 & 3.76 & .90 \\
\hline $\begin{array}{l}\text { 15. In my class, the length of time } \\
\text { for an activity is decided by } \\
\text { students. }\end{array}$ & 296 & 14.3 & 43.9 & 29.1 & 10.8 & 1.4 & 2.40 & .91 \\
\hline $\begin{array}{l}\text { 31. I provide opportunities for my } \\
\text { students to select from a variety of } \\
\text { learning activities. }\end{array}$ & 296 & 0.7 & 10.1 & 30.7 & 46.3 & 12.2 & 3.59 & .85 \\
\hline $\begin{array}{l}\text { 47. I give my students } \\
\text { opportunities to understand the } \\
\text { purpose of doing activities. }\end{array}$ & 295 & 0 & 1.7 & 17.3 & 52.2 & 28.8 & 4.08 & .72 \\
\hline $\begin{array}{l}\text { 52. I give opportunities for my } \\
\text { students to check their work for } \\
\text { mistakes. }\end{array}$ & 294 & 0 & 4.4 & 32.7 & 43.5 & 19.4 & 3.78 & .80 \\
\hline $\begin{array}{l}\text { 30. I encourage my students to } \\
\text { identify their strengths and } \\
\text { weaknesses as a language learner. }\end{array}$ & 295 & 0.7 & 5.4 & 20.3 & 53.9 & 19.7 & 3.86 & .81 \\
\hline $\begin{array}{l}\text { 19. I allow my students to learn } \\
\text { from their own mistakes. }\end{array}$ & 294 & 1.4 & 5.8 & 15.6 & 48.6 & 28.6 & 3.97 & .89 \\
\hline $\begin{array}{l}\text { 38. I give my students } \\
\text { opportunities to evaluate their } \\
\text { own work. }\end{array}$ & 293 & 1.0 & 9.9 & 30.7 & 46.1 & 12.3 & 3.59 & .87 \\
\hline $\begin{array}{l}\text { 36. I give opportunities for } \\
\text { students to use test results to } \\
\text { make decisions about their } \\
\text { learning. }\end{array}$ & 297 & 3.7 & 9.1 & 29.6 & 42.4 & 15.2 & 3.56 & .98 \\
\hline $\begin{array}{l}\text { 13. I give my students } \\
\text { opportunities to measure their } \\
\text { language learning progress. }\end{array}$ & 293 & 1.0 & 4.8 & 27.3 & 51.5 & 15.4 & 3.75 & .81 \\
\hline
\end{tabular}


According to Table 4.8 and Figure 4.3, only Items 19, 30, and 47 receive mean scores higher than 3.80. The remaining aspects of learning, except Item 15, receive average mean scores i.e. from 3.53 -3.78. This indicates that that Thai students might be given many opportunities to understand the purpose of doing activities (Item 47), to learn from their own mistake (Item 19) and to identify their own strengths and weaknesses as a language learner (Item 30). However, they are given average opportunities to carry out other aspects of their own learning process. Item 15, making decisions about time, is the item that receives the lowest mean score (2.40). This suggests that making decisions about use of time seems to be the area that Thai students will be given the least chance to carry out on their own.

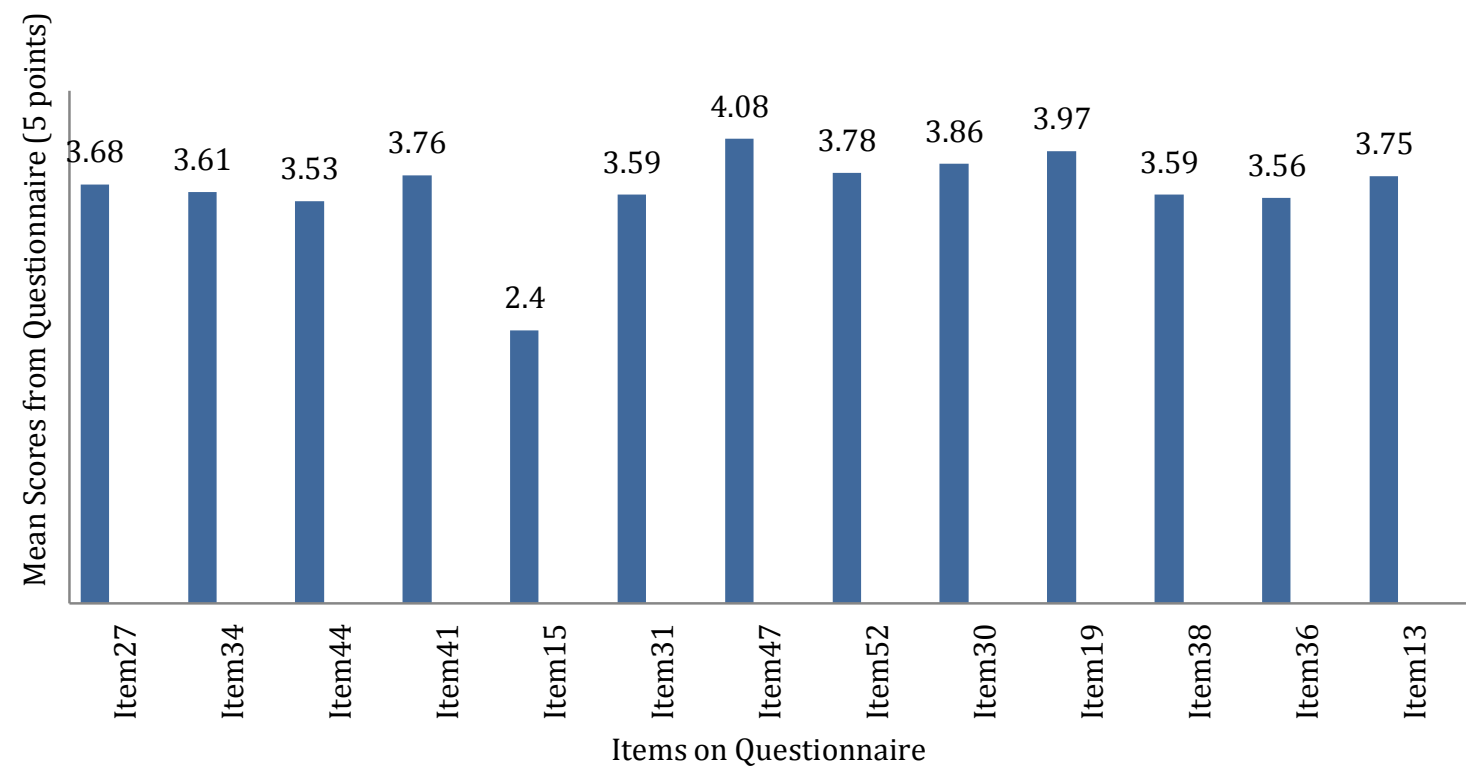

Figure 4.3. Mean scores of practice-related items 


\section{Influential Demographic Characteristics}

This section discusses the demographic characteristics of Thai lecturers' that might have some association with their beliefs, their confidence in students and their practices related to learner autonomy. Tables $4.9-4.13$ show the extent to which lecturers of different ages, lengths of teaching experience, bachelor degree fields, educational qualifications and university locations believed in learner autonomy, had confidence in students, and put learner autonomy into practice. A rating of 1 represents strongly disagree, 2 disagree, 3 neutral, 4 agree and 5 strongly agree.

Table 4.9

Beliefs, Confidence, and Practices with Ages

\begin{tabular}{|c|c|c|c|c|c|c|c|c|c|}
\hline \multirow{3}{*}{ Age } & \multicolumn{3}{|c|}{ Beliefs $(n=278)$} & \multicolumn{3}{|c|}{ Confidence $(n=290)$} & \multicolumn{3}{|c|}{ Practice $(n=275)$} \\
\hline & \multicolumn{3}{|c|}{$\mathrm{df}=3, \mathrm{~F}=.35, \mathrm{p}=.79$} & \multicolumn{3}{|c|}{$\mathrm{df}=3, \mathrm{~F}=2.23, \mathrm{p}=.09$} & \multicolumn{3}{|c|}{$\mathrm{df}=3, \mathrm{~F}=.69, \mathrm{p}=.56$} \\
\hline & $\mathbf{N}$ & Mean & SD & $\mathbf{N}$ & Mean & SD & $\mathbf{N}$ & Mean & SD \\
\hline Under 30 yrs & 41 & 3.91 & .45 & 40 & 3.20 & .56 & 38 & 3.63 & .47 \\
\hline $31-39$ yrs & 105 & 3.96 & .41 & 109 & 3.07 & .51 & 100 & 3.57 & .52 \\
\hline $40-49$ yrs & 62 & 3.93 & .43 & 70 & 3.22 & .49 & 67 & 3.67 & .45 \\
\hline 50 yrs up & 70 & 3.99 & .51 & 71 & 3.27 & .62 & 70 & 3.68 & .58 \\
\hline
\end{tabular}

Table 4.9 shows no significant difference in the extent to which lecturers in different age ranges believed in learner autonomy $(p=.79)$, were confident in students' ability to be autonomous ( $p=.09$ ), and reported putting learner autonomy into practice in their class $(p=.56)$. The findings suggest that age may not have any influence on Thai lecturers' beliefs, confidence and practice related to learner autonomy. 
Table 4.10

Beliefs, Confidence, and Practices with Teaching Length

\begin{tabular}{|c|c|c|c|c|c|c|c|c|c|}
\hline \multirow{3}{*}{ Teaching length } & \multicolumn{3}{|c|}{ Beliefs $(n=278)$} & \multicolumn{3}{|c|}{ Confidence $(n=290)$} & \multicolumn{3}{|c|}{ Practice $(n=275)$} \\
\hline & \multicolumn{3}{|c|}{$\mathrm{df}=4, \mathrm{~F}=1.20, \mathrm{p}=.31$} & \multicolumn{3}{|c|}{$\mathrm{df}=4, \mathrm{~F}=2.12, \mathrm{p}=.08$} & \multicolumn{3}{|c|}{$\mathrm{df}=4, \mathrm{~F}=1.53, \mathrm{p}=.19$} \\
\hline & $\mathbf{N}$ & Mean & SD & $\mathbf{N}$ & Mean & SD & $\mathbf{N}$ & Mean & SD \\
\hline $1-5$ yrs & 60 & 3.92 & .44 & 61 & 3.13 & .61 & 58 & 3.68 & .50 \\
\hline $6-10$ yrs & 60 & 4.02 & .39 & 62 & 3.07 & .47 & 57 & 3.57 & .54 \\
\hline $11-15$ yrs & 35 & 3.99 & .44 & 37 & 3.07 & .46 & 37 & 3.48 & .47 \\
\hline $16-20$ yrs & 35 & 3.84 & .44 & 40 & 3.23 & .49 & 35 & 3.63 & .48 \\
\hline 21 yrs up & 88 & 3.96 & .48 & 90 & 3.29 & .58 & 88 & 3.70 & .53 \\
\hline
\end{tabular}

According to Table 4.10, there was no significant difference in the extent to which lecturers with different lengths of teaching experience believed in learner autonomy ( $p=.31$ ), were confident in students' ability to be autonomous ( $p=.08$ ), and practiced learner autonomy in their class ( $p=.19$ ). This finding seemed to suggest that the number of years that a lecturer had been in the teaching profession was not associated with their beliefs and practice relating to learner autonomy or their confidence in students' ability to learn autonomously.

Table 4.11

Beliefs, Confidence, and Practices with Bachelor Fields

\begin{tabular}{|c|c|c|c|c|c|c|c|c|c|}
\hline \multirow[t]{2}{*}{ BA Field } & \multicolumn{3}{|c|}{$\begin{array}{c}\text { Beliefs }(n=277) \\
\text { df }=3, F=3.46, p=.02\end{array}$} & \multicolumn{3}{|c|}{$\begin{array}{l}\text { Confidence }(n=289) \\
d f=3, F=0.23, p=.87\end{array}$} & \multicolumn{3}{|c|}{$\begin{array}{c}\text { Practice }(n=274) \\
\text { df }=3, F=1.01, p=.39\end{array}$} \\
\hline & $\mathbf{N}$ & Mean & SD & $\mathbf{N}$ & Mean & SD & $\mathbf{N}$ & Mean & SD \\
\hline Arts & 126 & 3.91 & .46 & 131 & 3.16 & .53 & 123 & 3.61 &. .46 \\
\hline Education & 75 & 4.09 & .39 & 78 & 3.21 & .54 & 76 & 3.72 & .52 \\
\hline Humanities & 60 & 3.89 & .44 & 61 & 3.16 & .55 & 57 & 3.59 & .57 \\
\hline Others & 16 & 3.90 & .48 & 19 & 3.13 & .67 & 18 & 3.59 & .62 \\
\hline
\end{tabular}

According to Table 4.11, there was a statistically significant difference in the extent of beliefs held by lecturers who did their bachelor degrees in different fields ( $\mathrm{df}=3, \mathrm{~F}=3.46, p=.02$ ). Lecturers who did their bachelors in education were more likely to believe in learner autonomy. However, the differences in their confidence and practices was not statistically significant ( $p=.87$ and .39 , respectively). Thus, it can be said that field of study in bachelor degree might have some relationship with the lecturers' currently beliefs in learner 
autonomy, but not in their confidence in students' ability nor their current classroom practice.

Table 4.12

Beliefs, Confidence, and Practices with Qualifications

\begin{tabular}{|c|c|c|c|c|c|c|c|c|c|}
\hline \multirow{2}{*}{ Ed. qualification } & \multicolumn{3}{|c|}{$\begin{array}{c}\text { Beliefs }(n=278) \\
\text { df }=2, F=1.65, p=.20\end{array}$} & \multicolumn{3}{|c|}{$\begin{array}{l}\text { Confidence }(n=290) \\
d f=2, F=1.20, p=.30\end{array}$} & \multicolumn{3}{|c|}{$\begin{array}{c}\text { Practice }(n=275) \\
\mathrm{df}=2, F=1.66, p=.19\end{array}$} \\
\hline & $\mathbf{N}$ & Mean & SD & $\mathbf{N}$ & Mean & SD & $\mathbf{N}$ & Mean & SD \\
\hline Bachelors degree & 8 & 3.69 & .46 & 10 & 3.15 & .61 & 8 & 3.63 & .62 \\
\hline Masters degree & 179 & 3.95 & .42 & 186 & 3.14 & .55 & 176 & 3.59 & .50 \\
\hline Doctoral degree & 91 & 3.99 & .48 & 94 & 3.24 & .53 & 91 & 3.71 & .52 \\
\hline
\end{tabular}

Table 4.12 shows the mean scores for the extent of beliefs, confidence and practice reported by lecturers who had bachelors, masters and doctoral degrees as their highest qualification. The table shows that there was no significant difference in beliefs, confidence and practices among these lecturers ( $p=.20, .30$ and .19 respectively). This finding seems to suggest there is no evidence that the level of the lecturers' educational qualification has an influence on their support of leaner autonomy.

Table 4.13

Beliefs, Confidence, and Practices with University Locations

\begin{tabular}{|c|c|c|c|c|c|c|c|c|c|}
\hline \multirow[t]{2}{*}{ Uni Location } & \multicolumn{3}{|c|}{$\begin{array}{c}\text { Beliefs }(n=278) \\
\text { df }=2, F=1.33, p=.27\end{array}$} & \multicolumn{3}{|c|}{$\begin{array}{l}\text { Confidence }(n=290) \\
\text { df }=2, F=4.00, p=.02\end{array}$} & \multicolumn{3}{|c|}{$\begin{array}{c}\text { Practice }(n=275) \\
\mathrm{df}=2, \mathrm{~F}=2.25, \mathrm{p}=.11\end{array}$} \\
\hline & $\mathbf{N}$ & Mean & SD & $\mathbf{N}$ & Mean & SD & $\mathbf{N}$ & Mean & SD \\
\hline In Bangkok & 156 & 3.93 & .44 & 161 & 3.16 & .56 & 157 & 3.59 & .55 \\
\hline In a city & 92 & 3.96 & .46 & 99 & 3.26 & .50 & 92 & 3.72 & .46 \\
\hline In a small town & 30 & 4.07 & .41 & 30 & 2.94 & .55 & 26 & 3.60 & .48 \\
\hline
\end{tabular}

Table 4.13 shows the mean scores for the extent to which lecturers from Bangkok, cities or small towns believed in learner autonomy, were confident in students, and put learner autonomy into practice. The table indicates that there was a significant difference in the extent of confidence that lecturers from different university locations had in their students' ability to learn autonomously ( $\mathrm{df}=2, \mathrm{~F}=4.00, p=.02)$. Lecturers whose universities are located in small towns seem to have less confidence compared to those who taught in cities or Bangkok. While it is statistically evident that the university 
location may have a relationship with the extent of confidence that lecturers have in their students, there is no statistical evidence that the university location has a relationship with the extent of belief and practice related to learner autonomy.

\section{Activities Supportive to Learner Autonomy}

This section presents results from the 3 open-ended items in the questionnaires. These 3 items related to the activities that the lecturers performed at the beginning of their course, the frequency that they encouraged their students to self-assess, and the activities that they most often encouraged their students to carry out after class.

\section{Activities at the outset of the semester.}

The participants were asked which activities, from a selection of given options, they did with their students on the first day of their course. Out of 297 lecturers, 6 of them indicated that they did not do any of these activities with their students on the first day they started their course. The activities that the remaining lecturers did on the first day they met their students are displayed in the following figure. 


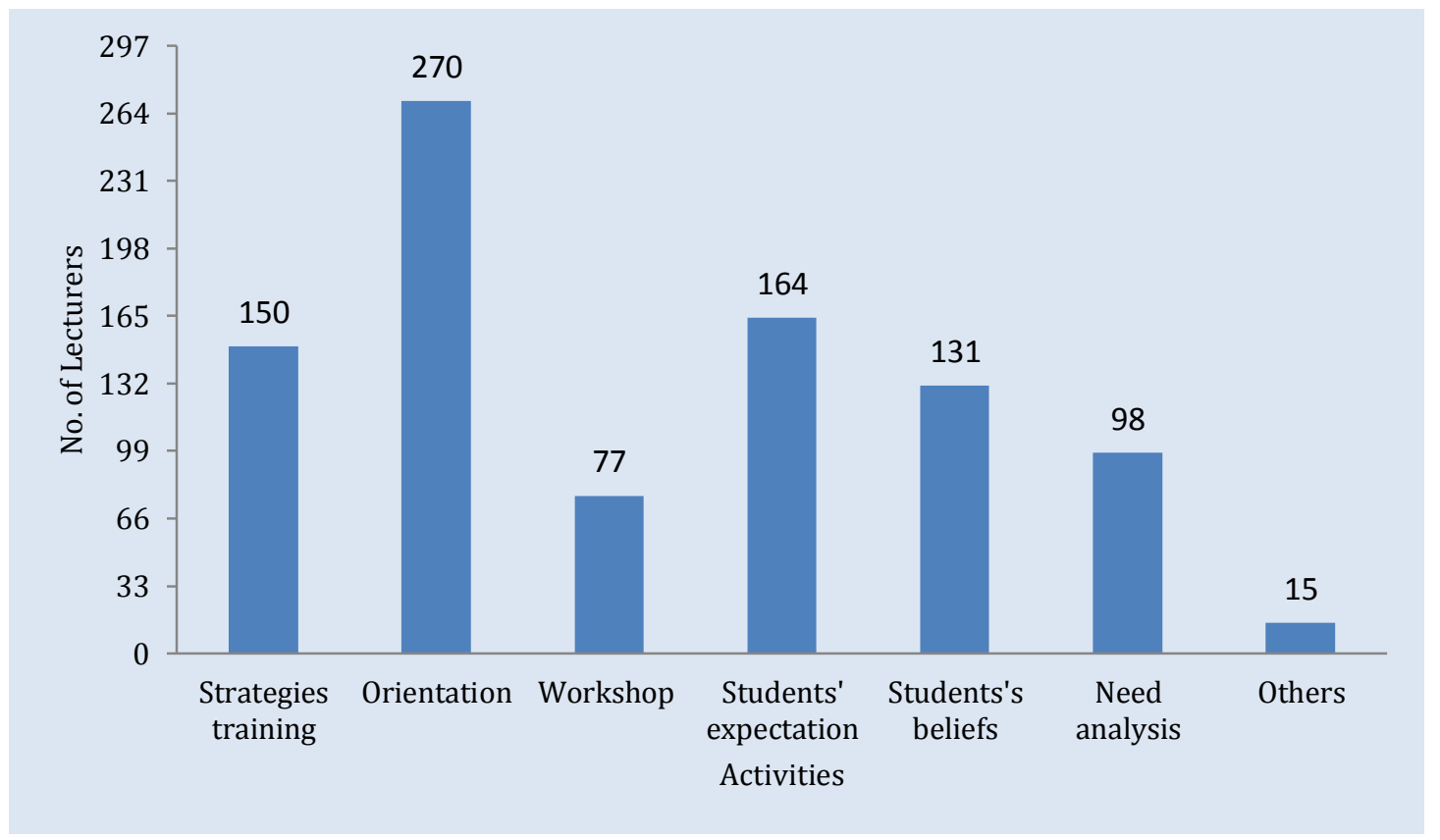

Figure 4.4. Activities at the outset of the course

Figure 4.4 shows that the three most popular activities that the surveyed lecturers carried out with their students on the first day of the course were, in descending order, giving an orientation about the course, finding out what students expect from the course (either by questionnaire, interview, dialogue etc.), and training students in learning strategies. Finding out students' attitudes or beliefs related to language learning was carried out by 131 lecturers and analyzing students' needs by 98 lecturers. Seventy seven lecturers reported that they held a workshop for students about how to learn. In addition to these, other activities that were carried out with students at the very first day of the course including giving a pre-test, doing a learning contract, telling the students about the teacher's expectation, and asking students to write a paragraph about what they wanted to see in the class. 


\section{Opportunities for self assessment.}

The participants were asked how often they encouraged their students to assess themselves. Of the 297 surveyed, 168 lecturers responded to this question. Among these, 17.3\% reported that they never encouraged their students to do self-assessment. Figure 4.5 shows that while almost half of the lecturers indicated that they always encouraged their students to carry out self-assessment, $13.1 \%$ of them reported that they did not often encourage their students to do so. The rest of the lecturers in the study (24.4\%) indicated that they sometimes encourage their students to self-assess.

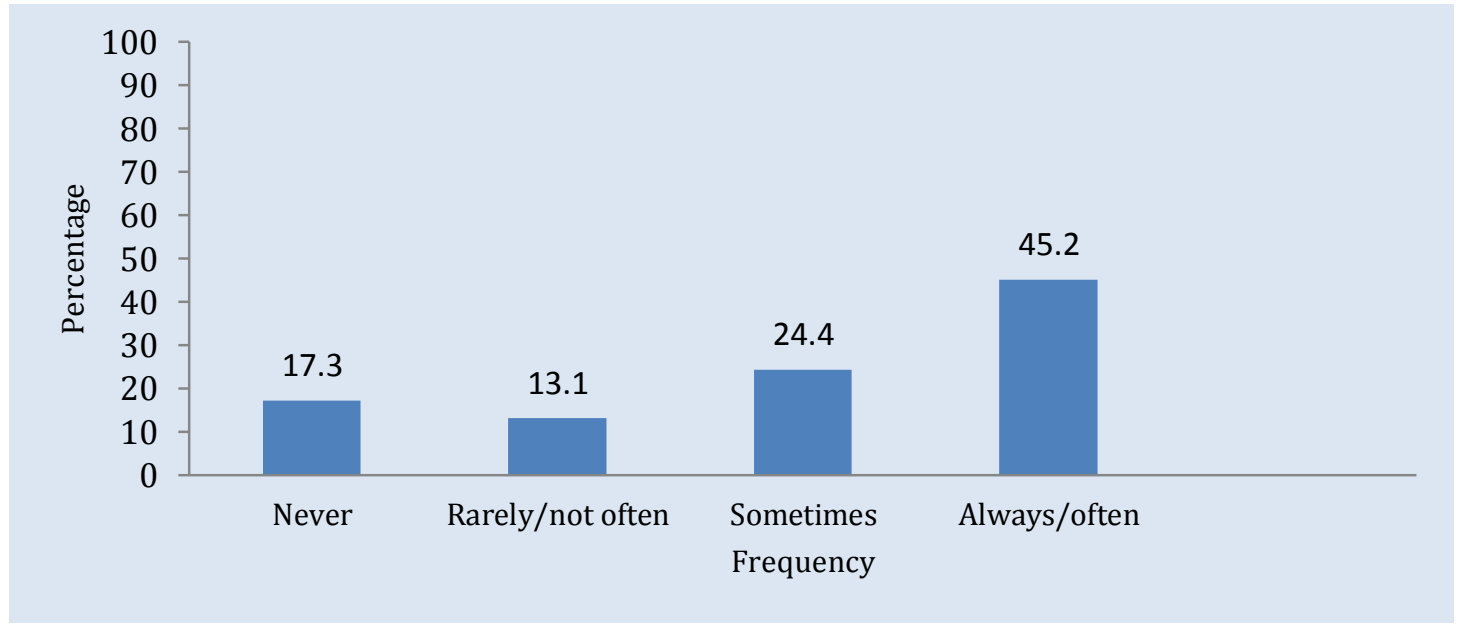

Figure 4.5. Frequency of encouraging students for self assessment 


\section{Favourite outside-class activity.}

The participants listed one activity that they most encouraged their students to do outside class. The activities can be grouped into 12 categories (Figure 4.6). Learning from internet/websites and external reading were the most favoured outside-class activities, which almost half of the participants encouraged their students to do. Learning from Internet/websites included students practicing their foreign language(s), doing exercises from websites/internet, making use of online resources (also the university's online system, VDO streaming), or searching for information from websites. External reading included lecturers assigning students to read printed materials in addition to textbooks/course books used in class. After that, there would be a quiz related to the assigned materials. Printed materials were in the form of books (short stories or novels), newspapers, magazines or grammar books. The third most popular activity that the lecturers encouraged their students to perform was to learn the language from entertainment media. Learning from entertainment media means learning at home (not at the university's self-access learning center) through movies, TV programs, cartoons, radio, CDs or commercial packages.

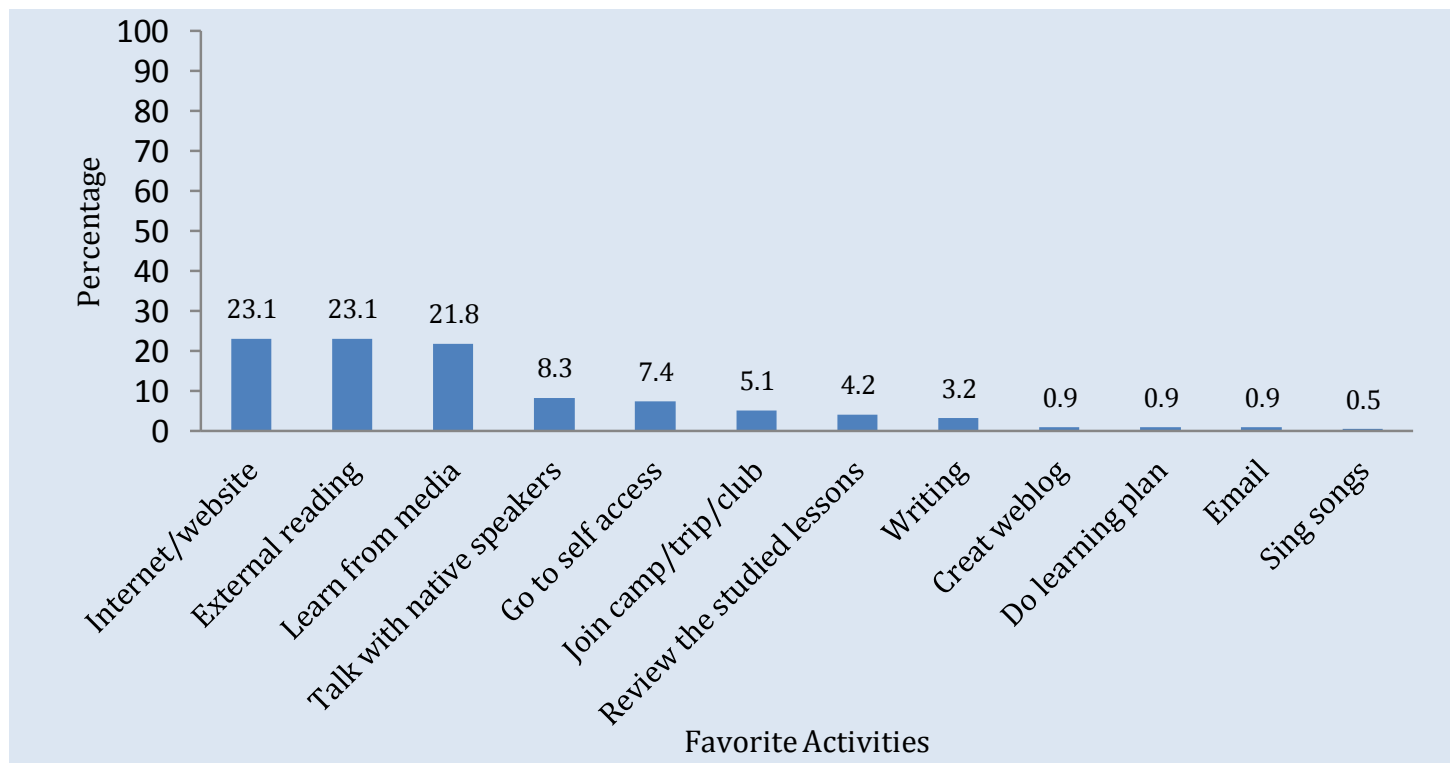

Figure 4.6. Favourite outside-class activities 


\section{Reliability of the Study}

The reliability of the survey was assessed via three subscales underpinning the questionnaire. Each subscale was analyzed with Cronbach's internal consistency coefficient alpha (Cronbach, 1951). The analysis was conducted with SPSS 17. The coefficient alpha for each scale was shown in Table 4.14.

Table 4.14

Questionnaire Internal Consistency

\begin{tabular}{|c|c|c|c|}
\hline Scale & Item & Total Correlation & If Item Deleted \\
\hline Beliefs & 11 & .451 & .762 \\
\hline \multirow[t]{12}{*}{$\alpha=.78$} & 12 & .482 & .760 \\
\hline & 33 & .574 & .753 \\
\hline & 32 & .363 & .771 \\
\hline & 17 & .124 & .795 \\
\hline & 40 & .360 & .771 \\
\hline & 49 & .427 & .765 \\
\hline & 43 & .433 & .764 \\
\hline & 28 & .437 & .764 \\
\hline & 48 & .353 & .772 \\
\hline & 29 & .367 & .770 \\
\hline & 21 & .381 & .770 \\
\hline & 45 & .594 & .747 \\
\hline Confidence & 24 & .516 & .852 \\
\hline in Students & 18 & .497 & .854 \\
\hline \multirow[t]{11}{*}{$\alpha=.86$} & 25 & .667 & .844 \\
\hline & 22 & .553 & .850 \\
\hline & 39 & .522 & .852 \\
\hline & 26 & .604 & .848 \\
\hline & 16 & .410 & .858 \\
\hline & 46 & .509 & .853 \\
\hline & 20 & .543 & .851 \\
\hline & 42 & .514 & .853 \\
\hline & 14 & .456 & .856 \\
\hline & 35 & .442 & .857 \\
\hline & 37 & .646 & .845 \\
\hline Practice & 27 & .576 & .832 \\
\hline \multirow[t]{12}{*}{$\alpha=.85$} & 34 & .533 & .835 \\
\hline & 44 & .583 & .831 \\
\hline & 41 & .555 & .833 \\
\hline & 15 & .249 & .854 \\
\hline & 31 & .536 & .834 \\
\hline & 47 & .436 & .841 \\
\hline & 52 & .456 & .840 \\
\hline & 30 & .604 & .830 \\
\hline & 19 & .374 & .845 \\
\hline & 38 & 639 & .827 \\
\hline & 36 & .525 & .835 \\
\hline & 13 & .490 & .837 \\
\hline
\end{tabular}


Table 4.14 shows the results of the reliability analysis of the scales measuring the lecturers' beliefs, confidence in students, and practices. The 13-item measure of beliefs had good internal consistency, $\alpha=.78$, and there was no need to delete any items from the scale. Though an increase in alpha would come from removing item 17 , deletion of this item would increase the alpha only by .014 .

The subscale for measuring lecturers' confidence in students' ability had good internal consistency, $\alpha=.86$. All data have item-total correlations above .3. There was no need to delete any items as no increase in alpha would come from deleting any item.

Table 4.14 shows that the subscale for measuring the extent of lecturers' practice of learner autonomy had a good internal consistency, alpha $=0.847$. The worst case is also Item 15 which is related to time decision as it has itemtotal correlation less than .3 and deleting this item would increase the alpha from .847 to .854 . However, this increase is not remarkable (only .007). Thus, it can be concluded that the subscale for measuring practice had a good internal consistency and there was no need to delete any items from this subscale.

The strength of the findings of the survey is also increased by the representativeness of the sample. The participants in this phase of the study were highly representative of Thai lecturers of language. This is because the parameter characteristics which I used as the sampling frame for recruiting sampling lecturers were set clearly at the start of the study, and strictly and systematically followed through the whole process of sample recruitment. Lecturers participating in my survey must be full-time Thai lecturers of language(s) in universities in Thailand. As Cohen et al., (2007) suggested, the high representativeness of a sample can be achieved through a clear sampling frame which needs to be set as a first priority. 
Overall, the three subscales underpinning the questionnaire appeared to have strong internal consistency and there was no need to delete any items from the questionnaire. Furthermore, as the samples in this phase of the study appeared to be representative of Thai lecturers of language, the results of the survey can be considered to have some degree of representativeness.

\section{Chapter Discussion}

Results from the survey suggest four main trends relevant to the lecturers' perceptions and practices of learner autonomy.

\section{Inconsistency between Beliefs and Practices}

Findings regarding the lecturers' general beliefs in the nature of language learning suggest a belief in the importance of learner autonomy, with the exception of their perception of grammatical knowledge. The lecturers' belief in the indispensability of knowledge of grammar and rules of the target language for the students reflects a focus on accuracy as a goal. This belief might pose a concern when it comes to their actual practices. Holden and Usuki (1999) claimed that learner autonomy might be diminished in an environment in which the learning goal is shifted to accuracy and learning is based on a grammar-translation approach. Such an environment limits learners' freedom to "express themselves and experiment using the language" (Usuki, 1999, p.196).

The findings of my survey suggest that Thai lecturers strongly believe in learner autonomy. However, the comparison of the mean scores of beliefs, confidence and practices in each aspect of the learning process indicated a disparity between their beliefs and practices. Figure 4.7 shows that the means of beliefs in most of the aspects of learning are higher than those of the participants' reported practice. 


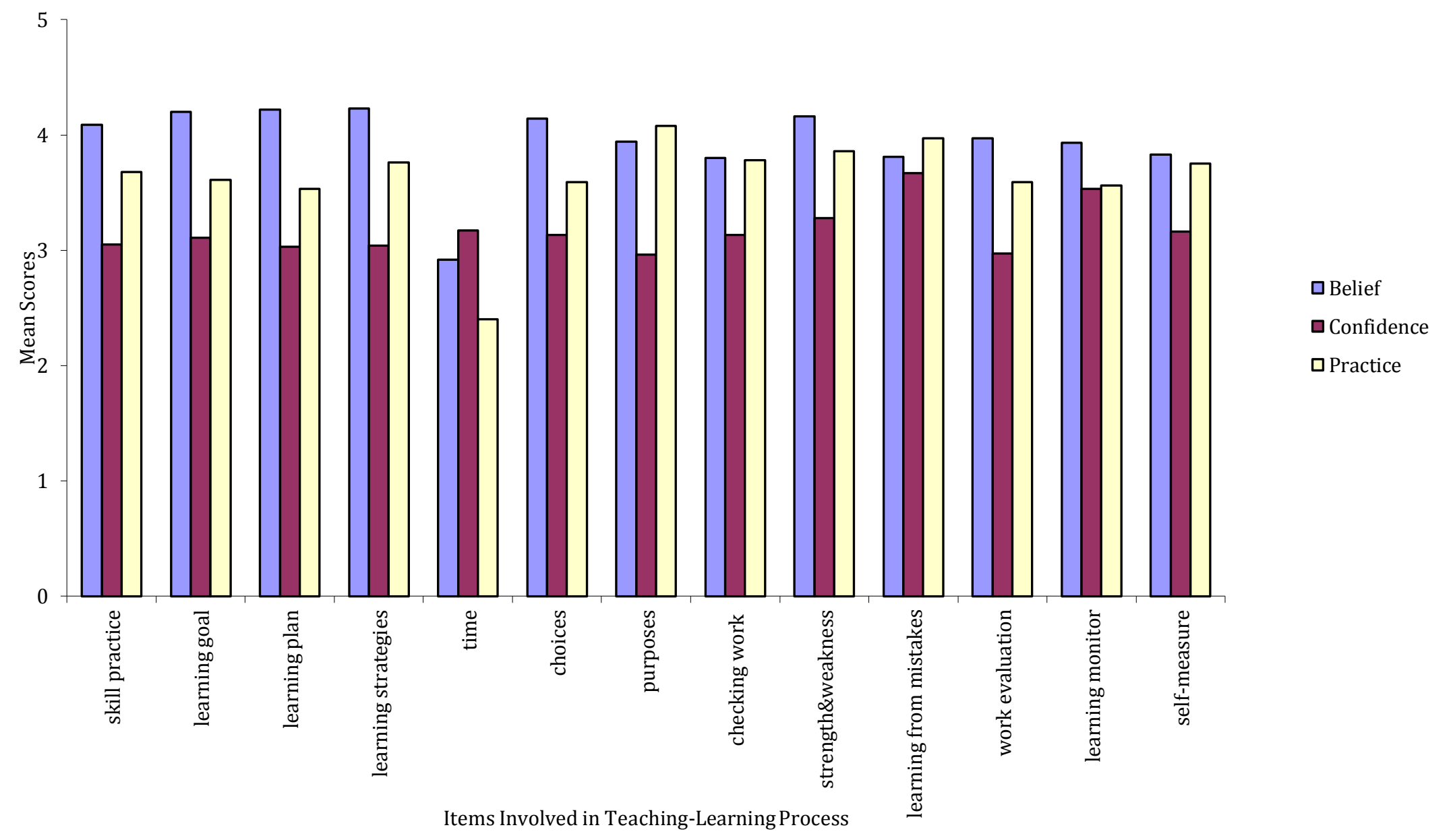

Figure 4.7. Comparison of beliefs, confidence and practice 
Inconsistencies between teachers' beliefs and actual classroom practices have been widely reported in the literature. Karaagac and Threlfall (2004) found that a disjunction between a teacher's teaching beliefs and his or her actual practices resulted from his or her school culture. Although the teachers admitted that they did not like the way they were teaching, they were not able to teach otherwise. Newstead (1999) reported on the implementation of a project that aimed to change teachers' teaching practices in order to support learner autonomy. In the interviews, the teacher expressed his or her belief in and knowledge of the philosophy of the project. However, observations of a teacher's classes revealed that there was no implementation in the classroom. The study suggested that the ability to talk about the project and the ability to implement it might not be the same thing.

Such inconsistencies between belief and practice identified in the above studies parallel the inconsistency found in my study. This finding supports Little's (1995) argument that, "A capacity to argue the importance of learner autonomy is not the same thing as a capacity to promote learner autonomy in the classroom" (p.180). The exemplified studies provided reasons for the tensions and suggested that the reasons for the tensions varied from context to context. As a result, this finding from my survey needed to be followed up in order to seek an explanation for the inconsistency.

\section{BA in Education and Beliefs in Learner Autonomy}

Findings from the survey showed that the discipline of the lecturers' bachelor degree made a difference in the degree of belief that lecturers had in learner autonomy, but not on their confidence in students and their practice. The lecturers who did their bachelors in Education appeared to have higher levels of belief in learner autonomy compared with lecturers with BAs in other fields. Lecturers with BAs in education may have been exposed to educational psychology, educational foundations, and education administration; attended courses related to learner autonomy and its related 
concepts; and thus gained an understanding of the value and practical benefits of learner autonomy. Therefore, the lecturers who did a BA in Education may be more inclined to believe in learner autonomy, compared with those who had not graduated in this discipline.

The relationship between lecturers' educational background and their current beliefs identified in my survey implies that additional education pertaining to education psychology and education management might be needed for Thai lecturers. Compounded with the fact university lecturers do not require teaching qualifications, my finding seems to imply a need for preservice and in-service professional development for university lecturers so as to widen their theoretical and methodological knowledge of teaching.

While the lecturers' educational background appeared to have an association with their belief in learner autonomy, the survey findings suggest that age and the length of teaching experience did not have any association with their beliefs in learner autonomy. This finding was discrepant from the finding of Patrick's (2008) study of teachers' changes in practices and beliefs. Patrick found the number of year for teaching influenced the professed knowledge and practices of teachers. Patrick suggested that the more experienced teachers make greater improvements in their understanding and teaching practices, and are more likely to believe in new innovations/concepts. Patrick's study also called for professional development for teachers.

The relationship between teachers' educational background and their current beliefs identified in my survey indicates the role that educational experience plays in defining pedagogic beliefs of a lecturer (Borg, 2003). However, my survey results show that a bachelor degree in education did not guarantee that lecturers would translate their beliefs into practices. This suggests that there might be some factors which act as a screen between lecturer's beliefs and their potential to act on them. 


\section{Low Confidence in Students' Abilities}

Data from the questionnaire suggest that Thai lecturers were not very confident in their students' ability to be autonomous learners. This finding is in-line with a number of studies. In the study of teachers' attitudes towards self-directed learning in self-access learning centers, Clemente (2001) identified teachers' had low confidence in students' ability to take charge of their own learning. Clemente referred to this low confidence as a "distrust of students", reflecting the teachers' perception that their students will not survive "without the teacher" (p.50). This low confidence in students' learning ability reflects teachers' perception that students are unable to be autonomous learners. The main source of teachers' distrust in the students, as the study explained, was the teachers' perception that students enrolled at the self-access learning center because of external reasons (i.e. they could not find enrollment elsewhere, not because they wanted to really achieve).

Teachers' low confidence in students, or the distrust of students as Clemente (2001) called it, may give a possible explanation to the inconsistencies between the lecturers' beliefs and practices identified in my survey results. That is, the lecturers' low confidence in students prevents the lecturers from allowing their students to take charge of their own learning, regardless of their perception of the benefits and understanding of the need for learner autonomy. Bakar (2007) explained that the teachers' lack of confidence is related to the students' level of English proficiency. This implies that the association of academic competence with the ability to learn autonomously might pose a challenge in the teachers' willingness to promote learner autonomy.

However, data from my survey was not sufficient to conclude whether students' learning proficiency has an impact on the lecturers' level of confidence. This would require a follow-up study. At this stage, the findings from my survey appear to suggest that university location might be one of the possible factors that impact the lecturers' level of confidence in students. 
Lecturers who teach in universities in small towns or rural areas of Thailand tended to be less confident in their students capability to be autonomous learners compared with lecturers teaching in Bangkok or big cities. Further investigation is needed to find out what differences in big city and small town universities are likely to be associated with the differences in Thai lecturers' confidence in their students' ability to be autonomous.

\section{Resistance to Students' Involvement in Decisions about Time and Assessment}

Results from the survey seemed to suggest that Thai lecturers had some reservations towards the feasibility of the promotion of learner autonomy in the classroom. That is, not every area of the learning processes should be made the students' responsibility, particularly in making decisions related to time of learning and in assessment/evaluation.

The findings from my survey show that time issues draw the strongest resistance from the lecturers. This resistance can be understood in terms of classroom contexts in Thailand, in which teaching is usually based on a predetermined curriculum. In such an environment the pace of learning has been already set and activities that take place need to operate within a fixed timeline (Sanprasert, 2010). Lecturers' resistance towards students' involvement in making decisions about time could reflect a lack of confidence in the students' time management skills. In Kongchan's (2002) study of learner profile-based consultations, he found that a number of Thai students had a problem with their time-management. This resulted in their inability to complete the assigned tasks. Students' lack of time management skills might be further associated with lack of self-discipline. As self-discipline and timemanagement skills are regarded as very essential in the development of learner autonomy in Thailand (Anantasate, 2001), this might give one explanation for why Thai lecturers were reluctant to allow decisions about time to be under their students' control. 
Assessment was another area that generated resistance from the lecturers. The lecturers understood and agreed that students' self-evaluation is an essential component in the development of learner autonomy. However, their low level of confidence in students' ability to evaluate their own work indicates their reluctance to have students' involvement in this aspect of learning. The lack of students' involvement in evaluating their own learning might be reflective of their close supervision and a focus on accuracy. According to SDT, these are external controls that endanger students' feeling of joy and enthusiasm for learning (Niemiec \& Ryan, 2009).

The lecturer's resistance to allow their students to be involved in learning evaluation/assessment might also indicate a lack of opportunity for students to use self-assessment to reflect on their learning. Knowledge obtained from reflection is a basis for metacognition and essential for being an autonomous learner (Cotterall \& Murray, 2009). It is possible that Thai lecturers have a limited understanding of different forms of assessment for learning and, thus, restrict themselves to tests and formal examinations. In reality, students can do self-assessment through other means such as through blogs (Mynard, 2008), portfolios (Meeus et al., 2008), and journal writing/diaries (Chuk, 2004; Srimavin \& Darasawang, 2004). Lecturers' limited understanding of assessment for learning possibly is indicated in another finding of the survey, in which the majority of the lecturers did not have professional qualifications in Education. This also seems to suggest a need for professional development for university lecturers so as to increase their understanding and knowledge about assessment for learning, as well as other fundamentals of education. 


\section{Chapter Summary}

This chapter reports the first phase of the study. Findings from this quantitative phase illustrate the existing state of the promotion of learner autonomy, in which an inconsistency exists between lecturers' beliefs and practices. Lecturers in Thailand's higher education system highly valued the philosophy of learner autonomy but in practice they might not organize their classroom in ways that support the development of learner autonomy. In addition, Thai lecturers were not very confident in their students' ability to learn autonomously. Some of the lecturers' demographic characteristics seem to have an association with their beliefs, confidence, and teaching practices. However, the analysis of the data from the survey did not provide an in-depth explanation for apparent inconsistencies and associations. These data posed a question that required further study, which was pursued in the second phase of the research (Figure 4.8).

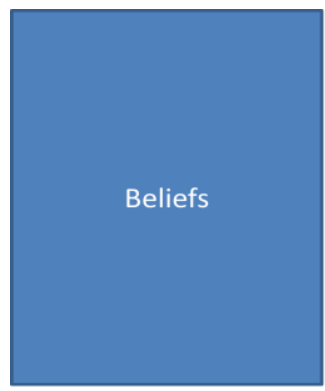

\section{What happens?}

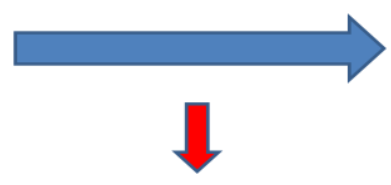

\section{Gap between beliefs and practice}

Figure 4.8. Questions to be followed-up 


\section{CHAPTER 5: PHASE 2 - CASES STUDIES}

\section{Introduction}

The results of the quantitative survey reported in Chapter 4 revealed several trends in perspectives of language lecturers in universities in Thailand in relation to learner autonomy. Briefly, these trends were: (a) inconsistencies between the lecturers' beliefs and practices; (b) an association between a Bachelors degree in education and higher levels of belief in learner autonomy; (c) lecturers' overall low confidence in students' abilities to take charge of their own learning; and (d) lecturers' resistance to students' involvement in time-management related decisions and assessment. However, the survey was not designed to gather data that might provide explanations for these trends. In addition, the survey did not provide a detailed analysis of the activities and strategies that the lecturers reported they used to promote learner autonomy. A follow-up study was planned to obtain this more detailed analysis. Therefore, this phase of the study aimed at obtaining qualitative data through case studies that might help to explain how factors internal and external to the lecturers had contributed to those trends revealed in Phase 1. Specifically, the second phase of the study was carried out to answer the final two research questions:

1. What factors explain the trends identified in the quantitative results?

2. How has the concept of learner autonomy been operationalized in university language classrooms?

\section{Method}

Though case studies have been criticized for not offering a scientific rigor and not addressing reliability and generalizibility, the approach contains a number of strengths that will aid the present purposes. As Simons (1989) argued, case studies "have several virtues over input-output models" (p.115). The use of a case study was intended to enable me to gain a more holistic view of a certain phenomenon within its "real-life context" (Yin, 2009, p.1), 
and hence allow "an accurate portrayal of realities" (Crossley \& Vulliamy, 1984, p.198). This is the strength of case study, which other research methods, such as a questionnaire or experiments, are perhaps less able to render (Crossley \& Vulliamy, 1984). My cases studies in this phase represent individual lecturers in their professional contexts, that is, in their classroom with their students, and their workplace.

\section{Participants and Selection Procedures}

I purposively selected five participants for this phase of study based on the results of Phase 1. Purposive sampling was appropriate for this phase of my study because it enabled me to identify people from whom I could learn the most. This is particularly pertinent when researchers are interested in understanding values, beliefs or practices within a given context, rather than making generalizations of findings to a population (Alexander \& Winne, 2006). Furthermore, this sampling strategy is appropriate when researchers can clearly define the desired characteristics of the people or events of interest (Le Compte \& Preissle, 1993).

The selection procedures are outlined in Figure 5.1. 
1. Put questionnaire results in SPSS (V17)

2. Calculate scores

(under 3 constructs: beliefs, confidence \& practice)

3. Select eight participants

( 3 with high scores, 3 with low and 2 in the middle)

4. Identify participants with pseudonyms

5.Classify participants according to their scores

(strong, weak and

mediocre supporters)

6. Invite participants

Figure 5.1. Participant selection procedures for phase 2 


\section{Explanation of Participant Selection}

Once the targeted number of completed questionnaires was obtained from Phase 1, I put the results of these questionnaires into SPSS 17 for analysis to obtain individual participants' total scores. Based on the scores calculated, eight participants were selected. The scores of three participants were ranked as the top three highest scores, suggesting that they could be regarded as strong supporters of learner autonomy. Another three participants had scores ranked as the lowest scores. The remaining two participants had scores that were neither high nor low. These eight participants were (pseudonyms): Malee, Bussaya, Wipakorn, Jensuda, Wassamon, Chokechai, Chomdao, and Thananya.

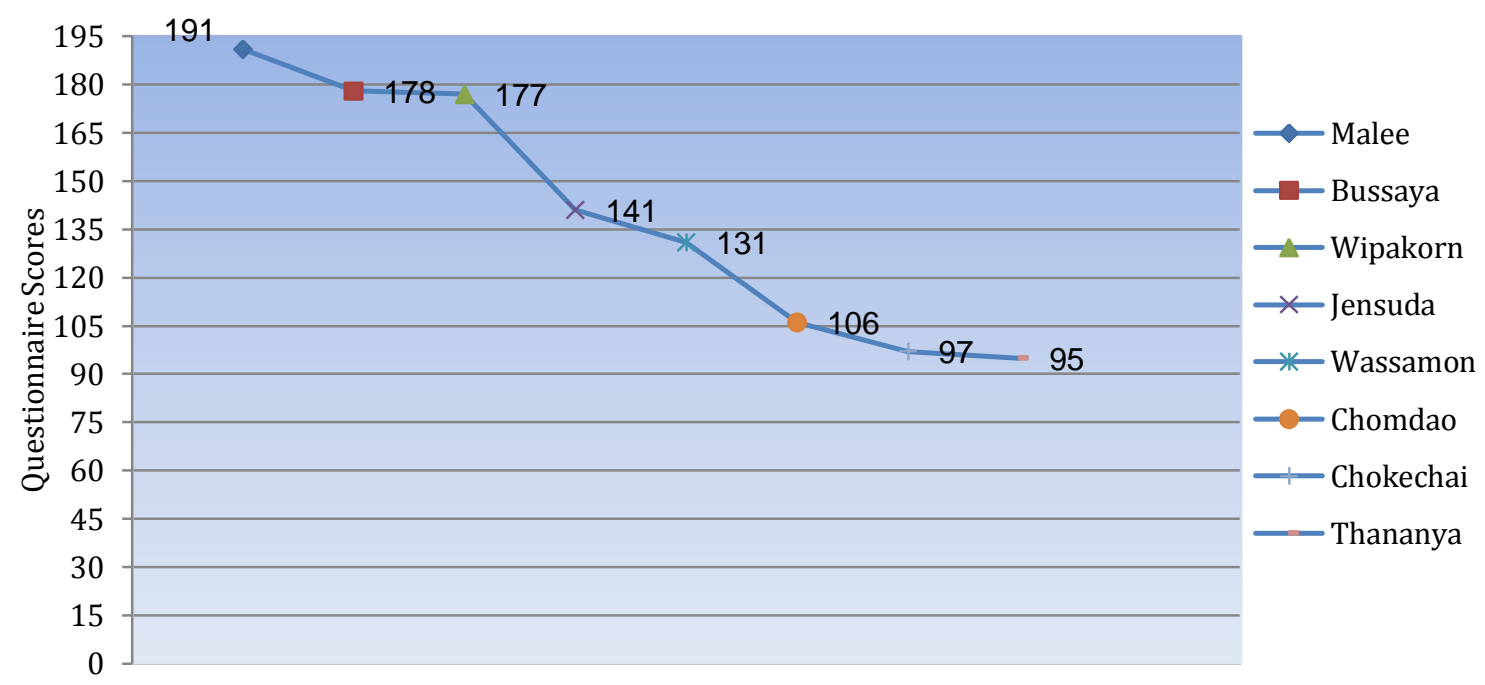

Figure 5.2. Questionnaire scores of potential participants

Based on the above scatter plot, I classified the eight potential participants by delineating their beliefs, confidence and practice scores. 


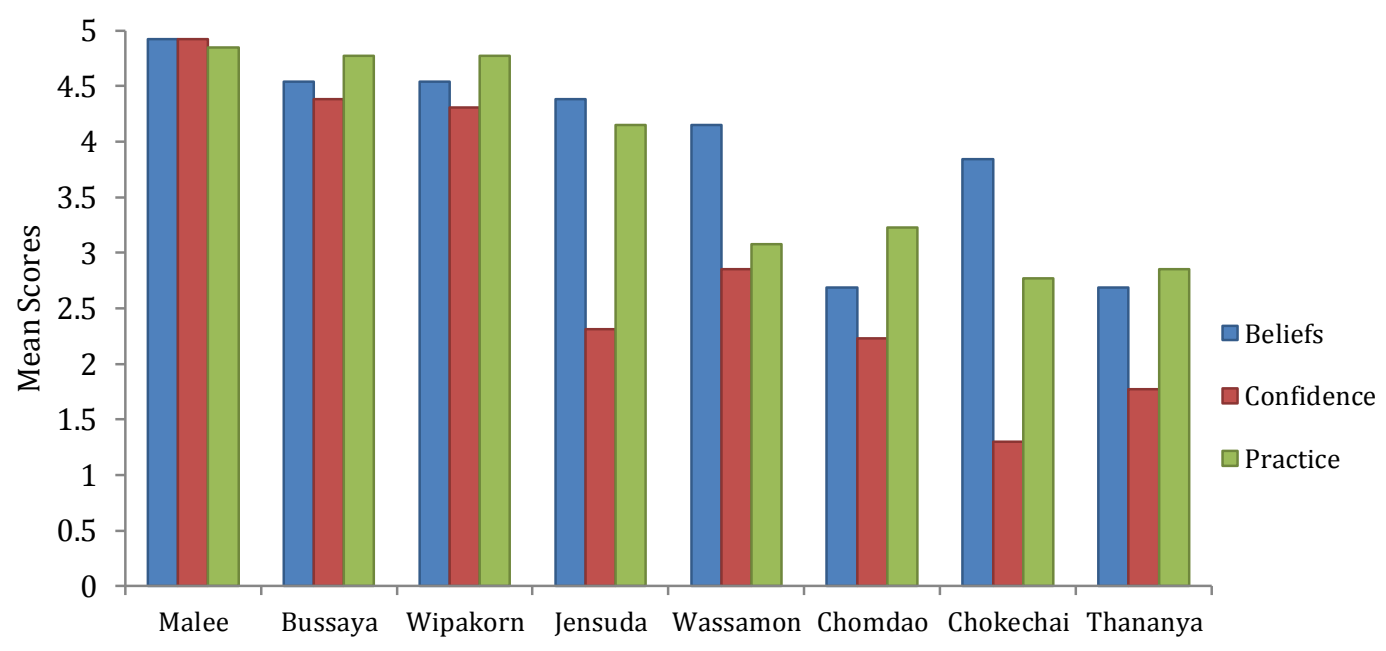

Participants

Figure 5.3. Potential participants' beliefs, confidence, and practices

Figure 5.3 shows that Malee, Bussaya and Wipakorn could be regarded as lecturers who highly valued and practiced learner autonomy. In contrast, Chomdao, Chokechai and Thananya were classified as showing low belief in learner autonomy and did not seem to practice learner autonomy. Jensuda and Wassamon, though not classified as strong or weak supporters of learner autonomy, were selected as cases that warranted study. In the case of Wassamon, a conflict existed between her reported beliefs and practice. Her scores on beliefs were high while those on practice were low. It implied that though she reported a strong belief in learner autonomy, she did not promote it much in her actual teaching practice. Her level of confidence based on the questionnaire results was consistent with her teaching practice in that she had not expressed a high level of confidence in her students' ability to take charge of their own learning and did not seem to give them opportunities to do so. In Jensuda's case, her responses indicated that she believed strongly in learner autonomy and she reported that she allowed her students to exercise it. What was interesting about Jensuda was that she reported that she still allowed her students to exercise their autonomy although her scores on confidence suggested that she was not confident in their ability to do so. This 
suggested a conflict in her practice and confidence that deserved further investigation.

The final step in the selection of participants for Phase 2 was to invite all eight lecturers for participation in the cases studies by email. This process resulted in five out of eight participants agreeing to take part in case studies: Bussaya, Wipakorn, Jensuda, Wassamon, and Thananya. Malee was on a conference trip abroad while Chokechai and Chomdao did not give reasons for not wishing to participate. The five lecturers and their rank related to learner autonomy are shown in Figure 5.4.

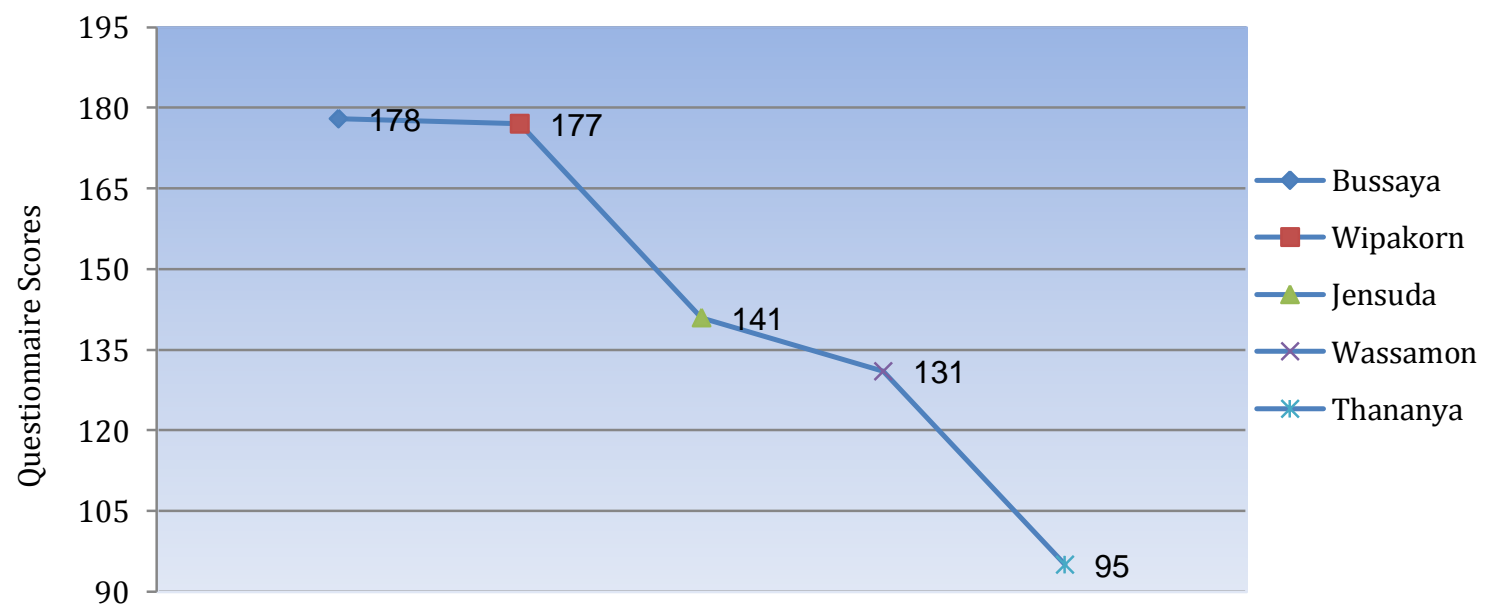

Figure 5.4. Participants in phase 2 and scores

\section{Data Collection Procedures}

Data for Phase 2 were gathered through the use of interviews, classroom observation and follow-up discussions with each participant after the classroom observation and document analysis. In qualitative studies, the use of different methods of data collection is recommended so that data can be triangulated to help increase the trustworthiness of the study (Lincoln $\&$ Guba, 1985; Yin, 2009). 


\section{Interview.}

Yin (2009) regards the interview as one of the most essential sources of data when doing a case study. It enables the participants to discuss things from their own perspectives (Cohen et al., 2007) and clarify or discuss some aspects in detail (Hague, 1987). In Phase 2, an interview was conducted with the participants to elicit in-depth data regarding many features of their past educational experience, views towards their current students, workplace and responsibilities, and features related to cultural, social and academic environments that they perceived as facilitating or hindering the promotion of learner autonomy. I created an interview protocol that provided a framework of the themes to be explored as well as a list of guiding questions. The protocol consisted of 4 main sections with 20 questions as shown in Appendix G.

Section 1 was related to the participants' past educational experience. Several studies have shown the influence of teachers' learning experience on their current teaching behaviors (e.g. Borg, 2003, Nicolaides, 2008; Sert, 2006). The teachers who had been shaped by traditional ways of learning are likely to behave in a similar way in their own classrooms. If the teachers had no experience of being autonomous learners, they are unlikely to assist their students to be so. Thus, this section aimed to explore whether or not the participants regarded themselves as autonomous learners, and how their educational experience influenced their current perception of the teaching/learning process.

Section 2 of the interview protocol solicited the participants' views of their students and the expectation they have of them. It is essential to know how a teacher views his or her students and what he or she expects from. Many studies have shown situations when a teacher's perception of their students prevents them from promoting learner autonomy (Littlewood, 2003; Meeus et al., 2008). 
Section 3 explored how learner autonomy was enacted in the lecturers' workplace contexts. This included whether there was evidence of the participant's university providing support for lecturers to promote learner autonomy, and how features of the classroom environment might influence the implementation of learner autonomy. The questions in this section were drawn from the assumption that learner autonomy depended to some extent on a teachers' current position in their career (La Ganza, 2008; Little, 1995; Murphey, 2003).

Section 4 aimed to draw out features of Thailand's society, culture and education system that may influence the promotion of learner autonomy. Research has shown that certain cultural aspects, social expectations and socialization processes as well as educational systems have certain impacts on the successful pursuit of learner autonomy (Borg, 2003; Cotterall, 1995; Januin, 2007; Jing, 2006a, 2006b; Roskams, 1999; Wisaijorn \& Tremayne, 2008).

Two participants (Jensuda and Wassamon) decided to use English in the interview while the other three participants (Bussaya, Wipakorn, and Thananya) preferred to be interviewed in Thai. I audio recorded and transcribed the interviews. I translated those interviews that were in Thai before the coding process.

\section{Classroom observations.}

I used observations as a means to gather "live data" from live situations (Cohen et al., 2007, p. 396). The observations enabled me to elicit information that might be not be available in the interview, such as the physical arrangement of the classroom, and how teaching strategies facilitated students' exercise of autonomy in their own learning.

I observed two classes taught by each participant. In total, 10 classes were observed, with approximately two hours per each observation. The 
participants decided the date and time for observation. A two-hour observation permitted me sufficient time to immerse myself in the classroom in order to obtain holistic pictures of the participants' situations (Morrison, 1993). On the observation date, I accompanied the participants to their class. After the participants greeted their students, I was introduced to the class. Such an introduction helped reduce the students' curiosity about having me in their class. During the observation in the participants' classrooms, I played the role of a non-participant observer, watching and making notes without being involved in the participants' activities (Creswell, 2005).

The main aim of observation in this phase of my study was to gain an understanding of the implementation of learner autonomy in its "natural setting" (Yin, 2009, p.109). That is, to examine how the physical settings, learning activities, lecturer and students discussion and behaviour, decisionmaking, and the learning atmosphere were all managed. These areas were developed from my literature review as indicators that might contribute to a picture of how autonomy is evident in a classroom. Examination of each area was guided with questions shown in Table 5.1. 


\section{Table 5.1}

\section{Guided Questions for Class Observations}

Physical settings
- How are the seats arranged?
- What are the classroom resources?
- Any interesting physical aspects?

\author{
Activities \\ - What activities are used in the class? \\ - How those activities are delivered? How did the \\ lecturer introduce a new activity/task to \\ students? \\ - How many activities are there in each class? \\ - Group, pair or individual work? \\ - Are students engaged in planning, setting a goal, \\ or finding their own learning strategies? \\ - How the activities/tasks are assessed? (by \\ teachers, students, or peers?)
}

\section{Students talk and behavior}

- What are students' reactions when the lecturer asks questions?

- How do they ask questions to the lecturer?

What kind of questions they ask?

- How much do they talk- to the lecturer and to their peers?

- How does the lecturer respond when the students ask questions?

- What the lecturer does when students are doing the given activity/task?

\begin{tabular}{ll}
\hline Decision making & Learning atmosphere \\
- Who makes most of the decisions? & - How does the lecturer respond to a student who \\
- What kind of decisions? & makes mistakes in the given task? \\
- Who decides about length of time for an & - How does the lecturer react to off-task behavior? \\
activity/task? & - Are the lecturer and students in a good \\
- Are there opportunities where students are & relationship? \\
required to make their own decisions? What & - How is the learning atmosphere like? \\
activities? &
\end{tabular}

Data from the observations were recorded in an observation fieldnote (see Appendix H), consisting of four main sections:

1. Class information: participant's pseudonym, course name, location (classroom no and the university pseudonym to ensure confidentiality), number of students registered and actual presence, and class actual begin time and actual end time;

2. Time and activities;

3. A reflective area, in which the researcher recorded personal opinion towards what was happening (Creswell, 2005);

4. Researcher's comments, which might be related to the classroom, students and the participants' pedagogy, and could be recorded on the scene or later. 
The reflective and comment sections in the fieldnotes enabled me to include my own perspectives on the cases and their actions. In doing qualitative cases study, Stake (1995) recommends researchers to include their own personal perspectives. It is because of this that the interpretation of data in cases studies is unique and depends on a researcher's view of their own cases. Thus, in qualitative cases studies, "personal valuing of the work" is what is expected, rather than "reproducibility" (Stake, 1995, p. 135).

\section{Follow-up discussions.}

Follow-up discussions took place approximately 10 minutes after the class finished. Each follow-up discussion took approximately 20 minutes. I used data from the observations to draw out the participants' rationale for actions and on-the-spot decision-making in relation to the strategies they employed. I used follow-up discussions in my study as a form of stimulated recall, which is an introspective method, and appropriate for studying reasoning and decision-making processes (Lyle, 2003).

In my study, the participants' responses were not audio recorded, but were noted in the comment section of the field notes. This is because I intended to make this discussion in a relaxed, conversational environment. It is my personal assumption the participants might feel tired after finishing their class and might feel more relaxed when not being recorded. Jensuda and Wassamon used English in the discussions while Bussaya, Wipakorn and Thananya preferred to discuss in Thai.

\section{Document analysis.}

Document analysis is particularly appropriate for qualitative cases studies. It is a "systematic procedure for reviewing or evaluating documents" that can be either printed or electronic (Bowen, 2009, p.27). Data from this source became another means for me to triangulate with data gathered from interviews, classroom observations and follow-up discussion. Documents that I examined were volunteered by the participants. After the interview, 
Bussaya, Wipakorn, Jensuda, Wassamon allowed me to examine their course syllabus, supplementary worksheets and textbooks/course books, but I was only allowed to take copies of the course syllabus. Thananya, after the second classroom observation, only allowed me to take a look at the textbook she used. Data from the examination of documents were recorded in "Document Analysis Worksheet" (see Appendix I).

The procedure for gathering data for Phase 2 is summed up in the following Figure 5.5. 


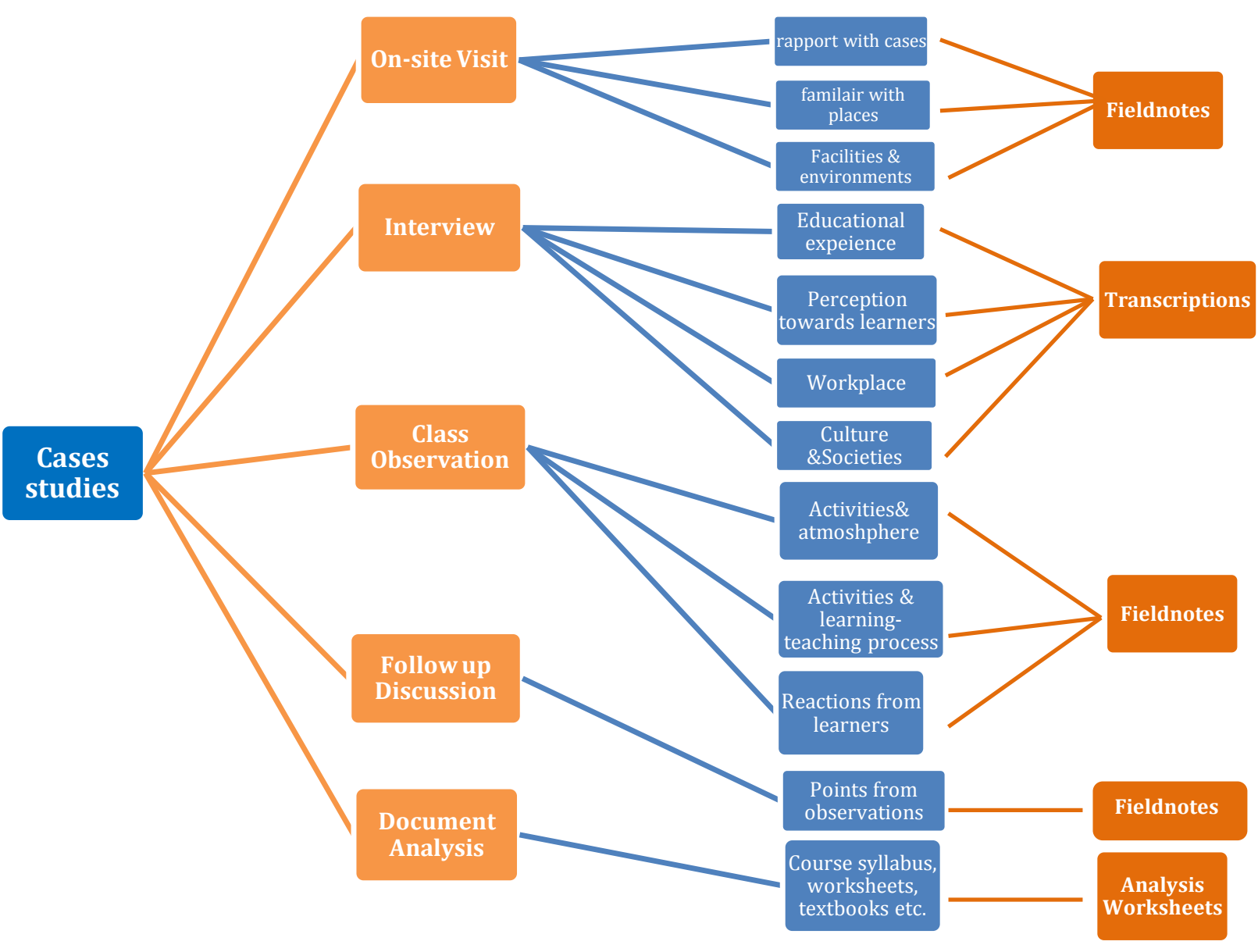

Figure 5.5. Procedure for cases studies 


\section{Timeframe for Cases Studies}

Completing each case study required four visits over a three week period. Data gathering started the last week of January, 2010. However, this period of time was not suitable for every case: February was the last month of the semester according to Thai education system. Only four participants, Bussaya, Jensuda, Wassamon and Thananya were able take part in this period. Wipakorn preferred data to be collected in June 2010 as in February she had finished all of her classes and started doing the final examination.

The first visit was to build rapport with each participant, the most important element for a successful interview (Powell, Fisher, \& Wright, 2005). In this first meeting, after giving a brief self-introduction, I explained the whole research project, the selection process for this phase of studies, ethical considerations (see detailed ethics information and consent form in Appendix F). I spent the rest of the day after meeting with each participant to observe the settings of their university: students, lecturers, the buildings, library, learning facilities, self-access centers to elicit overall atmosphere of the participants' universities.

In the second visit, I interviewed the participants. The interviews were audio-taped. The interview was a focused interview (Merton, Fiske \& Kendall, 1990). That is, each participant was interviewed for a short period of time (approximately 50-60 minutes). Although the interview was carried out in conversational style with open-ended questions, each interview still followed a structured protocol or interview guide (Yin, 2009). After the interview, I also spent the rest of the day observing the contexts of the participants' universities. This is to ensure that sufficient time was spent to understand the settings and the culture of the participants (Lincoln \& Guba, 1985).

Classroom observations followed the interviews within a few days. The classroom observations allowed me to see things first hand and to discover 
things that the participants may not have been comfortable to express or unintentionally overlooked in the interview. During classroom observation, I recorded fieldnotes descriptively and reflectively and drew a diagram of their classroom. The observation of each class took approximately two hours. The follow-up discussions took place immediately afterwards in the participants' offices, and data were recorded in the comment section of the field note form. Each follow-up discussion took approximately 20 minutes.

The in-depth studies of all five participants were carried out in the following timeframe:

22 Jan 2010

24 Jan 2010

26 Jan 2010

29 Jan 2010

1 Feb 2010

2 Feb 2010

4 Feb 2010

5 Feb 2010

6 Feb 2010

9 Feb 2010

13 Feb 2010

15 Feb 2010

16 Feb 2010

18 Feb 2010

22 Feb 2010

1 Mar 2010

2 Jun 2010

4 Jun 2010

7 Jun 2010

9 Jun 2010
- Visited Jensuda

- Interviewed Jensuda

- Observed Jensuda's class ( $1^{\text {st }}$-observation)

- Visited Wassamon

- Interviewed Wassamon

- Observed Jensuda's class (2 $2^{\text {nd }}$-observation)

- Visited Bussaya

- Interviewed Bussaya

- Observed Wassamon's class (1 $1^{\text {st }}$ - observation)

- Observed Bussaya's class (1 1 st-observation)

- Observed Wassamon's class (2 $2^{\text {nd }}$ observation)

- Visited Thananya

- Observed Bussaya's class (2 $2^{\text {nd }}$ observation)

- Interviewed Thananya

- Observed Thananya's class (1 $1^{\text {st }}$ - observation)

- Observed Thananya's class (2 ${ }^{\text {nd }}$ - observation)

- Visited Wipakorn

- Interviewed Wipakorn

- Observed Wipakorn's class (1 $1^{\text {st }}$ - observation)

- Observed Wipakorn's class (2 ${ }^{\text {nd }}-$ observation) 


\section{Data Management and Analysis}

I did all the transcription and translation. As the recordings from the interviews with Bussaya, Thananya and Wipakorn were done in Thai, the recordings were translated into English by me during the transcription process. The English transcriptions were returned via email to the participants for checking. This method is called a "member check", which helps researchers to avoid any misinterpretation or misunderstanding of the participants' words or actions (Daymon \& Holloway, 2002). All participants accepted the transcriptions as true and correct and did not request any changes.

Data across all of the participants were analysed in order to extract and interpret the similarities and differences across cases (Miles \& Huberman, 1994). The analysis was focused on similarities and differences among the cases' classroom practices, past educational experience, workplace, students, and their views towards the cultural and educational make-up of Thai contexts. I adopted a thematic analysis so as to locate similarities and differences of themes among cases. Boyatzis (1998) described this type of analysis as a process for encoding qualitative data. It allows researchers to more easily communicate what they have observed, discovered and interpreted to others. Because of this, thematic analysis enhances a "more comprehensive understanding of the phenomena" (Boyatzis, 1998, p.6). In addition, Braun and Clarke (2006) considered it as "an accessible and theoretically flexible approach to analysing qualitative data" (p. 77).

I undertook 6 steps in doing the thematic analysis, following Braun and Clarke's (2006) suggestion:

- Reading and re-reading data,

- Producing initial codes from the data,

- Identifying themes

- Reviewing themes, 
- Defining and naming themes

- Writing the reports in the form of my thesis

To facilitate the identification of initial codes and the identification of themes, I used NVivo 8.

\section{Trustworthiness of the Study}

Trustworthiness of the qualitative phase of this study is argued through consideration of the credibility, transferability, dependability, and confirmability of its findings (Guba, 1981; Lincoln \& Guba, 1985). The following table delineates methods that I used to establish the trustworthiness of my qualitative phase.

Table 5.2

Methods to Establish Trustworthiness

\begin{tabular}{|c|c|c|}
\hline Aspect & Criteria & Method \\
\hline $\begin{array}{l}\text { Credibility } \\
\text { Whether or not the } \\
\text { study measured what it } \\
\text { is intended to (Shenton, }\end{array}$ & $\begin{array}{l}\text { Triangulation } \\
\text { (Guba, 1981; Lincoln \& } \\
\text { Guba, 1985; Yin, 2009) }\end{array}$ & $\begin{array}{l}\text { Various methods were used to collect data: } \\
\text { questionnaire results, interviews, classroom } \\
\text { observations, follow-up discussion and document } \\
\text { analysis }\end{array}$ \\
\hline 2004) & $\begin{array}{l}\text { Prolong engagement } \\
\text { (Guba, 1981; Lincoln \& } \\
\text { Guba, 1985) }\end{array}$ & $\begin{array}{l}\text {-Time was spent in the participants' settings to } \\
\text { understand various aspects of their setting. } \\
\text { - I familiarized myself with the participants' settings } \\
\text { by visiting their universities' websites and } \\
\text { observing activities/events taking place in their } \\
\text { settings as reported in the websites. } \\
\text { - Rapport was built with the participants to reduce } \\
\text { a feeling of threat that the participants might have in } \\
\text { the participation in my study and enhance trust } \\
\text { between the participants and me }\end{array}$ \\
\hline & $\begin{array}{l}\text { Member checks (Guba, } \\
\text { 1981; Lincoln \& Guba, } \\
\text { 1985) }\end{array}$ & $\begin{array}{l}\text { - Transcriptions of the interviews, summaries of } \\
\text { classroom observations, and summaries of the } \\
\text { analysis were e-mailed to the participants. They } \\
\text { were asked to check the accuracy and give feedback } \\
\text { and comment on points that they did not agree with } \\
\text { or wished to change. }\end{array}$ \\
\hline
\end{tabular}




Informants' - - I ensured that the participants were aware that the
willingness and data obtained and the findings did not have any honesty (Shenton, effect on their profession, and their identifying 2004) details were kept with strict confidentiality

- The participants were informed that they can withdraw at any time of the study or even at the very beginning of the study.

Transferability
The extent to which the
findings can be transfer
to other contexts (Guba,
1981; Lincoln \& Guba,
1985).

Purposive sampling
The participants were purposively selected based (Guba, 1981) on their responses in Phase 1. They acted as an instrument to understand a phenomenon and might be an example of their broader population (Stake, 1995)

Thick description
- I present detailed information of the participants
including their demographic, educational and
professional data, and their contexts (in the
following "Results" section). Thick description
permits a baseline for the reader to make
comparisons and, as a result, transfer the findings to
other lecturers, situations, and contexts that have
similar characteristics (Guba, 1981; Lincoln \& Guba,
1985).

Dependability
The consistency of
results and the ability to
trace the sources of
variance or errors
(Guba, 1981)

Audit trail through
- Procedures for the participant selection were dense description clearly explained, so that the reader is able to audit (Guba, 1981) how these participants meet the criteria.

- I present detailed processes of how data were collected and analyzed, and give thick descriptive data of each participant.

\begin{tabular}{ll}
\hline Triangulation & As discussed in the credibility issue \\
\hline External auditor and & - My supervisors, acting as external auditors, went \\
stepwise replication & through my analysis and commented on "the degree
\end{tabular}
to which procedures used fall within generally accepted practice" (Guba, 1981, p. 87).

- Part of this qualitative phase was presented in an international conference in Thailand.

\begin{tabular}{lll}
\hline Confirmability & Triangulation & $\begin{array}{l}\text { Data collected from different methods were } \\
\text { The extent to which the }\end{array}$ \\
\cline { 2 - 3 } data are neutral and & Confirmability audit & My interpretations, conclusions and insights were \\
& cross-checked by my supervisors to ensure that they \\
& have been "made in ways consistent with the \\
& available data" (Guba, 1981, p. 88). \\
\hline
\end{tabular}




\section{Results}

This section presents the results of the in-depth studies of five participants. The presentation was based on the participants' categories identified in the questionnaire results: strong, unconfident and weak supporters of learner autonomy. I intend to make the presentation of each category dense so that they are understood within their categories and contexts (Guba, 1981; Lincoln \& Guba, 1985). Detailed description is also intended to facilitate an audit trail of the emergence of themes (Guba, 1981). The presentation starts with an introduction of the participants in each category; their past educational experience; students; classroom physical environments; classroom practices; workplace conditions; and cultural, social and educational contexts.

\section{Case Introduction}

\section{Strong supporters.}

Bussaya and Wipakorn could be regarded as strong supporters of learner autonomy. Their responses in the questionnaire reflected their strong advocacy of leaner autonomy, either in their own beliefs, confidence in students' capability or their reported practice. Beliefs were transferred into their reported practice, even more than the extent suggested by the strength of their beliefs recorded in the survey. The average scores of beliefs, confidence and practice from Bussaya's and Wipakorn questionnaire results were almost identical and were as follows: 


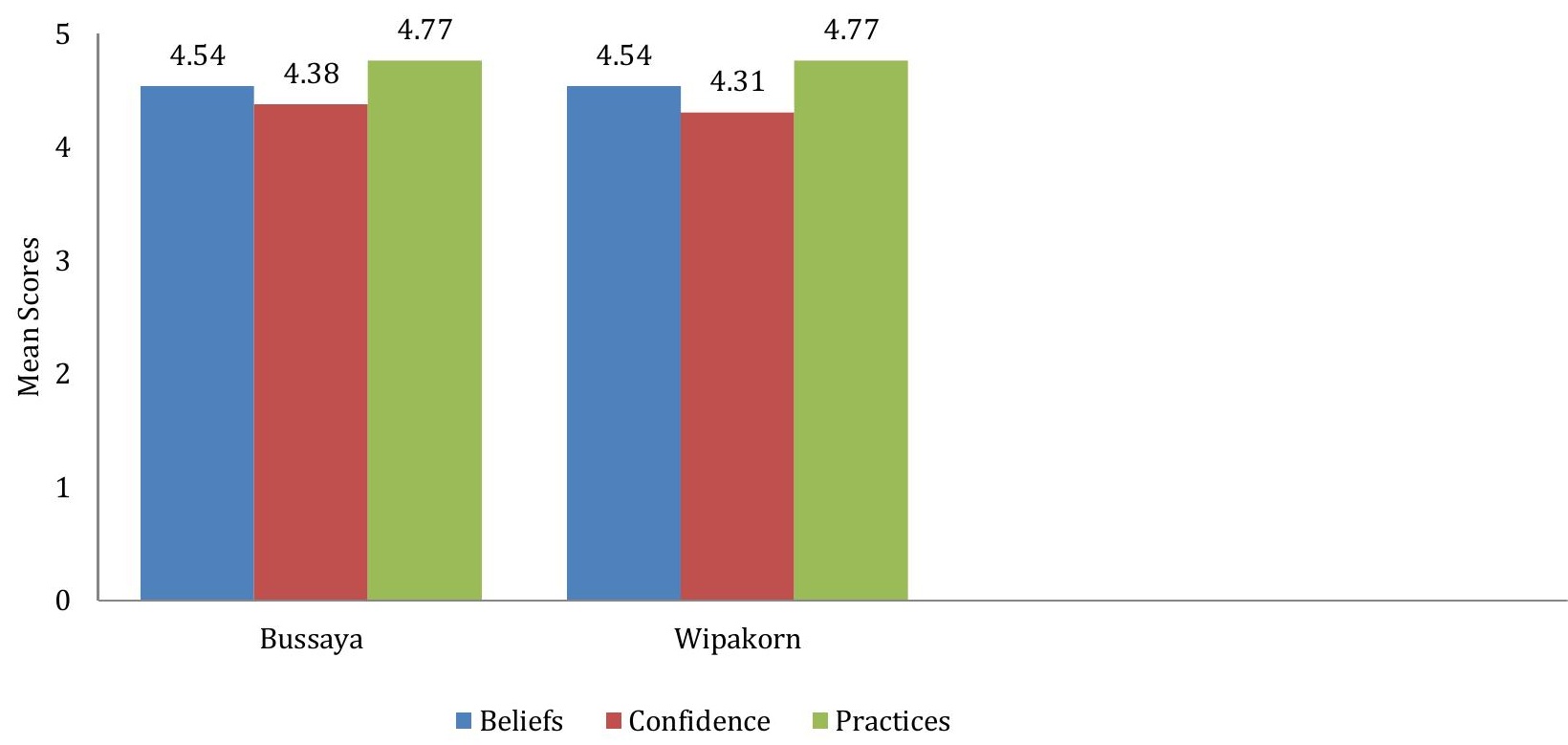

Figure 5.6. Bussaya's and Wipakorn's beliefs, confidence and practice

Both Bussaya and Wipakorn were born, raised and live in Bangkok. When the study began, Bussaya and Wipakorn were 53 and 55 years old respectively. They were female, full-time lecturers of English in universities in Bangkok and had engaged in teaching for more than 20 years.

Bussaya's and Wipakorn's universities were located in Bangkok. Their universities were well-established as some of the top universities in Thailand and were recognized nationally and internationally. Students who got a place into these two universities were regarded as the 'cream of the cream'. Each university had more than 10,000 students studying from bachelors to doctoral level in a variety of disciplines. Bussaya's university had another branch campus located in a small city. 


\section{Unconfident supporters.}

Based on the questionnaire results (Figure 5.7), Wassamon and Jensuda seemed to strongly believe in learner autonomy. However, their confidence and practice scores make them neither a strong nor a weak supporter of learner autonomy. Both of them had quite low confidence in students' ability to take charge of their own learning. Figure 5.7 further indicates an inconsistency between Wassamon's beliefs and practices. The inconsistency in Wassamon's beliefs and practices, and low confidence in students indicated by both of them were of particular interest and invited further investigation.

As both Jensuda and Wassamon had low confidence in their students, they were categorized as unconfident supporters of learner autonomy.

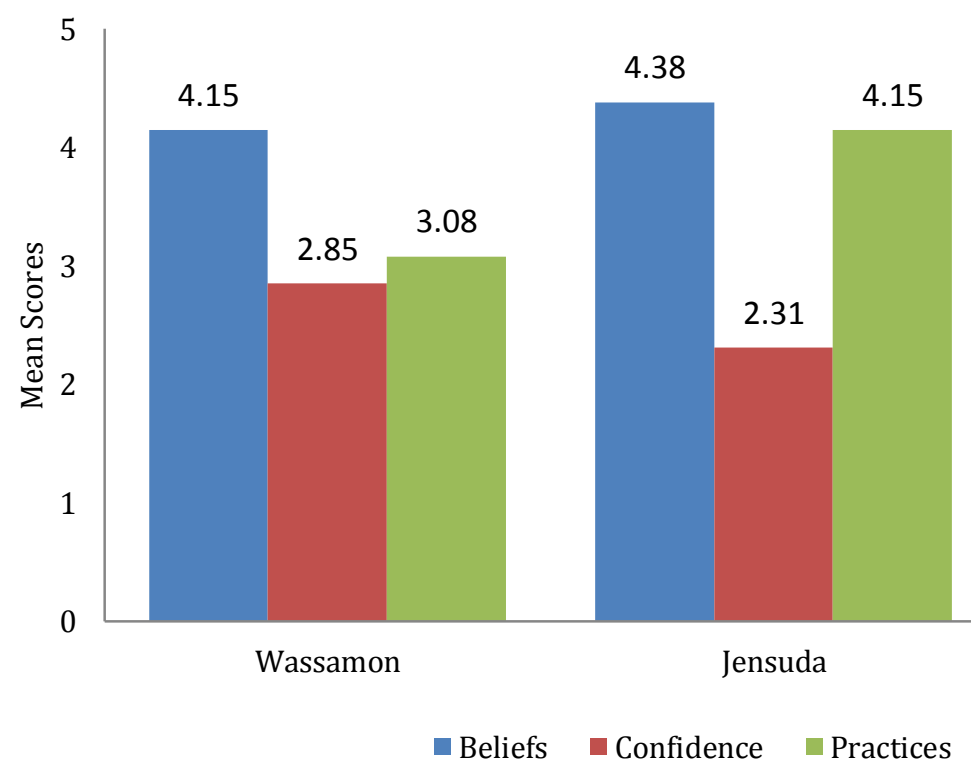

Figure 5.7. Wassamon's and Jensuda's beliefs, confidence and practice

Jensuda and Wassamon shared many similar characteristics. They were both in their 30s and had master's degrees as their highest qualification. They were full time lecturers of English in an undergraduate program. Both of them taught in branch campuses of high-ranking national universities in 
Thailand. Their campuses were newly established and offered only one faculty. While the home campuses were in the big cities, Wassamon's and Jensuda's campuses were located in rural areas.

Jensuda was born and raised in Bangkok. She had been teaching for 5 years. Wassamon was born in same province as her university was located and had been teaching for 7 years.

\section{Weak supporter.}

Based on her questionnaire results, Thananya was a weak supporter of learner autonomy. She had low average scores for her beliefs, confidence in students' capability and real practice (Figure 5.8).

When the study began, Thananya, PhD., was 60 years old and about to retire. She was born and grew up in Bangkok. She had been teaching for 35 years and was a full time lecturer of English in a branch campus of a well-known government university. Unlike the main campus, which located in Bangkok, Thananya's campus was newly established and located in a very small, quiet town. The campus had four faculties and most of the fields of study offered related to agriculture.

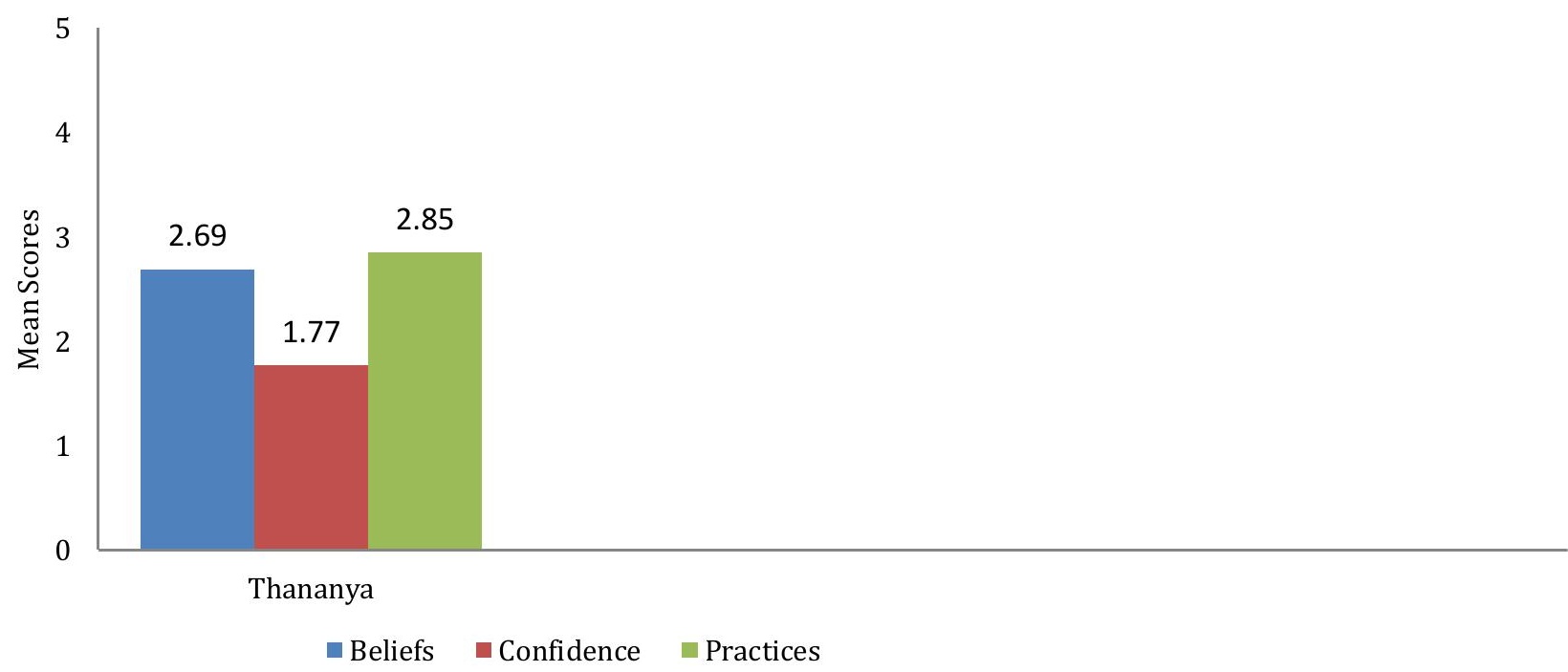

Figure 5.8. Thananya's beliefs, confidence and practices 


\section{Past Educational Experiences \\ Strong supporters.}

Bussaya's and Wipakorn's accounts of their learning experience indicated that their tertiary education influenced their preference for autonomous learning. Although in those days the concept of learner autonomy did not exist in the education system of Thailand, both of them reported that some lecturers had been implementing it into their classroom practices. Most of the promotion of learner autonomy was through classroom activities, not technology, internet, CALL, or self-access learning centers.

Bussaya mentioned an external reading activity in which she and her friends were to manage their own learning:

...discussed with friends and then we had a quiz. With this the teachers wouldn't help. We had to read, to take care of our reading and then had a quiz.

The reading activity acted as a platform for Bussaya to exercise her own autonomy. Through doing the activity, she gradually realized that she needed to take care of her own learning process:

They [lecturer] would tell us which books to read and then quiz. So, it became our responsibility to take care of our reading and to search for more information about the books or to do whatever to make sure that we understand the books, as the teachers would never talk about it at all. Usually we did it with friends-it was like a group study.

In addition to the realization of the need to take responsibility for her own learning, the above extract further shows that Bussaya was engaged in the idea of learning collaboratively with peers. The idea of learning with peers was strongly encouraged by her teachers. She described:

...when the teachers let us discuss with friends in group or let us do some searches and then present our work to class. They were also like a 'clinic' for us 
so that we could help each other. Usually we had our own groups and we did group discussion.

Like Bussaya, Wipakorn was encouraged by some of her teachers to engage in an activity called 'individual study'. She said:

...some teachers would encourage sort of individual study, which we were expected to do self-study by finding stories that we were interested in and report to friends.

In this activity, the teacher gave students freedom to make their own decisions, to choose the topics of study, to find their own ways to self-study and to design their own reports.

Bussaya admitted that when she was a student, her expectation of a teacher's role was in contrast to the role she currently played as a teacher:

At that time, I though the teachers' job was to teach us and to make sure that we understand. If we did not understand something, it was the teacher who needs to clarify or explain us. It seemed to me then that the teacher was the one who knew best, knew everything.

As a learner, Bussaya expected her teachers to 'teach' and to 'make sure' that students really understood. She perceived her teachers as the ones who 'knew best and knew everything'. However, now she did not think that the teacher needed to know everything. Below is an extract from the interview showing how she perceived herself as a teacher:

I realize that in class I may not know everything. Kind of I may not be the one who know best....

She reported that these days she did not perceive herself as 'the best knower'. Rather, as she expressed in the interview: 
It is like we grow a tree. Yes, we let it grow freely but at the same time we need to trim it to make it beautiful. We, teachers, need to help them.

For Bussaya, being a teacher was like growing a tree. Such a view of a teacher's role underpins a fundamental feature of learner autonomy, in which learner autonomy should not be equated with the absence of teachers.

Wipakorn learnt to take control of her own learning by being given the freedom to make her own decisions. She said:

....because the teachers gave us freedom in making our own decisions. I could remember that everyone in the class had a different topic; no one chose the same topic.

This seemed to be the foundation for her advocacy of having students taking control of their own learning. Wipakorn gave her students freedom in choosing the topics for a group project. However, as Wipakorn described, it was not a complete freedom:

...it was still under the scope of courses, like if it was the literature class, we then needed to do something related to literature.

Students still needed to make sure that all they did was within framework of the course. Like Bussaya, Wipakorn experienced chances to work collaboratively with friends. She believed that interactions with her friends during classroom discussions enhanced her sense of autonomy. She said in the interview:

..... we had class discussions, where everyone could voice out their opinion. But this did not mean that it went beyond the scope of the course; it was still under the scope of the course. Our teachers allowed us to express our opinions freely. We may agree or disagree with this or that; we could critique. What we needed is to give reasons for our ideas. 
During class discussion, Wipakorn described the freedom of thought that she had been given as a student. It was the freedom to voice one's opinion, to agree or disagree, to critique. This freedom, however, was limited within the scope of the course. That is, she could disagree with a point but she needed to justify her decision to demonstrate a degree of critical thinking.

The account of their education suggested that Bussaya and Wipakorn's own experience played a critical role in shaping their ideas about learning. The ways that their lecturers had treated them gradually instilled the feeling that they needed to take care of their own learning. This indicates the influence that teachers' classroom practice played on the development of the autonomy of student (Sert, 2006; Nicolaides, 2008). The likelihood that teachers would assist their students to be autonomous depended a lot on whether they had been assisted to be so by their previous teachers.

\section{Unconfident supporters.}

Wassamon's account of her learning experience indicates that her bachelor's degree became a strong foundation for the development of her autonomy in learning. When she was a university student, she did many assignments:

I've got a lot-a lot of homework and assignments, you know... After that, more than a half of the period I was assigned to do a lot of writing, I mean a lot of translation exercises.

The extract implies that given limited provision of learning facilities and materials, activities in the classroom played an important role in shaping Wassamon's learning philosophy. Her lecturers did not check who did or did not do the assignments. Wassamon assumed that by doing so, the lecturer gradually shaped the concept of responsibility and encouraged her to be autonomous:

It was like it is our responsibility to take care of our learning. If you did it before the class, you got it. 
Wassamon believed that her writing class was a scaffold for her autonomy. In this class she was given a frame of what she had to do:

The teacher let us know that ok you had to read books or theses of master's students. This is the frame for us and after that we could choose whatever we were interested in.

By having freedom of choice in thinking, planning and finding their own ways of doing things, Wassamon seems to have gradually learnt to manage her own learning. In addition to freedom in thinking, Wassamon had to constructing her own meaning of knowledge. Her lecturers would not give the answers. She said:

.... the teacher just wrote a guiding solution on the board, like suggested answers. If a student would like to initiate or to propose some ideas, he or she just raised the hand up. But if there was no suggestion or no question from the students, the teacher would then go to the next part or topic.

This suggests that Wassamon did not expect knowledge to be transmitted from her lecturers. Rather, she needed to do exercises and build her own knowledge.

Jensuda was like Wassamon. Her response below suggests that Jensuda's beliefs in learner autonomy may have been shaped during higher education, rather than in high school education. She explained:

I think at high school, not much. But in university, I learned by myself. I had to find some books to read---prepare myself before the examination or anything at the library.

Jensuda's school experience failed in providing opportunities to learn autonomously and was more teacher-centred. Unlike her high school teachers, Jensuda's university lecturers gave her opportunities to be an autonomous learner during her tertiary education: 
My language lecturers always tried to help me and other students to learn English. They acted as like a facilitator and helper at the same time. They tried to create other supplementary to make me get.um.. to help students to learn English easier.

Her lecturers suggested certain forms of self-study such as learning in the university self-access learning center or doing a reading activity outside class. In the latter, the lecturers would give a list of books, and then students needed:

.... to self- study. After that you have to summarize after you finish your reading. And then you have to make a report to them.

This independent reading activity provided Jensuda an opportunity to manage her own leaning, particularly in making decisions on which books to read and on the pace of her reading. The experiences of their own education became a scaffold for both Jensuda's and Wassamon's high level of belief in learner autonomy. Both of them have learnt from their own schooling to see the importance of learning activities and the classroom atmosphere.

\section{Weak supporter.}

Thananya's report of her learning experience indicated that learner autonomy was not promoted during her time as a student. She saw the role of a teacher as a person who taught and inspired students to learn:

I could remember when I was in secondary school, there was a teacher who graduated from England. I didn't study with her but I heard it when she spoke English. I felt her English, her accent, was different from other Thai teachers. That made me want to speak, to read English. She was like a role model. She played an important role in making me want to learn English.

The extract implies that Thananya saw the teacher as an important role model in motivating students. She explained that learning supports such as computer-assisted learning, commercial learning packages, learning software 
and self-access centres were not available at that time for self-study. Most of her teachers required students to take part in an independent reading' activity, as she said:

We had to read on our own and there would be an assessment at the end and the external reading activity. We read just because we wanted to pass the exam.

It seems that the assessment of this reading activity failed to encourage her to think critically. The conversation in the interview between Thananya and me demonstrates this:

Thananya: $\quad$... I just read only when it was close to the test. The test was a good stimulator. If there were no test, we did not want to read.

Researcher: What was the test for the external reading like?

Thananya: $\quad$ They asked in details. ... so we had to read all and to memorize so that we did not fail the test.

The extract shows that these reading activities were motivated by an examination which focused on memorization skills. The activities did not encourage her to use metacognitive skills in planning and to engage in selfassessment. Thus, it can be said that Thananya's own learning experience may not have provided many opportunities for her to exercise autonomy in her learning. 


\section{Students}

\section{Strong supporters.}

Both of the strong supporters of learner autonomy reported in the interviews that they had a good relationship with their students. Bussaya described the relationship with her students:

It's not like 'the teacher and the students 'in those old days. The students are very easy with me. They still realize that I'm their teacher but from their manners or the way they treat me, it seems like they think of me as one of their family members or their senior relatives.

Her relationship with students was not like a 'teacher and student relationship'. Rather, students regarded her as a senior member in their family. This kind of relationship made Bussaya and her students closer and seemed to facilitate her in dealing with students:

When I got angry or disappointed, they know it and try to behave themselves.

Wipakorn based her relationship with her students on trust and freedom. However, the freedom that she gave to her students did not mean she disregarded her responsibility as a teacher. She still played a role as a supporter and advisor. Thus, if the students encountered difficulties or strayed in the wrong direction, she would take action. She said:

If they can walk, I let them go. But once I realize they are going to get lost, then I will drag them back.

In addition to having a good rapport, Bussaya and Wipakorn had positive attitudes towards their students. Bussaya saw the potential in younger generations to be autonomous:

Students in this era have the capability to rely on themselves, so with guidance these students can be autonomous. We need to encourage them or help them when needed. Sometimes these students need a guide as they have a 
misconception about being themselves. They think this is the way that they are and so what?

Bussaya viewed her students as being confident individuals. They were English-major students and, in her opinion, students from different majors had different characteristics. She felt lucky to have students majoring in English in her class:

I think I'm sort of lucky in that mine are quite good and major students- I mean they're from English major. These students are pretty determined in their decision to study in this field. In addition, they are in the 3rd or the 4th years and know what they want or expect from study.

Bussaya's association of students' characteristics and their majors was based on her personal experience. The extract above indicated that she regarded English majors as likely to be more confident, individual, determined and extrovert than non-English majors. Despite her satisfaction with her students, for Bussaya, students' capability to take control of their own learning is more important than academic excellence. She said:

Just average students who truly care about their learning and always want to learn with us....have questions and take part all along the way of learning process.

Unlike Bussaya, Wipakorn felt that most of her students were not confident in expressing their opinion, particularly during their first two years in the university. An extract from the interview indicated this:

Researcher: So, do you see any changes in students when, let say, they are in the first year and the third year? I mean whether or not some years in university have transformed something in students?

Wipakorn: Yes. They will become more able to rely on themselves. When they are in the $3^{\text {rd }}$ or $4^{\text {th }}$ years, they become more confident. 
Wipakorn believed that the levels of students' confidence increased over their years of study. As their teacher, she believed that she must always be prepared and able to engage with the students:

....as the teacher, I need to get myself prepared. I mean I must be able to catch up with them, no matter what topics or stories they choose. If they give us resources, we should check to make sure that the students get it correctly.

It could be possible to conclude that Wipakorn did not trust her students, and that the students did not have freedom in their learning because she required students to present the sources of their information. However, she described how students still had freedom in their learning:

But still I give them freedom in choosing. They have the right to choose and change the topics as long as they follow the process that I suggest, because the process is very important. So, in the first place, I let them learn about the process, and then they find their own stories. Kind of I recommend them about study skills, but topics or what to study depends on them.

There are two interesting implications from this. First, Wipakorn regarded "freedom in making decision" as a student's right. Secondly, from Wipakorn's point of view, the essence of learning was not just the "product" or the answers; rather it was the process of learning, in which students should be given opportunities to become equipped with skills necessary for their learning. 


\section{Unconfident supporters.}

Jensuda and Wassamon reported that they had a good relationship with their students. However, both of them preferred not to make it too intimate. Wassamon made it more like a "trust", in which students could trust her in every dimension of their education. Wassamon described it:

We are close but it is more like a trust. I try to bridge the gap in terms of their confidence in asking questions. I try to offer time to them so that they can ask me questions, not just in class, not just at the end of the class but outside the class.

The extract above shows Wassamon's effort to build this "trust", by offering her private time and personal contact channels to students. It was her hope that this would make her students feel more comfortable in talking with her, so they so they would speak up in class. However, Wassamon sometimes felt disappointed as her students rarely asked her questions and seemed to be irresponsible. The extract from the interview shows this:

$$
\begin{array}{ll}
\text { Researcher: } & \text { Doyou think they are responsible students? } \\
\text { Wassamon: } & \text { I think they've tried to be. But I don't know whether it is } \\
& \text { because they have a lot of work or jobs that they have to } \\
& \text { do. Or maybe it is their nature. } \\
\text { Researcher: } & \text { Does this make them look like they are not responsible, in } \\
& \text { your opinion? } \\
\text { Wassamon: } & \text { Just like that. Because it seems to me that they will be } \\
& \text { Kesponsible for one thing and ignore others. } \\
\text { Rassamon: } & \text { That's right. English here is not the major subject. They } \\
& \text { usually focus on the subjects that are related to their field. }
\end{array}
$$

The extract indicates a motivation in learning English of Wassamon's students. Wassamon explained that her students were not English majors, thus they might put more effort into their major subjects over English. For 
them, they took English courses just to obtain the required credits. These may result in the impression that they did not need to put much effort into English; they just needed to complete it.

Like Wassamon, Jensuda experienced difficulties in acting on her beliefs in the need for learner autonomy. She believed that:

In a university level, students have to take their own responsibilities for study, not base it on only me.

However, in reality Jensuda claimed that few of her students were able to take responsibility for their own learning. According to Jensuda:

...most of my students try to base on teachers rather than themselves. ... I try to let them do in group work, pair work or share the idea with their friends. But anyway you cannot see that most students do self-study. If they don't understand, they keep quiet...

The extract above further points out Jensuda's view of her students' characteristics: quiet, shy and unconfident. Data from classroom observation confirms this, that is, Jensuda's students rarely responded and usually made note of what she said during the lecture.

Jensuda regarded her students' learning behaviors as 'unresponsive' and connected her students' shyness and lack of self-confidence to the fact that they were from rural areas. She regarded it as typical characteristics of students in rural areas. She claimed that the students' demographic backgrounds influenced their learning behaviors. The students felt embarrassed and tried to avoid speaking out because they spoke a southern dialect as their first language and had a rural accent when speaking the official central language. Jensuda noted: 
They are quite shy, keep quiet, do not respond and sometimes become very passive. I find that students' cultural background quite affect the way I teach in my class.

In addition to language they spoke at home, Jensuda claimed that students' characteristics also depended on the area of major in their degree:

It depends on the major of the students. If you're lucky, if you teach accounting students, most of them are quite good and they respond when you have a question or introduce something new...

Jensuda based this conjecture on her experience. In the example, students majoring in accounting tended to be more active and responsible in their learning compared with students from other majors.

In Jensuda's view, the students were old enough to go to university so they were at a stage when they should be able to direct their own learning. However, she was not confident that students in her campus could do so, as she further said:

But I can say that only for my university most students are not quite good.... I mean specifically not quite good in English

This suggested that her perception of students' competency made Jensuda uncertain in putting learner autonomy into practice because of the students' levels of English proficiency.

Like Jensuda, Wassamon found that students from different majors displayed different characteristics and learning habits. She referred to students in her class as an example:

Compared to students who major Tourism, I can notice some differences. Try to look at their learning habits, not just in here but also from their past experience. The way they were shaped in their high school, so we cannot use that 45 hours a semester to change them or make an improvement. 
Her students were Accounting-major students. Wassamon pointed out that, based on her 7 years experience, students in this major were more studious and attentive to their study when compared students from other majors. In addition, they were from vocational schools and had transferred to this university to pursue a two-year bachelor degree. Wassamon believed because they were transfer students (compared with four-year students) they were viewed as less competent and had less status in the working world. From Wassamon's point of view, this became a force driving them to be persistent with their study. The extract above further suggested the strong impact of students' pre-university education on their learning habits. Wassamon stated that students' learning experience in high school had shaped the ways they were even upon entry to university.

\section{Weak supporter.}

Like strong and unconfident supporters of learner autonomy, Thananya had a good relationship with her students. She was well respected and treated by her students as their mother. According to my reflective fieldnote from the classroom observation:

The students took her to the canteen, bought her dinner, cared about her health etc. The way they treated her was like they were treating their mother. It can be said that their relationship was very intimate.

The extract reflects that Thananya regarded her role as a second parent. Thananya's role as a second parent was obvious in her description of students. She described her students:

Thai students are like a child, not mature. They still love playing; only a few of them truly care about their study.

The terms Thananya used to refer to her students reflects her views of students as immature, lacking self-discipline and time management skills. Thananya tried to be understanding of their love of play. She assumed that 
many of her students lacked a 'driving force' for their study and were temped away from study by doing non-academic activities. She further explained this point:

....but you know kids are kids. They cannot control themselves. If they are good students, I mean if they control themselves or have self-discipline, they will get a lot from technology or those learning helpers you've mentioned. But many of my students want to be cheerleaders. Many of them are not mature enough and do not care about studying. It sounds like though we give them foods they don't eat. They prefer sport cheering activities.

Thananya saw extracurricular activities as having little relation to classroom learning. From her point of view, her students could not do extracurricular activities along with academic learning. Thananya assumed that her students did not have creative thinking skills and were likely to depend a lot on her, as she said:

I give them an assignment. They don't do it on their own. They either copy it from the Internet or books, or else they depend a lot on me.

Thananya claimed that the emphasis that Thai people place on conformity is the cause of her students' lack of creative thinking skills. She commented that Thai students are taught to believe what has been written in a book. She described this in the following extract:

In our culture, we've been taught to believe that when we use an idea from a book or a theory, it is wrong to say it in our own words.

This need for conformity seems to exert control over students' freedom to think. Thai students then might conclude that not following the words of a book, as an example, might be regarded as disrespectful and a challenge to the author(s) of the books. Thananya continued in her description of her students, confirming her conviction that her students were not able to take charge of their learning: 
.... my students' English is very poor. They write 'I am come.' or 'am go.' It is more useful to go in to these small details.

In her opinion, her students' English competence was very poor, and thereby, as beginners in learning English, they still were not able to direct their own learning without direct input from the teacher. The above extract further implies Thananya's emphasis on accuracy and precision. 


\section{Classroom Physical Environment}

\section{Strong supporters.}

The classes observed were a phonetics class for Bussaya, which was for thirdyear English major students. For Wipakorn, I observed a speaking class, which was for third-year non-major students. The physical environments in these two classes were similar. The seats were arranged in rows (Figure 5.9 and Figure 5.10):

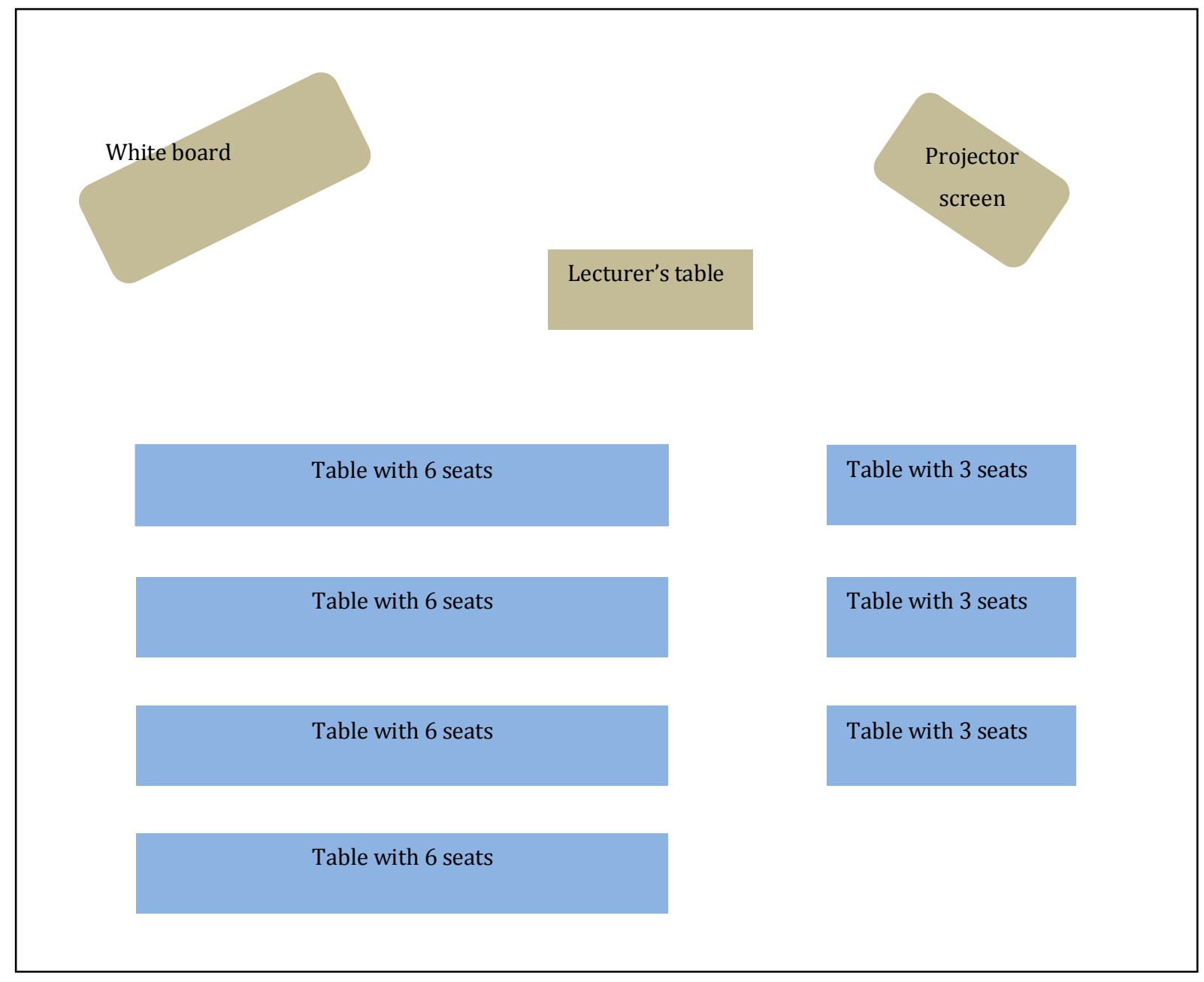

Figure 5.9. Bussaya's classroom seating arrangement 


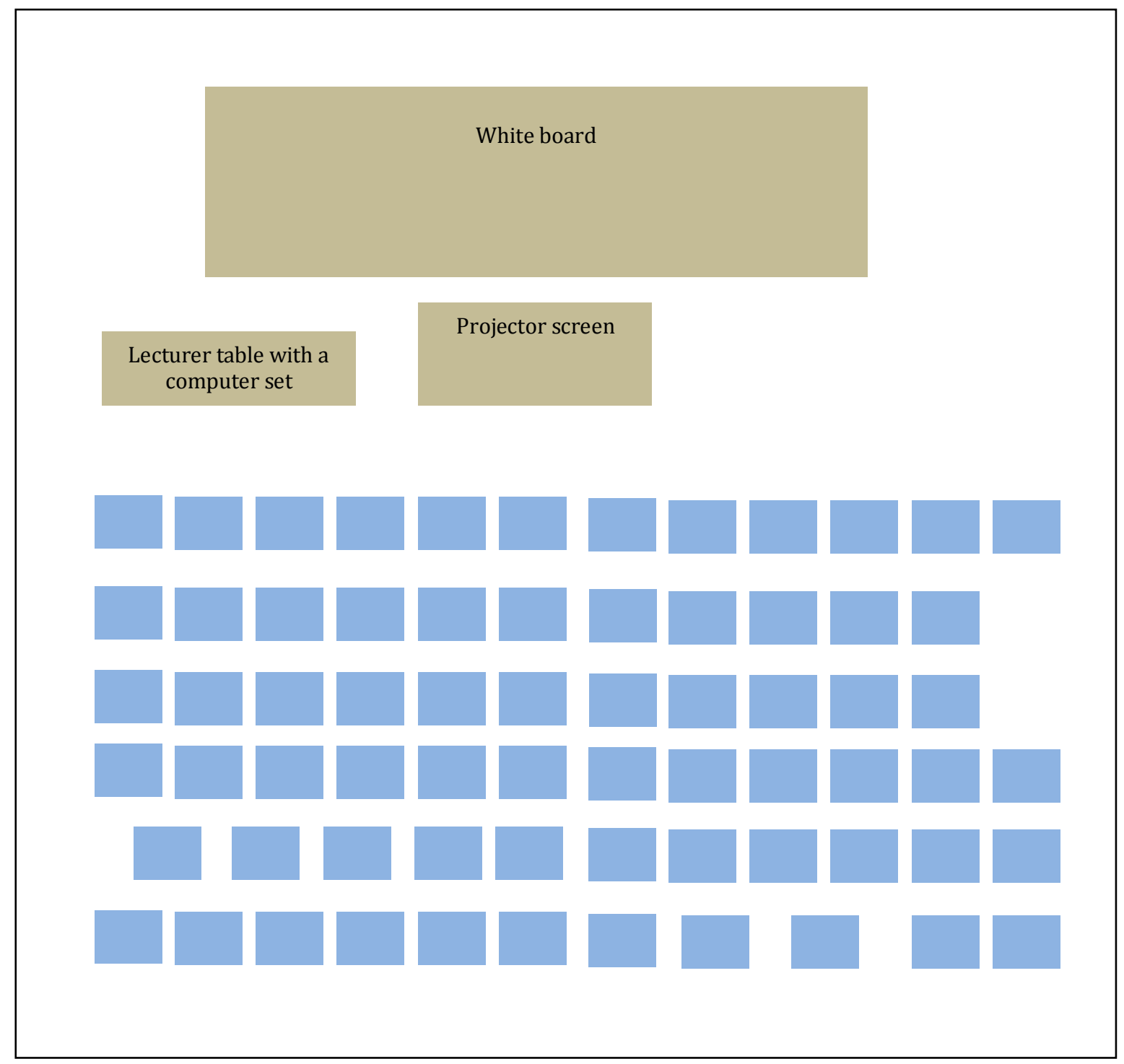

Figure 5.10. Wipakorn's classroom seating arrangement

Both of the strong supporters started their classes with greeting and short talks not related to academic issues. After the short talk with students, Wipakorn had the students re-arrange the seats into groups as shown in Figure 5.11: 


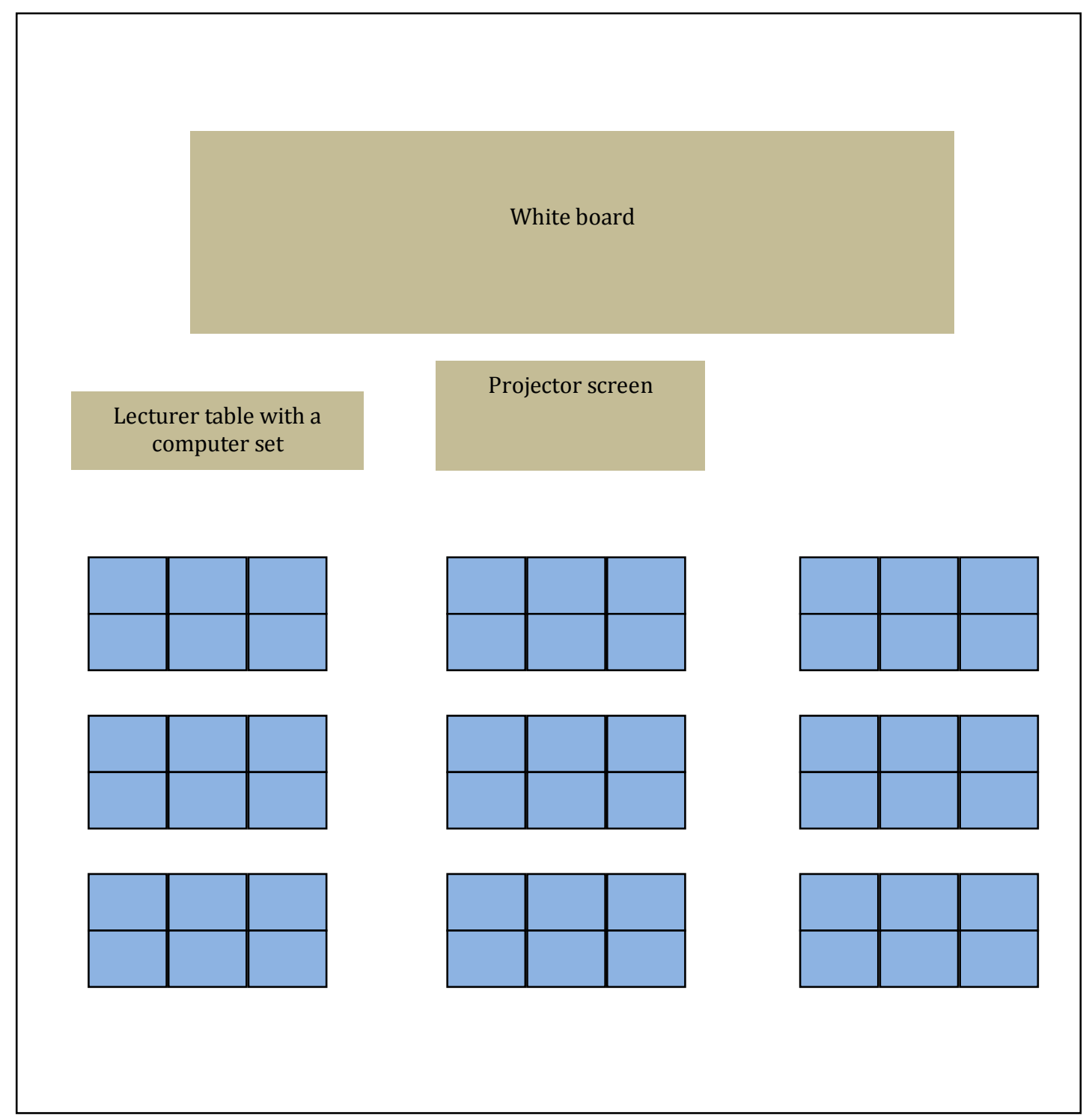

Figure 5.11. Wipakorn's classroom seating re-arrangement

Wipakorn let her students choose their own groups and sit where they preferred. She made sure that there was enough space left between groups so that she could get access to every group.

The short talks that took place at the beginning of Bussaya's and Wipakorn's classes seemed to form a relationship with students. Both of them did so by making references to students' life outside the classroom. The short talks also had an impact on the class atmosphere. The extract from my notes from the 
class observation described how Bussaya's started her class and how the classroom atmosphere appeared:

Bussaya started her class by having a small talk with the students. She asked them questions and talked about things not related to lessons, and students seemed to enjoy this small talk very much. The seating arrangement in Bussaya' class looked somewhat opposite to its atmosphere. The seats were arranged in rows and students sat confronting the lecturer. Physically, Bussaya's class looked boring and traditional. In addition, the classroom looked plain and had no decorations or special teaching tools and materials.

My comment indicates that the teacher plays an essential role in determining the class atmosphere regardless of the class physical arrangement.

\section{Unconfident supporters.}

I observed Jensuda's reading and writing class, and Wassamon's writing class. Jensuda had approximately 50 students registered. But from the observations, approximately 30 students attended. The seating arrangement in her class was like those of Bussaya and Wipakorn (Figure 5.12).

Figure 5.12 shows that students sat in rows facing Jensuda. Students who came to class earlier chose to set in the rear of the class, leaving the front row for those who came late. The aisle between rows was narrow; most of the time, Jensuda stood in the front, using a microphone when talking with the students. The room had a big white board and a projector, but Jensuda rarely used them. 


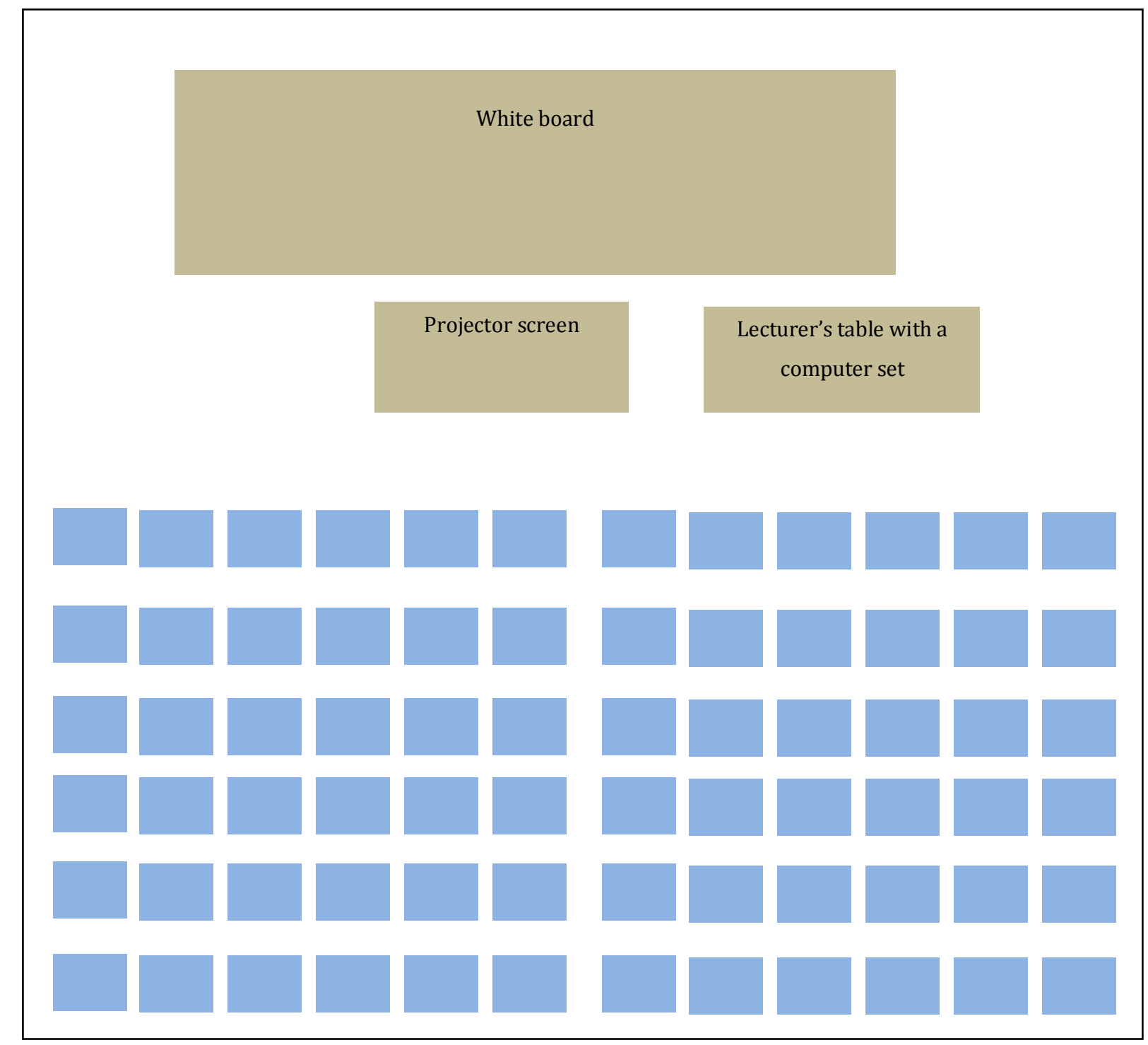

Figure 5.12. Jensuda's classroom seating arrangement

Wassamon's class was quite big, about 60 students. Although it was a writing class, Wassamon chose to teach in a laboratory room (Figure 5.13). She explained that the four skills of English - speaking, listening, reading and writing - could not be separated. Hence, in a language laboratory, she could utilize equipment for listening and speaking. 


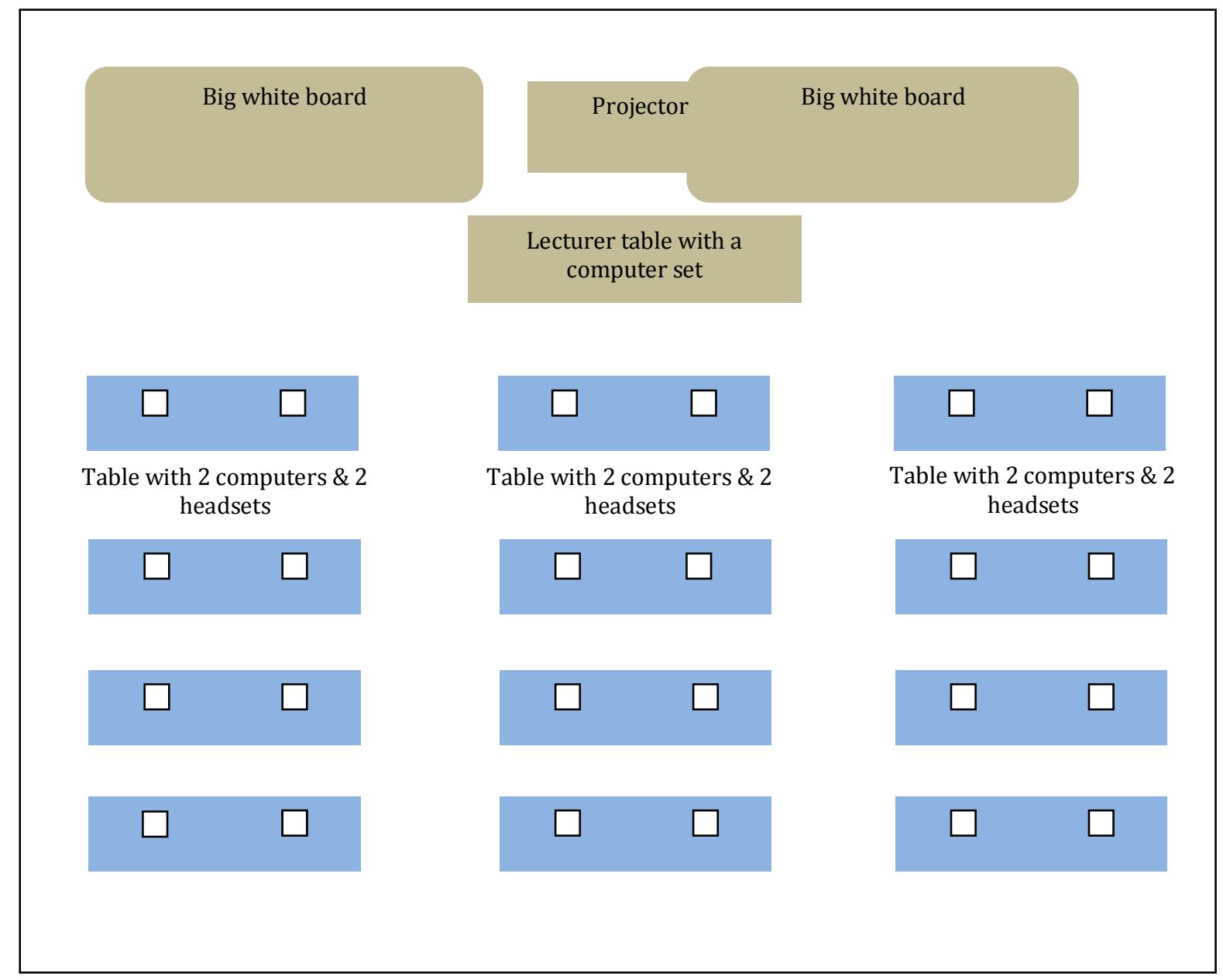

Figure 5.13. Wassamon's classroom seating arrangement

Wassamon used the equipment in the laboratory room. She used the microphone and periodically had the students use the headsets. She said when students used these tools they were more attentive to their learning and more likely to participate in activities. 


\section{Weak supporter.}

The observations were conducted in Thananya's writing class. This class took place in a language laboratory room. Like all other laboratory rooms, the room was well equipped with computers, CD players, tape recorders and headsets. Thananya noted in a follow-up discussion that she did not wish to teach in this room and felt uncomfortable there, but the university said all other rooms were occupied, leaving her with no choice. Her writing classroom was arranged as shown in Figure 5.14.

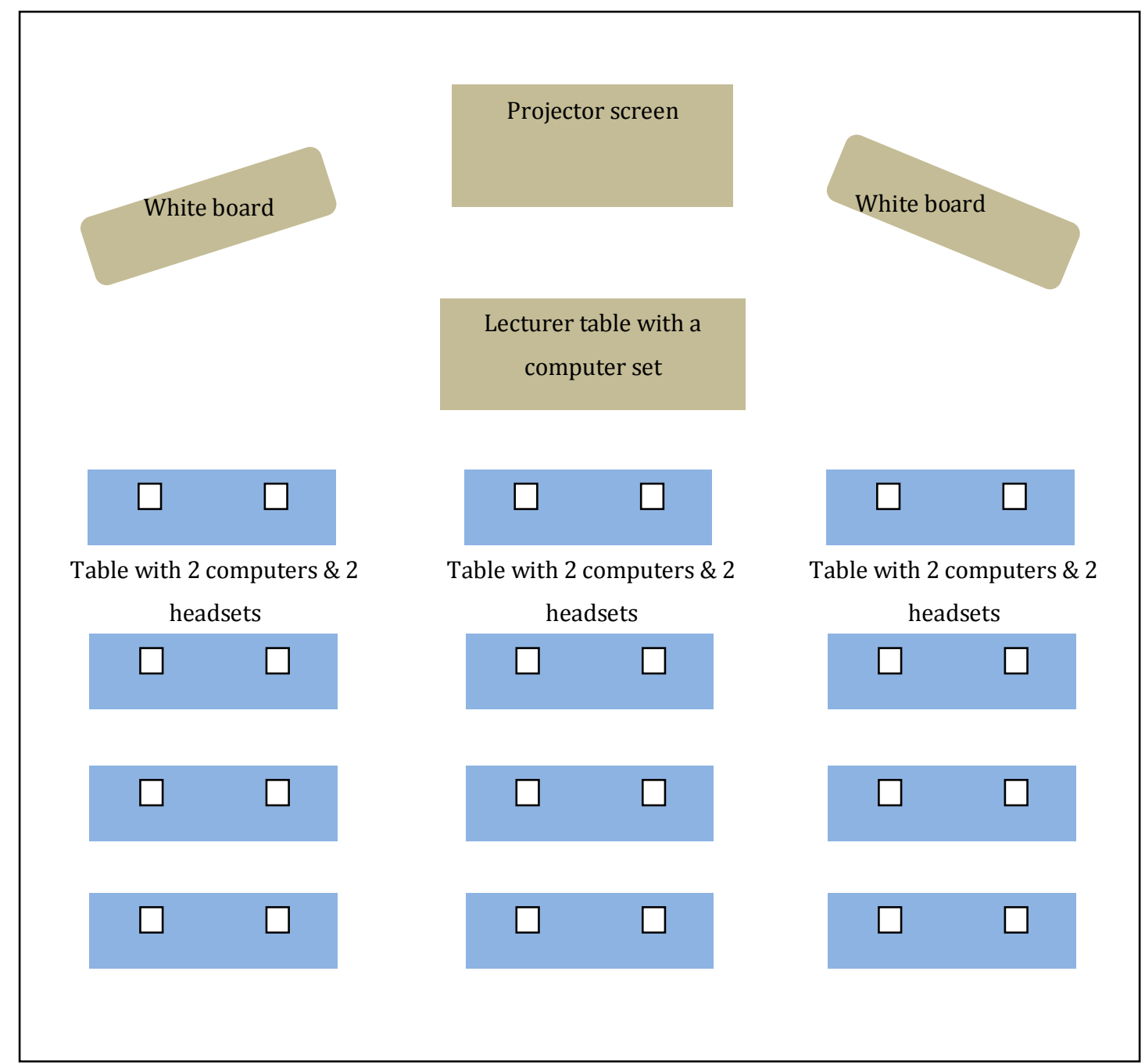

Figure 5.14. Thananya's classroom seating arrangement 
The seating was fixed and students were separated with a small partition on each table. The partition seemed problematic as I noted in the fieldnote:

It obstructed students from seeing the white board or the lecturer. Students looked uncomfortable with their seats; they could not discuss with friends and when doing group work, they needed to find other spaces in the room. Thananya almost could not walk to the students. Students worked individually and did not discuss with peers, as the seating was not suitable.

From the description above, the physical setting, particularly the seating arrangement, in Thananya's classroom contributed to an uncomfortable feeling in the learning environment. With the 11 students registered in the course, this room seemed too big. According to the schedule, the class started at 9 a.m. sharp but the real class started at 10.00 a.m because the students were late. Thananya assumed that this happened because of the students' immaturity and lack of discipline. 


\section{Classroom Practices}

\section{Strong supporters.}

Bussaya mainly used the white board even though the classroom was equipped with a computer and projector screen. Although the university promoted the use of technology, Bussaya said she did not employ it in her teaching because she did not have time and, more importantly, it did not fit with her personal beliefs. She said it was more important to engage students in completing the given exercises/tasks.

Findings from observation of her classroom supported her questionnaire results related to her practice. The class was not run as a lecture; rather Bussaya encouraged her students to work with their peers. In both the class observations, the students were allowed to move from their seats to work collaboratively with peers. Activities that took place in the class were led by students while Bussaya facilitated the flow of the activities. She would walk around the classroom, observing students working with their peers. She rarely intervened while the students were working unless asked. Rather than explaining or presenting grammar theory, Bussaya focused on letting students practice through exercises. This extract from my observation note shows an example of this:

It was about the passive voice. Bussaya did not tell what the passive voice was; she started by writing down some statements on the white board and then discussing the differences of those statements, particularly in terms of voices. After that she gave students an exercise with 20 items and let them finish by themselves. Students were allowed to discuss with their friends and could ask Bussaya if they needed help. Bussaya walked around the room looking at how students completed their work. But she just took a look, not explaining. She let the students finish their work and then asked for any volunteers to present their work on the white board. 
My own reflection in the extract below explains how this activity enabled students to exercise their metacognitive knowledge and construct their own knowledge:

By receiving freedom to complete the given tasks or activities without interruption from the lecturer, the students were practicing the skills in planning, deciding the strategies to use and assessing their answers. The fact that Bussaya did not pinpoint whether or not the students' answers were right or wrong, but in contrast let the students arguing together about their opinions, suggested that in Bussaya's class the concept of knowledge might be different.

In such a class students need to manage their own learning by planning, making their own decisions, and evaluating their answers. By doing this, students were exercising their metacognitive skills (Cotterall \& Murray, 2009). Bussaya modeled her perception of knowledge by not accepting just one correct answer. The following extract from my reflective notes shows how the idea of knowledge was perceived in Bussaya's class:

It was no longer something that had been written in stone and could no longer be transferred from the teachers' head to students'. In contrast, students were given opportunities to help each other to construct knowledge, with guidance and support from the lecturer.

Bussaya's classroom practices suggested her idea of knowledge. That is, knowledge does not exist by itself, but need to be discovered and coconstructed by students. In this sense, Bussaya was incorporating social dimensions of learning. In her class, students were regarded as social beings, and learning was not an individual endeavor, but a "naturally social acts" that need to be achieved in collaboration with peers (Gerlach, 1994, p.12).

The language Bussaya used in her class with students was positive and empowering; the terms gave a sense that it was the students' responsibility 
to complete the learning mission and the students were capable enough to do so. For example, she said:

Who could help me to do this exercise? or I need you to help me finish this statement.

This kind of language indicates that students are capable of helping the teacher and in doing so their self-esteem increases, which is regarded as one of the qualities of autonomous learners (Anantasate, 2001). Bussaya enhanced students' sense of power by letting students write their answers on the white board. As the white board symbolically represents a property of the teacher, when students are able to employ the teacher's tool or property, it implies that power is then shared by both students and teachers.

Bussaya did not do any correction and did not tell students the solution of the exercise. She let the students discuss the statements on the board and then asked:

Who agrees with this answer? and,

Who has different ideas about this? You can share with your friends.

Questions structured in this way gave students a sense that they can make mistakes and the aim of learning is not accuracy, but the opportunity to find out solutions on their own. Above all, the above questions suggests that Bussaya was allowing her students freedom in thinking, as there is no one specific answer expected in such questions.

From the observations, Bussaya's students seemed quiet in their class. However, my fieldnote indicates that the quietness must not be regarded as being passive:

These students usually sat still listening to Bussaya. But when they were asked to come up in the front and present their work, they did not hesitate to do so. They discussed quietly with their friends and were engaged the given task or 
exercise. In this way, it can be regarded that the students in Bussaya's class were mentally active.

Two implications can be drawn from the above extract. First, learning in Bussaya's class was an interdependent endeavor. That is, students helped each other to accomplish a given task. Second, Bussaya showed that teachers did not need to invest all their energy in creating teaching innovations; rather, they should focus on giving students opportunities to control their learning activities. This is because whether an activity/task promotes learner autonomy depends on how it is used by teachers and students. As Murphey (2003) emphasized, even "the best tools can be used autocratically to tie up learners with the specific desires of the teacher or curriculum" (p.5).

Bussaya's conception of her role contradicts the traditional view of teachers. In one observation of her class, a student asked her to clarify something. Bussaya was not sure, so she said:

Well, I'm not quite sure about it. I need to take a look at my book.

Would you mind if I give you the clarification next class?

The excerpt above suggests that from Bussaya's point of view, the teacher was not 'the best knower'. This view fits with what she expressed in the interview regarding her perception of herself as a teacher:

Sometimes I need to tell them that okay I don't know or I'm not sure, and why don't we discuss about it.

Bussaya was radically changing the prevailing traditional view of teachers as the best knower and the most authorial figure in classroom, which is a big obstacle for development of learner autonomy in Asian contexts (Januin, 2007; Roskams, 1999; Wisaijorn \& Tremayne, 2008).

In Wipakorn's class, learner autonomy was the ultimate goal of the course. Her course had a consultation session. The students were able to meet her 
outside of class to consult on academic and non-academic matters. Her course syllabus explicitly stated that strengthening students' ability to take control of their own learning was a course objective. This course aim focused on the use of metacognitive strategies: analyzing needs, setting one's own goals and plans, implementing these plans and assessing oneself.

Like Bussaya, Wipakorn did not run her class in the manner of a lecture. She had her students do group work and rarely intervened in their group discussion unless the students requested. The length of time for group discussion was not specified. The students presented the topics to class. She had some comments on some topics, but students had to make their own decision on whether they would take heed of her comments. They were allowed to change their topics. Wipakorn made two important points about this in a follow-up discussion:

They have the right to choose and change the topics as long as they follow the process that I suggest, because the process is very important.

First, she perceived freedom of choice as the students' right, as long as it complies with the scope of the course. Second, the experiences gained through the learning process were critical. Some might expect learning results, such as high scores or good grades, but in Wipakorn's class students were expected to really understand and direct the learning process. The extract from my fieldnote explains what Wipakorn's students were required to do:

To accomplish a given activity, students had to plan their own work and use their own strategy to complete the task given. They needed to set their own goal and thought about the timing of working with friends in groups. Wipakorn suggested a process that was about how to do self-study and where they could get information. She presented this on the power point. It was a recommended process, but not compulsory. Students could work in their own preferred way. 
The extract above suggests that the activity Wipakorn gave to her students provided them with opportunities to exercise their metacognitive skills. They needed to set their own goals, to plan and use strategies to accomplish the task, and finally manage their own time. A hidden message conveyed to students when doing this activity, as Wipakorn explained in the follow-up discussion, was that the teacher ought to:

..... try to make students realize that that is their work, try to make them think.

Thus, in addition to the use of metacognitive knowledge, students also gradually took ownership of their learning. In order to make students think, Wipakorn did not answer students' questions. The excerpt from my fieldnotes demonstrates an example of the conversation between her and the group of students:

Student: $\quad$ Lecturer, except food what else can be cultural differences between Korea and our country?

Wipakorn: Well, why don't you think about Korean movies you've ever watched?

Rather than giving the answer, Wipakorn gave them a thought-provoking question. Students then were encouraged to think further and rely on themselves to find out their own answers.

According to the researcher's fieldnotes from both of the observations of her class, students enjoyed discussing in groups though sometimes they used Thai and went beyond study topics. Wipakorn stated that despite some students talking too much when doing group work, she believed she was successful in accomplishing a goal of having students work in group. She explained in the follow-up discussion:

By working in groups, students will be very close and have good relationship with peers. 
Wipakorn's response shows her similarity with Bussaya in their considerations into social aspects of the learning. For both Wipakorn and Bussaya, students were to work together to accomplish their group goal, rather than their personal goal. Learning, then, becomes a social endeavor and needs to be accomplished in collaboration with peers.

\section{Unconfident supporters.}

Jensuda began her class without a greeting or a small talk with her students. According to my fieldnotes, this is how Jensuda began her class:

\footnotetext{
Jensuda: Ok, students. Turn on page 108. Did you review the exercise on this page before coming to class?

Students: $\quad$....(Silent)...

Jensuda: I think I told you to read that as homework. Anyway, what you need to do is to read the given story, then answer the following questions. You can share or discuss with friends, but you cannot open the dictionary. I give you 20 minutes, ok?

Students: ....silent (started doing the exercises)...
}

Although allowed to discuss with friends, most of the students did the exercises on their own. The class became quiet, and Jensuda stood at the front. When time was up, Jensuda told the whole class the answers of the exercises. After that she went on to next exercises, with the same routine: detailed instructions, including the length of time to be spent doing the exercises. In my fieldnotes, Jensuda ran her class like this:

Most of the time, this lecturer based her teaching on the textbook. When students finished one exercise, Jensuda gave the answers, and then went on to next exercise. Five to six exercises were completed in one and a half hours. The length of time for each activity was decided by her.

Jensuda explained in a follow-up discussion that she had to go very fast to finish the whole book before the final examination. The best way for her was to tell students what to do and what was correct and incorrect. Group work, 
class presentation, or group projects were impossible as time was limited. Thus, it was not surprising to see that in the class, it was Jensuda who talked most whereas students listened and followed.

Jensuda set all the course assessments. The examination, as Jensuda explained in the follow-up discussion, was in line with exercises in the textbook. Midterm and final examinations, together with quizzes and tests became a big concern for her students. According to my fieldnotes:

...after class, many students asked her about the final examination. The questions were related to how to prepare for the exam, what to read and what would be covered in the exam.

Jensuda's class seemed to be oriented towards the examination. By telling students exactly which pages to read and how the exam would be like, the examination tended to be focused on memorizing skills.

Compared with Jensuda, Wassamon seemed to be more active and wanted her students to become active. The extract from my fieldnotes shows how she did this:

She usually walked around the class asking students' questions or looking at their works; she never sat at her table. Sometimes she had all students stand up. Those who could answer her questions would be allowed to sit. With this activity, students were very active and tried their best to respond. Wassamon said with this 'stand-up-and-answer-my-question' activity, students woke up, physically and mentally, and became very active.

Wassamon said some students did not like this kind of activity as they just wanted to sit and do nothing. Often, she was afraid that these students vented their dislike in the evaluation of her teaching. Therefore, she tried to run this activity in a friendly manner so that students would not feel nervous or stressed; there was no punishment for those who could not answer. 
Although the course used a commercial book, Wassamon did not use it all the time. The book was used as a guideline; her own supplementary sheets played a greater role. The extract from my reflective note shows how students reacted when they were given complementary worksheets:

Students seemed more interested and excited when they were given sheets. In a way, supplementary sheets were more successful in drawing students' attention, as with the commercial book they may feel everyone had it and it was theirs and they could use it whenever and wherever. Students took it for granted.

The above extract suggests that worksheets from the lecturer gave the students a sense that their class was unique in the way the lecturer specially catered to their needs. Wassamon assumed that the commercial workbook was beyond the students' competence levels. The content used to teach language in the book was situated in the western world, which might be beyond students' frame of reference and not related to their personal experience.

In Wassamon's class, students were introduced to learning strategies. Students sang songs that Wassamon composed. These songs were related to tenses, passive and active voices, and writing rules. In addition to the 'songs strategy', mind-mapping was employed in her class. In her opinion, this activity helped the students organize their ideas, and think, plan and outline what they had to do in their writing. Wassamon also recommended her students use this mind-mapping activity with other subjects. She expected her students to have positive attitudes towards learning, and as a result participate actively. In the follow up discussion, she explained:

Well, the first thing is that I expect them to enjoy the class. You know, they share laughter with each other. They don't just sit and listen. They become more active.... When I give them an exercise and let them do it in class, they sing the song while doing the exercise. 
Wassamon believed that when students view learning a language positively, their willingness to learn will increase, which was a good start for the development of autonomy in her students. She noted:

...if they've got a positive attitude towards English learning, they will do things that are useful to their learning.

\section{Weak supporter.}

Unlike the strong supporters, Thananya did not start her class with a short talk. She started the class by asking her students about the assignment. The students did not respond to her; they talked with their friends. One of them used the cell phone. Then, Thananya decided to begin the lesson by saying:

Okay students, today we're going to learn about writing a causative paragraph. Turn on page 213 and read the first paragraph together.

The students turned on that page and read the paragraph. Then the conversation between Thananya and her students went like this:

$\begin{array}{ll}\text { Thananya: } & \text { Now, tell me the paragraph was about. } \\ \text { Students: } & \text {.....silent.... (two students chatting) } \\ \text { Thananya: } & \text { Let's try only the first sentence first. } \\ \text { Students: } & \text {.....silent....(two students still chatting; the others } \\ & \text { looked down on their books) } \\ \text { Thananya: } & \text { I told you to read it before class. Have you read it? } \\ \text { Students: } & \text { Not yet. } \\ \text { Thananya: } & \text { All right. Then we do it together. Start with the first } \\ & \text { sentence. }\end{array}$

Thananya was not angry with the students. She went on with translating the paragraph into Thai. She sometimes stopped at some vocabulary and asked students the meaning. She paused for a few seconds before letting two or three of them try to answer. Then she gave the meaning. Students noted down what Thananya said. It went on like this till she finished the paragraph. 
Thananya then went on to the next exercise. But her students did not start doing the exercise until told how to. Thananya had a strategy to make her students do in their work. She told them that:

I will let you go to lunch earlier if you can finish doing the cloze test on page 326. And,

You have to do this exercise because the examination will also be on this.

This example illustrates Thananya's use of an extrinsic motivator for her students, as students performed the learning task because of a separate consequence (Deci \& Ryan, 1985). However, the students actually could have performed the task with a degree of autonomy if Thananya helped them perceive the importance of the task (Deci et al., 1996) and why they should put effort into doing the activity (Reeve, Jang, Hardre, \& Omura, 2002).

Once the students finished the exercise, Thananya told them the right answers. Then the students wrote the answers. Two or three of the students did not do the exercise; they waited till Thananya walked over to them and told her they did not know how to do it. Thananya explained to each of them and told them what to write next. Based on my fieldnotes, the activities in Thananya's class:

...run quietly and Thananya spent time explaining and checking responses of each student. She would intervene with the students immediately if she found they were making a mistake. When this exercise was done, she went to the next exercise with the same process....

The extract indicates the considerable direct instruction from Thananya, with a large number of activities each session. The class was generally quiet while working; and the students worked alone, rarely discussing work with their classmates. In the follow-up discussion, Thananya explained that she liked her class to be like that. She said,

I'd love to see them come to class, sit and write. 
She expected her students to behave this way because she believed they were more engaged when they were writing. She explained,

They will have attention to their work or what they're writing. And the best of it is that they're learning. When they write, there will be a connection with their brain and students will remember it.

In her classes, Thananya used only the textbook. She justified this in one of the follow-up discussions. She had taught for a long time and did not need any support with teaching resources. The class routine did not vary until the bell rang. Once the bell rang, the students stood up and went to lunch. Thananya reminded them of the homework while students were walking out of the room.

Thananya's practices in her class suggest that hers was a teacher-directed learning process. She planned her teaching in this way and she was content and confident with her pedagogical style. 


\section{Workplace Conditions}

\section{Strong supporters.}

The interview on workplace conditions revealed that Wipakorn and Bussaya were satisfied with their teaching workload. However, they did not agree with the number of additional duties that were assigned to lecturers. A conversation with Wipakorn indicated this:

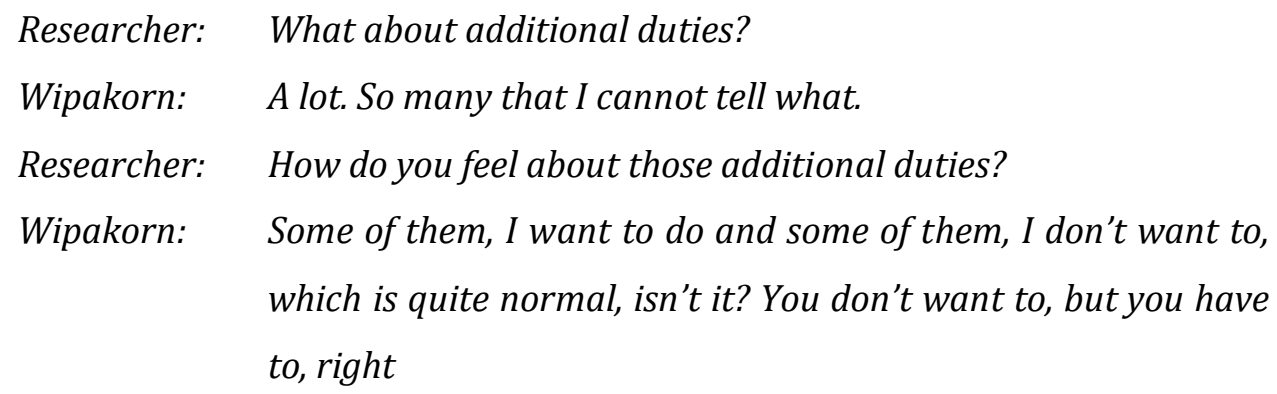

Although Wipakorn tried to regard these duties as normal, her response below implied that additional duties could be an obstacle for university lecturers in devising learning innovations or investing time on their teaching:

Actually with what the university gives us, we can do so many things if we want to. But we just don't have time.

Despite time limitations, Wipakorn perceived a number of features in her university that facilitated the development of learner autonomy. The extract below give some examples of supports provided in her university:

Wipakorn: Well, for example, we have language laboratories, which provide students with a wide range of learning materials, either in supplementary worksheets, computers, CDs or DVDs. And if teachers want to create their own materials, the university has people to support.

Researcher: $\quad$ Are you satisfied with the support from the university?

Wipakorn: I'm quite satisfied. 
Apart from materials/equipment support, the extract above points out that the intangible support in the form of human support is essential in the effort to promote learner autonomy. The provision of that support may result from learner autonomy being part of the university's strategic mission. Wipakorn's faculty explicitly encouraged lecturers to include the development of learner autonomy as one of course objectives. This resulted in support in terms of either learning/teaching facilities, or technical and human support. In her faculty, lecturers with more experiences helped those with less by offering advice on teaching that integrates autonomy into the course. By helping each other, the lecturers were empowered with theoretical knowledge and practical skills in promoting learner autonomy.

Lecturers in Wipakorn's university had the freedom to teach in their preferred ways. In the interview:

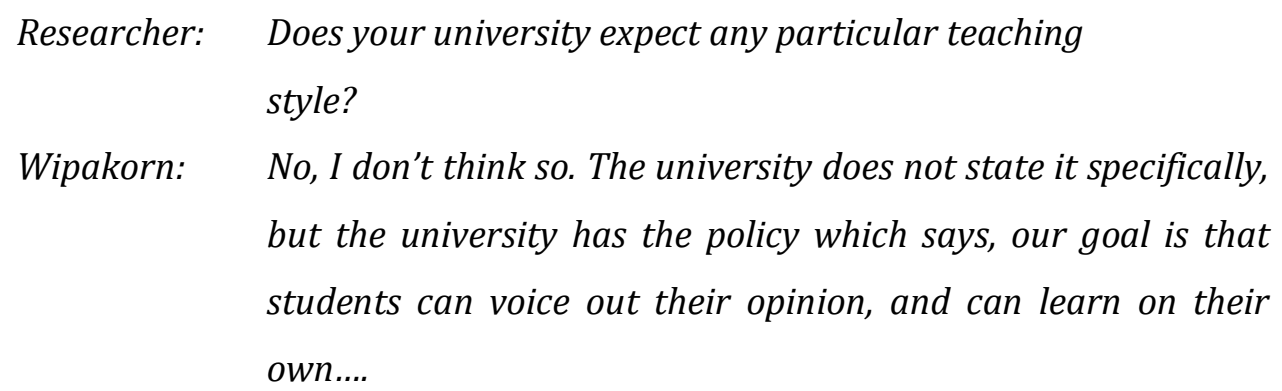

With this professional freedom, lecturers could make their own decisions about their choice of teaching methods. Along with lecturers' freedom, Wipakorn's university also placed an importance on acknowledging students' voice and learners' ability to take charge of their own learning.

Unlike Wipakorn's university, Bussaya's university did not officially state learner autonomy as being one of its goals. However, Bussaya realized that lecturers were encouraged to promote learner autonomy in their courses:

... the fact that we have to make our course syllabus available on the website and also the fact that there is a required format for the course syllabus, which we have to specify what teaching methodology we'll use or what the goals of 
the course are, I think by this the university wants to know how we run the course.

In addition, the availability of resources and support proved that her university encouraged its teaching staff to promote learner autonomy. However, Bussaya noted that a discrepancy existed between theory and reality:

The university expresses the desire. In many ways I feel the university has been trying to support by holding training workshops for lecturers. But you know sometimes in theory and in practice, it's different.

Bussaya believed that teachers' lack of knowledge of learner autonomy might prevent them from promoting it:

Some lecturers understand how to assist students to take care of their learning while others don't.

The extract further reflects her beliefs that lecturers' lack of operational knowledge may result in inconsistencies in teaching methods across lecturers. In some classes students were encouraged to direct their own learning and construct their own knowledge while in others they acted as a passive recipient of information:

We have many lecturers who still are very traditional. They spoon-feed students in every way. With these lecturers, students get used to being spoonfed and learning in that style.

As shown in the metaphor of spoon-feeding a class, Bussaya believed that students may form concepts of their roles and an expectation of teacher role that do not match with what happens in other lecturers' classes. Bussaya thought that such inconsistencies in teaching methods among lecturers results in students having: 
... a conflict in terms of the concept of what roles they should play. Kind of this teacher prefers them to do that while that teacher prefers them to do this.

Students' conflict of roles may later be a barrier for lecturers who want to promote learner autonomy. Bussaya regarded this as one of the constraints latent in her workplace.

\section{Unconfident supporters.}

Jensuda and Wassamon reported that they were satisfied with the professional freedom they received from their universities. Jensuda said:

I think I have a lot of freedom to teach my students. I can set my own goal basing on the course syllabus here. I can make my supplementary sheets for supporting my students. ..

Jensuda and lecturers in her university had the freedom in managing their own classroom practices. This probably resulted from the fact that her university did not mandate any particular teaching style. Lecturers' having freedom to choose their teaching style also was the case in Wassamon's university. Wassamon regarded this as freedom in her profession. She said:

I think this is the freedom of the lecturers here to look for the best for our students.

Wassamon agreed with her university in this aspect. In her view, lecturers should not be told how to teach because the 'best' teaching strategies or styles could not be specifically prescribed:

It depends on characteristics or background of the students, so only the teacher of the class knows what is best for his or her students.

However, in spite of their professional freedom, Jensuda disagreed with additional duties assigned to lecturers. She pointed out that those additional duties, such as scholarship committees, assessment committees, and project 
advisors, were not relevant to teaching. In her opinion, teachers' time should be invested to teaching and carrying out research. She said:

I think teachers should invest not much on that, but on teaching and doing research.

Jensuda felt extra duties interfered with the role she should play as a lecturer. Her frustration resulted from the comparison of the roles she was playing with the roles of her lecturers in her past education. She explained:

I saw my lecturers...they tried to concentrate only on teaching and doing research. But for doing projects, they had only a few- not too many. But for this university, I think there were a lot.

Jensuda's response reflected her own comparison with her previous schooling experiences. Jensuda based her perceptions of the job on her own teachers. Apart from the overload of extra duties, Jensuda's frustration was also rooted in her conjecture that she was not sufficiently supported. However, she admitted that her university gave her some support, although it was limited.

My university allows us to take any conference. However, they have some limitations. Well, kind of one semester not more than one time or something. It is like they have small or limited budget for lecturers to attend a seminar. Especially, if you want to expand your knowledge by attending a training seminar or conference abroad, it's quite impossible.

Jensuda assumed that the limited budget from university resulted in lack of professional support to its teaching staff. Limited finance further resulted in insufficient provision of technical and facilities-related support. She referred to her university's self-access center as an example:

Though the center right now is quite good, but we still need more ....more equipment like television so that students can watch live English news from satellite such as from $B B C$. I hope we will have this in the future. 
This example shows a lack of support from administration, which can limit the implementation of self-access learning centers (Darasawang, Singhasiri, \& Keyuravong, 2007).

Unlike Jensuda, Wassamon noted that she was satisfied with her teaching load. Although she felt overloaded with additional jobs, she volunteered to do a radio program. Despite having no financial support from the university, she did the program because:

I just want to do more than what I've been assigned to and I just think of what will help students. I want students to stay in an academic atmosphere, especially English atmosphere. I asked my colleague if she wanted to do this project with me or not, and she said go ahead.

The response implies Wassamon's recognition of the role of teachers in creating the atmosphere that maximizes students' learning. From her point of view, learning could take place everywhere and should not be limited to the classroom. The radio project revealed her understanding of the students' need for environments conducive to learning a foreign language. In doing this project, Wassamon admitted that she did face some difficulties such as lack of cooperation from people and lack of technicians. Further difficulties she and her students were facing are described:

Kind of we have the lab rooms but we cannot use them. You know even with courses that require the use of lab rooms like speaking and listening, what happens is that there are about 70 students while each lab has only 50 seats. And we have no lab boy to help the teachers run the equipment in the lab.

The extract reflects a lack of tangible support from the university administrators. This lack of tangible support was also the case in Jensuda's university, as discussed earlier.

In addition to tensions from a lack of support, both Wassamon and Jensuda claimed that their universities' use of students' feedback for staff promotion 
became another obstacle for innovation in her teaching. This kind of staff evaluation system resulted in their feeling nervous and made them try to teach in ways that matched students' preferences. Wassamon said:

I have to make sure that the students are happy with my teaching. Because, you know, some of them give an unfair rating in the evaluation.

\section{Weak Supporter.}

Thananya reported feeling uncomfortable with many features of her university. First of all, she was frustrated with the assigned additional duties. She said:

I feel the university has a misconception about lecturers' additional duties. They give us too many kinds of duties. One lecturer needs to be able to do many things.

In Thananya's view, these duties interrupted lecturers and took most of the lecturer's time and energy. This seemed to be the reason why she did not create new teaching-learning materials or activities. Thananya was also frustrated with the insufficient support from her university, particularly the lack of human resources. She said:

There are some technicians to help us, but that is not enough. Mostly I can say that the university feels like supporting new teaching methods or technology, but what about human resource to support lecturers? As a result, who suffers? Lecturers suffer.

The extract reflects a tension that might occur when ideas are mandated from senior management. From her point of view, the policies of many universities were under resourced. But she did not believe it was the university's fault; rather it was attributable to external systems that controlled the university. She explained: 
The university has been forced from the Association of Higher Education to have lecturers responsible for so many things..... Administration people think about numbers; they believe they can measure quality of things by using numbers.

Thananya reported her experience at a previous university at which she was employed, where she had tried something different:

There, lecturers are expected to use a computer program provided by the university. Lecturers need to integrate their lessons in the program and make it online. So students can study online from their home. They do exercises provided on the program and lecturers can correct students' exercises or interact with them online as well

The comparison of her previous and present universities highlights the important role of the university in having a clear direction for the ways its lecturers teach. It also indicates the level of support that Thananya believed should be provided to teaching staff when an innovation/or new teaching approach is to be implemented in the classroom. 


\section{Cultural, Social and Educational Contexts \\ Strong supporters.}

Both strong supporters thought educational contexts in the country imposed a huge influence on the promotion of learner autonomy. Bussaya perceived the context in the university as a factor that influenced students' capacity to be autonomous:

I think the contexts of our main campus here in Bangkok sort of encourage students to be autonomous.

However, Bussaya admitted that she could see differences between students' characteristics from the two campuses of her university. Students from the main campus in Bangkok were confident, individually and extroverted, while those in the small-town campus were the opposite of this. Bussaya believed that differences in environments in both campuses resulted in students' differences. She explained:

... when students from the branch campus move to study here, the main campus in Bangkok, in the following year, they become very individual and can rely on themselves.

The extract above shows Bussaya's conviction that the university environment had an impact on students' characteristics. Students' characteristics changed after moving to a new environment. Bussaya assumed that the small town campus was not conducive to autonomous learning and did not provide the facilities that students deserved. She said:

Students over there don't have what students here have. No activities for them to join. Students go to class, finish their class and go back to dormitory. The library there is sort of not modern. No activities, neither for academic purposes nor for relaxation. 
In Wipakorn's view, the system of university entrance examinations seemed to be the major obstacle for the development of autonomy in Thai students. She said:

As long as the entry of university is in this high competition, students won't have time to think about autonomous learning till they go to university.

Wipakorn explained that the highly competitive university entrance examination imposed huge pressure on junior school students and was a large obstacle to the development of learner autonomy. Students often went to private tutorial schools where they focused solely on 'exam-taking strategies'. Wipakorn believed that by limiting learning to shortcuts for examination preparation the process of learning itself was undermined:

....it becomes hardly possible for [pre-university] students to have freedom in their learning, in learning what and the way they want.

Wipakorn seemed to conclude that contexts in pre-university education failed to encourage the development of autonomy in students:

... it is impossible for these students to learn on their own. They go to tutorial schools every day. So it's very hard to promote learner autonomy.

The solution that Wipakorn suggested was to:

.... have special schools which have different curriculum. We have that kind of school. Students there are able to exercise autonomy in their learning. The school supports autonomous learning and give students freedom in choosing what they want to study.

But Wipakorn realized these 'special' schools with different curriculum brought about another problem, as she further said:

But we have only few of this kind of schools. And the major problem is that these schools are out of the educational system. They learn like this, so they 
could not get into the mainstream entrance examination or could not fit with other students. It is like what they learn is different from other students.

It seems that constraints imposed on Wipakorn's promotion of learner autonomy are beyond her control. She suggested that lecturers should:

...try our best to assist students to develop their autonomy. We can suggest or give them advice on how to learn on their own.

Wipakorn further suggested that the starting point for a lecturer to assist students was changing their attitudes towards making mistakes. She believed that lecturers needed to develop a classroom culture where mistakes are a normal part of learning. According to Wipakorn, without fear of making mistakes, students will be more confident to experiment in doing things on their own in the language class. She described this in the following extract:

They become more confident. Then with confidence, it becomes their starting point to do things on their own.

Apart from pre-university education and learning environments, the common Thai belief that young people must listen and be obedient to their seniors could impose constraints on the development of autonomy in Thai students. Bussaya explained that this belief:

... makes Thai kids not confident. They will wait for the teachers' order and then follow it.

or else, as Bussaya further discussed, these students would be regarded as disobedient.

Nevertheless, despite the presence of obstacles from within Thailand's cultural context, Bussaya believed in the possibility of the development of learner autonomy in Thailand's higher education system. But, as she insisted, it must be on the condition that: 
...they must receive sufficient guidance and advice from their teachers.

The response reflects that in this "era", there is a good chance of developing learner autonomy. It also implies the necessity of the teachers' assistance in that developmental process of students.

\section{Unconfident supporters.}

The unconfident supporters of learner autonomy found that many features of Thailand's society, culture and education might pose a challenge in the promotion of learner autonomy.

Wassamon viewed the idea of a 'hierarchy' of teachers and students as a major obstruction to the development of autonomy in Thai students:

We have what we call 'hierarchy'. When we talk about discussion in class, it is not a real discussion because the power of the teacher and the students in classroom is not quite balanced.

Wassamon explained that this view might be rooted in the traditional view of teachers as an authority figure that has the most power and know best in the class. She stated:

I think they've been taught to believe, to follow. Or maybe the way the students listen to the seniors is regarded as the way to show their respect. Possibly my students have their own ideas but they don't want to argue.

Wassamon admitted that she did give students opportunities to think differently or to do things in their own way. However, it seemed that the student's cultural perception of the role of the teacher as the giver of knowledge impeded their ability to do so as she said:

Sometimes I ask my students not to believe in what I said. You can share, you can question, you can oppose and you can propose your own idea. And we can 
find out if what I've told is true or not. But most of them just listen, follow the teacher and wait for the complete answers from the teacher.

Wassamon found that the university atmosphere affected students' learning habits and perception of learning. In her opinion, her university failed to provide an environment conducive to learner autonomy. She noted:

For our environments, students go to class, enjoy it and then leave. No one spends their time after that in the library or even in the self-access centre. Not even at the end of the day or during lunch time. For them lunch time is just for lunch.

In her opinion, the town where her university is located provided a 'too peaceful' atmosphere. She described:

Here there is nothing to make them ambitious. So we need some ambition. We need to create a challenging learning atmosphere.

Peacefulness was seen as good for living but it may diminish the competitiveness and challenges of an academic achievement, which Wassamon considered essential for the cultivation of learner autonomy.

Jensuda was similar to Wassamon in her stance towards the location of her university. She was not certain whether the pursuit of learner autonomy was possible in her campus:

I have little confidence that my students can learn autonomously especially here in this university campus. It's because my university doesn't provide sufficient facilities and resources for the students.

Furthermore, she posited that her campus was situated where:

Life here is slow and everything is easy. Kind of the contexts here do not provide the real learning environment. 
In addition to the university's location, Jensuda admitted that the social and cultural context affected her ways of teaching. She believed that Thai youngsters were quite shy and unresponsive in class. She said:

If compared with western students, Thai students are too shy to express their ideas to others or take their own actions. This is, I think, the main problem for being more autonomous. I believe that most of them can be autonomous learners, but anyway the backgrounds and Thai culture might hinder them or force them not to express themselves. When the teacher asks them to do something, they are quite shy and keep quiet. It is as if they feel it is quite safe for them to keep quiet.

The extract indicates that Thai people connect obedience and respect with keeping quiet and doing what they have been told. Jensuda thought that Thai students may have the capacity to behave otherwise but an expectation from their society and culture hinder them from doing so.

\section{Weak supporter.}

Thananya questioned the cultural appropriateness of the concept of learner autonomy in Thai society. She saw learner autonomy as the "virtue" of the West and culturally unfit to Asian contexts. This was reflected in her response in the following extract:

Unlike in the west, here you cannot be too critical because then you will be too aggressive rather than become autonomous. Let me make it short. Kids should keep in mind how they can be autonomous with the help of adults. In this manner, young generations are blending the virtue of old generations with the virtue of the west.

Thananya presumed that her students' immaturity and high level of dependency resulted from both internal and external factors. She compared her students with those in some well-known universities in Thailand: 
We need to understand one basic thing first. Students in some well-known universities rely a lot on themselves because they are smart. They do activities on their own; lecturers don't need to help them.

Thananya did not believe her students were able to direct their own learning as their English competency was still very poor. She connected the capacity to take charge of one's own learning with being 'smart', and regarded 'being smart' as an internal factor. Thananya expanded on external factors:

But here lecturers are in control.....here the budget for students' activities is given to lecturers, not directly to students. ......management of the budget is done by lecturers, not students. At (name of the university), students manage the budget themselves. So autonomy of students there is higher than here.......... think it may be because of the system here and there.

Such systems included the organizational culture, rules, and administration policies of each university. These systems become external factors that might inhibit or facilitate the students' autonomy. Her response suggests that systems in each university indicate the level of power bestowed on its students. By having a chance to manage the budget, for example, students feel empowered and responsible for the given mission.

Thananya claimed that within Thai educational systems a bigger system existed, which controlled smaller systems and its members. Bigger systems were, according to Thananya, for example, responsible for the entrance examination policy and policy-making powers. The idea of being controlled by 'systems' does not only exist only in university contexts but also in wider Thai academic systems. She gave an example:

I have one kid as an example. This kid is in Grade One but he is as smart as Grade Three students. If we look at his capability and performance, he should be in Grade Three. He's kind of a genius. However, according to the rule, he, with that age, is to stay in Grade One. You see, we respect the rules; sometimes to the extent that we destroy our autonomy. 


\section{Cross Case Analysis}

Data across all of the participants were analysed in order to extract and interpret the similarities and differences (Miles \& Huberman, 1994). The identification of similarities and differences was intended to identify strategies and activities that the lecturers could use to promote learner autonomy. It also sought to find out the factors that might impede the promotion of learner autonomy in each of the settings. Before identifying the similarities and differences among the participants, I discuss the similarities and differences identified in each group of the supporters. After that the themes identified across all five participants in this phase of the study are discussed. In order to facilitate the group-based analysis and the identification of similarities and differences across cases, NVivo 8 was used.

\section{Group-based Analysis}

\section{Strong supporters.}

Both of the strong supporters of learner autonomy shared many similarities in their past education experience, current pedagogy, their classroom management and workplace. Figure 5.15 shows aspects that they have in common.

Both of the strong supporters instilled the idea of taking responsibility for learning and realized its benefit from their own learning experience. Their schooling experiences, in turn, became a source of inspiration for their preferred teaching style and philosophy of teaching. Activities and tasks they used had much in common with what their previous teachers did in class.

Many features of Bussaya's and Wipakorn's classrooms facilitated the development of learner autonomy. The atmosphere in their classes gave students a sense of friendliness without stress. The short talk at the beginning of the class was related to students' personal lives. This short talk indicated to the students that their teachers take into account their feelings. 
SDT states that in such an atmosphere students feel more autonomous because they can feel cared for, supportive and relaxed (Deci \& Ryan, 1985).

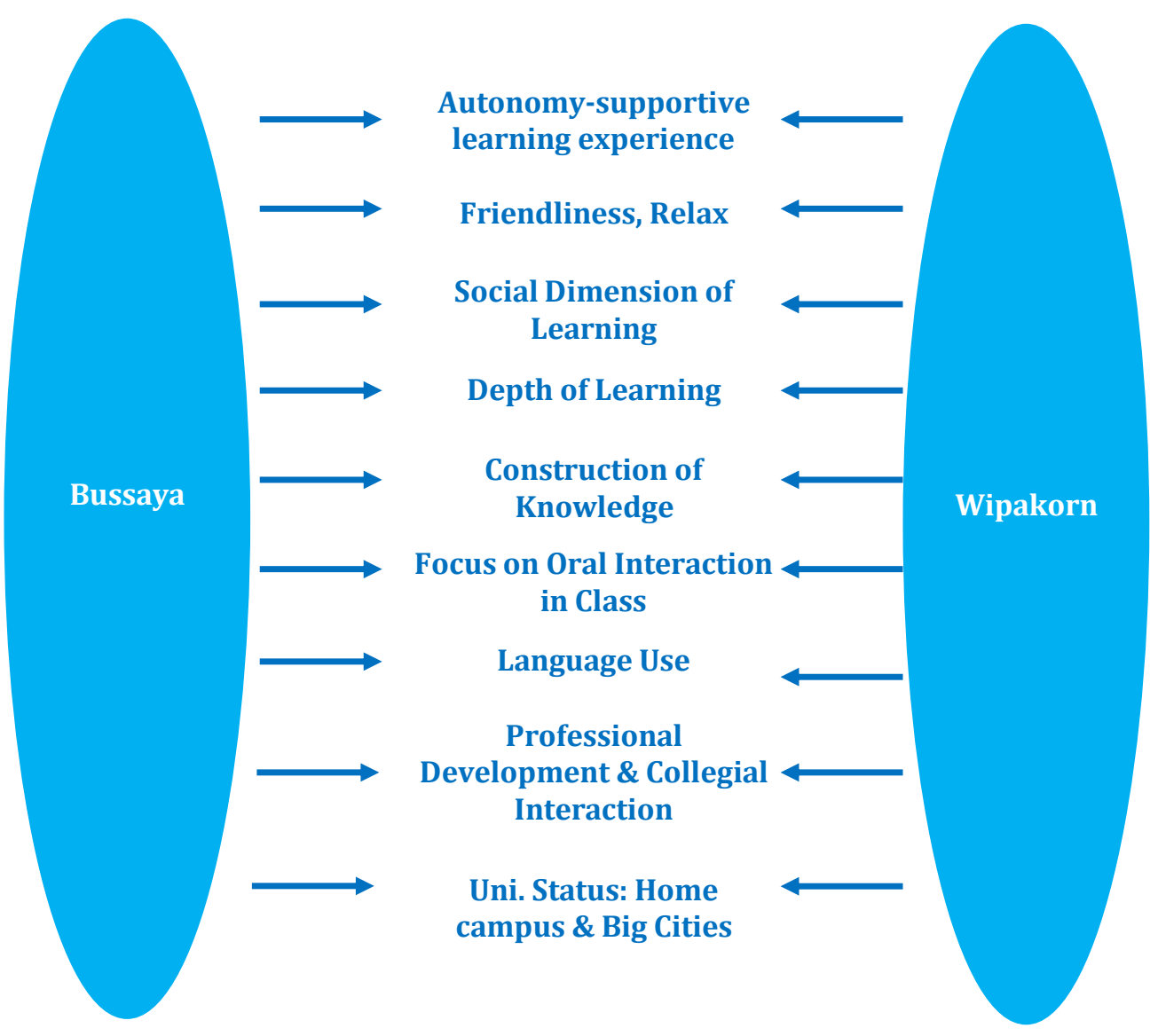

Figure 5.15. Similarities of strong supporters

Figure 5.15 indicates that pedagogic choices of the strong supporters reflect the social dimension of learner autonomy. Group-based activities in Wipakorn's class and pair-work and class discussion in Bussaya's emphasized the achievement of group goals, rather than individual ones. Through these activities, Bussaya and Wipakorn took the cultural background of their students into account. Thai students live in a collectivistic society in which achievement of group goals is more valued than an individual's personal goal (Dimmock, 2000). The association of leaner 
autonomy with interdependency was obvious in Wipakorn's provision of consultation sessions for her students. The consultation would give students the feeling that they were not left on their own and could always get support from teachers. This supportive feeling in the learning atmosphere is necessary when responsibilities are to be transferred from teachers to students (Liu, 2005).

Wipakorn and Bussaya were able to pace their teaching according to the needs of their students. This could be because there were no constraints imposed by textbooks or course books. Rather than the textbook dictating what students should learn, the group/class-based discussion and group/pair work encouraged students to personalize and pace their learning. Both Wipakorn and Bussaya did not focus on the number of the activities or tasks to be covered. Their primary concern was the depth of the students learning and the students' ability to try and find their own solutions. In Wipakorn's classroom, opportunities for students to engage in the use of metacognitive strategies were prevalent. Prior to doing any work, students were required to set their own goal and plan, find their own strategies to accomplish the goal, and finally assess their work progress. This was evidence of the skills needed for autonomous learning.

Wipakorn further supported her students' metacognition by focusing on the ability to 'think' and 'rethink'. When students 'think' and 'rethink', they are learning more about themselves as learners, knowing more about the task at hand, and evaluating the strategies they have used (Wenden, 1998). By making students aware that it was their own learning at stake, Wipakorn was gradually incorporating the transfer of responsibility from her to the students. Through shifting the responsibility, students were invited to exercise their autonomy (Murphey, 2003).

The concept of knowledge that Bussaya and Wipakorn conveyed to her students supported the development of their autonomy. Knowledge was no 
longer seen as rigid, to be transferred from the teacher's head to the students' heads. They were shifting their role from the transmitter of information to a "facilitator of learning and manager of learning resources" (Little, 1995, p.178).

Figure 5.15 indicates oral interaction as another feature that both Bussaya and Wipakorn used to encourage their students' involvement in learning. It is not the amount of conversation that matters. It is the purpose of the talk and the type of the interaction that play a critical role (Wells, 1989). Bussaya and Wipakorn usually started the interactions with a question that encouraged students to think, followed by opportunities for students to present their opinion, and finished with some praise. This structural sequence of the discussion encouraged students to talk more because it created space for alterative views, which could not be judged as simply 'correct' or 'incorrect'.

Another feature of classroom discourse that was prevailing in Bussaya's and Wipakorn's was the formality of language. Their use of informal language with their students helped their class feel comfortable and friendly. It also encouraged the students to be willing to take part in classroom activities. According to Alpert (1987), the formality of language use can make a difference between 'active' and 'controlled' discussion. Bussaya modeled the use of informal language when greeting and addressing the class, thus giving tacit permission for its use by students. The use of "you"' attitudes in oral interaction raised the students' awareness that they owned the process of learning. By using "you", rather than "I", Bussaya was helping her students to realize the value of leading their own learning. SDT regards actions that are performed with the realization of its utility or value to contain a great degree of autonomy even though the actions are extrinsically motivating (Ryan \& Deci, 2000a).

In the classes of the strong supporters, teacher control is minimized and the students' frame of reference is taken into account. These classroom features 
are regarded by SDT as supportive to students' sense of autonomy (Deci \& Ryan, 1985). Wipakorn regarded students' freedom of choice as their right, as long as it was within the scope of the course. Her perception of learner autonomy as a right serves the ideological perspective of learner autonomy, in which students as individuals have their right to have freedom in following their own choices (Crabbe, 1993). The view of freedom as a basic human right complies with SDT in which autonomy is regarded as one of humanity's basic needs (Deci \&Ryan, 1985). Thus, Wipakorn saw promoting learner autonomy as her duty to satisfy the basic needs of her students.

Figure 5.15 show that both stronger supporters perceived the ease of promoting learner autonomy in their universities. The ease of promoting learner autonomy that Bussaya and Wipakorn perceived was a product of the climate of their universities. It was not only materials, facilities or budgets that their universities supported, but human resources. Human support included the availability of technicians for technical assistance, as well as coworkers who had experience in the implementation of learner autonomy. In addition to the climate in their universities, the characteristics and learning habits of their students becomes another feature that contributed to their perceived ease of implementation. Confidence, individualism, and determinedness were the characteristics of their students, which increased Bussaya's and Wipakorn's perceived ease in promoting learner autonomy. 


\section{Unconfident supporters.}

The unconfident supporters of learner autonomy had a number of features in common. However, both of them also had some features that were different. Figure 5.16 shows similarities and differences between these two unconfident supporters of learner autonomy.

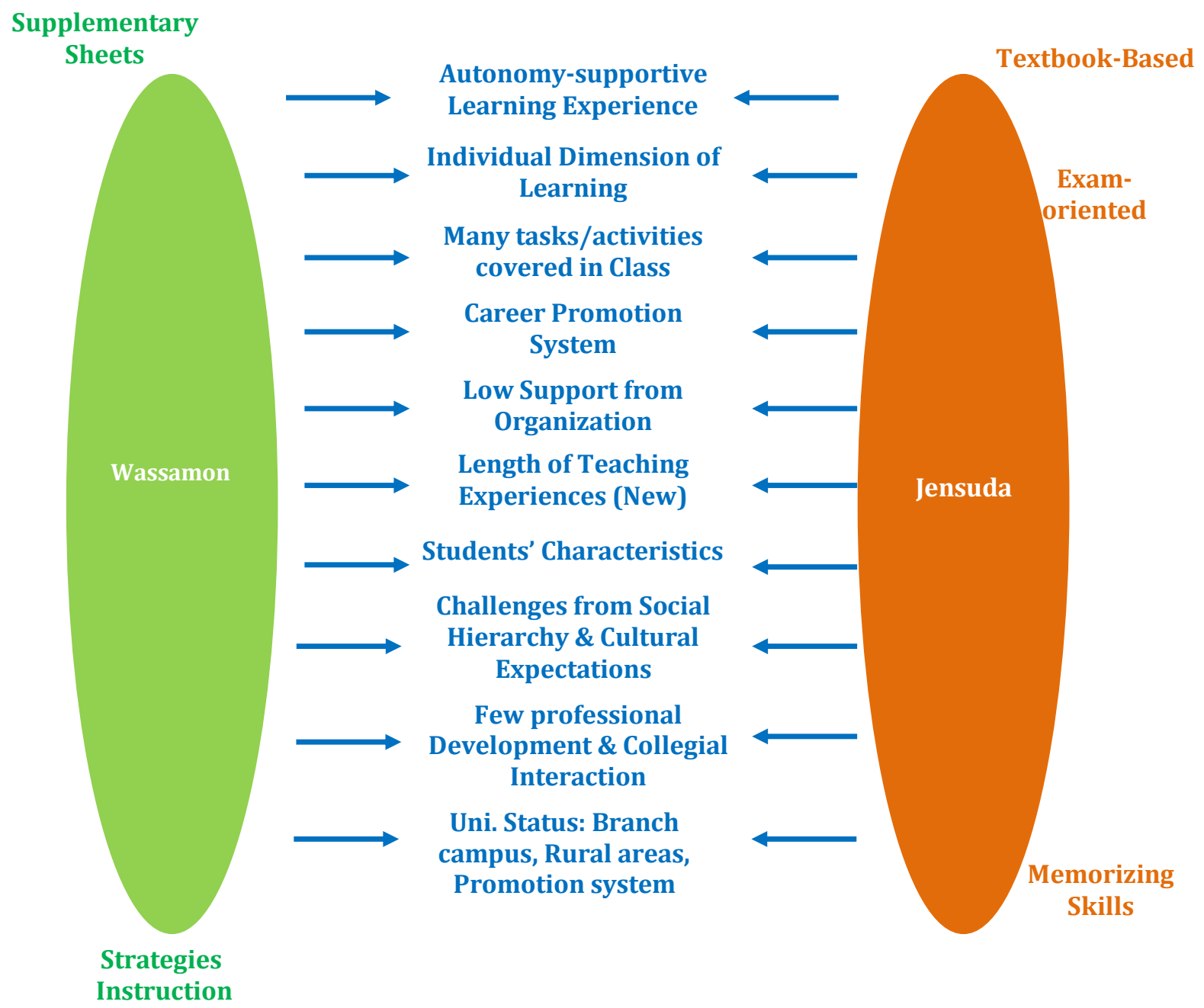

Figure 5.16. Similarities and differences of unconfident supporters

Like strong supporters of learner autonomy, unconfident supporters also shaped their beliefs in learner autonomy from their own learning experiences. But their current experience with students, social values, and anxiety and tensions from organizational demands in their current 
workplace left them with some doubt over the feasibility of putting their beliefs into practice. Both Wassamon and Jensuda perceived difficulties in promoting learner autonomy in their universities. As shown in Figure 5.16, these difficulties arose from the low level of support from their universities, the career promotion systems, the status of their universities, as well as characteristics of their students.

However, Wassamon was different from Jensuda in that she did not abandon her beliefs despite her doubt in the feasibility of promoting learner autonomy in her university. She was attempting her best to promote learner autonomy. Instruction in learning strategies was evident in Wassamon's class. The "songs" activity and mind-map techniques became a means by which Wassamon trained her students to understand grammatical rules. When students used these strategies to accomplish the given task it indicates that Wassamon was successful in boosting the students' metacognition, particularly in knowing the task demands and selecting a strategy to complete it (Cotterall \& Murray, 2009). This could be a starting point for both Wassamon and her students to realize that by being armed with how-to-learn knowledge, students will be able to obtain and retain the information more effectively (Wasilow, 2009).

Data from the classroom observations shows that to some extent Wassamon's students were actively engaged in their own learning process. However, they needed someone to initiate, to lead and direct them periodically. This phenomenon may result from their personal characteristics: they were shy to speak out and not confident in initiating activities. In addition, the students might view of their teacher as a 'giver' of knowledge. From Wassamon's point of view, her students had long been exposed to a learning environment conducive to this concept of teaching. She seemed to imply that the contexts of pre-university education in Thailand increase the likelihood of students viewing their teachers in this way. The existence of a 'hierarchy' in Thai society may also lead to a view of teachers 
as the dominant figure of the class. It becomes a cultural expectation that the teacher ought to be the leader of the class (Bell, 2008).

Jensuda found that students' demographic characteristics might pose a constraint in the promotion of learner autonomy. Her students' southern dialects and regional different accents in standard Thai made them feel embarrassed and so they avoided speaking out. Keeping quiet seems to be a common characteristic of Thai students, if considered from a Thai cultural perspective. It can be assumed that Jensuda's students might want to show obedience and respect to their teacher, by listening and following. These learning behaviors are considered as part of the "Thai" way of learning, which consist of listening, observing, imitating and repeating (Patamadit \& Bousquet, 2003). This assumption implies students' perception of teachers as authority figures. It confirms the traditional Asian view of teachers as the authority or dominant figure in the class (Januin 2007; Liu. 2005).

The career promotion system in Jensuda's university put pressure on their teaching choices. Jensuda said she did try not to talk about the examination, or try to tell them which pages in the textbook would be covered in the examination; the students became very angry because of this and some of them even evaluated her at the end of course with a very low score. As a result, Jensuda was not willing to implement activities that involve students taking charge of their own learning. In such a situation, students' feedback affects her teaching philosophy, and the choice of teaching style is influenced by the students' reaction (Eden, 2001). When a teacher's career depends on student feedback as part of their promotion criteria, then teachers use controlling rather than autonomy-supportive teaching methods (Niemiec \& Ryan, 2009).

The promotion of learner autonomy was not yet officially stated as a university goal at the universities of both Wassamon and Jensuda. Figure 5.16 shows that professional development such as in-house training was 
seldom provided in their universities. Furthermore, their universities were newly established, branch campus and the lecturers are not very experienced. This limits the intellectual support provided by colleagues. Collegial supports from co-workers who have experience are necessary for allaying teachers' uncertainties about their work-related issues (Lortie, 1975). When encountering difficulties and frustrations in their daily work, inexperienced lecturers such as Jensuda and Bussaya might not know where to seek assistance. 


\section{Themes Identified across Cases}

Analysis of data from all five cases results in differences and similarities emerging in two main areas. These two main areas fall under two themes: pedagogic practices on the one hand, and factors influencing perceptions and practices on the other. Under each main theme, four sub-themes can be identified, as follows:

Pedagogical practices:

- Classroom communication

- Activities/materials

- Student freedom

- Idea of knowledge

Factors influencing perceptions and practices:

- Student-related factors

- Workplace-related factors

- Teacher-related factors

- Context-related factors

The identification of themes and sub themes enabled me to classify classroom activities and classroom components that are currently used to promote learner autonomy. It also enabled me to find out factors that might influence the participants' perceptions towards the promotion of learner autonomy and their practices in classrooms. These two themes were used as a framework that will underpin the cross case analysis in the next section. 


\section{Pedagogic practices.}

Comparison and contrast of the pedagogical practices of all five participants revealed similarities and differences in four aspects of pedagogy employed by the participants as shown in Table 5.3.

Table 5.3

Participants and Pedagogies

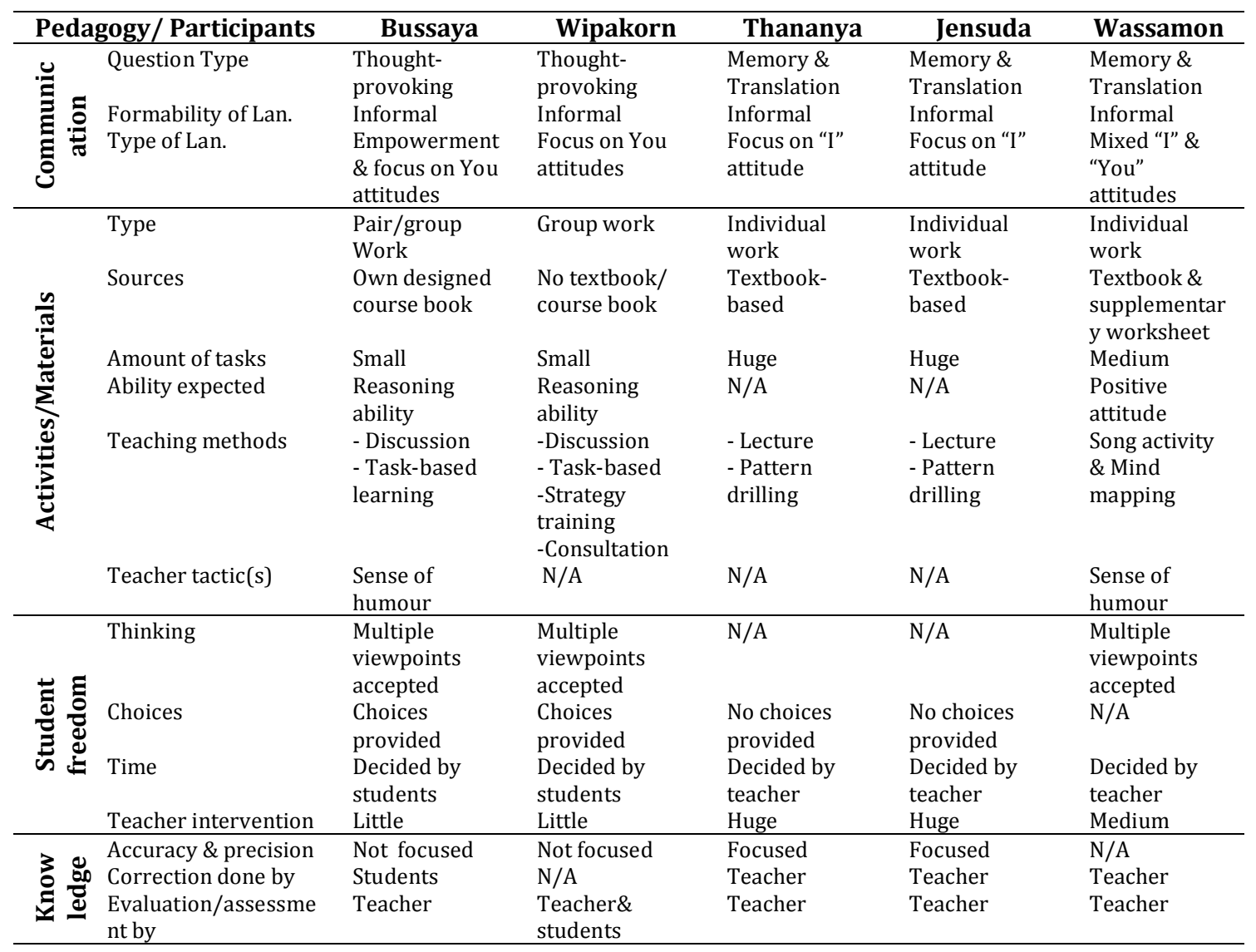

Factors influencing perceptions and practices.

Results of the examination of data across the participants identified similarities and differences in their educational experiences; students; climate in their workplace; and social, cultural and educational contexts (Table 5.4). These become factors that might influence their perceptions and practices of learner autonomy. 
Table 5.4

\section{Factors Influencing the Participants' Perceptions and Practices}

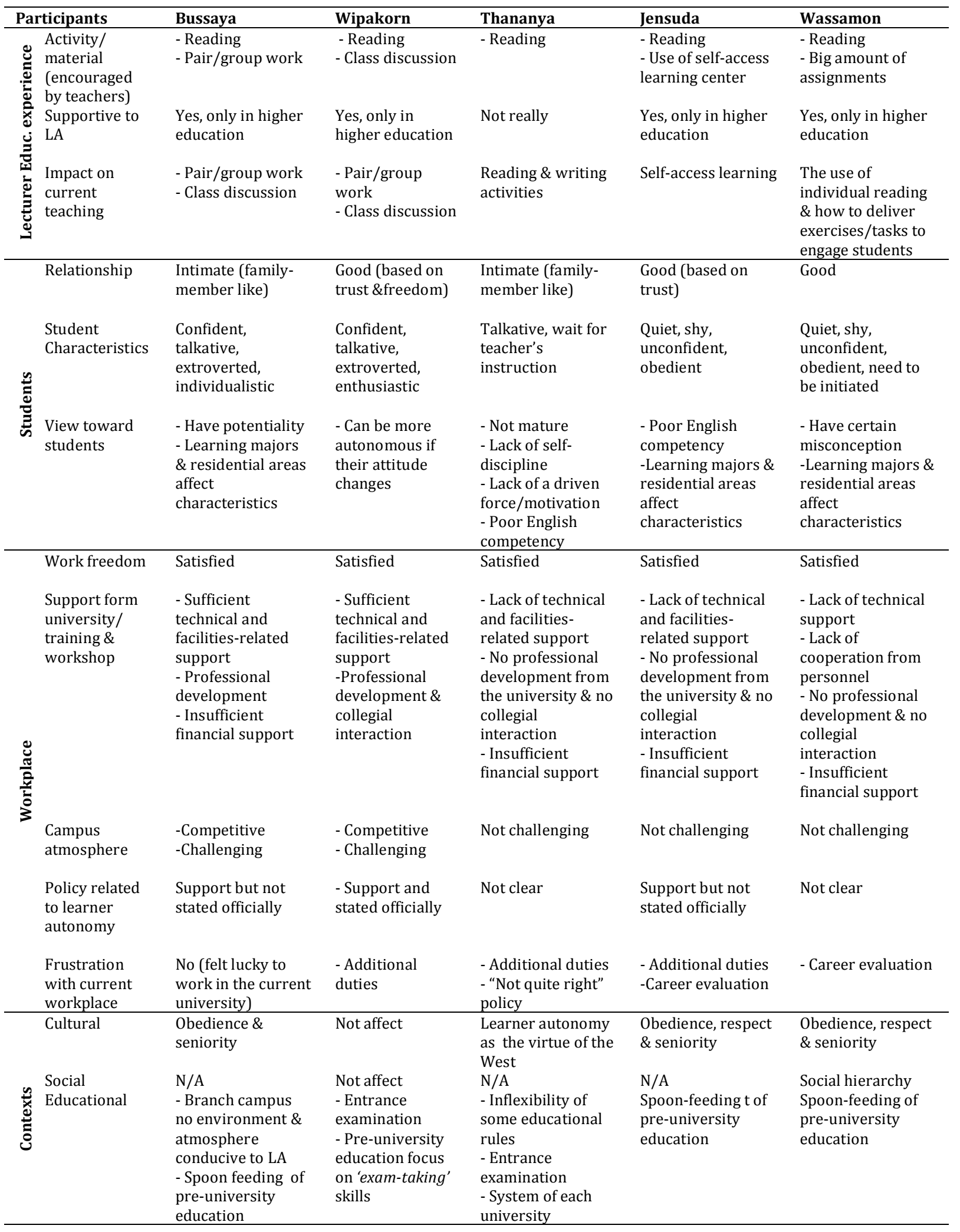




\section{Findings from Cross Case Analysis}

Examination of pedagogic practices across the five participants indicated that the promotion of learner autonomy is facilitated through the lecturers' communication strategies, teaching pedagogy and classroom atmosphere. Figure 5.17 shows the contribution of these three components to an autonomy-supportive classroom.

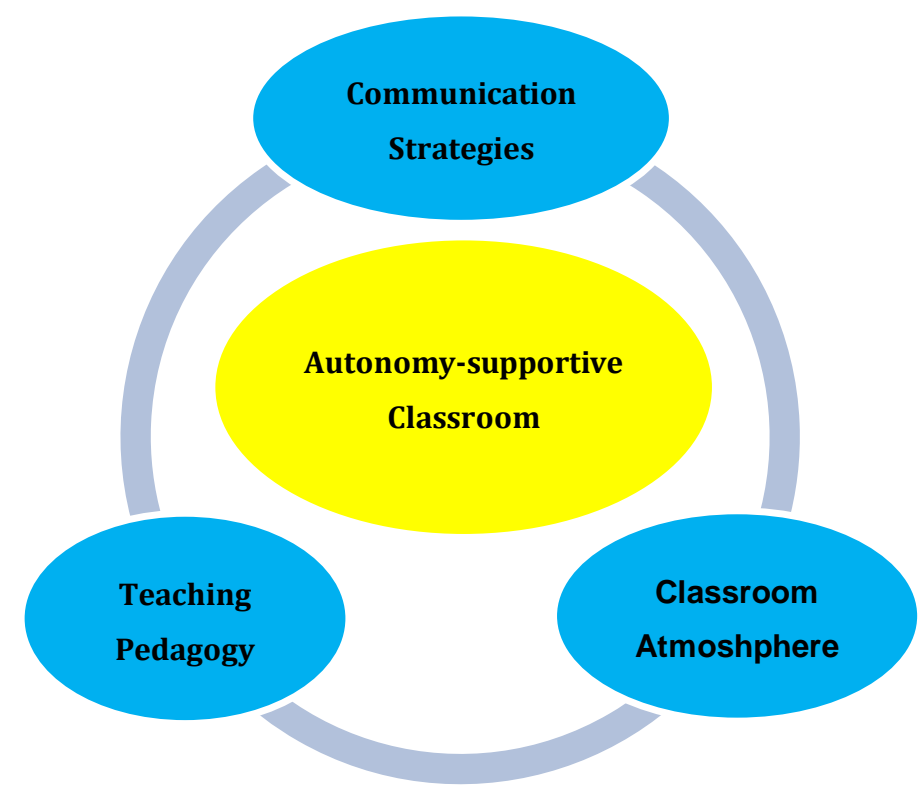

Figure 5.17. Components of an autonomy-supportive classroom

\section{Communication Strategies}

The examination of the participants' classroom discourses suggests that communication in classroom plays an essential role in inviting students to take responsibility for their learning. It determines students' degree of participation in classroom activities and impacts on how they perceive their learning and themselves (Ma, 2008). Results from the cross -cases analysis indicate three aspects in classroom communication that are used to encourage students to take charge of their learning. These aspects include the use of empowering language, the focus on "you" attitudes, and choice of question type. 


\section{Empowering language.}

Data from my classroom observations indicate that the language the lecturers uses in class play a crucial role in empowering their students. In an investigation of the language used among the doctors, Ventres and Gordon (1990) found that empowering language helped the doctors to remove the barrier between them and patients; it was the barriers which resulted from a "power asymmetry" (p.305) in the relationship between doctors and patients. Another study by Greenberg, Ganshorn and Danilkewich (2001), which was also carried out in a clinical setting, placed an importance on the physicians “ using empowering terms so that patients realised changes in their life were their own responsibilities. However, in the area of language education, it seems that the use of empowering language is rarely studied.

In Thailand, students are expected to speak to teachers in ways that show their respect for seniority. Teachers are supposed to speak with their students in ways that reflect their seniority and status. The language the teacher uses, thereby, usually conveys their higher status. It often becomes language that empowers the teacher, not the students, resulting in the feeling of a "power asymmetry" between teachers and students. This suggests that if the teacher use terms that make students feel empowered, the teacher can minimizes the students' feeling of this "power asymmetry". This will in turn remove their view of teachers as a power figure. Cotterall (1995) claimed such a view is a challenge to the development of learner autonomy. Empowering language is reflected in the choices of words (Ventres \& Gordon 1990), and phrases teachers use can either empower or belittle their students.

\section{Focus on "You" attitude.}

By using language reflecting "you" attitude, Wipakorn and Bussaya are conveying to their students that their classes are student-oriented. The use of "you" attitude implies that the priorities are given to the receivers of the 
messages (Jameson, 2004), which in this case are students. The concept of a "You" attitude signifies that successful communication must draw on the receiver's perspectives, not the sender. Its original and prevalent use is in writing, which respects the reader's point of view and emphasizes the reader's benefits (Spinks \& Wells, 1997). In classroom, communication that is framed upon "you" attitudes suggests that students' feelings and frame of references are taken into account, which is considered in SDT by Deci and Ryan (1985) as crucial for learner autonomy-supportive teaching. When students recognize that learning is their own responsibility, this is a starting point for the transfer of roles and direction in the class.

Bussaya and Wipakorn developed a "you" attitude in their communication by replacing "I" with "you" or "your" in a non-controlling manner. Another way to create "you" attitudes was by addressing their students by names (Brantley \& Miller, 2005). This enhances students' sense of ownership, in that they would perceive things happening in class as their own responsibility. The "you" attitude is also reflected in the use of positive terms and tone, which shows that the listener is well respected. The use of positive terms enables Bussaya and Wipakorn to open communication and encourage students to participate in the conversation. As Brantley and Miller (2005) suggest, the listener or the reader tend to be more open to positive messages.

\section{Choice of question type.}

Questions are not only for teachers to communicate their ideas and information, but also an important means to provoke students' creative thinking and active involvement (Ma, 2008). However, not all questions can achieve this; some questions may lead to adverse results. As Dillon (1978) argued, questions can either stimulate thinking and participation in learning, or suppress students' thinking.

The questions asked in classes of the strong supporters, Bussaya and Wipakorn, get students to think, rather than rendering "yes" or "no" 
responses. Their students were also provided with alternative ways to answer the questions so that they can show their depth of their understanding. According to McCoy (2009), questions that can trigger students to engage in higher-level thinking should have more than one correct answer, and inspire students to make connections with their prior knowledge. Questions structured in this way reflect the constructivist view of knowledge, in which knowledge is viewed as subjective and can be constructed by students (Aviram, 2000; Jonassen, 1992).

Teachers' reactions to students' questions is also critical. When Bussaya and Wipakorn were asked questions by students, they did not give them the answers. Rather, they answered their questions with questions (McCoy, 2009), or else suggested alternatives sources to find out the answers. In this way, students were inspired to think further and engage in higher-level thinking in order to elicit their own answers. It also triggers students' recognition that it is their own responsibility, not the teacher's, to take care of classroom activities and things related to the learning process.

The types of questions impact the level of learning that students gain. Questions asked in classes lead by Thananya, Jensuda and Wassamon tended to aim at knowledge and comprehension skills. Questions constructed on these levels require students to use their skills in recalling and retelling the information given to them by the lecturer or found in course materials (Bloom, Englehart, Furst, Hill, \& Krathwohl, 1956). In contrast, students in Bussaya's and Wipakorn's classes were triggered by questions structured on synthesis and evaluation levels. They were thus engaged in a type of learning in which they actively involved themselves in exercising their reasoning skills in order to make their own decisions and create their own understanding and knowledge. 


\section{Teaching Pedagogy}

The instructional methods used by the participants to promote learner autonomy included collaborative learning, task-based approaches and strategy instruction. The tools they used for teaching were not limited to a textbook or course book.

\section{Collaborative learning.}

Collaborative learning refers to a situation when students at different academic competence work together in groupwork or pairwork to accomplish a common goal (Gokhale, 1995). This method of learning is claimed to benefit language learning in many ways. It decreases students' anxiety related to learning (Ioannou \& Artino, 2010) and enhances students' thinking skills by providing students with opportunities to analyze, synthesize, and evaluate ideas when collaborating with their peers in pairs or in groups (Gokhale,1995).

The use of collaborative learning, either in the form of working in pairs/groups, or participating in group/class discussion prevailed in Bussaya's and Wipakorn's classes. Their students worked in pairs or in groups mutually searching for their solutions, constructing their own understanding of the given tasks, or creating the knowledge product for their group. The co-construction of knowledge that occurred during Bussaya's and Wipakorn's collaborative learning activities included elements of shared responsibility and interdependence. Because learners are social beings, being completely independent or detached is not an indicator of autonomy (Little, 1990). Roskams (1999) regarded collaborative learning as a form of "social scaffolding" (p. 106). It serves as a transitional platform for students to move away from dependency on the teacher. When learning collaboratively, students are experiencing "collaborative autonomy" (Roskams, 1999, p.106) before transforming this into personal autonomy. 
By working collaboratively with peers, students are situated in social environment and provided with opportunities to converse peers. Students can take these opportunities to learn some learning habits from peers who are more autonomous in their learning and who have different ways of "behaving, thinking, and choosing" (Murphey, 2003, p.5). Thus, their autonomy grows from interaction with peers. This resonates with Social Learning Theory as formulated by Bandura (1977), which claims that people learn from observing others. When working together, peers can be role models and demonstrate guidance models for the actions of other students. Collaborative activities also help increase students' sense of relatedness with their peers (Carson, 2007). While working collaboratively with peers the interactions become "horizontal", replacing the "vertical model" of classroom interaction, which is typical in the traditional teacher-dominated classroom (Carson, 2007, p.34).

\section{Task-based approach.}

A task-based approach refers to the administration of classroom activities with an emphasis on meaning, the process of doing things, authenticity, and communicative skills (Littlewood, 2004; Sánchez, 2004). Wipakorn adopted a task-based approach as one of her main instructional methods. The approach was carried out in the form of group projects, in which students needed to do some self-study and present their work to the class. The aim of this project work was, in addition to exposing students to the target-language environment, to provide students with opportunities to learn the "process" of self-study, which can then be used for their future study. Furthermore, this project work gave opportunities for students to interact with their peers. Through these interactions students develop their knowledge and their critical thinking skills are simultaneously enhanced (Lyle, 2008a).

In Bussaya's class, students were engaged in a meaningful process of completing the assigned tasks. Students were not informed what grammar lesson they were going to study. By completing the task given, students 
needed to construct their own rules of grammar. The goal of this was not the completion of the task; rather it aimed to stimulate students to contribute their efforts to the learning process by building their own theory of knowledge. According to Nunan (2004), the task-based approach enhances learners' personal experiences and makes an essential contribution to the learning process. The learning process becomes the focus of the learning in addition to the acquisition of the target language.

Ellis (2006) asserted that in traditional form-focused pedagogy language is seen as an "object" and students are to act as "learners" (p.29). In this traditional approach, the teacher plays a more active role and the class is rigidly structured. In contrast, the class with a task-based pedagogy is more flexible and students perform a wider range of roles (e.g. initiating, responding, and controlling the content). However, the administration of task-based pedagogy might not always be workable, particularly in a class where a strong asymmetry of power between teachers and students exists (Pica, 1987). Students might feel more comfortable in taking a risk in their language use without the presence of the teacher. In such case, task-based teaching, using pair and group work, might be a solution (Ellis, 2006).

\section{Strategy instruction.}

Providing learners with knowledge of how to learn is essential in the development of learner autonomy. Students' lack of knowledge about learning strategies minimizes their potentiality to learn autonomously (Rukthong, 2008). Usually this knowledge can be given to learners as training, which has two main aims: psychological preparation (Holec, 1981) and strategic preparation (Logan \& Moore, 2004; Lee, 1998; Usuki, 2002). Strategy instruction was evident in Wipakorn's and Wassamon's classes. However, a difference existed between the way Wassamon and Wipakorn put forth learning strategies. In Wipakorn's class, strategy instruction was explicitly integrated in the course syllabus, and thus organized and offered in a more systematic and consistent way. The strategy was based on students' 
use of metacognitive skills in setting their own learning goals, planning, and assessing their own progress. In Wassamon's class, the instruction was not explicit as it was not specified in the course syllabus. She introduced learning strategies whenever she felt her students needed them.

Although the research recommended the systematic integration of learner training into the classroom/course (Lee, 1998), my observation of classrooms suggest that strategy instruction might be administered with more flexibility, and should be delivered in ways that support learner autonomy. Both Wassamon and Wipakorn explained to their students the rationale behind the instruction of learning techniques, so that the students perceived the importance of the activity. According to SDT, students will exercise a greater degree of autonomy and willingness when they accepted the value of the task (Ryan \& Deci, 2000a). The introduction of learning techniques to students further reflects that learning is process-oriented, not product-oriented, and classrooms become a scaffold for students to develop lifelong-learning skills (Tepsuriwong \& Srisunakrua, 2009).

\section{Freedom in textbook use.}

The textbook itself does not diminish autonomy of students. It is the ways that lecturers administer the textbook that is important. It may lead learning to be under "course book pressure if teachers place more importance on finishing the textbook than on training students about learning strategies" (Logan \& Moore, 2004, p.4). Learning then becomes "teacher-directed", where teachers regard the author of the textbook as the main resource for learning and try to dominate discussion in the classroom without soliciting and using students' input (Areglado et al., 1996, p.19).

In classrooms where learning is not under pressure from a textbook, lecturers may have more choice to employ a wider range of strategies. In Bussaya's and Wipakorn's classes learning goes beyond the boundaries of the classroom and books. Their students were able to select materials or topics 
of learning from various sources. My observations suggest that when the lecturers did not struggle with trying to cover all the lessons in the textbooks, they had more freedom to employ various instructional activities to encourage active engagement in students' learning. Learning in these classes then becomes "challenging, relevant and meaningful" as the lecturers had freedom to cater learning activities/tasks to students' needs and interests (Tepsuriwong \& Srisunakrua, 2009, p. 365)

On the contrary, Thananya and Jensuda used the textbook as the sole tool for their teaching. They used it in ways that might thwart students' development of autonomy. That is, they tried to finish all the exercises and content in the textbooks, which left them with less control over their teaching (Mustafa \& Cullingford, 2008). Questions and tasks in their classes were mainly from the textbook or related to the textbook content. The questions that were sourced from the textbook were useful, but the lecturers did not provoke the students to think further than the information at hand. Learning in their classes became a matter of finding information in the textbook itself to answer the teacher's question, rather than of constructing knowledge or triggering students' higher-level thinking.

\section{Classroom Atmosphere}

The findings from the cross case analysis show that the classroom atmosphere was crucial to the learners' sense of autonomy. The classroom atmosphere conducive to the development of learner autonomy is comprised of a constructivist view of knowledge, an optimal degree of students' freedom, and a teachers' sense of humour.

\section{Constructivist view of knowledge.}

The ways the lecturers deliver activities/tasks in the classroom can reflect their perception of knowledge. The uses of class discussion, project work, and group/pair work prevalent in Bussaya's and Wipakorn's classroom practices suggest that knowledge would not be transferred from teachers but 
be constructed by students. With this notion, students are no longer the passive recipients of knowledge. They are to take an active role in acquiring or constructing the knowledge. In order for students to take this active role, the roles of the teacher can no longer be one of being the sole purveyor or transmitter of knowledge (Barnes, 1992; McDevitt, 1997). This view of teachers is in line with the constructivist approach, in which teachers no longer transmit knowledge, interpret the meaning or provide information to students. On the contrary, teachers are to create an environment in which students can explore and discuss their answers in real world contexts, either individually or collaboratively with their peers (Aviram, 2000).

Bussaya's and Wipakorn's questions are open to multiple answers. Acceptance of students' multiple views implies the idea of knowledge as universal and subjective. This view of knowledge is fundamental to constructivism which proposes that "there is no single reality or any objective entity" (Jonassen, 1992, p. 139). In constructivist classrooms students learn and develop their ability through "questioning and objection" (Aviram, 2000, p.466). By accepting knowledge as a subjective entity, one to be constructed by students, Bussaya and Wipakorn represent a radical opposition to the traditional perception of the teacher as an authority and chief source of knowledge. Furthermore, the radical role that Bussaya and Wipakorn play requires students' contribution and involvement in their learning in order to discover their own knowledge, as knowledge will not be passively transmitted. In this sense Bussaya and Wipakorn are overturning the prevailing notion of teaching methodology in Thailand, which nurtures memorization, rather than critical thinking skills (Richmond, 2007).

\section{Optimal degree of students' freedom.}

Freedom is believed to be a fundamental feature of learner autonomy (Trebbi, 2008). The presence of restrictions and external compulsions within the formal educational systems might lead to the conviction that students have no freedom and their autonomy is suppressed in these contexts. 
However, the findings from the cross case analysis suggests that in the promotion of learner autonomy, freedoms given to students do not need to be absolute freedoms.

Learning activities in Wipakorn's and Bussaya's classes were based upon their belief in students' freedom, either freedom in thinking, making choices and deciding about pace and rhythm of learning. However, the students still needed to work within the scope of the courses, to be in line with the curriculum and the university's regulation, and to justify their decisions or disagreement with plausible reasons. The requirements Bussaya and Wipakorn put on their students can be justified through the paternalistic principle, which holds that intervention from another person is acceptable on the condition that that person has good intentions for the intervention (Lindley, 1986). It is tolerable for teachers to impose restrictions on their students if the rationale behind this is for students' autonomy on a long-term basis.

The idea of optimal degree of students' freedom suggests a way of conceptualizing learner autonomy which allows it to be pursued within a formal educational context. In classrooms with a pre-established curriculum, both the teacher's and the students' freedom, particularly in terms of choice, is inevitably reduced (Carroll \& Head, 2003). But this is to view the matter of 'curriculum' and 'free choice' as two opposing constructs. Free choice, as suggested by Carroll and Head, should not be regarded as "being an all-ornothing construct" (p.69). Thus, the framework that Bussaya and Wipakorn gave to their students should be viewed in a "more useful and realistic way": that is, it allows students to carry out their learning "more effectively than they could without any frame" (Carroll \& Head, 2003, p.70).

\section{The teacher's sense of humour.}

Though the teacher's sense of humour has no direct correlation with the development of learner autonomy, it is claimed to be beneficial to learning 
and teaching. Highet (1950) regarded a sense of humour as one of the important qualities of a good teacher. The use of sense of humour in a class results in an atmosphere that is conducive to learning (Kher, Molstad \& Donahue, 1999). It enhances understanding, sustains students' attentions, minimizes anxiety, reduces undesirable behaviours and fosters positive attitudes towards the subject (Powell \& Andresen, 1985; Warnock, 1989).

The sense of humour which prevailed in the classes of Bussaya and Wassamon was based on their beliefs that students will participate more and give more contributions to their learning when they enjoy the class. The lecturers' sense of humour in class leads to openness and good rapport with their students, which is important when promoting learner autonomy in Thai classrooms. This is because Thai classrooms are influenced by the hierarchal structure which dictates that students are considered as juniors, and are not supposed to argue with teachers, who are considered their seniors (Foley, 2005). My classroom observations suggests that the lecturers can use openness and good rapport resulting from their sense of humour to minimize students' perception of the teacher as an authority figure and reduce the gap resulting from the notion of seniority between teachers and students. Lecturers' sense of humour further cultivates students' confidence and willingness to question and voice out their ideas. This is because it reduces the feeling of pressure and coercion, promoting a classroom atmosphere as a safe place. In such an atmosphere learner autonomy is facilitated (Niemiec \& Ryan, 2009). 


\section{Chapter Summary}

This chapter presented the qualitative phase of the study. Findings from this phase indicated that three main elements have been incorporated to create an autonomy-supportive classroom: communication, teaching pedagogy and learning atmosphere. The use of "you" attitudes and empowering language in their classroom discourse help lecturers to create a sense of ownership in their students. Questions the lecturers ask should trigger students' active involvement and critical thinking. For choices of teaching methods, collaborative learning, a tasks based approach, and strategies instruction were used to promote learner autonomy. Furthermore, teaching which is not mainly based on textbooks or course books gives the lecturers more freedom in their choices of teaching methods. The findings suggest classrooms tend to be autonomy-supportive when knowledge is perceived as constructivist, students are granted freedom to an optimal degree, and teachers make use of their sense of humor. 


\section{CHAPTER 6: THE CONVERGENCE OF TWO STRANDS}

\section{Introduction}

The two previous chapters reported findings from the quantitative and qualitative phases of the research project. This chapter links the findings from the quantitative survey to those from the qualitative case studies. The results from both phases, when linked and examined in greater detail, enable me to discern factors that might mediate the lecturers' beliefs and practices related to learner autonomy. The linkage of the two study phases also results in the promotion of learner autonomy being conceptualized as a pathway. This pathway starts from lecturers' beliefs as reported in Phase 1 and ends with lecturers' practices as reported in Phase 2.

\section{A Pathway to the Promotion of Learner Autonomy}

One might assume that the beliefs lecturers hold should determine their current classroom behaviours and choice of teaching methods. However, the findings from my survey suggest that there might be hidden mechanisms that prevent lecturers from putting what they believe into practice. The in-depth examination of the educational experiences, working histories and social milieu of the five selected lecturers in the follow-up cases studies enabled me to discover factors that influence these Thai lecturers' teaching behaviours and pedagogy.

Considered together, the findings of the survey and the cases studies portray a pathway to the promotion of learner autonomy in Thailand's higher education system. I model the pathway as follows: 


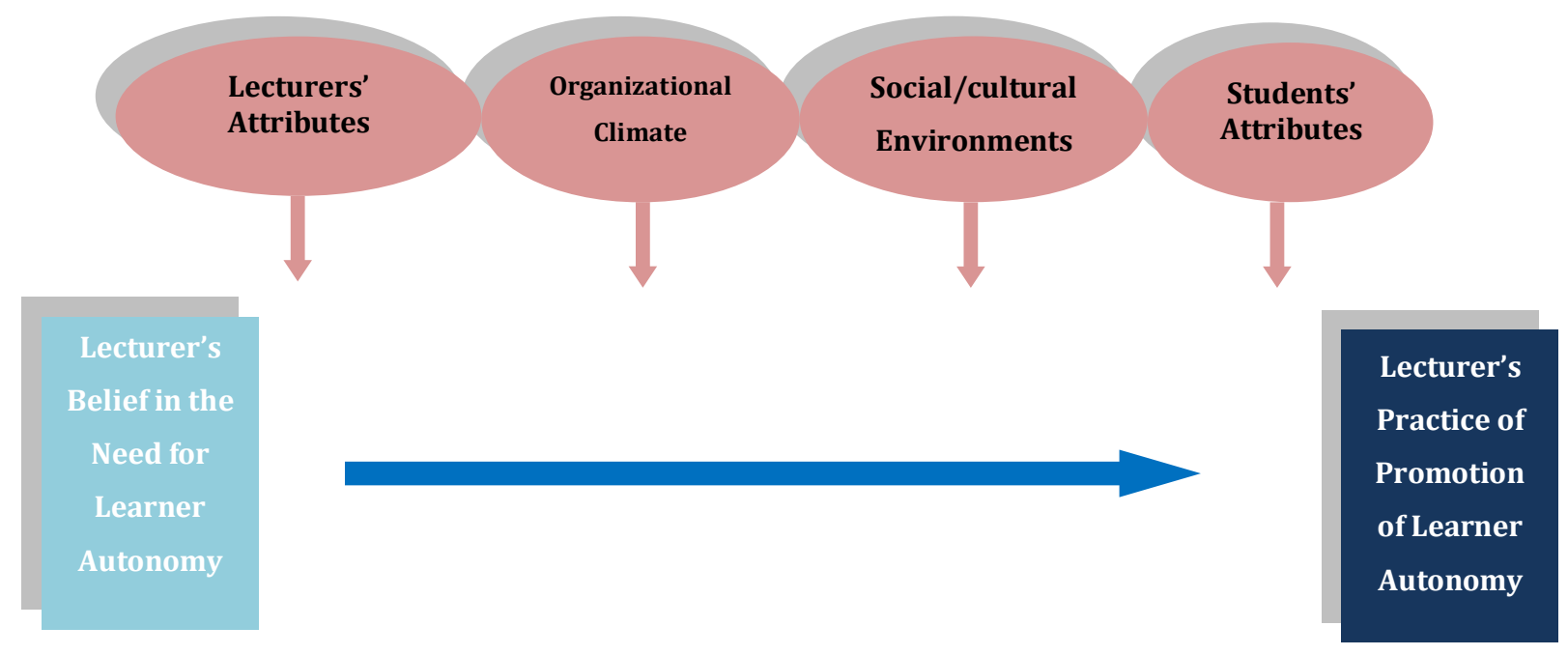

Figure 6.1. Pathway to the promotion of learner autonomy 
The model in Figure 6.1 illustrates that the promotion of learner autonomy in higher education in Thailand is not only the concern of learners and lecturers. There are multitudes of factors that intervene in this pathway. The model explains the question that arose from the survey results, in which a gap existed between lecturers' beliefs and practices (Figure 4.8 in Chapter 4). According to the model in Figure 6.1, the starting point for promotion of learner autonomy is lecturer beliefs. Ideally, lecturers should be able to act on their beliefs and their beliefs should determine their classroom practices. However, results from both phases of the study suggest that in reality lecturer beliefs in learner autonomy alone cannot determine their actual classroom practices.

The model indicates that a lecturer's choice of any pedagogic method involves a complex decision making process. Lecturers act as "active, thinking decision-makers", whose instructional choices are influenced not only by their beliefs but also other factors (Borg, 2003, p. 81). Findings from my cases studies suggest that the likelihood that lecturers will act on their beliefs is associated with four factors- the lecturers' theoretical and pedagogical knowledge pertaining to learner autonomy; the climate in their university; their students' attributes; and the socio/cultural environment. These factors are often more influential than their beliefs, and support or inhibit the potential that the lecturers have to act on the beliefs they have about learner autonomy.

The ideal pathway is one in which lecturers do not experience the pressures of any of the four factors, allowing lecturers to teach in ways that are congruent with the beliefs they have about learner autonomy. However, in reality lecturers usually experiences some pressures from any of those four factors. Ones who experience the least pressure are ones who are more likely to act on their beliefs in learner autonomy. Using this model to explain the lecturers in my cases studies, Bussaya and Wipakorn illustrate lecturers who experience least pressures. Wassamon and Jensuda, on the other hand, 
exemplify cases where pressure from any of the four mentioned factors prevents them from translating their beliefs into practice. Those four factors represent pressures placed on lecturers, which might encourage them to use controlling, rather than autonomy-supportive, strategies (Ryan \& Brown, 2005).

The proposed model is applicable to lecturers who believe in learner autonomy but do not know how to promote it, or encounter difficulties when promoting it. For lecturers who do not believe in learner autonomy, such as Thananya, further research is needed to investigate how to make them see the value of learner autonomy and have positive attitudes towards promoting autonomy amongst their students.

\section{Mediators of Lecturers' Beliefs and Practices}

As presented in Figure 6.1, the mechanisms that influence a lecturer's promotion of learner autonomy result from the interplay of four factors: lecturers' attributes, organizational climate, socio/cultural environments and students' attributes. This section discusses how each of these factors might support or inhibit the lecturers' translation of beliefs into practice. Although the diagram in Figure 6.1 represents these factors as discrete influences, the factors are, in reality, interconnected. For the sake of this thesis, I discuss them one by one.

\section{Lecturers' Attributes}

Lecturers' fear of losing power and lecturers' fear of losing their high status in class may inhibit teachers from assisting their students to be autonomous (Nicolaides, 2008; Sert 2006). However, findings from my study indicate that power and status are not the concerns for Thai lecturers. Rather, it is their limited understanding of learner autonomy that prevents them from promoting learner autonomy in their class. Their educational background might also have an impact on their perceptions of learner autonomy. 


\section{Lecturers' understanding of learner autonomy.}

As argued in Chapter 2, learner autonomy signifies the learners' capability to direct their own learning (Holec, 1981). However, the findings from my study suggest that the development of this capacity in students may depend largely on the teachers' theoretical and pedagogic knowledge of learner autonomy.

Both Jensuda and Wassamon were uncertain about the effectiveness of their current instructional style and did not know how to modify their teaching behaviours to foster students' autonomy. Their uncertainty about the roles the teacher ought to play and instructional methods they should use in order to promote learner autonomy reflect their lack of a true understanding of the principles of learner autonomy. Darasawang et al., (2007) regarded teachers' lack of true understanding of the principles of autonomy as one of the factors limiting the successful pursuit of learner autonomy in Thai schools. Darasawang et al., (2007) claimed this lack of understanding as a lack of intellectual support from teachers' workplaces in providing training or workshops to its teaching staff.

The lack of understanding of learner autonomy is also reflected in the fact that the term "learner autonomy" does not have its own equivalent in Thai language. It is used interchangeably with "independent learning" or "independent learner". This interchangeable use suggests two propositions. First, learner autonomy is viewed as a mode or a way of organizing learning and teaching, rather than as a capacity of a learner. Viewing learner autonomy in such a way might make the successful pursuit of this concept difficult, because when learner autonomy is treated as a "method", it can be discarded when it is judged unsuccessful (Little, 2007, p.7). Second, learner autonomy is equated with independence, suggesting the notion of learning without teachers. Such a view of learner autonomy clashes with SDT, which posits that autonomy does not involve a dichotomy of dependence versus independence (Deci \& Ryan, 1985). Equating learner autonomy with learning 
independently of teachers or learning in isolation is a misrepresentation of learner autonomy (Smith, 2003).

\section{Educational background.}

The findings from my survey suggest a relationship between a teacher's educational background and their beliefs in learner autonomy. These findings are congruent with Borg's (2003) proposition that schooling plays a role in defining teachers' beliefs. According to my survey results, lecturers who did their bachelor's degree in education were more likely to have stronger belief in learner autonomy than teachers from other fields. This may be because they were required to study educational theories including autonomous learning, and were thus inclined to see the value of having students take control of the learning process. On the other hand, lecturers who did bachelors in other fields such as arts, liberal arts, and computer science were not required to learn any theories related to teaching methodologies and thus were not likely to realize the benefit and the need for learner autonomy. Past schooling experiences and former teachers can be one indicator of teachers' support for autonomy (Sert, 2006). It is unrealistic to expect teachers to use tools for promoting the autonomous learning of their students if they themselves "have been shaped" by a traditional system (Sert, 2006, p.196).

However, although educational experience plays a role in shaping lecturers' beliefs, there is no guarantee that lecturers who did bachelor's degree in education will transform their beliefs of leaner autonomy into practice. This is because the findings on reported practice suggest no association between holding a bachelor's degree in Education and the extent to which learner autonomy will actually be practiced in their class. Lecturers' previous education is only one factor and cannot guarantee their actual classroom practices. 


\section{Organizational Climate}

The findings from the qualitative data in Phase 2 suggested that the organizational climate played an important role in ensuring the potential that a lecturer will promote learner autonomy. The climate of an organization reflects the values, norms, attitudes, behaviours, and feelings of its members (Payne, 1971). It is the prevailing atmosphere of an organization, which is related to the amount of control it has over its members and the ways in which this control is exercised (Dondero, 1997). The results of Phase 2 of my study indicate three prevailing features contributed to the organizational climate. They are professional development and level of support; career evaluation and work requirements; and university location.

\section{Professional development and level of support.}

The organizational climate can negatively or positively affect the ways in which its members work (Dondero, 1997). A lecturer's belief in learner autonomy may be hampered in a climate where it is felt difficulties result from having to do routine work. Adequate administrative support and teaching-learning resources enhance the likelihood that a lecturer who believes in learner autonomy will act on their beliefs. Lecturers are more likely to assist their students to be autonomous if they, as lecturers, were adequately supported by their universities. Strong supporters of learner autonomy in my qualitative phase perceived there was adequate support from their universities whereas the perception of insufficient provision of support led lecturers to see difficulties in the promotion of learner autonomy in their workplace.

The level of support the lecturers receive from their workplace influences their perception of the feasibility of the promotion of learner autonomy. Lecturers who are sufficiently supported and satisfied with their workplace, such as Wipakorn and Bussaya, are more likely to perceive the promotion of learner autonomy as relatively easy. On the other hand, Jensuda and 
Thananya, who perceived that there was inadequate support and constraints imposed by their university climate, were frustrated with difficulties in their jobs and, therefore less motivated to adopt new teaching methods. This indicates that a lack of intellectual resources and teaching materials might result in teachers' lack of motivation and creativity in their teaching (Saman, 2004).

Professional development might represent the level of support that the university provides to its staff - particularly intellectual support - and this has been identified in my findings as insufficient in many universities. Oftentimes, the universities do not have in-house training/workshops for its staff. Budgets given to lecturers to seek development in their profession from external providers are limited, resulting in many lecturers feeling discouraged about strengthening their teaching repertoire. Nonkukhetkhong et al. (2006) indicated that Thai teachers' lack of confidence in putting the concept of learner-centered into practice is due to insufficient support from their school administrators, particularly training or workshops about relevant theoretical and practical knowledge.

The level of support may be connected to the status of the particular university in Thailand. My qualitative data suggest differences in learningteaching resources and support between home campuses and branch campuses. Most of the branch campuses of each university in Thailand are newly established and located in rural areas. In addition, the findings from the survey indicate that teaching staff in these newly established campuses tend to be younger, less experienced and have lower educational qualifications. Consequently, the professional assistance they can seek from more experienced colleagues may be scarce.

A high degree of collegial collaboration among lecturers, particularly from more experienced lecturers, may help less experienced lecturers to make informed decisions about instructional methods appropriate for leaner 
autonomy. Such collegial interactions are evident in Bussaya's and Wipakorn's universities, which are the home campus.

\section{Career evaluation and work requirements.}

In many universities, teaching competence is measured by specific, established criteria. Such a career evaluation system may disempower teachers because teachers have to teach in a way that meets criteria already set and to use specified teaching methods (Vieira, 1997). Moreover, the career evaluation system in many universities includes students' feedback. Jensuda is an example of a teacher who undergoes such a career evaluation system. Even though she preferred to have students work collaboratively, she was not able to do so due to pressure to finish the syllabus and the fear that students might not agree with this style of learning and vent their dissatisfaction in her evaluation. Jensuda represents a case where career evaluation results in the teacher's feeling threatened or in a state of disagreement (Burden, 2009).

Work requirements were found as another feature of an organization climate that imposed constraints on the lecturers' daily working experiences. In addition to teaching load, work requirements include additional duties that lecturers are required to perform, such as being scholarship committees, assessment committees, and project advisors. It also includes the requirement for lecturers to strictly follow the course syllabus. This may explain the finding in Phase 1 related to the issue of time. As discussed in Chapter 4, use of time was identified by Thai lecturers as the area that students were least likely to be allowed to make decisions. The finding about control over time in the survey may be explained by taking into account the educational system and atmosphere in Thailand. Findings from the class observations during case studies indicated that the quantity of materials from the textbook that needs to be taught may be the reason for lecturers' resistance to having students make their own decision about time needed for learning activities. Lecturers may need to teach as many as 10 to 15 chapters 
in a 15-weeks semester. Each chapter has to be taught within one and a half week (mostly 3 hours per week). As a result, Thai lecturers are caught between allowing students to manage class time on the one hand, and catching up with the course syllabus on the other. Lecturers are reluctant to hand over this kind of decision making and continue to make decisions about time themselves.

\section{University location.}

Findings from the qualitative phase of my study confirm the findings from the survey phase, which suggest an association of lecturers' levels of confidence in their students with their university location. That is, lecturers in smalltown universities are less confident in their students' capability than lecturers that teach in Bangkok or other major cities.

In the follow-up qualitative study, all five lecturers claimed that university location has an impact on students' characteristics and learning habits. Data from my class observations also confirm this claim. Students from universities located in rural areas were more likely to be introverted, shy, and unconfident. In class they preferred to listen and follow the lecturer. Consequently, lecturers' confidence in their students' potential to learn autonomously may be hampered by a context which encourages such a perception of the students. Students in Bangkok or in big cities, in contrast, tended to be more talkative and more comfortable with themselves. In class, they took more initiative and were more likely to be confrontational. This finding is supported by Wang (2009)'s investigation of the promotion of learner autonomy in Chinese contexts. According to Wang, Chinese students tend to be introverted, shy and quiet, and prefer to listen to the teacher and avoid answering questions and taking initiative. These personalities perhaps result in Chinese teacher's use of teaching styles that do not support the development of learner autonomy, such as a teacher-centered, bookcentered, or grammar-translation method. 
Although the variation in lecturers' confidence level is related to university location, the university location itself does not have a direct impact on teachers' level of confidence in students. Rather, it determines the atmosphere of the university. Participants in my qualitative phase explain that universities located in rural areas did not provide a challenging learning atmosphere. The participants believed that the university atmosphere shape students' perception of learning and, in turn, their motivation of learning. Without a sense of competition and challenge, students might not see the value of making an active contribution through their own effort to their own learning. Furthermore, students in rural areas may have fewer opportunities for autonomous learning in the environment outside the classroom because there is less of the target language in the environment - foreigners, books, and films. Thus, if teachers are to help students make maximum use of their autonomy in learning, the findings from both the quantitative and qualitative data signal the need to increase teachers' level of confidence in students, as well as students' motivation in their learning.

\section{Social/cultural Environment}

The pathway illustrated in Figure 6.1 suggests the role that contextual factors play in determining the extent to which lecturers are able to teach in ways that are congruent with their beliefs. It indicates that the lecturer's actual classroom practices are "context-sensitive" (Borg, 2003, p.81). Findings from Phase 2 of the study echo challenges in the promotion of learner autonomy that exist in Thai contexts. Like other Asian countries, Thai society is tightly organized, hierarchical, and collectivistic. The typical cultural and social makeup of the country influences its educational practices and determines the behaviours of its members. My study found some structures in Thai society which may challenge the lecturers' practices of promoting learner autonomy. 


\section{Thai cultural expectations of the role of teachers.}

Thai teachers seem to play a double role: firstly, as the teacher dispensing knowledge; secondly, as the second parent of students. The view of teachers as the second parent leads to another concept that impacts on the ideology of Thai teachers: 'Bunkhun', which refers to when one does a favor to others (Foley, 2005). Thais believe teachers sacrifice themselves to the good of their students. Thus students and their parents are indebted to the teacher and, so, are under an obligation to express their gratitude to teachers. Conformity and obedience are usual choices for Thai students to repay this debt. Accordingly, no matter what teachers teach and say, students are to follow and believe. It is not that the teacher is the authority and children cannot disagree, but because parents and students themselves believe that teachers are good persons with good intentions and knowledge, there is no purpose in questioning anything teachers do or say. In such an intimate relationship between students and their second parent, students might not see the need to take control of their own learning. They expect that their education will be taken care of by their second parent, rather than being given the opportunity to become autonomous. As a result, students expect knowledge to be delivered to them.

\section{Thai cultural expectations of the role of students.}

Like other Asian countries, Thai culture values obedience, conformity, seniority and respect for older people. Thai parents expect their children to behave in ways that conform to such values. This way of child-rearing impacts on the concept of appropriate student behaviours. In response to the notion of teachers as the second parents, Thais believe students are indebted of their teachers. To display their gratitude to teachers' 'Bunkhun', they are expected to be conformist and obedient. To question is regarded as inappropriate and as a sign of ingratitude (Foley, 2005). 
The high status that Thai society gives to teachers cultivates students' passitivity and makes them reluctant to take charge of their own learning. The notion that the teacher is the giver of knowledge might make students jump to the conclusion that there is no need for them to make any contribution to their learning, as the knowledge will be given to them by the teacher. The view of students as 'inexperienced and not in the position to share or express ideas' (Baker, 2008, p. 139) suppresses students' spirit to discover, argue, and initiate.

However, although Thai societal values lead to the asymmetric sharing of power between teachers and students, not all Thai lecturers expect to see their students as that conformist. Many of them want their students to be more skeptical and self-reliant. The problem is that students at a university level come with a code of conduct which has been molded during their infancy and their many years in pre-university education. It is hard for university lecturers to change students' presumption of the roles they ought to play in just four years of higher education.

\section{Pre-university educational system.}

The lecturers in my cases studies found that teaching styles in pre-university education cultivate in students some tendencies that might make it hard for them to be autonomous. They believed many schools tend to be spoonfeeding in nature, which results in students' limited creative thinking and knowledge-searching skills. Furthermore, students are shaped by the idea of schools as the place for receiving knowledge, rather than the place for discovering and constructing their own knowledge.

Furthermore, the lecturers in my cases studies pointed out that education in Thailand, like in many other Asian countries, is heavily dominated by a university entrance examination. The high stakes university entrance examination imposes huge pressure on Thai students, not only those at a junior high school level but also those from earlier levels of education. The 
constraint on the development of learner autonomy imposed by entrance examination is paralleled in Lo's (2010) study of Taiwanese students. Lo pointed out that the entrance examination is one of the challenges in the promotion of learner autonomy in Asian contexts. In a similar vein, the domination of entrance examinations in Thailand leads Thai students, their parents, and their teachers to perceive learning as an end product and the goal of pre-university education is reduced to passing the entrance examination. A popular resolution for students, and even their parents, is to go to private tutorial school. Tutorial schools mainly aim to prepare students for the university entrance examination (Karaagac \& Threlfall, 2004). Lessons are structured around the practices of previous examinations and students are trained to answer questions expected in the prospective entrance examination. Accordingly, students have been shaped in an environment where learning is viewed as an end-product produced by the teacher, and students are regarded as the consumers of the knowledge (Sinlarat, 2007). The participants in my cases studies claimed that when learning is treated as a preparation and a shortcut for examination, the process of learning itself is neglected.

\section{Student Attributes}

The pathway presented in Figure 6.1 takes student attributes as another factor that might influence on the lecturer's translation of beliefs into practices. Macaro (1997) explained this situation as the "push and pull" of autonomy, in which the teacher's intention to develop autonomy is compared to "push" and the learner's desire to take it to "pull" (p.186). Student factors include their characteristics and their perception of learning.

\section{Student characteristics.}

In my study, the lecturers' low level of confidence in their students' ability to direct their own learning, which is identified in the survey results, can be explained by the results of the follow-up case studies. The perception of 
students' inability to take control of their learning process results in lecturers' reluctance to give students opportunities to take control of learning activities. Thananya's perception of her students as immature, lacking in self-discipline and having poor language competence resulted in her conjecture that her students were not able to direct their own learning. Similarly, despite strong belief in learner autonomy, Wassamon's and Jensuda's reluctance to let students take control of their own learning arose partly from their students' characteristics such as introverted personalities, unquestioning obedience, lack of confidence and low language competence. This also suggests the lecturers' association of students' personalities and their preferred style of learning. For example, students with extrovert personalities are more likely to prefer to engage in collaborative learning. (Ramsay, Hanlon, \& Smith, 2000). As a result, the lecturers whose students are extrovert and confident, such as Bussaya and Wipakorn, are likely to adopt collaborative learning activities in their teaching.

Lecturers also perceive an association between the students' learning habits and their study majors. Students who study in the same majors seem to display similarities in their personalities and learning habits. For example, students who major in English were perceived by some participants as more individualistic, extroverted and confident than those from a Thai major. Similarly, another participant believed that students who major in Accounting were extroverted, persistent with learning and confident than students majoring other fields of business. Students with the same personalities may be likely to select the same academic majors in their tertiary education (Furnham, 1992).

\section{Students' perception and motivation about learning.}

How students perceive language knowledge can impose difficulties on lecturers' attempts to promote learner autonomy. As found in my study, the lecturers found it hard to encourage students, who had the perception of themselves as knowledge receivers, to make an active contribution to their 
own learning. This is because students who "cling to the perception that knowledge must be transferred" will wait for the teacher to "spoonfeed them" (Thamraksa, 2003, p.67).

While students' view of teachers as a knowledge giver results in students acting as a knowledge receivers, students' low motivation to learn results in students' not putting effort into their learning. Borg (2006) claimed unmotivated students as one of the factors that influence the teacher to abandon their pedagogic beliefs. My participants in Phase 2 believed that students' lack of learning motivation results from their inability to see the link between what they are learning and the outside world. Some universities in my studies, particularly those branch campuses located in rural areas, do not facilitate students to see the practical benefits of possessing language competence. The environments surrounding these universities may not provide the students with challenges to drive students to put effort in their learning. The link between classroom knowledge and the world outside is hard to make when knowledge is perceived as only a step towards passing examination. Such a view about knowledge seems to be predominant in Asian students. In Japan, for example, knowledge is regarded as necessary only for "filling the exam sheets, filling out forms and proving to the authorities that one has persevered through the ordeal of ingesting large amounts of data" (McVeigh, 2002, p.96).

The participants in the qualitative phase indicated that Thai students are likely to be extrinsically motivated. Students put effort into their learning because of the desire to get good grades, pass the course, or satisfy their parents. SDT regards behaviours that are pressured by such external contingencies as controlled behaviors (Black \& Deci, 2000). Thus, learning behaviours of students who are extrinsically motivated can be regarded as controlled, rather than autonomous, learning. As the controlled learning is sustained by external contingencies, it might be hard for these students to 
continue to learn with an absence of rewards. In this sense, it can be said that the chance that they will develop lifelong learning skills is hampered.

\section{Chapter Summary}

The interlinking of findings from Phase 1 to those from Phase 2 shows a pathway to the promotion of learner autonomy. Along this pathway, lecturers have experienced an interplay of factors that support or inhibit them from promoting learner autonomy. These factors include the lecturers' own attributes, students' attributes, the climate of their workplace and their social/cultural environments. This indicates that the decisions for instructional choices of a lecturer are complex in nature. When making decisions related to the promotion of learner autonomy, the lecturers do not merely draw on their beliefs, but also on the mentioned four factors. 


\section{CHAPTER 7: CONCLUSSION}

\section{Introduction}

This chapter concludes the research. The chapter presents a summary of the research by revisiting the research questions and the major findings of the research. The findings from the research have contributed to the theory and practice of learner autonomy. After presenting these contributions, I discuss the limitations encountered in conducting this research and suggest directions for future research. The chapter ends with my concluding statement regards the research as well as the promotion of learner autonomy in Thailand.

\section{Summary of the Research}

This thesis aimed to investigate the existing state of the promotion of learner autonomy in Thai higher education. Results of the systematic review of literature (Chapter 2) informed a need to undertake this investigation from the perspectives of lecturers. To address this need, five research questions were formed:

1. To what extent does the sample of Thai lecturers report that they believe in or value learner autonomy?

2. To what extent does the sample of Thai lecturers report that they are confident in the students' ability to exercise autonomy in their learning?

3. To what extent does the sample of Thai lecturers report that they allow their students to exercise autonomy in their learning?

4. What factors may be associated with the trends identified in the quantitative results?

5. How has the concept of learner autonomy been operationalized in university language classrooms? 
The five research questions suggested the use of a mixed-method approach, which, in my study, started with a quantitative survey and was followed up in further depth by qualitative cases studies. Statistics obtained from the quantitative survey presents the existing state of the promotion of learner autonomy, in which Thai lecturers reported high belief in learner autonomy, but moderate effort towards putting it into practice. Furthermore, the lecturers tended to be lacking in confidence with respect to their students' ability to be autonomous learners. These findings from the quantitative phase needed further explanation.

Given the nature of closed-ended questions which limited the "breadth" of the participants' responses (Hesse-Biber, 2010, p.462), the quantitative data did not allow a broader understanding of the phenomenon and was not able to provide an explanation for the quantitive results. This raised a question that was answered by the multiple cases studies in the second phase of the research.

The second, qualitative phase was conducted with five participants selected from the first phases. Based on their responses in the questionnaire, two of these participants were categorized as strong supporters of learner autonomy; one as a weak supporter; and the other two as unconfident supporters. The analysis across the categorizes as well as across the five participants was done. This analysis resulted in the identification of tasks/activities and class elements that are currently used to promote learner autonomy. The identified strategies/activities were formed as a framework that might serve as a preliminary guideline for promoting learner autonomy.

The analysis of the qualitative phase further yielded an insight into factors that impact on the lecturers' practices of promoting learner autonomy. These factors include the lecturers' theoretical and pedagogical knowledge pertaining to learner autonomy; the climate in their university; their 
students' attributes; and the socio/cultural environment. Linking quantitative findings to qualitative findings has shaped a pathway for the promotion of learner autonomy in Thailand, in which teachers' practices of promoting learner autonomy are mediated by the interplay of the mentioned four factors.

Table 7.1 delineates three main findings from the quantitative and qualitative data:

Table 7.1

Summary of Research Findings

Existing State of Learner Autonomy

- A discrepancy between beliefs and practices (strong beliefs but moderate practices)

- $\quad$ Low confidence in students' ability to direct their own learning

Autonomy-supportive Classroom Practices

- Autonomy-supportive communication: use of empowering language, use of "you" attitude, and choice of question type

- Autonomy-supportive instructional methods: collaborative learning, task-based approach, learning- strategy instruction, and freedom in textbook use

- Autonomy-supportive atmosphere: constructivistic idea of knowledge, optimal degree of freedom, and lecturer's sense of humor

Mediators of Lecturers' Beliefs and Practices

- $\quad$ Lecturer attributes

- Organizational climate

- Thai contexts: Cultural, social, and educational

- $\quad$ Student attributes

Taken together, the quantitative and qualitative information obtained create "complementary insights" and a "bigger picture" (Brannen, 2005, p.12) of the state of learner autonomy in Thailand. 


\section{Contributions of the Study}

This study has two main contributions: theoretical and applied. The thesis contributes to the theory of learner autonomy by giving a model to understand learner autonomy in its wider contexts (Figure 7.1). The model indicates that learner autonomy is not merely what happens in classroom, and stresses cooperation from members of contexts outside the classroom in facilitating the successful pursuit of learner autonomy. The applied contributions centre around classroom practices. The outcomes of the research provide strategies/activities that lecturers may adopt in their teaching to promote learner autonomy. The research also suggests the concepts lecturers should incorporate in their practices of promoting learner autonomy. The strategies and concepts suggested are not limited to classrooms in Thailand, but also classroom practices in other contexts which have contextual, cultural and educational elements similar to Thailand.

The research also specifically gives recommendations for practices of learner autonomy in Thailand, by highlighting areas that need to be taken into account in order to facilitate the promotion of learner autonomy in the country.

\section{Contribution to the Field of Learner Autonomy}

The outcomes of the research findings give rise to the conceptualization of learner autonomy as illustrated in the model in Figure 7.1. In this model, learner autonomy is built upon the concept of human autonomy in SDT, in which autonomy is a basic need of human beings and does not signifies a dichotomy of dependency versus independence (Deci \& Ryan, 1985). The model signifies a need to take wider contexts into account in the promotion of learner autonomy. 


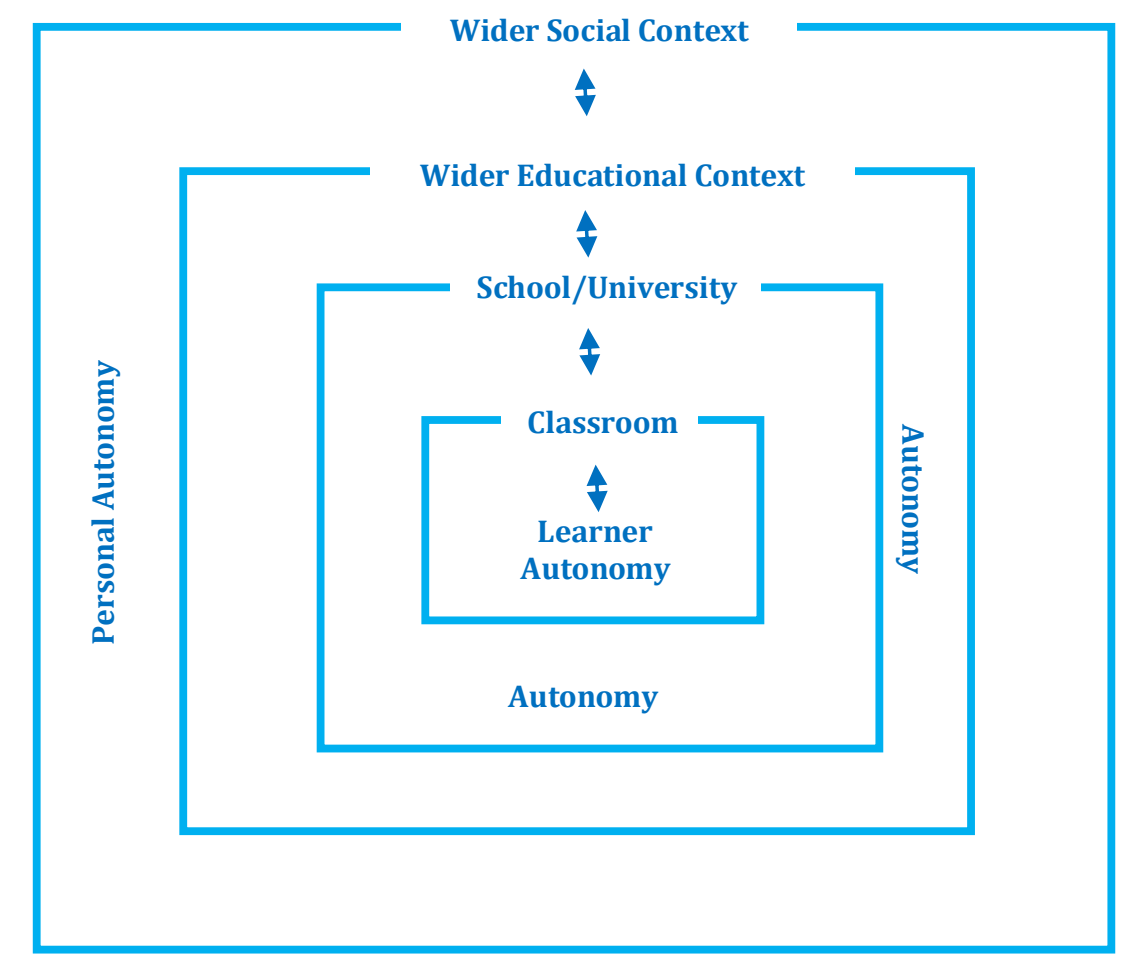

Figure 7.1. Learner Autonomy in its wider contexts

The model illustrates the interaction of learner autonomy, personal autonomy, and the surrounding contexts of an individual. In line with the concept of personal autonomy in SDT, the model signifies autonomy as the basic need of members of all societies and suggests the impact that elements in a context have on the autonomy of its members (Deci \& Ryan, 1985). According to this model, a learner is part of a number of layers of contexts, starting from the immediate layer of the classroom context to the larger layer of his/her country. Each layer is part of the wider contexts (e.g. a classroom is the immediate layer of students and is part of a school/university, the educational systems of a country, and finally of the country). Students are members of the classroom as well as members of the wider contexts (i.e. of the school/university, of the national educational systems, and of the nation). To understand the development of learner autonomy, then, one needs to look beyond the immediate environment of the classroom (i.e. to the social/cultural environment of wider contexts such as community or a country). 
On the basis of the evidence provided by my research, the proposed model views learner autonomy as a nurtured-capacity and one that is contextsensitive. That is, a learner was not born to be autonomous, but can be assisted to be so, given the opportunities furnished by his/her immediate environment as well as his/her interactions with more complex, larger contextual layers. The degree of autonomy of a learner can be high or low in different contexts as contextual elements influence the autonomy of its members, either by support or thwarting it (Deci \& Ryan, 1985). In this regard, the extent to which a learner is autonomous is dependent on the quality of the environments that the learner is situated within. If elements in the learner's immediate environment (e.g. in class or in school are supportive of autonomy, the learner is likely to be autonomous in their learning). As the model proposed that autonomy is context-sensitive, a learner might be more autonomous in one class and less autonomous in other classes, depending on the extent that the teacher facilitates it in classroom. There might also be situations that some learners have been raised to be dependent on their parents, but in the classroom they might be more autonomous given that they are assisted by their teachers to take charge of their learning.

The two-headed arrows in the model in Figure 7.1 illustrate the bi-directional impact of contexts in each layer on the others. The findings from both phases of my study indicate that elements in wider social environments of a country, (e.g. social norms, ideologies of proper practices of its members, and cultural expectations of the roles of teachers/students) influence its smaller contexts (e.g. the country's educational systems, the national curriculum, and university entrance examination policy). The educational systems, in turns, have influences on schools' policies, missions, and codes of conduct for teaching staff and students. That is, social norms and values determine what is proper conduct of students and lecturers, and further influence the mission of a school (such as requiring students to pass the university entrance examination). The school policies/ missions, in turn, signify classroom practices of individual teachers. 
At the same time, the smaller units of context (e.g. the classroom) have influences on the bigger units in the society. Students whose elements in classroom support their autonomy may grow up as autonomous adults and may seek to manage elements in their wider contexts (e.g. their workplace and their community) to support autonomy of its members. In line with this, if education is to fulfill autonomy of students, elements in educational contexts should be managed in ways that facilitate students to exercise their autonomy. Classrooms then should be a scaffold for students to build up their autonomy.

The proposed model starts from classroom as a small unit of a learner's life to the bigger units of their life such as their community. Ideally, the ultimate end of the model suggests that autonomous learners should grow up as autonomous members of their wider contexts (e.g. their workplace, their community and their nation). In order to do so, elements of each context, then, should support the autonomy of its members.

\section{Contribution to Classroom Practices}

The strategies/activities that the lecturers in this study used to promote learner autonomy, as presented in Chapter 5, reflect three key concepts that underpin the promotion of learner autonomy. They are the concepts of the shift of responsibility, power symmetry, and dialogic teaching. These concepts are interwoven and achieved through the combined use of classroom strategies. Classroom components and strategies that contribute to these concepts are conceptualized a framework in Figure 7.2. 

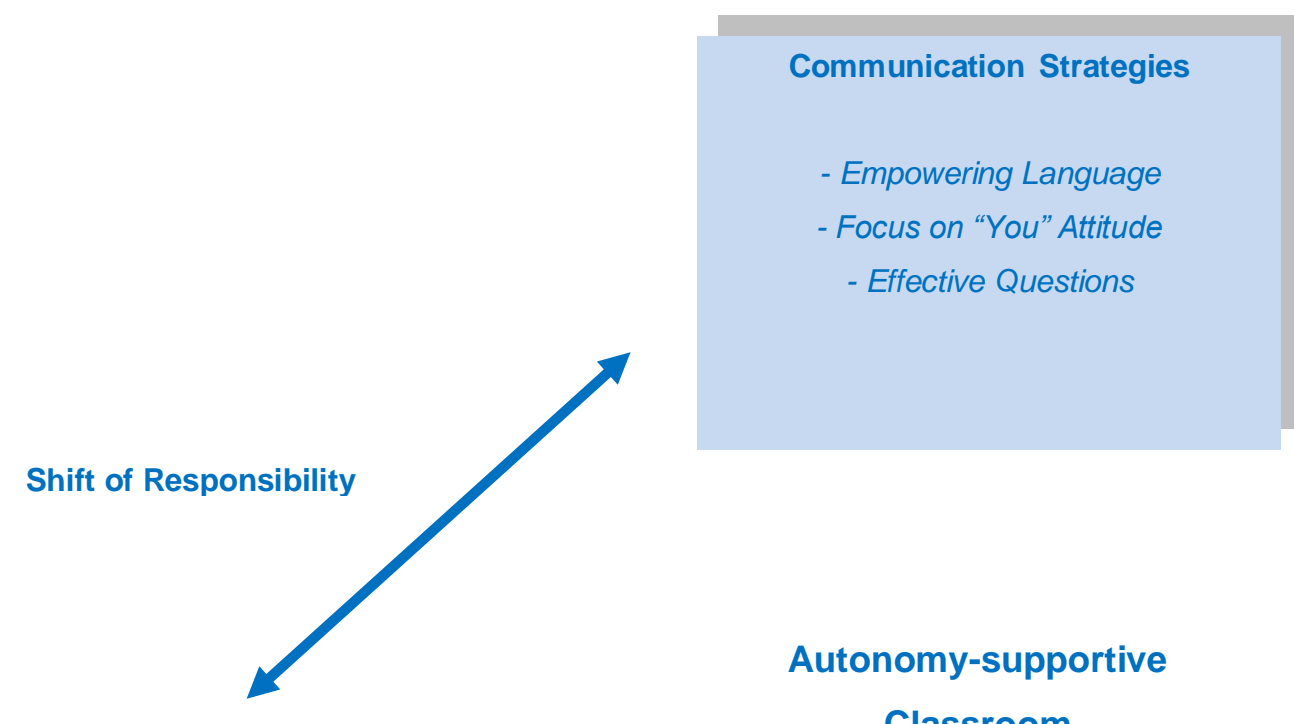

Classroom

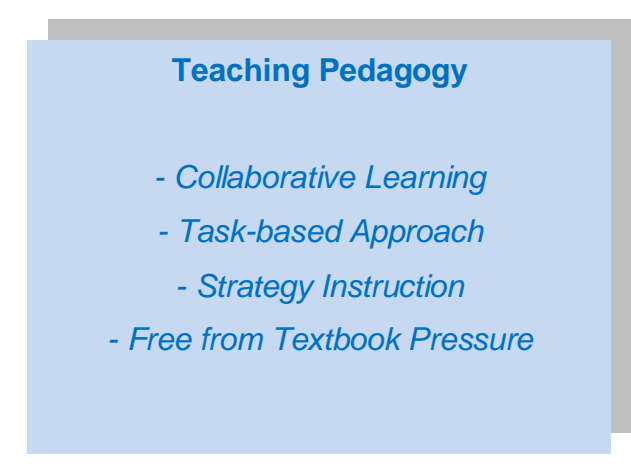

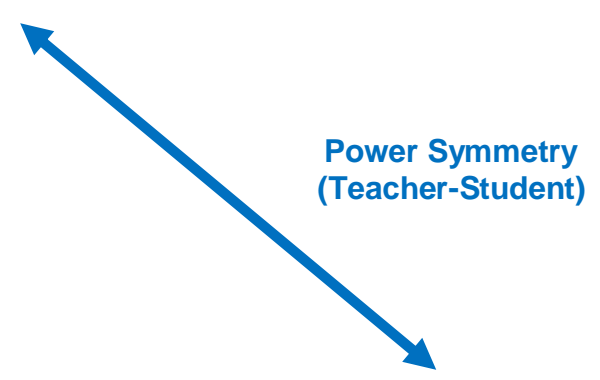

Classroom Atmosphere

Constructivist View of Knowledge

- Optimal Degree of Students'

$$
\text { Freedom }
$$

- Teacher Sense of Humour

Figure 7.2. A framework of strategies and concepts underpinning the promotion of learner autonomy 


\section{Dialogic teaching.}

Through a collaborative learning and task-based approach, students are engaged in the social dimensions of learning, as students help each other to accomplish the common goals of their own group. These strategies reflect a move away from didactic teaching, which has the teacher as a center of classroom, to dialogic teaching, in which students play an active role in their own learning (Lyle, 2008a).

Dialogic teaching puts an emphasis on collaborative talk among students. Through this talk students make sense of their own learning. Thus, the function of teachers in dialogic teaching is to organize classroom to "harness the power of talk to engage children, stimulate and extend their thinking, and advance their learning and understanding" (Alexander, 2004, p. 37). This signifies the social dimensions of learning. As Lyle (2008a) asserted, it is through genuine dialogues with their peers in collaborative settings that students engage in the "co-construction of meanings" (p.229).

Dialogic teaching also embraces a constructivist view of knowledge. This is because in dialogic teaching practices, students' voices are valued and knowledge is constructed by students, not by transmission from the teacher. In addition, my classroom observations indicated that dialogic teaching was facilitated through an optimal degree of freedom that the lecturers bestowed to students. Lecturers cultivate a spirit of freedom in students, particularly freedom of though and expressing oneself by accepting different patterns of interaction. Questions that the lecturers ask do not have pre-specified answers to (Lyle, 2008a). Instead, the lecturers adjust discourses in the class to fit the students' responses and students' responses are included in the following dialogue (Nystrand, Gamoran, Kachur, \& Prendergast, 1997). In this sense, collaborative talk is not limited to interactions between students in their small group work; it instead can include collaborative talk throughout the whole classroom (Lyle, 2008b). 
A dialogic teaching classroom, then, is conceptualized as a learning community in which learners as its member create "knowledge as part of doing things with others" (Watkins, 2003, p.38). This kind of learning community challenges the predominance of teachers' voices and, instead, nurtures students' contributions, engagement and responsibility in their learning. Because of this, classroom activities that engage students in collaborative talk in meaning-making processes can be used to create opportunities for students to exercise their own autonomy (Alexander, 2004).

\section{Power symmetry.}

The asymmetric power relationship between teachers and students in classrooms might hinder autonomous learning (Dongmei, 2007; Lo, 2010). The asymmetry of the power in classroom results from the perceptions of teachers as an authoritarian figure playing a dominant role in students' learning (Januin, 2007). In many Asian countries, an orientation toward collectivism can intensify the power asymmetry in classrooms (Littlewood, 1999). Compounded by a collectivist orientation, in Thailand in particular, the power asymmetry in classroom is even stronger given the historical background of education, which was originally administered by monks (Baker, 2008). Teachers are perceived as being in a high position and students are not in the position to question the teachers. Within the classroom, where the teachers are perceived in a "traditional authoritarian view" students are likely to view themselves more as the "consumer", instead of a "producer" in their own learning process (Dongmei, 2007, p. 130)

The model in Figure 7.2 illustrates that the lecturers can use empowering language and focus on a "You" attitude in order to reduce the tension from the asymmetric power relationship. The lecturers use such language to convey the equality of students and teachers in their contribution to the learning community, suggesting an environment where students' active contribution to classroom activities is valued. My classroom observations 
show that the lecturers could also trigger their students' spirit of questioning and critical thinking by asking questions that are open to multiple answers, instead of those that require recitation and memorization. In a similar vein, a classroom atmosphere which embraces a constructivist view of knowledge, students' freedom and a teacher's sense of humour enable the lecturers to reduce the power asymmetry. These elements in a classroom atmosphere create a supportive environment where students' voices are valued and students feel safe and confident to speak out. As Niemiec and Ryan (2009) pointed out, the teacher can support their students' autonomy by minimizing any sense of coercion in the classroom as well as by maximizing students' perceptions of having a voice in their academic life.

\section{Shift of responsibility.}

Learner autonomy signifies students' acceptance of responsibility for their own learning (Boud 1981; Cotterall, 1995, 1999; Scharle \& Szabó, 2000). It is necessary for teachers to help students to realize and accept that the learning process is the students' responsibilities. Findings from my study show that the lecturers could facilitate this process through the language they use with their students, that is, by incorporating "You" attitudes and the empowering terms into their language. In addition, questions asked can encourage students to give active involvement into the learning process if the questions are open alternative ways to answer. Lecturers may also answers students' questions by questions or suggest students alternatives sources to find out the answers. This is one way for lecturers to increase students' recognition that it is students' own responsibility to take care of classroom activities.

The transference of responsibility from the lecturer to the students is also reflected in the use of collaborative learning activities. While working with peers to accomplish a given task, students feel less anxious, experience a sense of shared control and gain a degree of empowerment (Ioannou \& Artino, 2010). When the sense of shared control and empowerment are increased, students enjoy learning and feel safe to take responsibility in their 
learning process (Wanpen \& Fisher, 2004). Scharle \& Szabó (2000) regarded opportunities given students to analyze, synthesize, and evaluate ideas when collaborating with their peers in pairs or in groups as a way to let them share the responsibility of their own actions. It signifies students' capacity to reflect on their own learning process and be conscious that the learning is under their control (Little, 1995).

\section{Contribution to the Promotion of Learner Autonomy in Thailand}

The outcomes of this study provide a framework of teaching methods, classroom management and underlying concepts appropriate for the promotion of learner autonomy in Thai contexts. This framework, as presented in Figure 7.2, indicates that the promotion of learner autonomy in Thailand should involve the incorporation of the concepts of the shift of responsibility, power symmetry and dialogic teaching into classroom teaching. Despite this, the framework in Figure 7.2 illustrates that no one strategy is sufficient for promoting learner autonomy, and is not intended to be a prescription for the promotion of learner autonomy.

In addition to the teaching strategies/activities and the concepts that should be incorporated when promoting learner autonomy, the research identified factors pertaining to lecturers, students, workplace, and social milieus that exist in Thai contexts. The interplay of these factors represents a hidden mechanism that might prevent lecturers from translating their belief in learner autonomy into actual practice. The interplay of factors presented in the pathway of the promotion of learner autonomy (Figure 6.1) indicates that there are several possibilities that Thai teachers will encounter inconsistencies in their beliefs and practices, and this signifies a need to empower lecturers to overcome these factors or manage them in way that facilitates the promotion of learner autonomy.

Based on the conceptualization of learner autonomy in its wider contexts (Figure 7.1) as well as the understanding of the complexities of the factors 
that might challenge the promotion of learner autonomy (Figure 6.1), the following are recommendations for practice. These practices should help reduce pressures that impose on Thai lecturers, and in turn, minimize the inconsistencies of their beliefs and practices pertaining to learner autonomy. The recommendations signify what members of wider contexts, in addition to lecturers in the classroom context, should do in order to facilitate the promotion of learner autonomy in Thailand.

\section{Managing professional development.}

The implementation of learner autonomy may cause fear, uncertainly and questions among lecturers who may not have experience and a true understanding of the concept. Thus, prior to an effort to commence promotion, university administrators, education planners and policy makers need to make sure that lecturers understand the principles of the concept.

The inability of lecturers to translate their belief into actual practice found in my study might be reflective of insufficient continuing professional development. Furthermore, the fact that university lecturers do not receive teacher education becomes another factor that intensifies the need for professional development in Thailand. Most university lecturers come directly from a master's in education or the career related to their discipline. They have expertise in their disciplines, whereas their skills to manage their classes in ways that foster learner autonomy might be limited. The preservice training they receive before entering their career path might not be enough to equip them with the skills and knowledge they need for promoting learner autonomy, as well as for success in the entire career in general.

Based on these findings, my study implies a need for professional development as a process that should occur hand in hand with the promotion of learner autonomy. Professional development should be implemented in ways that boost lecturers' capability to act on their belief in learner autonomy. Lecturers may recognize the inconsistencies between their beliefs 
and their actual practices, but tend to keep quiet and adopt old teaching strategies. This happens because lecturers might be aware of their "low status of their own voice" (Vieira, 2000, p.232). To remedy this, the findings from my study imply a need for development programs, which should help lecturers realize the significance of making their voices heard within their professional community.

How professional development should be implemented needs further investigation. It has to be seen as a "collective responsibility" (Bubb \& Earley, 2007 , p. 6) of both staff and the university, that is, the university as the employer has to provide professional development opportunities for teachers. Professional development should aim to increase lecturers' understanding of the principles of learner autonomy, and classroom practices supportive the students' development of autonomy. Importantly, professional development should not be treated as a mere series of workshops or training, but a continuous, life-long learning process in which lecturers act as an active learner engaging in "on-going process of education, training, learning and support activities" (Bubb \& Earley, 2007, p. 6). In this sense I suggest the implementation of professional development for lecturers as a process which occurs in tandem with the promotion of learner autonomy, and which should reciprocally benefit each other.

\section{Resolving lecturers' tensions from organizational demands.}

In addition to empowering lecturers through professional development, it may be beneficial to reduce the tensions and difficulties occurring from required daily work that lecturers experience. Administrators might have more personnel to handle such administrative work as assessment committees, project committees, and examination invigilation. Administrators could encourage their lecturers to go beyond textbooks and employ innovations in teaching by having more personnel to help lecturers cope with technical issues e.g. technicians, homepage consultants and laboratory officers. This is because a number of lecturers give up their 
intention to implement technology to help students to learn autonomously such as the use of computer, virtual classrooms, or do not encourage students to use laboratories, due to their own anxiety about using it.

Some universities could also increase the level of learning materials and resources so that lecturers have more options for their teaching. One way to do this is to consult lecturers to find out what they need. In doing so, lecturers will feel empowered as their voices are valued by this action (Vieira, 1997). Care should be taken when dealing with tangible materials and resources, however. It is not the material itself that thwarts or supports learner autonomy; instead it is how the material is administered. For example, the presence of students in self-access centres is not an indicator that learner autonomy is really taking place. Thus, the university as well as lecturers should have some structure to ensure that students are using the materials and resources in an autonomous manner. This might be done by having a staff at the self-access centers or library who can advise students as to how to learn autonomously with materials and resources.

Students' feedback in the staff promotion system need to be used with discretion as it might impose pressure on teachers. To reduce such pressure, Burden (2009) suggested that rationales as well as consultation for its operations need to be fully explained to the users (i.e. administrations, students and teachers). Instead of focusing on a summative purpose which allows management to make decisions about promotion or retention, the evaluation should focus on informative feedback that lecturers can use to improve their teaching. Its implementation should enhance lecturers' morale and sense of ownership so that recommendations resulting from it are used for real improvement in teaching. Furthermore, the promotion system should not be based on students' rating as the sole criteria and feedback should be used with discretion (Yao \& Grady, 2005). There is also the need for new timing of evaluation in many universities in Thailand, which typically take place in the last week of the semester. With evaluation occurring at this 
time, lecturers might not be able to use the students' feedback to improve their teaching in the course's lifetime. The evaluation could alternatively be undertaken at mid-semester and questions in the evaluation could elicit formative feedback for teaching improvement during the lifetime of the course (Burden, 2009).

\section{Increasing students' motivation.}

Unmotivated and extrinsically motivated students were identified in my study as one of the factors that results in difficulties in the promotion of learner autonomy. Lecturers and universities should enable students to perceive pragmatic benefits of language proficiency and of learner autonomy. Language knowledge should not be viewed as just a fulfillment of the required credits. Lecturers as well as university administrators must create chances for students to see the link between possessing language competence and future career advancement, and ultimately better quality of life. Students should be made aware of the necessity of having a good command of that language if they want to be competitive in the working world. The connection of classroom language lessons with authentic contexts outside it will help students to realize the usefulness of language competency and see how to apply it in real life outside the classroom. Universities located in rural areas may need to introduce more challenges to students' learning environment to stimulate students' interest in learning a foreign language. This is because students are likely to be more motivated to learn in the learning environment where there are "optimal challenges, rich sources of stimulation..." (Deci \& Ryan, 1985, p.245).

Once students are motivated to learn, they should also be motivated to learn autonomously. Students can be motivated to be autonomous when they are aware of the value of exercising autonomy in their own learning. According to SDT, people feel motivated to do an activity when they see the value of doing it (Deci \& Ryan, 1985). Lecturers as well as university administrators will need to create occasions where students can see the value of possessing 
autonomous learning skills. To raise students' motivation to take control of their own learning, lecturers need to demonstrate why learner autonomy is essential to language learning. Better learning outcomes, an increased sense of self-esteem, development of skills needed for mass higher education and autonomous user of languages in the future are examples of rationales lecturers might give to their students. Field trips and site visits of companies where students are engaged in foreign language communication will enable students to see that to remain competitive in their future job, they need to develop life-long learning skills. In the working world professional staff needs to update their knowledge and competencies, which means that their life always involves a life-long learning process. Students should be able to realize that their university life is a scaffold for their professional life, in which learning is a life-long process.

The scenario presented above may represent an extrinsic motivation to learning because the learning is treated as an instrument to separable consequences. But the findings in this study suggest that in some situations extrinsic motivation is still necessary, such as in many university contexts, particularly those in rural areas of the country. As SDT posits, although intrinsic motivation is an essential basis for learning, many tasks and learning activities that students are required to perform are not enjoyable in and of themselves and are not designed to be intrinsically interesting (Ryan \& Deci, 2000a). Lecturers can extrinsically motivate their students to perform learning activities with a degree of autonomy through the process of internalization and integration. Lecturers can facilitate these processes by helping students to perceive the meaning and importance of the activity (Deci et al., 1996). Explaining reasons as to why people should put effort into doing an activity is suggested by Reeve et al., (2002) as a way to encourage such a process. Importantly, the rationale needs to be delivered to students in a noncontrolling way so that students perform activities with "an attitude of willingness that reflect an inner acceptance of the value or utility of a task" (Ryan \& Deci, 2000b, p. 55). 


\section{Negotiating Thai vales.}

The conceptualization of learner autonomy that arises from the outcome of this research (Figure 7.1) suggests that the growing of learner autonomy does not depend solely on the teacher, and does not merely occur in the classroom. Instead, the promotion of learner autonomy needs cooperation from other members of wider society. In such a sense, certain values that Thais hold, particularly the concept of obedience, conformity, and appropriate behavior, should be modified as they have an impact on the concept of appropriate learning behaviors.

Rather than overemphasizing on conformity and obedience, Thais should nurture a spirit of self and free expression. Conformity and unquestioned acceptance should not be viewed as a way to express gratitude to the teacher. To repay gratitude to the teacher can be done in many other ways, such as by being autonomous in their own learning, because by being so they can take control of their own life. Autonomy in one's own life should be viewed as the ultimate goal of education and the goodness that their teachers who are their second parents want to see in students.

To negotiate these cultural values, lecturers should be open-minded and make it clear to their students that to question is actually to question the information received, not the question the lecturers themselves. In doing so, lecturers need to view leaner autonomy through a new lens, that is, learner autonomy is not a loss of the high status of teachers. Rather, learner autonomy entails teachers' essential role in creating environments that gear students to speak for themselves and value their own contribution. Schools and universities, then, become the place where students go to construct their own knowledge, rather than receive it.

Finally, the promotion of learner autonomy in Thai contexts needs to take into account Thai students' tendency towards collectivism and their acceptance of the high status of teachers. Thus, learner autonomy in Thai 
sense may not have to focus on individualism. Rather, autonomy may start from social end of autonomy and progress towards the individual end of autonomy. As Benson (1996) suggested, the social dimensions of autonomy may be more appropriate to Asian culture.

\section{Research Limitations}

The first limitation of the study is related to the questionnaire used in the first phase. The questionnaire was not originally intended for use by lecturers, nor was it based in research in the Thai tertiary context. As a result, there might be dimensions of learner autonomy or lecturers' perspectives and practice which were not captured by that choice of questionnaire. The self-report nature of the questionnaire may elicit response distortion. Some responses may be a reflection of socially desirable responses rather than reality. Furthermore, the rating-scale items might not precisely and adequately assess the participants' beliefs, confidences and practices. The questionnaire could have included more items to measure the constructs and to reduce measurement error. The addition of a box which elicited additional comments might also have enriched the data that was gathered. But this may have made the time required to fill it in burdensome for the participants and may have reduced the number of questionnaires returned.

The use of interviews in the qualitative phase of the study may have produced some response distortion, as some participants in this phase may provide responses which are more socially desirable than truthful. Furthermore, the study did not survey, interview or observe students, university administrators or university staff. As a result, the findings related to students, workplace, and social milieu were grounded in the lecturers' perceptions.

Another limitation of the study is related to the participants. They were language lecturers from universities located in southern Thailand, Bangkok, and its vicinities. The study did not cover universities in all regions of the 
country, due to the total number of universities, which is up to 167 excluding branch campuses. Moreover, these universities are geographically dispersed. However, the purposive sampling for the second phase of the study enabled me to recruit the lecturers that represent each category of support for learner autonomy: strong, unconfident, and weak. By getting the right participants, I was able to gain the appropriate data to answer the research questions.

\section{Implications for Future Research}

The study represents a first step to investigate the promotion of learner autonomy in Thailand's higher education system from the perspectives and practices of the lecturers. Findings from the study might be used as a baseline for future research to draw on. Firstly, the study suggests the inconsistencies between lecturers' beliefs and practice, and presents possible factors that contribute to the inconsistencies. This was conceptualized as a pathway from lecturers' beliefs to practice, which indicates that a lecturer's decision for choice of teaching methods is complex. However, the proposed pathway was conceptualized from the data provided by the participants, and was not tested. Future research might need to test this pathway and examine how different lecturers with different personal background and in different contexts will respond to each of the suggested factors. Results from such a study might give rise to a solution to the inconsistencies between beliefs and practice.

My study suggests that one way to resolve the inconsistencies between lecturers' beliefs and practice is to implement professional development. Future research, then, might be needed to explore how to implement professional development to suit Thai educational contexts, and establish a link between professional development and the outcomes of the lecturers taking part in professional development. Future study may also include the search for activities that contribute to an increase in the lecturer's likeliness to promote learner autonomy. Research in this area would reflect the impact 
of professional development on the lecturer's classroom behaviours (Logan \& Moore, 2004; Patrick, 2008)

Future study might be needed to investigate perspectives and practices of the students of lecturers who take part in the study of professional development in order to measure the effectiveness of professional development. The comparisons of two groups of students - one whose the lecturer undergoes professional development and the other whose the teacher does not - would enable one to see the outcome of the implementation of professional development on students' perspectives. This area of research would reflect the impact of teachers' classroom behaviors on students' perceptions, which is prominent under SDT (Black \& Deci, 2000; Zhou, Ma \& Deci, 2009)

My study also proposes a framework of teaching strategies/ classroom activities that might be used to promote learner autonomy. Future research on the implementation of the suggested strategies in the framework would enable lecturers/course designers to make informed decisions as to how to incorporate them into their courses. An experimental study which has a control group might enable the examination of the effectiveness of the strategies suggested. This calls for an inclusion of student participants in addition to lecturer participants in the future study.

Finally, my study might be replicated to examine the promotion of learner autonomy in other subjects as well as in other levels of education. Other sources of data, such as students, administrators, policy makers, and parents would enable a greater variety of perspectives, and reflect the wider picture of the existing state of learner autonomy in Thailand. 


\section{Concluding Statement}

In Thai higher education the promotion of learner autonomy is not mandated; Thai lecturers have the freedom to reject or adopt it in their teaching practices. Despite my emphasis on the significant role that teachers play in assisting their students to be autonomous, learner autonomy is not just about what happens in classroom, and it is not only the teacher who can help students. Learner autonomy, then, is not just what the education system, the teachers, and the university can offer to students. Instead, students should be encouraged to take control of every part of their life, and their environment in which they learn and live should be conducive to exercising their autonomy. Care should be taken, however, when promoting learner autonomy. The framework of strategies that I have presented in this thesis serve as a primary suggestion, and is not intended to be a prescription that must be strictly followed. Lecturers, administrations and all parties involved will need to adapt it to suit their students and contexts.

Although certain features of Thai contexts and education may thwart the fulfillment of students' autonomy, perspectives and practices of the lecturers reported in this thesis suggest the potential to promote learner autonomy in Thailand. There is nothing wrong with Thai values and Thai ways of living. Obedience, seniority and a highly respectful view of teachers are the root of being Thai and the virtue of the nation. To gain one thing, one does not need to lose the other. To promote learner autonomy in Thai students, thus, does not mean that we are teaching our young generation to abandon these virtues.

I would conclude then that learner autonomy can be promoted in Thailand. This is because learner autonomy is not an educational or social reform, but a basic need of students which needs to be satisfied in every level of their academic life. 


\section{${ }^{1}$ References}

*Abar, B., \& Loken, E. (2010). Self-regulated learning and self-directed study in a pre-college sample. Learning and Individual Differences, 20(1), 25-29.

Aksornkul, N. (1980). EFL planning in Thailand: A case study in language planning. Unpublished doctoral dissertation, Georgetown University, Washington DC, USA.

Alexander, P.A., \& Winne, P.H. (2006). Handbook of educational psychology (2 ${ }^{\text {nd }}$ ed.). Mahwah, NJ: Lawrence Erlbaum Associates.

Alexander, R. (2004). Towards dialogic teaching: Rethinking classroom talk. Cambridge, England: Dialogos.

*Alexiou, A., \& Paraskeva, F. (2010). Enhancing self-regulated learning skills through the implementation of an e-portfolio tool. Social and Behavioral Sciences, 2(2), 3048-3054.

Alpert, B. R. (1987). Active, silent and controlled discussion: Explaining variations in classroom conversations. Teaching and Teacher Education, 3(1), 29-40. doi: 10.1016/0742-051X(87)90032-1

*Anantasate, B. (2001). The development of a teaching and learning process to promote learners' autonomy for university students Unpublished doctoral dissertation, Chulalongkorn University, Bangkok, Thailand.

*Anderson, S., \& Bourke, B. (2007, October). Beyond the classroom: SILK for promoting autonomous Kanji learning. Paper presented at the Independent Learning Association 2007 Japan Conference: Exploring theory, enhancing practice: Autonomy across the disciplines. Kanda University of International Studies, Chiba, Japan.

*Anderton, B. (2006). Using the online course to promote self-regulated learning strategies in pre-service teachers. Journal of Interactive Online Learning, 5(2), 156-177.

\footnotetext{
${ }^{1}$ Citations marked with an asterisk indicate studies that were included in the systematic review of literature.
} 
Areglado, R. J., Bradley, R.C., \& Lane, P. S. (1996). Learning for life: Creating classrooms for self-directed learning. CA: Corwin Press.

Auerbach, E. (2007). Commentary on part one: Necessary contradictions and beyond. In A. Barfield \& S.H. Brown (Eds.), Reconstructing autonomy in language education: Inquiry and innovation (pp. 84-92). NY: Palgrave Macmillan.

Aviram, A. (2000). Beyond constructivism: Autonomy-oriented education. Studies in Philosophy and Education, 19(5-6), 465-489. doi: 10.1023/A:1005267111741

*Bakar, N.A. (2007, October). Technology and learner Autonomy: Teachers' and students' perceptions towards learner autonomy in a computer-based learning environment in a Malaysian context. Paper presented at the Independent Learning Association 2007 Japan Conference: Exploring theory, enhancing practice: Autonomy across the disciplines. Kanda University of International Studies, Chiba, Japan.

Baker, W. (2008). A critical examination of ELT in Thailand: The role of cultural awareness. RELC Journal, 39(1), 131-146. doi: $10.1177 / 0033688208091144$

Baker, C., \& Phongpaichit, P. (2005). A history of Thailand. New York, NY: Cambridge University Press.

*Balcikanli, C. (2007, May). The investigation of the instructors' attitudes towards learner autonomy at Preparatory School. Paper presented at the Language Teaching and Learning in Multilingual Europe International Conference, Vilnius University, Vilnius, Lithuania. Retrieved from http://websitem.gazi.edu.tr/balcikanli/DosyaIndir Bandura, A. (1977). Social learning theory. Englewood Cliffs, NJ: Prentice Hall.

Barnes, D. (1992). From communication to curriculum (2 ${ }^{\text {nd }}$ ed.). Portsmouth, NH: Heinemann.

Bell, J. (2008). Reading between texts: Thai postgraduate students' 
intellectual framing and metacognition use in reading. The Reading Matrix, 8(2), 39-54.

Benson, P. (1996). Concepts of autonomy in language. In R. Pemberton, E. S. L, Li, W.W. F. Or, \& H. D. Pierson (Eds.), Taking control: Autonomy in language learning (pp. 27-34). Hong Kong: Hong Kong University Press.

Benson, P. (2008). Teacher's and learner's perspectives on autonomy. In T.Lamb \& H. Rienders (Eds.), Learner and teacher autonomy: concepts, realities and responses (pp. 15-32). PA: John Benjamins.

Benson, P., \& Voller, P. (1997). Introduction: Autonomy and independence in language learning. In P. Benson \& P. Voller (Eds.), Autonomy and independence in language learning (pp. 1-12). London: Longman.

*Bhattacharya, A., \& Chauhan, K. (2010). Augmenting learner autonomy through blogging. ELT Journal, 64(4), 376-384.

doi:10.1093/elt/ccq002

*Black, A. E., \& Deci, E. L. (2000). The effects of instructors' autonomy support and students' autonomous motivation on learning organic chemistry: A self-determination theory perspective. Science Education, 84(6), 740-756.

Bloom, B., Englehart, M. Furst, E., Hill, W., \& Krathwohl, D. (1956). Taxonomy of educational objectives: The classification of educational goals. Handbook I: Cognitive domain. NY: Longman.

*Bolhuis, S., \& Voeten, M.J.M. (2001). Toward self-directed learning in secondary schools: What do teachers do? Teaching and Teacher Education, 17(7), 837-855.

Borg, S. (2003). Teacher cognition in language teaching: A review of research on what language teachers think, know, believe, and do. Language Teaching, 36(2), 81- 109. doi: 10.1017/S0261444803001903

Borg, S. (2006). Teacher cognition and language education: Research and practice. London: Continuum.

Boud, D. (1981). Towards student responsibility for learning. In D. Boud 
(Ed.), Developing student autonomy in learning (pp. 21-37). London: Kogan Page.

Bowen, G.A. (2009). Document analysis as a qualitative research method. Qualitative Research Journal, 9(2), 27-40. doi: 10.3316/QRJ0902027 Boyatzis, R.E. (1998). Transforming qualitative information: Thematic analysis and code development. Thousand Oaks, CA: Sage.

Brannen, J. (2005). Mixed-methods research: A discussion paper. ESRC National Centre for Research Methods. Retrieved from http://eprints.ncrm.ac.uk/89/1/MethodsReviewPaperNCRM-005.pdf Brantley, C.P., \& Miller, M.G. (2005). Effective communication for colleges. (11 ${ }^{\text {th }}$ ed.). Canada: Thomson South-Western.

Braun, V., \& Clarke, V. (2006). Using thematic analysis in psychology. Qualitative Research in Psychology, 3(2), 77-101.

Breen, M.P., \& Mann, S.J. (1997). Shooting arrows at the sun: Perspectives on a pedagogy for autonomy. In P. Benson \& P. Voller (Eds), Autonomy and Independence in Language Learning (pp.132149). Harlow: Longman.

Bubb, S., \& Earley, P. (2007). Leading and managing continuing professional development ( $2^{\text {nd }}$ ed.). London: Sage.

*Bullock, D. (2010). Learner self-assessment: an investigation into teachers' beliefs. Retrieved from http://eltj.oxfordjournals.org/content/early/2010/07/24/elt.ccq041. full

Burden, P. (2009). A case study into teacher perceptions of the introduction of Students Evaluation of Teaching Surveys (SETs) in Japanese tertiary education. Asian EFL Journal, 11(1), 126-149. Retrieved from http://www.asian-efl-journal.com/March_2009.pdf

*Butler, S. (1999). Catalysing student autonomy through action research in a problem centred learning environment. Research in Science Education, 29(1), 127-140.

*Büyükduman, I., \& Şirin, S. (2010). Learning portfolio (LP) to enhance 
constructivism and student autonomy. Social and Behavioral Sciences, 3, 55-61. doi:10.1016/j.sbspro.2010.07.012.

Carroll, M., \& Head, E. (2003). Institutional pressures and leaner autonomy. In A. Barfield \& M. Nix (Eds.), Learner and Teacher Autonomy in Japan 1: Autonomy you ask! (pp.69-86). Japan: JALT

*Carson, L. (2007). Relatedness and learner autonomy: A case study of an adult refugee learning English in Ireland. Reflections on English Language Teaching, 6(2), 21-38.

*Carter, B.A. (1999). Begin with beliefs: Exploring the relationship between beliefs and learner autonomy among advanced students. Texas Papers in Foreign Language Education, 4(1), 1-20. Retrieved from http://www.eric.ed.gov/PDFS/ED467863.pdf

Carter, B.A. (2006). Teacher/student responsibility in foreign language learning. NY: Peter Lang.

*Chantarasombat, C. (2009). Development of a management action learning process facilitating student-centered learning: Education management for local development course 0501803. The Social Sciences, 4(5), 424-427. doi: 10.3923/sscience.2009.424.427

*Charupan, S., Soranastaporn, S., \& Suwatttananand, N. (2001). The use of the Internet for ELT in Thai public universities. SLLT, 10, 38-50.

${ }^{*}$ Chen, C.S. (2002). Self-regulated learning strategies and achievement in an introduction to Information System course. Information Technology, Learning, and Performance Journal, 20(1), 11-25.

*Chinprahut, N. (2001). A development of data collection techniques and instrument for assessing self-directed learning in project activities of elementary school students. Unpublished master's dissertation, Chulalongkorn University, Bangkok, Thailand.

${ }^{*}$ Chiu, C.Y. (2008). The discourse of an English teacher in a Cyber Writing course: Roles and autonomy. The Asian EFL Journal, 10(1), 79-110.

*Chuk, J. (2004). Promoting learner autonomy in the EFL classroom: The 
Exploratory Practice way. In H. Reinders, H. Anderson, M. Hobbs, \& J. Jones-Parry (Eds.), Supporting independent learning in the 21st century. Proceedings of the inaugural conference of the Independent Learning Association, Melbourne September 13-14, 2003 (pp.57-74). Auckland, New Zealand: Independent Learning Association Oceania. *Clemente, M. A. (2001). Teachers' attitudes within a self-directed learning scheme. System, 29(1), 45-67. doi: 10.1016/S0346-251X(00)00045-2

Cohen, L., Manion, L., \& Morrison, K. (2007). Research methods in education (6 $6^{\text {th }}$ ed.). NY: Routledge.

Costa, L.(1997). Exploring the history of women's education and activism in Thailand. Journal of the Southeast Asian Studies Student Association, 1(2). Retrieved from http://scholarspace.manoa.hawaii.edu/bitstream/10125/2288/1/Ex ploring\%20the\%20History\%20of\%20Women's\%20Education\%20an d\%20Activism\%20in\%20T.pdf

*Cotterall, S. (1995). Readiness for autonomy: Investigating learner beliefs. System, 23(2), 195-205. doi:10.1016/0346-251X(95)00008-8

*Cotterall, S. (1999). Key variables in language learning: What do learners believe about them? System, 27(4), 493-513. doi: 10.1016/S0346251X(99)00047-0

*Cotterall, S., \& Murray, G. (2009). Enhancing metacognitive knowledge: Structure, affordances and self. System, 37(1), 34-45. doi:10.1016/j.system.2008.08.003

Crabbe, D. (1993). Fostering autonomy from within the classroom: The teacher's responsibility. System, 21(4), 443-452. doi: 10.1016/0346251X(93)90056-M

Creswell, J. W. (2005). Educational research: Planning, conducting, and evaluating quantitative and qualitative research ( $2^{\text {nd }}$ ed.). Upper Saddle River, NJ: Merrill.

Creswell, J. W., \& Plano Clark, V.L. (2007). Designing and conducting mixed methods research. Thousand Oaks, CA: Sage. 
Cronbach, L. J. (1951). Coefficient alpha and the internal structure of tests. Psychometrika, 16(3), 297-334. doi: 10.1007/BF02310555

Crossley, M., \& Vulliamy, G. (1984). Case-study research methods and comparative education. Comparative Education, 20(2), 193-207. Retrieved from http://www.jstor.org/stable/3098564

*Cubukcu, F. (2009). Learner autonomy, self-regulation and metacognition. International Electronic Journal of Elementary Education, 2(1), 53-64.

Darasawang P., Singhasiri, W., \& Keyuravong, S. (2007). Developing student support in self-access centers. In A. Barfield \& S.H. Brown (Eds.), Reconstructing autonomy in language education: Inquiry and innovation (pp. 167-179). NY: Palgrave Macmillan.

Daymon, C. \& Holloway, I. (2002). Qualitative research methods in public relations and marketing communications. NY: Routledge.

Deci, E. L., \& Ryan, R. M. (1985). Intrinsic motivation and self-determination in human behavior. New York: Plenum.

Deci, E.L., Ryan, R.M., \& Williams, G.C. (1996). Need satisfaction and the self-regulation of learning. Learning and Individual Differences, 8(3), 165-183.

Deci, E. L., Schwartz, A. J., Sheinman, L., \& Ryan, R.M. (1981). An instrument to assess adults' orientations toward control versus autonomy with children: Reflections on intrinsic motivation and perceived competence. Journal of Educational Psychology, 73(5), 642- 650. doi: 10.1037/0022-0663.73.5.642

*Delfino, M., Dettori, G., \& Persico, D. (2008). Self-regulated learning in virtual communities. Technology, Pedagogy and Education, 17(3), 195205.

Dickinson, L. (1987) Self-instruction in language learning. Cambridge: Cambridge University Press.

Dickinson, L. (1996). Learner autonomy 2: Learner training for language learning. Ireland: Authentik Language Learning Resources.

Dillon, J.T. (1978). Using questions to depress student thought. The 
School Review, 87(1), 50-63. Retrieved from

http://www.jstor.org/stable/1084745

Dimmock, C. (2000). Designing the learning-centred school: A cross-

cultural perspective. London: RoutledgeFalmer.

Dondero, G.M. (1997). Organizational climate and teacher autonomy:

Implications for educational reform. International Journal of

Educational Management, 11(5), 218-221.

*Dongmei, C. (2007, November). The experimental study on cultivating students autonomous learning competence in multimedia enhanced environment. Paper presented at the $1^{\text {st }}$ International Conference on Education Reform Mahasarakham University, Thailand.

*Drexler, W. (2010). The networked student model for construction of personal learning environments: Balancing teacher control and student autonomy. Australasian Journal of Educational Technology, 26(3), 369-385.

Durongphan, M., Aksornkul, N., Sawangwong, W., \& Tiancharoen, S. (1982). The Development of English teaching in Thailand: A Rattanakosin experience. Bangkok, Thailand: Aksorn Charoentat for Tahi/TESOL.

Eden. D.(2001). Who controls the teachers?: Overt and covert control in schools. Educational Management \& Administration Leadership, 29(97), 97-111.

Ellis, R. (2006). The methodology of task-based teaching. Asian EFL Journal, 8(3), 19-45.

*Erstad, 0. (2003). Electracy as empowerment: Student activities in learning environments using technology. Nordic Journal of Youth Research, 11(1), 11-28.

*Farajollahi, M., \& Moenikia, M. (2010).The compare of self regulated learning strategies between computer - based and print - based learning students. Social and Behavioral Sciences, 2(2), 3687-3692.

*Feng-qin, Z. (2010). Leaner autonomy in self-access language learning: 
An exploration of the self-access center in Wuhan University. Retrieved from

http://www.computer.org/portal/web/csdl/doi/10.1109/ETCS.2010 .181

*Figura, K., \& Jarvis, H. (2007). Computer-based materials: A study of learner autonomy and strategies. System, 35(4), 448-468.

Flavell, J.H. (1979). Metacognition and cognitive monitoring: A new area of cognitive-developmental inquiry. American Psychologist, 34(10), 906-911. doi: 10.1037/0003-066X.34.10.906

Foley, J.A. (2005). English in...Thailand. RELC, 36(2), 223-234.

Fry, G.W. (2002). Synthesis report: From crisis to opportunity, the challenges of educational reform in Thailand. Prepared for the Office of the National Education Commission and the Asian Development Bank (TA 3585-THA). Retrieved from http://www.edthai.com/publication/0002/fulltext.pdf

Furnham, D. (1992). Personality and learning style: A study of three instruments. Personality and Individual Differences, 13 (4), 429-438.

*Garrett, P., \& Shortall, T. (2002). Learners' evaluations of teacher-fronted and student-centred classroom activities. Language Teaching Research, 6(1), 25-57.

Gerlach, J. M. (1994). Is this collaboration? In K. Bosworth, \& S. J. Hamilton (Eds.), Collaborative Learning: Underlying processes and effective techniques, new directions for teaching and learning (pp. 1219). San Francisco, CA: Jossey-Bass

Gibbs, B. (1979). Autonomy and authority in education. Journal of Philosophy of Education, 13(1), 119-132. doi: 10.1111/j.1467-9752.1979.tb00527.x

${ }^{*}$ Goh, C. (1997). Metacognitive awareness and second language listeners. ELT Journal, 51(4), 361-369.

Gokhale, A. A. (1995). Collaborative learning enhances critical thinking. 
Journal of Technology Education, 7(1). Retrieved from http://scholar.lib.vt.edu/ejournals/JTE/v7n1/gokhale.jte-v7n1.html

*González, J. A. (2009). Promoting student autonomy through the use of the European Language Portfolio. ELT Journal Volume, 63(4), 373-382. Greenberg, G., Ganshorn, K., \& Danilkewich, A. (2001). Solution-focused therapy: Counseling model for busy family physicians. Canadian Family Physician, 47(11), 2289-2295.

Guba, E.G.(1981). Criteria for assessing the trustworthiness of natural inquiries. Educational Communication and Technology, 29(2), 75-91. doi: 10.1007/BF02766777

Hague, P. (1987). The Industrial market research handbook. London: Kogan Press.

Hammond, M., \& Collins, R. (1991). Self-directed learning: Critical practice. London: Kogan Page.

Hedge, T. (2000). Teaching and learning in the language classroom. Oxford: Oxford University Press.

Hesse-Biber, S. (2010). Qualitative approaches to mixed methods practice. Qualitative Inquiry, 16(6), 455-468. doi: $10.1177 / 1077800410364611$

Highet, G. (1950). The art of teaching. NY: Wiley and Sons.

*Ho, J. \& Crookall, D. (1995). Breaking with Chinese cultural traditions: Learner autonomy in English language teaching. System, 23(2), 235243.

*Holden, B., \& Usuki, M. (1999). Learner autonomy in language learning: A preliminary investigation. Bulletin of Hukuriku University, 23(2), 191203.

Holec, H. (1981). Autonomy and foreign language learning. Oxford: Pergamon.

*Holme, R., \& Chalauisaeng, B. (2006). The learner as needs analyst: The use of participatory appraisal in the EAP reading classroom. English for Specific Purposes, 25(4), 403-419. doi:10.1016/j.esp.2006.01.003 
*Hongsa-ngiam, A. (2006). An investigation of Physics instructors' beliefs and students' beliefs, goals and motivation for studying Physics in Thai Rajabhat Universities. Unpublished doctoral dissertation, Edith Cowan University, Perth, Western Australia.

*Hongsranagon, P., Pongpanich, S., Eamratsameekool, W., Prachusilpa, G., Havanond, P., \& Deelertyuenyong, N. (2008). How ready are the distance education learners in Thailand context? Retrieved from http://www.waseda.jp/DLI2008/program/proceedings/pdf/session6 $-3 . p d f$

*Hurd, S., Beaven, T., \& Ortega, A. (2001). Developing autonomy in a distance language learning context: Issues and dilemmas for course writers. System, 29(3), 341-355.

Ioannou, A., \& Artino, A. (2010). Learn more, stress less: Exploring the benefits of collaborative assessment. College Student Journal, 44(1), 189-199.

*Intaraprasert, C. (2007). Out-of-class language learning strategies and Thai universities students learning English for Sciences and Technology. Suranaree Journal of Social Science, 1(1), 1-18.

*Israsena, V. (2007). Thai teachers' beliefs about learner-centered education: Implication for Success For Life Thailand. Unpublished doctoral dissertation, University of North Texas, Texas, USA.

*James, P.T.J. (2009). Mobile-learning in Thai universities: Potential technological impacts. Retrieved from http://ejournals.thaicyberu.go.th/index.php/ictl/article/viewFile/10 $/ 11$

Jameson, D. A. (2004). Conceptualizing the writer-reader relationship in business prose. Journal of Business Communication, 41(3), 227-264.

*Januin, J. (2007). Exploring readiness for language learning autonomy among distance learners in Sabah, Malaysia. Asian Journal of Distance Education, 5(2), 16-26.

*Jing, H. (2006a). Fostering learner autonomy within constraints: 
Negotiation and mediation in an atmosphere of collegiality. Prospect, 21(3), 38-57.

*Jing, H. (2006b). Learner resistance in metacognition training? An exploration of mismatches between learner and teacher agendas. Language Teaching Research, 10(1), 95-117.

*Jing-yuan, F. (2007). Developing learner autonomy for oral language on the base of emergent metacognition. US-China Education Review, 4(9), 38-45.

Johnson, R.B., \& Onwuegbuzie, A.J. (2004). Mixed methods research: A research paradigm whose time has come. Educational Researcher, 33(7), 14-26.

Johnson, R. B., Onwuegbuzie, A. J., \& Turner, L. A. (2007). Toward a definition of mixed methods research. Journal of Mixed Methods Research, 1(2), 112-133.

Jonassen, D. H. (1992). Evaluating the constructivistic learning. In T.M. Duffy \& D H. Jonassen (Eds.), Constructivism and the technology of Instruction: A conversation (pp.137-148). Hillsdale, NJ: Lawrence Erlbaum.

Karaagac, K. M., \& Threlfall, J. (2004, July). The tension between teacher beliefs and teacher practice: The impact of the work setting. Paper presented at the $28^{\text {th }}$ Conference of the International Group of the Psychology of Mathematics Education, Bergen, Norway.

*Karagözoğlu, Ş (2009). Nursing students' level of autonomy: A study from Turkey. Nurse Education Today, 29(2), 176-187.

*Kaur, R., \& Embi, M.A. (2007). Learner autonomy through computer mediated communication (CMC). Jurnal Teknologi, 46(E), 99-112.

*Kaur, R., \& Embi, M.A. (2009). Self-directedness through asynchronous online interactions: a Malaysian experience. European Journal of Social Sciences, 9(1), 48-60.

*Kavanoz, S. (2006). An exploratory study of English language 
teachers' beliefs, assumptions and knowledge about learner centeredness. The Turkish Online Journal of Educational Technology, 5(2), 3-9. Retrieved from http://www.eric.ed.gov/PDFS/ED501430.pdf

Khamkhien, A. (2006). Thai and Vietnamese university students' language learning strategies. Unpublished master's dissertation, Chulalongkorn University, Bangkok, Thailand.

Kher, N., Molstad, S., \& Donahue, R. (1999). Using humor in the college classroom to enhance teaching effectiveness in 'Dread Courses'. College Student Journal, 33(3), 400-406.

*Kiddee, K. (2004). A development of the evaluation model of the studentcentered learning management. Unpublished doctoral dissertation, Chulalongkorn University, Bangkok, Thailand.

Kirtikara, K. (2001, January). Higher education in Thailand and the national reform roadmap. Paper presented at the Thai-US Education Roundtable, Bangkok, Thailand. Retrieved from http://www.kmutt.ac.th/pi/backup/fileKK/Higher\%20Edu\%20Refor m\%20Roadmap.pdf

*Klunklin, A., Viseskul, N., Sripusanapan, A., \& Turale, S. (2010). Readiness for self-directed learning among nursing students in Thailand. Nursing and Health Sciences, 12(2), 177-181.

*Kongchan, C. (2002). Using learning profile to inspire effective consultations. rEFLections , 4, 15-30.

*Kriwattanapong, T. (2001). Factors related to self-directed learning readiness of non-formal education students in the vocational certificate program in Bangkok metropolis. Unpublished master's dissertation, Chulalongkorn University, Bangkok, Thailand.

*Kusanagi, Y. (2007, October). Montage: Activities to increase EFL learner autonomy and understanding of others. Paper presented at the Independent Learning Association 2007 Japan Conference, Kanda University of International Studies, Chiba, Japan. 
La Ganza, W. (2008). Learner Autonomy-teacher autonomy: Interrelating and the will to empower. In T. Lamb \& H. Reinders (Eds.), Learner and teacher autonomy: Concepts, realities, and responses (pp. 63-79). PA: John Benjamins.

Le Compte, M. D., \& Preissle, J. (1993). Ethnography and qualitative design in educational research. London: Academic Press.

*Lee, I. (1998). Supporting greater autonomy in language learning. ELT Journal, 52(4), 282- 290.

Lindley, R. (1986). Autonomy. London: Macmillan.

Lincoln, Y.S., \& Guba, E.G. (1985). Naturalistic inquiry. Newbury Park, CA: Sage.

Little, D. (1990). Autonomy in language learning: Some theoretical and practical considerations. In I. Gathercole (Ed.), Autonomy in language learning (pp. 7-15). London: CiLT.

Little, D. (1995). Learning as dialogue: The dependence of learner autonomy on teacher autonomy. System, 23(2), 175-181. doi: 10.1016/0346251X(95)00006-6

Little, D. (1999). Developing learner autonomy in the foreign language classroom: A social - interactive view of learning and three fundamental pedagogical principles. Revista Canaria de Estudios Ingleses, 38, 77-88.

Little, D. (2007). Introduction: Reconstructing learner and teacher autonomy in language education. In A. Barfield \& S.H. Brown (Eds.), Reconstructing autonomy in language education: Inquiry and innovation (pp. 1-12). New York: Palgrave Macmillan.

Littlewood, W. (1999). Defining and developing autonomy in East Asian contexts. Applied Linguistics, 20(1), 71-94

*Littlewood, W. (2003). Students' perception of classroom learning in East Asia and Europe. HKBU Papers in Applied Language Study. Retrieved from http://lc.hkbu.edu.hk/book/pdf/sample.pdf

Littlewood, W. (2004). The task-based approach: Some questions and 
suggestions. ELT Journal, 58(4), 319-326.

*Liu, J. (2005). The mode of promoting learner autonomy for non-English majors through classroom instruction. US-China Education Review, 2(11), 46-52.

*Lo, Y. (2010). Implementing reflective portfolios for promoting autonomous learning among EFL college students in Taiwan. Language Teaching Research, 14(1), 77-95.

*Logan, S., \& Moore, N. (2004). Implementing learner training from a teacher's perspective. Proceedings of the Independent Learning Conference 2003. Retrieved from http://independentlearning.org/ILA/ila03/ila03_logan_and_moore.pdf

Lortie, D. C. (1975). Schoolteacher: A sociological study. Chicago: Chicago University Press.

*Luke, C.L. (2006). Fostering learner autonomy in a technology-enhanced, inquiry- based foreign language classroom. Foreign Language Annals, 39(1), 71-86.

Lyle, J. (2003). Stimulated recall: A report on its use in naturalistic research. British Educational Research Journal, 29(6), 861-878. Retrieved from http://www.jstor.org/stable/1502138 Lyle, S (2008a). Dialogic teaching: Discussing theoretical contexts and reviewing evidence from classroom practice. Language and Education, 22(3), 222-240.

Lyle, S. (2008b). Learners' collaborative talk. In M. Martin-Jones, A-M. de Mejia \& N. Hornberger (Eds), Encyclopaedia of Language and Education Vol. 3:Discourse and Education (pp. 279-290). NY: Springer. Ma, X. (2008). The skills of teacher's questioning in English classes. International Education Studies, 1(4), 92-100.

Macaro, E. (1997). Target language, collaborative learning and autonomy. Clevedon, UK: Multilingual Matters.

Mahidol Population Gazette. (2009). Retrieved from 
http://www.ipsr.mahidol.ac.th/ipsr/Contents/Documents/Gazette/G azette2009EN.pdf

*Mailloux, C. G. (2006). The extent to which students' perceptions of faculties' teaching strategies, students' context, and perceptions of learner empowerment predict perceptions of autonomy in BSN students. Nurse Education Today, 26(7), 578-585.

*Maneekhao, K., \& Tepsuriwong, S. (2009). A case study of CALL integration into English courses at a Thai university. In L.J. Zhang, R. Rubdy, \& L. Alsagoff (Eds.), English and Literatures-in-English in a globalised world: Proceedings of the $13^{\text {th }}$ International Conference on English in Southeast Asia (pp.301-317). Singapore: National Institute of Education, Nanyang Technological University.

Marshall, J.D. (1996). Michel Foucault: Personal autonomy and education. NY: Kluwer Academic.

*Martin, L., West, J., \& Bill, K. (2008). Incorporating problem-based learning strategies to develop learner autonomy and employability skills in Sport Science undergraduates. Journal of Hospitality, Leisure, Sport and Tourism Education, 7(1), 18-30.

*McBrien, J. L., Jones, P. \& Cheng, R. (2009). Virtual spaces: Employing a synchronous online classroom to facilitate student engagement in online learning. International Review of Research in Open and Distance Learning, 10(3), 1-14.

McCoy, L. (2009). Asking questions that count. Retrieved from http://mysite.verizon.net/vze3h8h7/Documents/AskingQuestionsTh atCount.pdf

McDevitt, B. (1997). Learner autonomy and the need for learner training. Language Learning Journal, 16, 34-39.

*McLachlan, S., \& Hagger, M. S. (2010). Effects of an autonomy-supportive intervention on tutor behaviors in a higher education context. Teaching and Teacher Education, 26(5), 1204-1210. doi:10.1016/j.tate.2010.01.006 
McVeigh, B.J. (2002). Japanese higher education as myth. Armonk, NY:

M.E. Sharpe.

*Meeus, W., Van Petegem, P., \& Meijer, J. (2008). Portfolio as a means of promoting autonomous learning in teacher education: A quasiexperimental study. Educational Research, 50(4), 361-386.

Merton, R.K., Fiske, M., \& Kendall, P.L. (1990). The focused interview: A manual of problems and procedures (2nd ed.). London: Collier MacMillan.

Miles, M.B., \& Huberman, M. (1994). Qualitative data analysis: An expanded sourcebook ( $2^{\text {nd }}$ ed.). Thousand Oaks, CA: Sage.

Ministry of Education (1996). The 1996 English Curriculum. Bangkok, Thailand: Ministry of Education.

Ministry of Education (2008). Towards a learning society in Thailand: An introduction to education in Thailand. Bangkok, Thailand: Bureau of International Cooperation, Ministry of Education.

Monette, D.R., Sullivan, T.J., \& DeJong, C.R. (2011). Applied social research: A tool for the human services ( $8^{\text {th }}$ ed.). Belmont, CA: Cengage Learning.

Morrison, K.R.B. (1993). Planning and accomplishing school-centered evaluation. Norfolk, VA: Peter Francis.

Murphey, T. (2003). Learning to surf: Structuring, negotiating, and owning autonomy. In A. Barfield, \& M. Nix (Eds.), Leaner and Teacher Autonomy in Japan 1: autonomy you ask! (pp.1-10). Tokyo, Japan: JALT.

*Murphy, L. (2008). Supporting learner autonomy: Developing practice through the production of courses for distance learners of French, German and Spanish. Language Teaching Research, 12(1), 83-102.

*Mustafa, M., \& Cullingford, C. (2008). Teacher autonomy and centralised control: The case of textbooks. International Journal of Educational Development, 28(1), 81-88. doi:10.1016/j.ijedudev.2007.07.003

*Mynard, J. (2008). A blog as a tool for reflection for English language 
learners. The Philippine ESL Journal, 1, 77-90. Retrieved from http://www.philippine-esl-journal.com/August-2008-Vol1.pdf

*Na ranong, S., Neancharoensuk S., Boonsom, N., \& Siriratanawit S.

(2004, December). The role of e-learning in teaching Japanese for Thai students. Paper presented at the CLaSIC 2004 Conference, National University of Singapore, Singapore.

Natri, T. (2007). Active learnership in continuous self- and peer-evaluation. In A. Barfield \& S.H. Brown (Eds.), Reconstructing autonomy in language education: Inquiry and innovation (pp. 108-119). NY: Palgrave Macmillan.

Newstead, K. (1999). Teacher beliefs, teacher practice and learner learning: a case study. In J. Kuiper (Ed.), Proceedings of the Seventh Annual Conference of the Southern African Association for Research in Mathematics and Science Education (pp.325-330). Harare, Zimbabwe.

*Nicolaides, C.S. (2008). Roles learners believe they have in the development of their language learning- autonomy included? In T. Lamb \& H. Reinders (Eds.), Learner and teacher autonomy: Concepts, realities and responses (pp. 141-160). PA: John Benjamins.

Niemiec, C.P., \& Ryan, R.M. (2009). Autonomy, competence, and relatedness in the classroom: Applying self-determination theory to educational practice. Theory and Research in Education, 7(2), 133-144. doi: $10.1177 / 1477878509104318$

Nunan, D. (2004). Task-based language teaching. Cambridge: Cambridge University Press.

Nonkukhetkhong, K., Baldauf Jr., Richard B., \& Moni, K. (2006, January). Learner centeredness in teaching English as a foreign language: Teachers' voices. Paper presented at the 26 Thai TESOL International Conference, Chiang Mai, Thailand.

*Nuntrakune, T., Nason, R., \& Kidman, G. C. (2009). Two Thai teachers' 
perceptions of cooperative learning. In: AARE 2008 Conference Papers Collection, 30 November - 4 December 2008, Queensland University of Technology.

Nystrand, M., Gamoran, A., Kachur, R. and Prendergast, C. (1997) Opening dialogue: Understanding the dynamics of language and learning in the English Classroom. NY: Teachers College Press.

Office of the Higher Education, Thailand (2011). http://www.mua.go.th/ Patamadit, I., \& Bousquet, F.(2003). The Thai traditional learning process in folk culture: Implications for the companion modelling approach. Retrieved from http://afm.cirad.fr/documents/3_Organisations/ActionCollective/EN /AC_Patamadit.pdf

*Patrick, F. K. (2008, December). Early career teachers' changes to practice, confidence and understandings in cooperative learning: A case study doctoral project update. Paper presented in the AARE 2008 Changing climates: Education for Sustainable Features Conference, University of Technology, Brisbane, Australia.

Payne, R.L. (1971). Organizational climate: The concept and some research findings. Prakseologia, 39(40), 143-158.

*Perry, N.E., Hutchinson, L. \& Thauberger, C. (2008). Talking about teaching self-regulated learning: Scaffolding student teachers' development and use of practices that promote self-regulated learning. International Journal of Educational Research, 47(2), 97-108.

Pica, T. (1987). Second language acquisition, social interaction, and the classroom. Applied Linguistics. 8(1), 3-21. doi: 10.1093/applin/8.1.3

*Pinkman, K. (2005). Using blogs in the foreign classroom: Encouraging learner independence. JALT CALL Journal, 1(1), 12-24.

*Poonruksa, S. (2007). The integration of student-centered approach for field trip in mental health and psychiatric nursing practicum: Case studies among Third year nursing students of Assumption University 
of Thailand. Assumption University Journal of Technology, 10(4), 225231.

Porto, M. (2007). Learning diaries in the English as a Foreign Language classroom: A tool for assessing learners' perceptions of lessons and developing learner autonomy and reflection. Foreign Language Annals, $40(4), 672-696$.

Powell, M.B., Fisher, R.P., \& Wright, R. (2005). Investigative interviewing in N. Brewer \& K. D. Williams (Eds.), Psychology and law: An empirical perspective (p.11-42). NY: The Guildford Press

Powell, J.P., \& Andresen, L.W. (1985). Humour and teaching in higher education. Studies in Higher Education, 10(1), 79-90.

Punch, K.F. (2005). Introduction to social research: Quantitative and qualitative approaches. London: Sage

Ramsay, A., Hanlon, D., \& Smith, D. (2000). The association between cognitive style and accounting students' preference for cooperative learning: An empirical investigation. Journal of Accounting Education, 18(3), 215-228. doi:10.1016/j.jaccedu.2004.01.001

*Reeve, J., Jang, H., Carrell, D., Jeon S., \& Barch, J. (2004). Enhancing students' engagement by increasing teachers' autonomy support. Motivation and Emotion, 28(2), 147-169.

Reeve, J., Jang, H., Hardre, P., \& Omura, M. (2002). Providing a rationale in an autonomy-supportive way as a strategy to motivate others during an uninteresting activity. Motivation and Emotion, 26(3), 183207.

Richmond, J.E.D. (2007). Bringing critical thinking to the education of developing country professionals. International Education Journal, 8(1), 1-29. Retrieved from http://the-tech.mit.edu/ richmond/professional/jriejfinal.pdf Rigby, C. S., Deci, E. L., Patrick, B.C. \& Ryan R.M.(1992). Beyond the 
intrinsic-extrinsic dichotomy: self-determination in motivation and learning. Motivation and Emotion, 16(3), 165-185. doi: 10.1007/BF00991650

Riley, P. (1997). The guru and the conjurer: Aspects of counselling for self-access. In P. Benson, \& P. Voller (Eds.), Autonomy and independence in language learning (pp. 114-131). London: Longman.

*Rivers, W. P. (2001). Autonomy at all costs: An ethnographic of metacognitive self-assessment and self-management among experienced language learners. The Modern Language Journal, 85(2), 279-290.

*Roskams, T. (1999). Chinese EFL students' attitudes to peer feedback and peer assessment in an extended pair work setting. RECL Journal, 30(1), 79-123. doi: 10.1177/003368829903000105

*Rubdy, R. (1998). Sensitizing learners towards a more productive classroom participation: An 'exploratory' approach. RELC Journal, 29(2), 1-26.

*Rukthong, A. (2008). Readiness for autonomous language learning: Thai university learners' beliefs about EFL learning and use of learning strategies. Unpublished master's dissertation, Mahidol University, Bangkok, Thailand.

*Rumpagaporn, M. W., \& Darmawan, I.G.N. (2007). Students' critical thinking skills in a Thai ICT schools pilot project. International Educational Journal, 8(2), 125-132.

Ryan, R.M., \& Brown, K.W. (2005) Legislating competence: High-stakes testing policies and their relations with psychological theories and research', In A.J. Elliot \& C.S. Dweck (Eds), Handbook of Competence and Motivation, (pp. 354-72). NY: Guilford Publications.

Ryan, R. M., \& Deci, E. L. (2000a). Intrinsic and extrinsic motivations: Classic definitions and new directions. Contemporary Educational Psychology, 25(1), 54-67. doi:10.1006/ceps.1999.1020

Ryan, R. M., \& Deci, E. L. (2000b). Self-determination theory and the 
facilitation of intrinsic motivation, social development, and well-being. American Psychologist, 55(1), 68-78.

Ryan, R. M., \& Deci, E. L. (2002). Overview of self-determination theory: An organismic dialectical perspective. In E. L. Deci \& R. M. Ryan (Eds.), Handbook of self-determination research (pp. 3-33). New York: The University of Rochester Press.

*Saman, S. (2004). A development of the process for enhancing teachers' self-directed learning ability: A multi-case study research. Unpublished doctoral dissertation, Chulalongkorn University, Bangkok, Thailand.

Sánchez, A. (2004). The task-based approach in language teaching. IJES, 4(1), 39-71.

*Sanprasert, N. (2010). The application of a course management system to enhance autonomy in learning English as a foreign language. System, 38(1), 109-123. doi: 10.1016/j.system.2009.12.010

*Sarsar, N.M. (2008). Textbook addiction treatment: A move towards teacher and student autonomy. Retrieved from http://www.eric.ed.gov/ERICDocs/data/ericdocs2sql/content_storag e_01/0000019b/80/41/e7/76.pdf

*Sert, N. (2006). EFL student teachers' learning autonomy. The Asian EFL Journal Quarterly, 18(2), 180-201.

Scharle, Á., \& Szabó, A. (2000). Learner autonomy: A guide to developing learner responsibility. UK: Cambridge University Press.

Shenton, A. K. (2004). Strategies for ensuring trustworthiness in qualitative research projects. Education for Information, 22(2), 63-75. Retrieved from http://www.angelfire.com/theforce/shu_cohort_viii/images/Trustwo rthypaper.pdf

Simons, H. (1989). Ethics of case study in educational research and evaluation. In R. G. Burgess (Ed.), The ethics of educational research (pp. 114-138). London: Routledge.

Sinlarat, P. (2004). Thai universities: Past, present, and future. In Philip G. 
A., \& Toru U. (Eds.). Asian universities: Historical perspective and contemporary challenges (pp. 201-219). Marryland: The Johns Hopkins University Press.

Sinlarat, P. (2007). New leadership and new globalization in Thai higher education: The path to the future. ASAIHL - Thailand Journal, 10(2), 38-65.

*Sirithongthaworn, S., Krairit, D., Dimmitt, N.J. \& Paul, H. (2006). The study of e-learning technology implementation: A preliminary investigation of universities in Thailand. Education and Information Technologies, 11(2), 137-160.

Smalley, W. A. (1988). Thailand's Hierarchy of Multilingualism. Language Sciences, 10(2), 245-261. doi: 10.1016/0388-0001(88)90016-2

Smalley, W. A. (1994). Linguistic diversity and national unity: Language ecology in Thailand. Chicago: University of Chicago Press.

Smith, R.C. (2003). Teacher education for teacher-learner autonomy. Retrieved from http://www.warwick.ac.uk/ elsdr/Teacher_autonomy.pdf

*Sojisirikul, P., \& Intrarat, J. (2008). The initial step of autonomous learning. Retrieved from http://digital.lib.kmutt.ac.th/journal/text/kmuttv31n1_3.txt

Spinks, N., \& Wells, B. (1997). Intercultural communication: A key element in global strategies. Career Development International, 2(6), 287-292.

*Spratt, M. (2001). The value of finding out what classroom activities students like. RELC Journal, 32(2), 80-101. doi: $10.1177 / 003368820103200206$

*Spratt, M., Humphreys, G.,\& Chan, V. (2002). Autonomy and motivation: Which comes first? Language Teaching Research, 6(3), 245-266.

*Srimavin, W., \& Darasawang, P. (2004). Developing self-assessment through journal writing. Proceeding of the Independent Learning Conference, 2003. Publish in 20 September, 2004.

Stake, R. E. (1995). The art of case study research. Thousand Oaks, CA: 
Sage.

Tashakkori, A., \& Teddlie, C. B. (2003). The past and the future of mixed methods research: From "methodological triangulation" to "mixed model designs". In A. Tashakkori \& C. B. Teddlie (Eds.), Handbook of mixed methods in social and behavioral research (pp. 671702).Thousand Oaks, CA: Sage.

*Teeraputon, D. (2003). The implementation of self-regulated learning strategy on computer network for undergraduate students. Unpublished doctoral dissertation, Chulalongkorn University, Bangkok, Thailand.

Tepsuriwong, S., \& Srisunakrua, T. (2009). Degrees of learnercentredness in Thai tertiary English courses. In Zhang, L. J., Rubdy, R., \& Alsagoff, L. (Eds.). (2009). Englishes and Literatures-in-English in a Globalised World: Proceedings of the 13th International Conference on English in Southeast Asia (pp. 363-377). Singapore: Nanyang Technological University.

Thamraksa, C. (2003). Student-centered learning: Demystifying the myth. SLLT, 12, 59-71.

*Thongmon, L. (1998). A comparison of self-directed learning characteristics between researcher teachers and non researcher teachers. Unpublished master's dissertation, Chulalongkorn University, Bangkok, Thailand.

Trebbi, T. (2008). Freedom- a prerequisite for learner autonomy: Classroom innovation and language teacher education. In T. Lamb \& H. Reinders (Eds.), Learner and teacher autonomy: Concepts, realities and responses. (pp.33-46). The Netherlands: John Benjamins.

Tudor, I. (1996). Learner-centeredness as language education. Cambridge: Cambridge University Press.

*Usuki, M. (2002). Learner autonomy: Learning from the student's voice. 
Retrieved from

http://www.eric.ed.gov/ERICWebPortal/contentdelivery/servlet/ERI CServlet?accno $=$ ED478012

*van den Boom, G., Pass, F., van Merrienbore, J.J.G., \& van Gog, T.

(2004). Reflection prompts and tutor feedback in a web-based learning environment: Effects on students' self-regulated learning competence. Computers in Human Behavior, 20(1), 551-567.

*Vandiver, D. M., \& Walsh, J.A. (2010). Assessing autonomous learning in research methods courses: Implementing the studentdriven research project. Active Learning in Higher Education, 11(1), 31-42.

*Vanijdee, A. (2003). Thai distance English learners and learner autonomy. Open Learning, 18(1), 75-84.

*Varol, B., \& Yilmaz, S. (2010). Similarities and differences between female and male learners: Inside and outside class autonomous language learning activities. Social and Behavioral Sciences, 3, 237-244. doi:10.1016/j.sbspro.2010.07.038.

Ventres, W., \& Gordon, P. (1990). Communication strategies in caring for the underserved. Journal of Health Care for the Poor and Underserved, 1(3), 305-314.

Victori, M., \& Lockhart, W. (1995). Enhancing metacognition in selfdirected language learning, System, 23(2), 223-234. doi: 10.1016/0346-251X(95)00010-H

Vieira, F. (1997). Teacher development for learner autonomy: Ideas from an in-service teacher training project. English Language Teaching News, 33, 61-67.

Vieira, F. (2000). Teacher development towards a pedagogy for autonomy in the foreign language classroom. In R. Ribé (Ed.), Developing learner autonomy in foreign language learning (pp.221-236). Barcelona, Spain: Universitat de Barcelona.

Voller, P. (1997). Does the teacher have a role in autonomous learning? In 
P. Benson \& P. Voller (Eds.), Autonomy and independence in language learning (pp. 98 - 113). London: Longman.

*Vonderwell, S., Liang X., \& Alderman, K. (2007). Asynchronous discussion and assessment in online learning. Journal of Research on Technology in Education, 39(3), 309-328.

Wall, S. (1998). Liberalism, perfectionism and restraint. Cambridge: Cambridge University Press.

*Walters, J., \& Bozkurt, N. (2009). The effect of keeping vocabulary notebooks on vocabulary acquisition. Language Teaching Research, 13(4), 403-423.

Wang, H. (2009). Learner autonomy and the Chinese context. Asian Social Science, 4(7), 114-120.

*Wang, J., \& Fang, Y (2005). Benefits of cooperative learning in weblog networks. Retrieved from http://www.eric.ed.gov/ERICDocs/data/ericdocs2sql/content_storag e_01/0000019b/80/1b/c4/82.pdf

*Wanpen, S., \& Fisher, D. (2004, June). Creating a collaborative learning environment in a computer classroom in Thailand using the constructivist learning environment survey. Paper presented at the IASCE Conference, Singapore.

Warnock, P. (1989). Humor as a didactic tool in adult education. Lifelong Learning, 12(8), 22-24.

Wasilow, T. (2009). Implications of metacognition on instructional technology for today's differentiated learners. Retrieved from http://www.scribd.com/doc/16975400/Implications-ofMetacognition-on-Instructional-Technology-for-TodaysDifferentiated-Learners

Watkins, C. (2003). Learning: A sense-makers guide. London: ATL. Wei, Z. (2009). Changing teachers' role to facilitate learner autonomy of college English majors in E-education. Retrieved from http://ieeexplore.ieee.org/stamp/stamp.jsp?arnumber=05279819 
Wells, G. (1989). Language in the classroom: literacy and collaborative talk. Language and Education, 3 (4), 251-273. doi:

10.1080/09500788909541266

Wenden, A. (1998). Metacognitive knowledge and language learning. Applied Linguistics, 19(4), 515-537.

Wiersma, W., \& Jurs, S.G. (2005). Research methods in education: An introduction. ( $8^{\text {th }}$ ed.). Boston, MA: Allyn and Bacon.

*Wilson, D., Edmunds, P., \& Meyer, D. (2008). Learning at the speed of business: Learner autonomy in business schools. Review of Business Research, 8(4), 215-225.

*Williams, G. C., \& Deci, E. L. (1996). Internalization of biopsychosocial values by medical students: A test of self-determination theory. Journal of Personality and Social Psychology, 70(4), 767-779.

Winch, C. (1999). Autonomy as an educational aim. In R. Marples (Ed.), The aims of education (pp. 74-84). London: Routledge.

*Wiriyakarun, P. (2002). Can Thai students become self-directed learners? rEFLections ,4, 31-40.

*Wiriyakarun, P. (2003). Designing task-based materials to promote learner autonomy in classroom. rEFLections,5,1-9.

*Wisaijorn, P., \& Tremayne, B. (2008). Thai university students' attitudes towards learner autonomy and self-directed learning. Humanities and Social Sciences Journal, Khon Kaen University, 25(1), 92-115.

Wongsothorn, A. (2004). Thailand. In H. W. Kam, \& R. Y. L. Wong (Eds.), Language policies and language education: The impact in East Asian countries in the next decade (2nd ed., pp. 329-341). Singapore: Eastern University Press.

*Yamkate, K., \& Uantrai N. (2003). A study of upper and lower secondary school students' difficulties with language in using Internet for independent learning. rEFLections, 5, 32- 40.

*Yang, N.D. (1998). Exploring a new role for teachers: Promoting learner 
autonomy. System, 26(1), 127-135. doi: 10.1016/S0346251X(97)00069-9

Yao, Y., \& Grady, M.L. (2005). How do faculty make formative use of student evaluation feedback?: A multiple case study. Journal of Personal Evaluation in Education, 18(2), 107-126. doi: $10.1007 / \mathrm{s} 11092-006-9000-9$

*Yeung, L., \& Hyland, F. (1999). Bridging the gap: Utilising self-access learning as a course component. RECL Journal, 30(1), 158-174.

Yin, R.K. (2009). Case study research: Design and methods. (4th ed.). California: Sage.

*Zhang, L. (2008). Cognitive distortions and autonomy among Chinese university students. Learning and Individual Differences, 18(2), 279 284.

*Zhe, W. (2009). A contrastive study of Chinese \& Western learner autonomy. US-China Foreign Language, 7(12), 9-11.

*Zhou, M., Ma, W. J., \& Deci, E. L. (2009). The importance of autonomy for rural Chinese children's motivation for learning. Learning and Individual Differences, 19(4), 492-498. doi:10.1016/j.lindif.2009.05.003

*Zhou, Z., \& Zhang, C. (2005). A study of the relationship of language learners' beliefs and autonomous learning. US-China Foreign Language, 3(4), 64-68. 
Appendices 


\section{Appendix A: Detailed Data Extraction}

\section{Studies Conducted in International Contexts}

\begin{tabular}{|c|c|c|c|c|c|c|c|}
\hline no. & Study & Setting & $\begin{array}{l}\text { Fields/ } \\
\text { Subjects }\end{array}$ & Aim/Question & $\begin{array}{l}\text { Participants } \\
\text { /Sources of data }\end{array}$ & Methodology/Instruments & Findings / Implications \\
\hline 1 & $\begin{array}{l}\text { Cotterall } \\
\text { (1995) }\end{array}$ & $\begin{array}{l}\text { New } \\
\text { Zealand } \\
\text { (Tertiary) }\end{array}$ & Language & To gauge learners' readiness for autonomy & $\begin{array}{l}139 \text { ESL learners in } \\
\text { EAP courses }\end{array}$ & Questionnaire & $\begin{array}{l}\text { 1. Teachers need to prepare learners for their new role by developing } \\
\text { learners' self-awareness } 3 \text {. Obstacles for independence include: } \\
\text { - experience of a traditional education system } \\
\text { - some types of socialization processes } \\
\text { - culture \& educational background } \\
\text { - lack of experience in language learning } \\
\text { 2. Confidence is a defining characteristic of autonomous learners. }\end{array}$ \\
\hline 2 & $\begin{array}{l}\text { Ho \& Crookall } \\
\text { (1995) }\end{array}$ & $\begin{array}{l}\text { Hong Kong } \\
\text { (Tertiary) }\end{array}$ & Language & $\begin{array}{l}\text { To promote learner autonomy by using the } \\
\text { simulation in classroom }\end{array}$ & $\begin{array}{l}21 \text { students (working } \\
\text { together as a team) }\end{array}$ & $\begin{array}{l}\text { A large-scale, world-wide, computer-mediated } \\
\text { simulation } \\
\text { (each team represented a particular nation and } \\
\text { was to achieve the assigned goal; the } \\
\text { simulation lasted for } 7 \text { weeks) } \\
\text { Post-activity questionnaire }\end{array}$ & $\begin{array}{l}\text { 1. The simulation created learning environments conducive to the } \\
\text { development of learner autonomy as students were provided with } \\
\text { opportunities to take responsibility of their learning, that is, to make } \\
\text { decisions, plan, evaluate, monitor and assess their learning; } \\
\text { 2. The simulation created opportunities for students to self-direct their } \\
\text { learning in these skills: conflict resolution skills, language skills for } \\
\text { professional communication, and time management and contingency } \\
\text { planning; } \\
\text { 3. Working as a team, students had a sense of group identity and group } \\
\text { cohesion, which became their intrinsic motivation. In this way, students } \\
\text { were deeply engaged in all tasks, which is a key of autonomous learning. }\end{array}$ \\
\hline 3 & $\begin{array}{l}\text { William \& Deci } \\
\text { (1996) } \\
\text { (Study 1) }\end{array}$ & $\begin{array}{l}\text { USA } \\
\text { (Tertiary) }\end{array}$ & Medicine & $\begin{array}{l}\text { To test the hypothesis that an autonomous- } \\
\text { supportive learning climate in an } \\
\text { interviewing course facilitate students' } \\
\text { becoming more autonomous }\end{array}$ & $\begin{array}{l}2^{\text {nd-year medical }} \\
\text { students }\end{array}$ & Two sets of questionnaire & $\begin{array}{l}\text { 1. Autonomy support led to r essential changes in the students' autonomy } \\
\text { and perceived competence } \\
\text { 2. Students became more autonomous if they felt their teachers were } \\
\text { supportive to learner autonomy. }\end{array}$ \\
\hline 4 & $\begin{array}{l}\text { William \& } \\
\text { Deci (1996) } \\
\text { (Study 2) }\end{array}$ & $\begin{array}{l}\text { USA } \\
\text { (Tertiary) }\end{array}$ & Medicine & $\begin{array}{l}\text { ( the study replicating and extending the } \\
\text { findings from the } 1 \text { st study) } \\
\text { - To test the hypothesis that an autonomy- } \\
\text { supportive learning climate will facilitate } \\
\text { internalization of psychosocial values }\end{array}$ & $\begin{array}{l}\text { 2nd-year medical } \\
\text { students }\end{array}$ & $\begin{array}{l}\text { A 30-month longitudinal study } \\
\text { 1. Four sets of questionnaire } \\
\text { 2. Audio record of students while interviewing } \\
\text { patients }\end{array}$ & $\begin{array}{l}\text { Students who perceived their instructors as more autonomy-supportive } \\
\text { became more autonomous in their learning. This led to a significant } \\
\text { increase in their perceived competence and psychosocial beliefs, more } \\
\text { autonomy support when interviewing a simulated patent, and stronger } \\
\text { psychosocial beliefs. }\end{array}$ \\
\hline
\end{tabular}




\begin{tabular}{|c|c|c|c|c|c|c|c|}
\hline 5 & $\begin{array}{l}\text { Goh } \\
\text { (1997) }\end{array}$ & $\begin{array}{l}\text { Singapore } \\
\text { (Tertiary) }\end{array}$ & Language & $\begin{array}{l}\text { To examine learners' beliefs and knowledge } \\
\text { about their listening through the use of } \\
\text { dairies }\end{array}$ & 40 ESL learners & Learners' diaries & $\begin{array}{l}\text { 1. The students had a high degree of metacognitive awareness. } \\
\text { 2. Keeping diaries stimulated students to reflect on their learning and its } \\
\text { various aspects which in turn helped them to evaluate and improve their } \\
\text { learning. } \\
\text { 3. When students are fully aware of themselves and learning aspects, } \\
\text { they are ready to become more autonomous. }\end{array}$ \\
\hline 6 & Lee (1998) & $\begin{array}{l}\text { Hong Kong } \\
\text { (Tertiary) }\end{array}$ & Language & $\begin{array}{l}\text { To help students to become autonomous } \\
\text { (by participating in the self-directed } \\
\text { learning program) }\end{array}$ & 15 students & $\begin{array}{l}\text { Case study : } \\
\text { 1. Students' self-evaluations } \\
\text { 2. Interview } \\
\text { 3. Teacher's observations }\end{array}$ & $\begin{array}{l}\text { 1. The success of the program depended to some extent on students' } \\
\text { readiness for independent learning. } \\
\text { 2. Learner training should be offered together with the program. This will } \\
\text { increase students' potentiality to be autonomous; } \\
\text { 3. The constraint of the program is that the limited availability of learning } \\
\text { materials; this resulted in limited choices for students. }\end{array}$ \\
\hline 7 & Rubdy (1998) & $\begin{array}{l}\text { Singapore } \\
\text { (Tertiary) }\end{array}$ & Language & $\begin{array}{l}\text { To explore ways in which classroom } \\
\text { participation could be more productive }\end{array}$ & $\begin{array}{l}58 \text { first year students } \\
\text { in English tutorial } \\
\text { sessions in a } \\
\text { university }\end{array}$ & $\begin{array}{l}\text { Students performed the following tasks } \\
\text { - a classroom observation sheet } \\
\text { - two questionnaire } \\
\text { - learner diaries } \\
\text { - audio recordings of tutorial sessions }\end{array}$ & $\begin{array}{l}\text { 1. When in students are involved in observation and analysis of their } \\
\text { classroom behavior, teaching is seen as a research enterprise, rather } \\
\text { than a process if delivering knowledge and a set of skills } \\
\text { 2. Some types of questions and tasks can limit the students' ability to } \\
\text { analyze or think critically; } \\
\text { 3. To empower students, knowledge should be viewed as accessible } \\
\text { without the help of teachers. }\end{array}$ \\
\hline 8 & Yang (1998) & $\begin{array}{l}\text { Taiwan } \\
\text { (Tertiary) }\end{array}$ & $\begin{array}{l}\text { Language } \\
\end{array}$ & $\begin{array}{l}\text { To teach students how to learn and how to } \\
\text { become autonomous in their language } \\
\text { learning (by combining learning strategy } \\
\text { instruction with the course content) }\end{array}$ & 40 students & $\begin{array}{l}\text { 1. class evaluation } \\
\text { 2. students' learning diaries }\end{array}$ & $\begin{array}{l}\text { 1. Students had positive reactions and attitudes toward the project \& the } \\
\text { strategy training; } \\
\text { 2. Students' diaries was a way to provide information about how student } \\
\text { made decisions when setting goals, how they felt and what they did when } \\
\text { they encountered a learning problem; } \\
\text { 3. For students who studied on their own, teachers should help them to } \\
\text { assess their own learning. }\end{array}$ \\
\hline 9 & Butler (1999) & $\begin{array}{l}\text { USA. } \\
\text { (Secondary } \\
\text { level) }\end{array}$ & Science & $\begin{array}{l}\text { To investigate the effectiveness of problem- } \\
\text { based learning approach in classroom } \\
\text { practices }\end{array}$ & $\begin{array}{l}\text { Students from two } \\
\text { biochemistry classes }\end{array}$ & $\begin{array}{l}\text { 1. Students' conversational interchanges } \\
\text { 2. the researcher's (the teacher's) interactions } \\
\text { with students } \\
\text { 3. Samples of student work, class handouts, } \\
\text { lesson plans, etc. }\end{array}$ & $\begin{array}{l}\text { 1. By working in groups to solve the given problem, students were taking } \\
\text { the main responsibility of their own learning, and thereby realized that } \\
\text { they were self-reliant learner; } \\
\text { 2. The average teacher talk time decreased while that of student talk time } \\
\text { increased. Students took more active roles, by acting as group member, } \\
\text { expressing their own ideas during group discussions, and evaluating } \\
\text { their own self and their peers etc. } \\
\text { 3. Students' thinking skills were enhanced. They had freedom in } \\
\text { achieving the group targets in their own way, and accepted responsibility } \\
\text { of their own learning. }\end{array}$ \\
\hline 10 & Carter (1999) & $\begin{array}{l}\text { Trinidad } \\
\text { and Tobago } \\
\text { (Tertiary) }\end{array}$ & Language & $\begin{array}{l}\text { - To discover advanced language learners' } \\
\text { beliefs about language and language } \\
\text { learning } \\
\text { - To determine whether or not these } \\
\text { students were likely to be autonomous by } \\
\text { analyzing the beliefs they hold }\end{array}$ & $\begin{array}{l}35 \text { advanced learners } \\
\text { of French }\end{array}$ & $\begin{array}{l}\text { Survey } \\
\text { BALLI questionnaire (the Beliefs About } \\
\text { Language Learning Inventory) }\end{array}$ & $\begin{array}{l}\text { 1. Language learning was seen as an open-ended endeavor and time } \\
\text { needed for fluency in a language vary among people; } \\
\text { 2. The participants regarded fluency more important than accuracy. This } \\
\text { is one of the erroneous beliefs that needs to be corrected as for truly } \\
\text { autonomous learners, accuracy is important especially those who want to } \\
\text { make a career that requires linguistic competence. }\end{array}$ \\
\hline 11 & $\begin{array}{l}\text { Cotterall } \\
\text { (1999) }\end{array}$ & $\begin{array}{l}\text { New } \\
\text { Zealand } \\
\text { (Tertiary) }\end{array}$ & Language & $\begin{array}{l}\text { To investigate learners' beliefs about } \\
\text { language learning, specifically those related } \\
\text { to learner autonomy }\end{array}$ & 131 students & Questionnaire & $\begin{array}{l}\text { 1. Students considered the teacher's ability to show students how to } \\
\text { learn more important than their ability to teach; } \\
\text { 2. Students valued feedback from the teacher more highly that feedback }\end{array}$ \\
\hline
\end{tabular}




\begin{tabular}{|c|c|c|c|c|c|c|c|}
\hline & & & & & & & 4. Students lacked skills in monitoring and evaluating their own learning \\
\hline 12 & $\begin{array}{l}\text { Holden \& } \\
\text { Usuki (1999) }\end{array}$ & $\begin{array}{l}\text { Japan } \\
\text { (Tertiary) }\end{array}$ & Language & $\begin{array}{l}\text { - To investigate students' beliefs about } \\
\text { learning; } \\
\text { - To find out what students expect of } \\
\text { themselves and of their teachers }\end{array}$ & $\begin{array}{l}\text { Approximately 24-30 } \\
\text { students }\end{array}$ & Survey by group interview & $\begin{array}{l}\text { 1. Students were aware of learning strategies but were not able to apply } \\
\text { this strategies-knowledge into their learning process } \\
\text { 2. Students were aware of their own responsibility and role as } \\
\text { knowledge seekers and expected the teachers not to play role of } \\
\text { knowledge-transmitters; } \\
\text { 3. Students did not like studying in a classroom in which they could not } \\
\text { perform active roles or express themselves. }\end{array}$ \\
\hline 3 & $\begin{array}{l}\text { Roskams } \\
\text { (1999) }\end{array}$ & $\begin{array}{l}\text { Hong Kong } \\
\text { (Tertiary) }\end{array}$ & Language & $\begin{array}{l}\text { To assess affective response to an extended } \\
\text { collaborative learning arrangement }\end{array}$ & 217 Chinese students & $\begin{array}{l}\text { Survey } \\
\text { A questionnaire before and after the } \\
\text { collaborative learning arrangement }\end{array}$ & $\begin{array}{l}\text { 1. Though students had quite a positive attitude toward peer assessment, } \\
\text { they were unsure ab out its fairness and felt uncomfortable about it as an } \\
\text { assessment. } \\
\text { 2. These students had a strong "collectivist orientation"; They preferred } \\
\text { to work as a group rather than as a pair, and did not like working alone } \\
\text { 3. Collaborative learning acted as social scaffolding. It became a step in } \\
\text { decreasing learners' reliance on the teacher. }\end{array}$ \\
\hline 14 & $\begin{array}{l}\text { Yeung \& } \\
\text { Hyland (1999) }\end{array}$ & $\begin{array}{l}\text { Hong Kong } \\
\text { (Tertiary) }\end{array}$ & Language & $\begin{array}{l}\text { To evaluate whether the integration of SALL } \\
\text { component in the course was successful }\end{array}$ & $\begin{array}{l}\text { Students }+ \text { Teachers } \\
\text { involving in teaching } \\
\text { the course } \\
\text { (number unclear) }\end{array}$ & $\begin{array}{l}\text { 1. Interviews with students, } \\
\text { 2. Interview with eight teachers } \\
\text { 3. Students' self-record forms and log entries } \\
\text { at the SAC, } \\
\text { 4. Focused discussion, } \\
\text { 5. Questionnaire }\end{array}$ & $\begin{array}{l}\text { 1. Students felt they did not receive sufficient guidance; } \\
\text { 2. Students regarded SALL as a way to improve their general English than } \\
\text { rather than a way to achieve their course aims. } \\
\text { 3. Students did not take enough responsibility and commitment to their } \\
\text { learning. }\end{array}$ \\
\hline 15 & $\begin{array}{l}\text { Black \& Deci } \\
(2000)\end{array}$ & $\begin{array}{l}\text { USA } \\
\text { (Tertiary) }\end{array}$ & $\begin{array}{l}\text { Organic } \\
\text { chemistry }\end{array}$ & $\begin{array}{l}\text { To investigate the effects of students' } \\
\text { course-specific self-regulation and their } \\
\text { perceptions of their instructors' autonomy } \\
\text { support on adjustment and academic } \\
\text { performance. }\end{array}$ & 137 students & $\begin{array}{l}\text { Two sets of questionnaire } \\
\text { (1) The General Causality Orientation Scale } \\
\text { (GCOS), (Deci \& Ryan, 1985) } \\
\text { (2) The Learning Climate Questionnaire (LCQ), } \\
\text { (Williams \& Deci, 1996) }\end{array}$ & $\begin{array}{l}\text { Students' perceptions of their instructors' autonomy support predicted } \\
\text { increases in autonomous self-regulation, perceived competence, and } \\
\text { interest/enjoyment, and decrease on anxiety over the semester }\end{array}$ \\
\hline 16 & $\begin{array}{l}\text { Bolhuis \& } \\
\text { Voeten (2001) }\end{array}$ & $\begin{array}{l}\text { The } \\
\text { Netherlands } \\
\text { (Secondary } \\
\text { level) }\end{array}$ & $\begin{array}{l}\text { Many subject } \\
\text { areas }\end{array}$ & $\begin{array}{l}\text { To examine the extent to which teaching } \\
\text { behaviors in classroom supported students' } \\
\text { self-regulation }\end{array}$ & 68 teachers & Classroom observations (130 classes) & $\begin{array}{l}\text { 1. Teachers tended to engage in activating teaching rather process- } \\
\text { oriented teaching. } \\
\text { 2. Explicit teaching of how to learn should be incorporated. } \\
\text { 3. Self regulation was not just stimulating students to take active part in } \\
\text { their learning, but also helping them in obtaining learning skills. }\end{array}$ \\
\hline 17 & $\begin{array}{l}\text { Clemente } \\
\text { (2001) }\end{array}$ & $\begin{array}{l}\text { Mexico } \\
\text { (Tertiary) }\end{array}$ & $\begin{array}{l}\text { Language } \\
\text { (Not specified) }\end{array}$ & $\begin{array}{l}\text { To examine teachers' attitudes towards } \\
\text { self-directed learning and the self access } \\
\text { center }\end{array}$ & 15 language teachers & $\begin{array}{l}\text { An ethnographic approach } \\
\text { 1. An anonymous open questionnaire } \\
\text { 2. Researcher's own knowledge } \\
\text { 3. Comments from teachers' meetings and } \\
\text { informal conversations with the coordinator of } \\
\text { SAC and the teachers }\end{array}$ & $\begin{array}{l}\text { Counsellor teachers had negative attitudes towards the implementation } \\
\text { of SAC. Three main attitudes were exhibited: } \\
\text { 1. Distrust of students } \\
\text { 2. Unbelief in principles } \\
\text { 3. Rejection of innovation }\end{array}$ \\
\hline 18 & $\begin{array}{l}\text { Hurd, Beaven } \\
\text { \& Ortega } \\
(2001)\end{array}$ & $\begin{array}{l}\text { UK. } \\
\text { (Diploma) }\end{array}$ & $\begin{array}{l}\text { Language } \\
\text { (Spanish) }\end{array}$ & $\begin{array}{l}\text { To investigate how the highly structured } \\
\text { language courses in distance learning can } \\
\text { foster learner autonomy }\end{array}$ & $\begin{array}{l}\text { A Spanish course for } \\
\text { diploma }\end{array}$ & $\begin{array}{l}\text { Cases study } \\
\text { Materials in these courses, } \\
\text { 2. Course syllabuses; } \\
\text { 3. Documents related to course structures }\end{array}$ & $\begin{array}{l}\text { The course book included these features which support students to } \\
\text { exercise autonomy in their learning: } \\
\text { 1. Study charts, including course syllabus, clear learning objectives, } \\
\text { content, timing and materials. These charts gave students a sense of } \\
\text { ownership of their learning as they could foresee what was going to }\end{array}$ \\
\hline
\end{tabular}




\begin{tabular}{|c|c|c|c|c|c|c|c|}
\hline 19 & Rivers (2001) & $\begin{array}{l}\text { USA. } \\
\text { (Informal } \\
\text { education: } \\
\text { a language } \\
\text { project) }\end{array}$ & $\begin{array}{l}\text { Language } \\
\text { (Russian) }\end{array}$ & To examine students' autonomy & 11 adult learners & $\begin{array}{l}\text { Survey } \\
\text { Two questionnaires }\end{array}$ & $\begin{array}{l}\text { 1. Students were autonomous, which can be seen through their request } \\
\text { some changes in the course. } \\
\text { 2. Students were not satisfied with teaching style which focused on rote } \\
\text { memorization. }\end{array}$ \\
\hline 20 & Spratt (2001) & $\begin{array}{l}\text { Hong Kong } \\
\text { (Tertiary) }\end{array}$ & $\begin{array}{l}\text { Language } \\
\text { (English) }\end{array}$ & $\begin{array}{l}\text { To investigate learners' preferences } \\
\text { amongst } 48 \text { English language learning } \\
\text { activities }\end{array}$ & 997 students & Questionnaire & $\begin{array}{l}\text { 1. Students' preferences for activities are not accurately recognized by } \\
\text { teachers; } \\
\text { 2. It is useful to find out students' preferences so that lessons and } \\
\text { materials can be planed and catered for them. Learner autonomy, thus, } \\
\text { might be approached within this teaching and learning context. }\end{array}$ \\
\hline 21 & Chen (2002) & $\begin{array}{l}\text { USA } \\
\text { (Tertiary) }\end{array}$ & $\begin{array}{l}\text { Business } \\
\text { information } \\
\text { system }\end{array}$ & $\begin{array}{l}\text {-To investigate what self-regulated } \\
\text { strategies are effective for learning in a } \\
\text { lecture and in a computer lab; } \\
\text { - To study the effects of students' prior } \\
\text { computer experience and software used in } \\
\text { these two learning environments }\end{array}$ & 197 students & $\begin{array}{l}\text { 1. Demographic questionnaire } \\
\text { 2. MSLQ : to assess students' self-regulated } \\
\text { learning strategies used } \\
\text { 3. Test scores and lab assignment scores }\end{array}$ & $\begin{array}{l}\text { 1. The effective strategy for learning in a lecture environment was effort } \\
\text { regulation; in a computer lab, students who had ability to handle } \\
\text { distractions and maintain concentration would achieve higher scores; } \\
\text { 2. Prior computer experience did not help students to get better test } \\
\text { scores. }\end{array}$ \\
\hline 22 & $\begin{array}{l}\text { Garrett \& } \\
\text { Shortall } \\
(2002)\end{array}$ & $\begin{array}{l}\text { Brazil } \\
\text { (a language } \\
\text { school) }\end{array}$ & 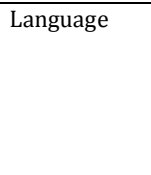 & $\begin{array}{l}\text { To investigate language learners' attitudes } \\
\text { towards their experiences of different types } \\
\text { of classroom activities (teacher-fronted } \\
\text { activities and student-center pairwork } \\
\text { activities) }\end{array}$ & 103 EFL students & Questionnaire & $\begin{array}{l}\text { 1. Students preferred to learn grammar with teachers rather than } \\
\text { learning with peers; } \\
\text { 2. Students were afraid that they would not get enough feedbacks and } \\
\text { corrections if they learn without teachers; } \\
\text { 3. Students from lower levels seemed to rely on teachers more than those } \\
\text { from higher levels. }\end{array}$ \\
\hline 23 & $\begin{array}{l}\text { Spratt, } \\
\text { Humphreys \& } \\
\text { Chan } \\
(2002) \\
\end{array}$ & $\begin{array}{l}\text { Hong Kong } \\
\text { (Tertiary) }\end{array}$ & Language & $\begin{array}{l}\text {-To assess students' readiness for learner } \\
\text { autonomy in language learning; }\end{array}$ & 508 students & Questionnaire & $\begin{array}{l}\text { 1.Motivation may be a precondition for learner autonomy; } \\
\text { 2. It is, therefore, teachers' duty to motivate students to learn, especially } \\
\text { when there is learner resistance to engaging in autonomous practice; }\end{array}$ \\
\hline 24 & Usuki (2002) & $\begin{array}{l}\text { Japan } \\
\text { (Tertiary) }\end{array}$ & Language & $\begin{array}{l}\text { - To explore what students think of their } \\
\text { role as a learner \& the role of classroom } \\
\text { learning }\end{array}$ & Students & $\begin{array}{l}\text { 1. Focus-group } \\
\text { 2. A case study of an autonomous learner } \\
\text { 3. Open-ended questionnaire }\end{array}$ & $\begin{array}{l}\text { 1. Roles that the learner should play included: self-direction; seeking } \\
\text { opportunities for self-growth; seeking learning opportunities; being } \\
\text { aware of objectives \& goal setting; self-monitoring; self-motivation; } \\
\text { environmental structuring; and getting information. } \\
\text { 2. Learning in classroom should encourage interdependence; discovery; } \\
\text { organizing; getting new things; getting support \& help; getting learning } \\
\text { opportunities; and solving problems. }\end{array}$ \\
\hline 25 & Erstad (2003) & $\begin{array}{l}\text { Norway } \\
\text { (Secondary } \\
\text { level) }\end{array}$ & & $\begin{array}{l}\text { To examine how ICT can empower and } \\
\text { support students to be the center of their } \\
\text { own learning }\end{array}$ & 3 secondary schools & $\begin{array}{l}\text { Cases studies } \\
\text { 1. interviews (students, teachers, school } \\
\text { principals, \& parents) } \\
\text { 2. Classroom observations }\end{array}$ & $\begin{array}{l}\text { 1. Imp ortant decisions related to learning process were still made by the } \\
\text { teacher, thus none of these schools are truly student-centred. } \\
\text { 2. High and flexible access to technology and the internet facilitated the } \\
\text { use of project-based approach, which in turn enabled students to work } \\
\text { more independently of the teacher; } \\
\text { 3. Integrating technology in learning-related activities enhanced } \\
\text { students' sense of empowerment. }\end{array}$ \\
\hline 26 & Littlewood & Hong Kong & Language & To question some commonly held & 2,655 students & Questionnaire & 1. It is wrong to conclude that Asian students are more ready to accept \\
\hline
\end{tabular}




\begin{tabular}{|c|c|c|c|c|c|c|c|}
\hline & (2003) & (Tertiary) & & $\begin{array}{l}\text { assumptions about the learning preferences } \\
\text { of Asian \& Western students }\end{array}$ & & & $\begin{array}{l}\text { the traditionally role of the teacher than European students are. } \\
\text { 2. Asian students claimed that the main cause of their 'apparent } \\
\text { passitivity' was how they were expected to learn. }\end{array}$ \\
\hline 27 & Chuk (2004) & $\begin{array}{l}\text { Hong Kong } \\
\text { (Diploma) }\end{array}$ & $\begin{array}{l}\text { Language } \\
\text { (English) }\end{array}$ & $\begin{array}{l}\text { To investigate how the integration of } \\
\text { Exploratory Practice into classroom } \\
\text { practice can foster learner autonomy }\end{array}$ & 18 diploma students & $\begin{array}{l}\text { 1. Group discussions } \\
\text { 2. Oral presentations } \\
\text { 3. Learner diary records } \\
\text { 4. Teacher-researcher records }\end{array}$ & $\begin{array}{l}\text { 1. Students' past experience of learning affected their concept of learning. } \\
\text { 2. Learner diary became a means for students to monitor and evaluate } \\
\text { their learning progress. } \\
\text { 3. By reading students' dairy, the teacher was provided with immediate } \\
\text { feedback and became more reflective. By keeping a teaching dairy, the } \\
\text { teacher gained a fuller understanding of their practice; }\end{array}$ \\
\hline 28 & $\begin{array}{l}\text { Logan \& } \\
\text { Moore (2004) }\end{array}$ & $\begin{array}{l}\text { New } \\
\text { Zealand } \\
\text { (language } \\
\text { school) }\end{array}$ & $\begin{array}{l}\text { Language } \\
\text { (English) }\end{array}$ & $\begin{array}{l}\text { To investigate teachers' perceptions of } \\
\text { professional development program }\end{array}$ & 22 teachers & $\begin{array}{l}\text { 1. Self-administered questionnaire, } \\
\text { 2. Follow-up interview }\end{array}$ & $\begin{array}{l}\text { 1. Teachers had difficulties in applying lessons from the training in their } \\
\text { teaching practices. } \\
\text { 2. This may result from (a) pressure from completing the course book } \\
\text { rather than training learner, and (b) the teachers themselves - some of } \\
\text { them had forgot what had been practiced in the training. }\end{array}$ \\
\hline 29 & $\begin{array}{l}\text { Reeve, Jang, } \\
\text { Carrell, Jeon, \& } \\
\text { Barch (2004) }\end{array}$ & $\begin{array}{l}\text { USA. } \\
\text { (High } \\
\text { school } \\
\text { level) }\end{array}$ & Unspecified & $\begin{array}{l}\text { To test two hypothesizes: } \\
\text { Hypothesis 1: Teachers exposed to a } \\
\text { workshop on autonomy-support and a self- } \\
\text { study website showed an increase in their } \\
\text { autonomy-supportive behaviors in their } \\
\text { classroom practices; } \\
\text { Hypothesis 2: Students whose teachers } \\
\text { underwent the above experimental } \\
\text { workshop became more engaged in their } \\
\text { learning }\end{array}$ & 20 teachers & $\begin{array}{l}\text { An experimental study (10-week period) } \\
\text { Classroom observations } \\
\text { Interventions: a workshop }\end{array}$ & $\begin{array}{l}\text { 1. Teachers in the experimental group (participating in a workshop and a } \\
\text { self-study website) displayed more autonomy-supportive behaviors in } \\
\text { their teaching practices than those from the control group; } \\
\text { 2. Students of the experimental-group teachers became more engaged in } \\
\text { their learning than those of the control-group teachers. }\end{array}$ \\
\hline 30 & $\begin{array}{l}\text { van den Boom, } \\
\text { Pass, van } \\
\text { Merrienbore, } \\
\& \text { van Gog } \\
(2004)\end{array}$ & $\begin{array}{l}\text { The } \\
\text { Netherlands } \\
\text { (Tertiary) }\end{array}$ & $\begin{array}{l}\text { Heath } \\
\text { Psychology }\end{array}$ & $\begin{array}{l}\text { To explore the effects of reflection prompts } \\
\text { and teachers' feedback on students' self- } \\
\text { regulated learning (SRL) in a web-based } \\
\text { learning environment }\end{array}$ & 42 teacher students & Experimental design (Pretest-posttest design) & $\begin{array}{l}\text { 1. Students who received reflection prompts relevant to SRL exhibited } \\
\text { higher self-regulated learning skills than those who received prompts } \\
\text { which were relevant to other aspects of learning but not to SRL; } \\
\text { 2. Tutor feedback alone seemed not to promote self-regulated learning } \\
\text { skills; }\end{array}$ \\
\hline 31 & Liu (2005) & $\begin{array}{l}\text { China } \\
\text { (Tertiary) }\end{array}$ & $\begin{array}{l}\text { Language } \\
\text { (English) }\end{array}$ & $\begin{array}{l}\text { To investigate the readiness of Chinese } \\
\text { university students' learner autonomy }\end{array}$ & 300 students & $\begin{array}{l}\text { Survey by Questionnaire } \\
\text { Adapted from Sheerin's } 1997\end{array}$ & $\begin{array}{l}\text { 1. Teachers were viewed as a knowledge transmitter and and students as } \\
\text { a knowledge recipient; } \\
\text { 2. The students still depend a lot on the teacher and got used to the } \\
\text { teacher-dominated methodology. }\end{array}$ \\
\hline 32 & $\begin{array}{l}\text { Pinkman } \\
(2005)\end{array}$ & $\begin{array}{l}\text { Japan } \\
\text { (Tertiary) }\end{array}$ & $\begin{array}{l}\text { Language } \\
\text { (English) }\end{array}$ & $\begin{array}{l}\text { To investigate how blogs could encourage } \\
\text { learner independence and out of class } \\
\text { learning }\end{array}$ & 15 students & $\begin{array}{l}\text { Small-scale action research } \\
\text { 1. Pre- \& Post-questionnaire (15 students) } \\
\text { 2. Interviews (10 students) }\end{array}$ & $\begin{array}{l}\text { 1. Students were positive with the use of blogs. The interaction with } \\
\text { classmate when keeping blogs resulted in enjoyment and improved } \\
\text { writing skills. } \\
\text { 2. Blogs can be integrated as a class activity, which inspired students to } \\
\text { go beyond the classroom, and interact with new people. This in turn } \\
\text { helped encourage learner independence. }\end{array}$ \\
\hline$\overline{33}$ & $\begin{array}{l}\text { Wang \& Fang } \\
\text { (2005) }\end{array}$ & $\begin{array}{l}\text { Taiwan } \\
\text { (Tertiary) }\end{array}$ & $\begin{array}{l}\text { Language } \\
\text { (English) }\end{array}$ & $\begin{array}{l}\text { To explore the benefits of cooperative } \\
\text { learning via weblogs }\end{array}$ & Students & $\begin{array}{l}\text { 1. Students' online response (asynchron ous } \\
\text { communication) } \\
\text { 2. Questionnaire }\end{array}$ & $\begin{array}{l}\text { 1. Benefits of cooperative learning via weblogs include learner autonomy, } \\
\text { cooperative learning and time management. } \\
\text { 2. Students felt more confident when using blogs working within their } \\
\text { group members; } \\
\text { 3. However, almost all of the students believed that face-to-face } \\
\text { interaction also helped their group to accomplish their goal. }\end{array}$ \\
\hline 34 & $\begin{array}{l}\text { Zhou \& } \\
\text { Zhang (2005) }\end{array}$ & $\begin{array}{l}\text { China } \\
\text { (Tertiary) }\end{array}$ & $\begin{array}{l}\text { Language } \\
\text { (English) }\end{array}$ & $\begin{array}{l}\text { To explore EFL college students' beliefs } \\
\text { about language learning }\end{array}$ & 120 students & Questionnaire & $\begin{array}{l}\text { 1. Learners are becoming the source of information for classroom } \\
\text { activities and the focus of curriculum design; }\end{array}$ \\
\hline
\end{tabular}




\begin{tabular}{|c|c|c|c|c|c|c|c|}
\hline 35 & $\begin{array}{l}\text { Anderton } \\
(2006)\end{array}$ & $\begin{array}{l}\text { USA } \\
\text { (Tertiary) }\end{array}$ & Education & $\begin{array}{l}\text { - To examine whether the use of goal } \\
\text { planning, weekly monitoring and evaluation } \\
\text { forms in an online class can promote SRL } \\
\text { skills; } \\
\text { - To study whether the use of materials to } \\
\text { promote SRL influence student academic } \\
\text { achievement. }\end{array}$ & $\begin{array}{l}28 \text { pre-service } \\
\text { teachers taking online } \\
\text { courses }\end{array}$ & $\begin{array}{l}\text { Quasi-experimental } \\
\text { Intervention: goal planning, strategy } \\
\text { monitoring and evaluating forms }\end{array}$ & $\begin{array}{l}\text { 1. Requiring the learners to fill up goal planning, weekly monitoring and } \\
\text { evaluation forms promoted the use of SRL strategies; } \\
\text { 2. The use of the above forms did not influence the learners' academic } \\
\text { achievement }\end{array}$ \\
\hline 36 & $\begin{array}{l}\text { Kavanoz } \\
(2006)\end{array}$ & $\begin{array}{l}\text { Turkey } \\
\text { (Primary } \\
\text { level) }\end{array}$ & $\begin{array}{l}\text { Language } \\
\text { (English) }\end{array}$ & $\begin{array}{l}\text { To explore teachers' beliefs, understanding } \\
\text { and actual practices of learner- } \\
\text { centeredness }\end{array}$ & $\begin{array}{l}13 \text { teachers from two } \\
\text { schools }\end{array}$ & $\begin{array}{l}\text { Cases studies } \\
\text { 1. Focus group interviews } \\
\text { 2. Individual interviews } \\
\text { 3. Class observations } \\
\text { 4. Pre-and after-observation reflections } \\
\text { 5. Document analysis }\end{array}$ & $\begin{array}{l}\text { 1. Teachers from the public school had a misunderstanding of the } \\
\text { principles of learner-centered ness, while those from the private school } \\
\text { did not. } \\
\text { 2. The study called for more support from schools in providing training } \\
\text { and workshops for teachers where they should be presented with } \\
\text { fundamental principles of the learner-centeredness, and a framework of } \\
\text { instructional methods supportive to learner-centeredness. }\end{array}$ \\
\hline 37 & Jing (2006a) & $\begin{array}{l}\text { Hong Kong } \\
\text { (Tertiary) }\end{array}$ & $\begin{array}{l}\text { Language } \\
\text { (English) }\end{array}$ & $\begin{array}{l}\text { To foster learner autonomy within the } \\
\text { constraints of classroom context }\end{array}$ & $\begin{array}{l}30 \text { students }+13 \\
\text { teachers }\end{array}$ & $\begin{array}{l}\text { Grounded Approach } \\
\text { 1. Interviews } \\
\text { 2. Field notes } \\
\text { 3. Personal experience of the researcher in } \\
\text { supervising the participant students }\end{array}$ & $\begin{array}{l}\text { 1. The students' lack of initiatives in the writing course was a result of } \\
\text { their view of the course and the examination. } \\
\text { 2. Rather than giving students topics for writing, the researcher involved } \\
\text { students in small-scale classroom research project. As a result, students } \\
\text { became more initiative and gradually learned to take responsibility for } \\
\text { their own learning. }\end{array}$ \\
\hline 38 & Jing (2006b) & $\begin{array}{l}\text { Hong Kong } \\
\text { (Tertiary) }\end{array}$ & $\begin{array}{l}\text { Language } \\
\text { (English) }\end{array}$ & $\begin{array}{l}\text { To examine how and why learner resistance } \\
\text { occurred in a metacognition-training (MT) } \\
\text { project }\end{array}$ & Students & $\begin{array}{l}\text { 1. Learner diaries } \\
\text { 2. Classroom observation } \\
\text { 3. End-of-course questionnaire } \\
\text { 4. Group interviews }\end{array}$ & $\begin{array}{l}\text { Learner resistance resulted from: } \\
\text { - institutional pressures and societal expectations, which led to the value } \\
\text { in examination culture } \\
\text { - approach in the classroom, which was product-oriented } \\
\text { - the mismatch between the teacher and the students' goals and } \\
\text { expectations }\end{array}$ \\
\hline 39 & $\begin{array}{l}\text { Luke } \\
(2006)\end{array}$ & $\begin{array}{l}\text { Spain } \\
\text { (Tertiary) }\end{array}$ & Language & $\begin{array}{l}\text { To increase learner autonomy through self- } \\
\text { directed learning activities }\end{array}$ & 17 students & $\begin{array}{l}\text { Case study } \\
\text { 1. The researcher's anecdotal records } \\
\text { 2. Classroom observations } \\
\text { 3. Phenomenological interviews } \\
\text { 4. Documents submitted from students }\end{array}$ & $\begin{array}{l}\text { 1. Negotiating the curriculum is a way to empower the students Though } \\
\text { negotiation of the curricular is encouraged, the teacher sometimes does } \\
\text { not know what is best for students; } \\
\text { 2. There is a mismatch between students' expectation for a language class } \\
\text { and the reality of the inquiry-based classroom. }\end{array}$ \\
\hline 40 & $\begin{array}{l}\text { Mailloux } \\
(2006)\end{array}$ & $\begin{array}{l}\text { USA. } \\
\text { (Tertiary) }\end{array}$ & $\begin{array}{l}\text { Nursing } \\
\text { education }\end{array}$ & $\begin{array}{l}\text { To investigate the extent to which students' } \\
\text { perception of faculties' teaching strategies, } \\
\text { students' contexts and perceptions of } \\
\text { learner empowerment affected their } \\
\text { perception of autonomy }\end{array}$ & 198 female students & $\begin{array}{l}\text { Correlational study } \\
\text { 1. Learner Empowerment Measure (LEM) } \\
\text { 2. Caring Perspective (ACP) (Boughn, 1995) } \\
\text { 3. Demographic data questionnaire (designed } \\
\text { by the researcher) }\end{array}$ & $\begin{array}{l}\text { 1. Students' age and perceptions of empowerment had a direct impact on } \\
\text { their perceptions of autonomy; } \\
\text { 2. The teaching strategies used by nursing schools under this study were } \\
\text { various, but which strategies supportive to autonomous learning were } \\
\text { not emphasized }\end{array}$ \\
\hline 41 & Sert (2006) & $\begin{array}{l}\text { Turkey } \\
\text { (Tertiary) }\end{array}$ & $\begin{array}{l}\text { Language } \\
\text { (English) }\end{array}$ & $\begin{array}{l}\text { To investigate EFL student teachers in the } \\
\text { program are able to direct and monitor } \\
\text { their language learning process }\end{array}$ & $\begin{array}{l}57 \text { first-year teacher } \\
\text { students }\end{array}$ & $\begin{array}{l}\text { Case Study } \\
\text { 1. Structured/unstructured class observation } \\
\text { 2, Structured/unstructured interviews } \\
\text { 3. Document analysis } \\
\text { 4. Swiss version of Council of Europe's self- } \\
\text { assessment checklists } \\
\text { 5. One of past examination papers of FCE } \\
\end{array}$ & $\begin{array}{l}\text { 1.The activities used in the classrooms do not aim at preparing the } \\
\text { students to be aware of their needs, goals, strengths and weaknesses as } \\
\text { learners; } \\
\text { 2. These student teachers will not probably be able to enable their future } \\
\text { students to take responsibility for their own learning, as the beliefs about } \\
\text { language teaching and learning as well as teaching habits exp osed to } \\
\text { them while being learners are traditional and not conducive to }\end{array}$ \\
\hline
\end{tabular}




\begin{tabular}{|c|c|c|c|c|c|c|c|}
\hline & & & & & & & autonomy. \\
\hline 42 & $\begin{array}{l}\text { Anderson \& } \\
\text { Bourke (2007) }\end{array}$ & $\begin{array}{l}\text { Australia } \\
\text { (Tertiary) }\end{array}$ & $\begin{array}{l}\text { Language } \\
\text { (Japanese/Kan } \\
\text { ji) }\end{array}$ & $\begin{array}{l}\text { To examine the use of explicit strategy } \\
\text { instruction, teacher guidance and the } \\
\text { reflectivity on learning in assisting learners } \\
\text { to be more autonomous }\end{array}$ & 30 students & $\begin{array}{l}\text { Pre- and Post-SILK Test; } \\
\text { Pre- and Post-interviews }\end{array}$ & $\begin{array}{l}\text { 1. SILK enabled learner to reflect on and evaluate their kanji learning. It } \\
\text { raised their learning awareness particularly their learning patterns and } \\
\text { choices; } \\
\text { 2. The curriculum in which strategy training was incorporated enabled } \\
\text { students to reflect on their learning and provided them with a range of } \\
\text { learning strategies. }\end{array}$ \\
\hline 43 & Bakar (2007) & $\begin{array}{l}\text { Malaysia } \\
\text { (Secondary) }\end{array}$ & $\begin{array}{l}\text { Language } \\
\text { (English) }\end{array}$ & $\begin{array}{l}\text { - To examine how teachers and students } \\
\text { perceived the use of computers in their } \\
\text { classroom } \\
\text { - To examine teachers' and students' } \\
\text { attitudes towards learner autonomy }\end{array}$ & $\begin{array}{l}2 \text { classes of students }+ \\
2 \text { teachers }\end{array}$ & $\begin{array}{l}\text { Case study (of a school) } \\
\text { 1. Interviews } \\
\text { 2. Classroom observation }\end{array}$ & $\begin{array}{l}\text { 1. Students preferred to have the teachers teach them rather than } \\
\text { learning independently with computers, and felt more comfortable when } \\
\text { learning with teachers. Students perceived that computers did not help } \\
\text { them to learn much. This indicated that students still relied on teachers } \\
\text { and were not able to learn by themselves. } \\
\text { 2. The teachers perceived the benefits of using computers in the class and } \\
\text { acknowledged the needs for learner autonomy. However, they were not } \\
\text { confident whether their students were able to take charge of their } \\
\text { learning. The teachers regarded students' English proficiency as a major } \\
\text { indicator for students ability to be autonomous learners. } \\
\text { 3. The teachers regarded the pressure to cover the course syllabus and } \\
\text { the examination requirements as the main limitation of their ability to } \\
\text { promote learner autonomy. }\end{array}$ \\
\hline 44 & $\begin{array}{l}\text { Balcikanli } \\
\text { (2007) }\end{array}$ & $\begin{array}{l}\text { Turkey } \\
\text { (Tertiary) }\end{array}$ & $\begin{array}{l}\text { Language } \\
\text { (English) }\end{array}$ & $\begin{array}{l}\text { To investigate the instructors' attitudes } \\
\text { towards learner autonomy }\end{array}$ & 51 lecturers & Survey by questionnaire & $\begin{array}{l}\text { 1. Learner autonomy is viewed positively by nearly all of the participant } \\
\text { instructors; } \\
\text { 2. These instructors believe not every point of teaching and learning are } \\
\text { feasible for the implementation of learner autonomy; } \\
\text { 3. Professional training should be given to instructors. }\end{array}$ \\
\hline 45 & Carson (2007) & $\begin{array}{l}\text { Ireland } \\
\text { (Non- } \\
\text { formal } \\
\text { education) }\end{array}$ & $\begin{array}{l}\text { Language } \\
\text { (English) }\end{array}$ & $\begin{array}{l}\text { - To examine the role inn motivating of } \\
\text { goal-setting in the curriculum which was } \\
\text { generated from learners' needs and targets } \\
\text { - To illustrate the importance of students' } \\
\text { sense of relatedness in their autonomy in } \\
\text { their learning }\end{array}$ & 1 adult refugee student & $\begin{array}{l}\text { Case study } \\
\text { 1. Participant observation } \\
\text { 2. Audio interviews } \\
\text { 3. Attitudinal questionnaires } \\
\text { 4. Archival data from school records }\end{array}$ & $\begin{array}{l}\text { 1. The use of group/pairwork enhanced the case's sense of relatedness to } \\
\text { his class; } \\
\text { 2. When learners were involved in setting goals of their learning, they } \\
\text { were more motivated and related to their own learning. This resulted in a } \\
\text { shift in their learning behaviors, that is to self-directed learning. }\end{array}$ \\
\hline 46 & $\begin{array}{l}\text { Dongmei } \\
(2007)\end{array}$ & $\begin{array}{l}\text { China } \\
\text { (Tertiary) }\end{array}$ & $\begin{array}{l}\text { Language } \\
\text { (English) }\end{array}$ & $\begin{array}{l}\text { - To find out how to integrate CALL with } \\
\text { strategy training } \\
\text { - To examine the extent to which this } \\
\text { integration helped develop learner } \\
\text { autonomy }\end{array}$ & 460 students & A questionnaire & $\begin{array}{l}\text { 1. Most students regarded their roles as a follower and consumer in } \\
\text { learning process; } \\
\text { 2. Teachers were viewed as an authoritarian and played a dominant role; } \\
\text { 3. Despite their positive ideas towards learner autonomy, students were } \\
\text { not confident in their ability to take charge of their own learning. }\end{array}$ \\
\hline 47 & $\begin{array}{l}\text { Figura \& Jarvis } \\
\text { (2007) }\end{array}$ & $\begin{array}{l}\text { UK } \\
\text { (Non- } \\
\text { formal } \\
\text { education) }\end{array}$ & $\begin{array}{l}\text { Language } \\
\text { (English) }\end{array}$ & $\begin{array}{l}\text { To investigate students' use of computer- } \\
\text { based materials (CBMs) in a self-access } \\
\text { learning center (SAC) }\end{array}$ & 26 students & $\begin{array}{l}\text { 1. Questionnaire } \\
\text { 2. Interview } \\
\text { 3. Snap-shot observations }\end{array}$ & $\begin{array}{l}\text { 1. Most of students preferred to use their L1 rather than English and } \\
\text { rarely use social strategies; } \\
\text { 2. Students were satisfied with the degree of control they had when } \\
\text { learning with computers, in that they could learn at their own pace and } \\
\text { own ways. }\end{array}$ \\
\hline 48 & Januin (2007) & $\begin{array}{l}\text { Malaysia } \\
\text { (Tertiary) }\end{array}$ & $\begin{array}{l}\text { Language } \\
\text { (English) }\end{array}$ & $\begin{array}{l}\text { To investigate distance students' readiness } \\
\text { for language learning autonomy }\end{array}$ & 72 distance students & A questionnaire & $\begin{array}{l}\text { 1. Students viewed teachers as a 'dominant figure' (p.24) in their } \\
\text { learning, and relied a lot on teachers and believed that learning mostly } \\
\text { take placed in classroom. Thus, outside-class activities were regarded } \\
\text { less imp ortant to their language learning; } \\
\text { 2. The students were not sure about their ability to learn L2. }\end{array}$ \\
\hline 49 & Jing-yuan & China & Language & To explore how learner autonomy & 466 first-year diploma & 1. Sensation-Seeking Scale & 1. Not many excellent learners were able to develop their metacognitive \\
\hline
\end{tabular}




\begin{tabular}{|c|c|c|c|c|c|c|c|}
\hline & (2007) & $\begin{array}{l}\text { (Tertiary; } \\
\text { diploma) }\end{array}$ & & improving learners' oral language; & & 2. Metacognitive strategy questionnaires & $\begin{array}{l}\text { strategy; } \\
\text { 2. Teachers could help students fostering their metacognition by } \\
\text { highlighting fundamental principles and giving a conclusion at an } \\
\text { appropriate moment. }\end{array}$ \\
\hline 50 & $\begin{array}{l}\text { Kaur \& Embi } \\
(2007)\end{array}$ & $\begin{array}{l}\text { Malaysia } \\
\text { (Tertiary) }\end{array}$ & $\begin{array}{l}\text { Language } \\
\text { education } \\
\text { (English) }\end{array}$ & $\begin{array}{l}\text { To investigate the extent to which } \\
\text { asynchronous online interactions between } \\
\text { learners and tutors assist the development } \\
\text { of learner autonomy }\end{array}$ & 30 first-year students & $\begin{array}{l}\text { 1. Questionnaire } \\
\text { 2. Semi-structured interview } \\
\text { 3. Email interactions }\end{array}$ & $\begin{array}{l}\text { 1. Tutors did not give prompt responses to students' email, resulting in } \\
\text { students' dissatisfaction; } \\
\text { 2. In order for a distance online learning to be successful, students need } \\
\text { computer-literacy and knowledge about planning, organizing, monitoring } \\
\text { and evaluating. }\end{array}$ \\
\hline 51 & $\begin{array}{l}\text { Kusanagi } \\
(2007)\end{array}$ & $\begin{array}{l}\text { Japan } \\
\text { (Tertiary) }\end{array}$ & $\begin{array}{l}\text { Language } \\
\text { (English) }\end{array}$ & $\begin{array}{l}\text { - To examine the use of an art activity } \\
\text { "Montage" to foster students' relatedness } \\
\text { and leaner autonomy } \\
\text { (Montage was introduced to EFL class as a } \\
\text { means to deal with students' negative } \\
\text { towards teamwork \& class participation) }\end{array}$ & 27 students & $\begin{array}{l}\text { 1. Observations } \\
\text { 2. Pre- and Post Questionnaire }\end{array}$ & $\begin{array}{l}\text { 1. Students enjoyed the montage activities, and were more enthusiastic, } \\
\text { confident to voice out, and engaged in their learning; } \\
\text { 2. While doing montage activities, students shared their feelings and } \\
\text { thoughts with their peers. This enhanced their sense of relatedness with } \\
\text { their peers. This in turns affected their motivation and autonomy in } \\
\text { learning. }\end{array}$ \\
\hline 52 & $\begin{array}{l}\text { Vonderwell, } \\
\text { Liang, \& } \\
\text { Alderman } \\
\text { (2007) }\end{array}$ & $\begin{array}{l}\text { USA } \\
\text { (Tertiary; } \\
\text { Postgrad ) }\end{array}$ & $\begin{array}{l}\text { Educational } \\
\text { technology }\end{array}$ & $\begin{array}{l}\text { - To examine the use of asynchronous } \\
\text { discussions in the assessment process of } \\
\text { online learning }\end{array}$ & $\begin{array}{l}\text { Unspecified number of } \\
\text { master students }\end{array}$ & $\begin{array}{l}\text { Case study } \\
\text { 1. Observation of the asynchronous } \\
\text { discussions } \\
\text { 2. Online survey }\end{array}$ & $\begin{array}{l}\text { 1. Essential elements for successful learning and assessment in online } \\
\text { discussion included structure of an online discussion, learning } \\
\text { community, self-regulatory cognitions, learner autonomy, and students } \\
\text { writing skills. } \\
\text { 3. To increase student interest and engagement in discussion, methods } \\
\text { and strategies for assessment should be various. }\end{array}$ \\
\hline 53 & Chiu (2008) & $\begin{array}{l}\text { Taiwan } \\
\text { (Tertiary) }\end{array}$ & $\begin{array}{l}\text { Language } \\
\text { (English) }\end{array}$ & $\begin{array}{l}\text { To investigate the relationships of teachers } \\
\text { roles and learner autonomy in the cyber } \\
\text { teaching }\end{array}$ & $\begin{array}{l}1 \text { teacher and } 2 \mathrm{EFL} \\
\text { adult learners }\end{array}$ & $\begin{array}{l}\text { Case study } \\
\text { 1. Course schedules } \\
\text { 2. Grammar lessons } \\
\text { 3. Written assignment } \\
\text { 4. Online grammar assessment } \\
\text { 5. Online needs assessment } \\
\text { 6. Online course evaluation } \\
\text { 7. E-mails from the participants }\end{array}$ & $\begin{array}{l}\text { 1. The email pal activity made class less structured. Teaching roles need } \\
\text { to be reduced while counseling roles are essential in developing learner } \\
\text { autonomy } \\
\text { 2. Leaner autonomy is enhanced when learners are actively involved in } \\
\text { the productive use of language }\end{array}$ \\
\hline 54 & $\begin{array}{l}\text { Delfino, } \\
\text { Dettori, \& } \\
\text { Persico (2008) }\end{array}$ & $\begin{array}{l}\text { Italy } \\
\text { (Tertiary)) }\end{array}$ & $\begin{array}{l}\text { Preservice } \\
\text { teachers } \\
\text { training }\end{array}$ & $\begin{array}{l}\text { To gain understanding of the role SRL } \\
\text { competences play in VLCs (virtual learning } \\
\text { communities) }\end{array}$ & $\begin{array}{l}95 \text { preservice teacher } \\
\text { students }\end{array}$ & $\begin{array}{l}\text { Content analysis } \\
\text { of messages that students exchanged in two } \\
\text { learning activities }\end{array}$ & $\begin{array}{l}\text { 1. A well- structured online course could be a good opportunity to } \\
\text { practice SRL with peers but may not be able to significantly increase SRL } \\
\text { ability, at least over a short period of time; } \\
\text { 2. Social indicators of SRL were found more frequent than individual } \\
\text { indicators. }\end{array}$ \\
\hline 55 & $\begin{array}{l}\text { Martin, West \& } \\
\text { Bill (2008) }\end{array}$ & UK & $\begin{array}{l}\text { Sport and } \\
\text { exercise } \\
\text { science }\end{array}$ & $\begin{array}{l}\text { To investigate whether the use of problem- } \\
\text { base learning approach would promote } \\
\text { learner autonomy }\end{array}$ & 25 students & $\begin{array}{l}\text { Intervention: 12-week PBL approach } \\
3 \text { scales } \\
\text { :The academic motivation scale } \\
: \text { Rosenberg's self-esteem scale } \\
\text { : The academic locus of control scale }\end{array}$ & $\begin{array}{l}\text { 1. Most of the students perceived the use of PBL approach positively; PBL } \\
\text { gave them a chance to learn independently, and they felt more } \\
\text { responsible and had a greater ownership of their own learning } \\
\text { 2. As there was an increase in students' level of motivation, locus of } \\
\text { control and self-esteem, it can be concluded that the PBL approach could } \\
\text { help promote learner autonomy. }\end{array}$ \\
\hline 56 & $\begin{array}{l}\text { Meeus, Van } \\
\text { Petegem \& } \\
\text { Meijer (2008) }\end{array}$ & $\begin{array}{l}\text { Flanders } \\
\text { (Tertiary) }\end{array}$ & Language & $\begin{array}{l}\text { To examine whether the use of portfolio as } \\
\text { a dissertation model has a greater effect on } \\
\text { the students' capacity for autonomous } \\
\text { learning than the literature study }\end{array}$ & $\begin{array}{l}174 \text { teacher students \& } \\
44 \text { supervisors }\end{array}$ & $\begin{array}{l}\text { Pre- and post-test quasi experiment } \\
\text { Questionnaire }\end{array}$ & $\begin{array}{l}\text { 1. The portfolio model enabled the students to acquire greater } \\
\text { metacognitive knowledge. However, the students only get a chance to use } \\
\text { metacognitive skills when supervisors give them sufficient autonomy. } \\
\text { 2. The teachers' confidence in students' capacity greatly affected their } \\
\text { decisions to allow students to learn autonomously. The increased learner } \\
\text { autonomy results in some supervisors feeling loss of control, hence likely } \\
\text { to limit students' autonomy. }\end{array}$ \\
\hline
\end{tabular}




\begin{tabular}{|c|c|c|c|c|c|c|c|}
\hline 57 & $\begin{array}{l}\text { Murphy } \\
\text { (2008) }\end{array}$ & $\begin{array}{l}\text { UK } \\
\text { (Tertiary; } \\
\text { Open } \\
\text { education) }\end{array}$ & $\begin{array}{l}\text { Language } \\
\text { (French, } \\
\text { German \& } \\
\text { Spanish) }\end{array}$ & $\begin{array}{l}\text { To explore how course materials in Open } \\
\text { University facilitate 'autonomization' }\end{array}$ & No participants & Document analysis Of course materials & $\begin{array}{l}\text { To fully support 'autonomization', course writers need to ensure that the } \\
\text { materials: } \\
\text { - enable students to gain experience \& gain confidence in reflection and } \\
\text { metacognitive strategies; } \\
\text { - focus more on metacognitive or learning strategies; } \\
\text { - advice and practice activities in publications or the course website }\end{array}$ \\
\hline 58 & $\begin{array}{l}\text { Mustafa \& } \\
\text { Cullingford } \\
(2008)\end{array}$ & $\begin{array}{l}\text { Jordan } \\
\text { (Secondary) }\end{array}$ & $\begin{array}{l}\text { Islam } \\
\text { Education }\end{array}$ & $\begin{array}{l}\text { To investigate factors which hinder } \\
\text { teachers from using different teaching } \\
\text { methods }\end{array}$ & $\begin{array}{l}1242 \text { students+98 } \\
\text { teachers }+46 \text { Head } \\
\text { teachers }+8 \\
\text { supervisors+ } \\
\text { 3 Learning Resource } \\
\text { Center Principals } \\
\end{array}$ & $\begin{array}{l}\text { Questionnaire } \\
\text { Interview }\end{array}$ & $\begin{array}{l}\text { Teachers used only one teaching method: lecturing, which was due to } \\
\text { (1) The shortage of materials and technology } \\
\text { (2) Lack of training } \\
\text { (3) Class size } \\
\text { (4) Excessive workload } \\
\text { (5) The pressure of getting through the textbooks }\end{array}$ \\
\hline 59 & $\begin{array}{l}\text { Mynard } \\
\text { (2008) }\end{array}$ & $\begin{array}{l}\text { Japan } \\
\text { (Tertiary) }\end{array}$ & Language & $\begin{array}{l}\text { To examine whether or not the blogs were } \\
\text { used by students as a tool for reflecting on } \\
\text { their learning }\end{array}$ & 22 female students & Students' blogs & $\begin{array}{l}\text { 1. Students used blogs a medium for reflecting on their learning; } \\
\text { 2. Students reflected on their learning in different times and aspects, e.g. } \\
\text { about the test results, ways to improve their English, or their language } \\
\text { skills. However, the frequency of using blogs cannot be treated as an } \\
\text { indicator of being autonomous. }\end{array}$ \\
\hline 60 & $\begin{array}{l}\text { Nicolaides } \\
\text { (2008) }\end{array}$ & $\begin{array}{l}\text { Brazil } \\
\text { (Tertiary) }\end{array}$ & Language & $\begin{array}{l}\text { To investigate the development of learner } \\
\text { autonomy of student teachers }\end{array}$ & 9 teacher students & $\begin{array}{l}\text { Ethnographic Approach } \\
\text { 1. Counseling meetings } \\
\text { 2. Filming \& class observation } \\
\text { 3. Viewing sessions } \\
\text { 4. Meeting with teachers } \\
\text { 5. The researcher's diary }\end{array}$ & $\begin{array}{l}\text { 1. These student teachers realize the importance of ability to control their } \\
\text { own learning, but they feel there is an "imaginary territory" academic } \\
\text { contexts, which prevent them from exercising autonomy; } \\
\text { 2. Outside classroom, these student teachers feel they have more freedom } \\
\text { to follow their own beliefs and make their own decisions. }\end{array}$ \\
\hline 61 & Patrick (2008) & $\begin{array}{l}\text { Australia } \\
\text { (Primary) }\end{array}$ & Not specified & $\begin{array}{l}\text { To explore results after two teachers taking } \\
\text { in a professional development in } \\
\text { cooperative learning (CL) }\end{array}$ & Two teachers & $\begin{array}{l}\text { Case study } \\
\text { 1. Classroom observations } \\
\text { 2. interviews }\end{array}$ & $\begin{array}{l}\text { The number of years of teaching influenced the professional learning of } \\
\text { teachers. That is, the more experienced teacher made more } \\
\text { improvements in understanding and practice related to CL. }\end{array}$ \\
\hline 62 & $\begin{array}{l}\text { Perry, } \\
\text { Hutchinson, \& } \\
\text { Thauberger } \\
(2008)\end{array}$ & $\begin{array}{l}\text { Canada } \\
\text { (Tertiary } \\
\text { level) }\end{array}$ & $\begin{array}{l}\text { Teacher } \\
\text { education } \\
\text { (for } \\
\text { elementary } \\
\text { teachers) }\end{array}$ & $\begin{array}{l}\text { To explore whether and how student } \\
\text { teachers can be assisted to develop } \\
\text { instructional practices supportive to self- } \\
\text { regulated learning }\end{array}$ & $\begin{array}{l}19 \text { student teachers }+ \\
2 \text { faculty associates }+ \\
19 \text { mentor teachers }\end{array}$ & $\begin{array}{l}\text { 1. Teaching journals of student teachers } \\
\text { 2. Observations of mentors' teaching their } \\
\text { student teachers } \\
\text { 3. Observations of student teachers' teaching } \\
\text { 4. Student teachers' lesson plans } \\
\text { 5. Discussions with student teachers and } \\
\text { mentors }\end{array}$ & $\begin{array}{l}\text { What mentors should do to scaffold student teachers included explicitly } \\
\text { referring to practices that support SRL; using example or suggesting what } \\
\text { student teachers could do to encourage SRL; proving feedback to student } \\
\text { teachers about their choices of instructional practices; using questions } \\
\text { that encourage student teachers' metacognition; encouraging student } \\
\text { teachers to transfer their teaching methods into general practices; } \\
\text { modeling of what the mentors should do if they were to teach in the class } \\
\text { and pointing out concrete examples of behaviors or practices supportive } \\
\text { to SRL. }\end{array}$ \\
\hline 63 & Sarsar (2008) & $\begin{array}{l}\text { UAE } \\
\text { (Secondary) }\end{array}$ & Not specified & $\begin{array}{l}\text { - To examine what causes students throw } \\
\text { away textbooks and learning materials at } \\
\text { the end of each academic term, } \\
\text { - To find out how to stop students from } \\
\text { such a practice }\end{array}$ & $\begin{array}{l}\text { Teachers and students } \\
\text { in a school }\end{array}$ & $\begin{array}{l}\text { An inquiry-based approach } \\
\text { 1. Teacher questionnaire } \\
\text { 2. Conversational interviews with teachers } \\
\text { 3. Conversational interview with students }\end{array}$ & $\begin{array}{l}\text { 1. Many teachers depended exclusively on the textbook and were exam- } \\
\text { oriented, as a result of the standardized test that took place at the end of } \\
\text { each term; } \\
\text { 2. Textbook-oriented teaching was claimed by students as poor teaching } \\
\text { techniques and became a factor that put them off the lessons. }\end{array}$ \\
\hline 64 & $\begin{array}{l}\text { Wilson, } \\
\text { Edmunds \& } \\
\text { Meyer (2008) }\end{array}$ & $\begin{array}{l}\text { USA. } \\
\text { (Tertiary) }\end{array}$ & Business & $\begin{array}{l}\text { - To examine students' degree of autonomy } \\
\text { - To present approach teachers could } \\
\text { employ in enhancing students' levels of } \\
\text { autonomy }\end{array}$ & 202 students & Learner Autonomy Profile (LAP) & $\begin{array}{l}\text { 1. Levels of learner autonomy correlate with students' years in college; } \\
\text { 2. Teacher should help students build the connection between their prior } \\
\text { knowledge and new learning, experiences and achievement of learning } \\
\text { goals; } \\
\text { 3. Assignments given to students should engage them to directing their } \\
\text { own learning by practicing various ways of learning. }\end{array}$ \\
\hline
\end{tabular}




\begin{tabular}{|c|c|c|c|c|c|c|c|}
\hline 65 & Zhang (2008) & $\begin{array}{l}\text { China } \\
\text { (Tertiary) }\end{array}$ & Unspecified & $\begin{array}{l}\text { To examine association of students' } \\
\text { cognitive dist ortion and their sense of } \\
\text { autonomy }\end{array}$ & 103 students & $\begin{array}{l}\text { 1. Iowa Developing Autonomy Inventory } \\
\text { 2. Cognitive Distortion Scales }\end{array}$ & $\begin{array}{l}\text { 1. Cognitive distortion might be a hinder of learner autonomy as well as } \\
\text { serve as a driven force for stud ents to develop their own autonomy; } \\
\text { 2. Students' cognitive errors should be removed and their confidence } \\
\text { should be enhanced. It required cooperation from educators, faculty } \\
\text { members and university administrators. }\end{array}$ \\
\hline 66 & $\begin{array}{l}\text { Cotterall \& } \\
\text { Murray (2009) }\end{array}$ & $\begin{array}{l}\text { Japan } \\
\text { (Tertiary) }\end{array}$ & $\begin{array}{l}\text { Language } \\
\text { (English) }\end{array}$ & $\begin{array}{l}\text { To investigate the extent to which students } \\
\text { develop their language proficiency and } \\
\text { metacognitive knowledge in the course } \\
\text { called self-directed language learning }\end{array}$ & 400 students & $\begin{array}{l}\text { Ethnographic design } \\
\text { 1. Language belief questionnaire (Pre/Post) } \\
\text { 2. Language learning histories (written by } \\
\text { students)/Learner portfolios } \\
\text { 4. Course evaluation } \\
\text { 5. Interviews \& Focus group discussion }\end{array}$ & $\begin{array}{l}\text { 1. Students' beliefs ab out self-directed learning changed positively; } \\
\text { 2. Students' were more able to plan, monitor and evaluate their learning; } \\
\text { 3. The pedagogical structure of this course facilitated students' } \\
\text { metacognitive growth. }\end{array}$ \\
\hline 67 & $\begin{array}{l}\text { Cubukcu } \\
\text { (2009) }\end{array}$ & $\begin{array}{l}\text { Turkey } \\
\text { (Tertiary) }\end{array}$ & $\begin{array}{l}\text { Teacher } \\
\text { education }\end{array}$ & $\begin{array}{l}\text { To study the association among learner } \\
\text { autonomy, self-regulation and } \\
\text { metacognition }\end{array}$ & 82 teacher students & Interviews & $\begin{array}{l}\text { 1. Students perceived themselves as not ready for being an autonomous } \\
\text { learner. } \\
\text { 2. Students who expected their learning to be directed by the teacher } \\
\text { tended to exhibit low self-regulated learning behaviors. Thus, there was a } \\
\text { relation between autonomy and self-regulation habits. }\end{array}$ \\
\hline 68 & $\begin{array}{l}\text { González } \\
\text { (2009) }\end{array}$ & $\begin{array}{l}\text { Spain } \\
\text { (Informal } \\
\text { education: } \\
\text { Adult } \\
\text { education) }\end{array}$ & $\begin{array}{l}\text { Language } \\
\text { Lang }\end{array}$ & $\begin{array}{l}\text { To investigate how ELP (European } \\
\text { Language Portfolio) helped students in } \\
\text { their learning process }\end{array}$ & students and teachers & Questionnaire & $\begin{array}{l}\text { 1. Both students and teachers had positive attitudes towards the use of } \\
\text { ELP; } \\
\text { 2. The ELP could foster learner autonomy, as it raised students' } \\
\text { metacognitive knowledge about language learning and provided students } \\
\text { with opportunities to assess their own learning. }\end{array}$ \\
\hline 69 & $\begin{array}{l}\text { Karagözoğlu } \\
\text { (2009) }\end{array}$ & $\begin{array}{l}\text { Turkey } \\
\text { (Tertiary) }\end{array}$ & $\begin{array}{l}\text { Nursing } \\
\text { education }\end{array}$ & $\begin{array}{l}\text { To identify the level of autonomy of nursing } \\
\text { students }\end{array}$ & $\begin{array}{l}326 \text { students from } 1^{\text {st }} \\
\text { to } 4^{\text {th }} \text { years. }\end{array}$ & $\begin{array}{l}\text { Personal Information Form Sociotropy } \\
\text { Autonomy Scale (SAS) }\end{array}$ & $\begin{array}{l}\text { 1. The lack of an increase of autonomy suggested that the curriculum was } \\
\text { not able to support students' development of autonomy; } \\
\text { 2. Society's negative image of nursing profession affected nursing } \\
\text { students' perception of themselves which in turn obstructed them from } \\
\text { developing their autonomy. }\end{array}$ \\
\hline 70 & $\begin{array}{l}\text { Kaur \& Embi } \\
(2009)\end{array}$ & $\begin{array}{l}\text { Malaysia } \\
\text { (Tertiary) }\end{array}$ & $\begin{array}{l}\text { Language } \\
\text { (English) }\end{array}$ & $\begin{array}{l}\text { To investigate the extent to which } \\
\text { asynchronous online interactions (AOI), } \\
\text { enhanced self-directed learning skills of } \\
\text { adults learners }\end{array}$ & $\begin{array}{l}-1 \text { tutor } \\
-16 \text { students }\end{array}$ & $\begin{array}{l}\text { A mixed-method approach } \\
\text { 1. Quantitative survey questionnaire } \\
\text { 2. Semi-structured interview; } \\
\text { 3. Analysis of asynchronous online interactions } \\
\text { \& students' learning blogs } \\
\end{array}$ & $\begin{array}{l}\text { 1. AOI enhanced self-directed learning skills of the participants; } \\
\text { 2. Tutors and learners should share a balance power in the interactions. } \\
\text { Their relationship become "partner", rather than teacher-student } \\
\text { relationship. }\end{array}$ \\
\hline 71 & $\begin{array}{l}\text { McBrien, } \\
\text { Jones, \& } \\
\text { Cheng (2009) }\end{array}$ & $\begin{array}{l}\text { USA } \\
\text { (Tertiary) }\end{array}$ & $\begin{array}{l}\text { Social } \\
\text { foundations \& } \\
\text { special } \\
\text { education }\end{array}$ & $\begin{array}{l}\text { - To examine whether synchronous online } \\
\text { platforms (specifically, Elluminate Live!) } \\
\text { increase the social interaction }\end{array}$ & 62 students & $\begin{array}{l}\text { Survey } \\
\text { Short open-ended questionnaire }\end{array}$ & $\begin{array}{l}\text { 1. Students experienced technical difficulties in online learning; this } \\
\text { negatively affected their involvement and engagement; } \\
\text { 2. Technical problems experienced by students may lead them to feel } \\
\text { losing control, which reducing their sense of autonomy. }\end{array}$ \\
\hline 72 & $\begin{array}{l}\text { Walters \& } \\
\text { Bozkurt } \\
(2009)\end{array}$ & $\begin{array}{l}\text { Turkey } \\
\text { (Tertiary) }\end{array}$ & $\begin{array}{l}\text { Language } \\
\text { (English) }\end{array}$ & $\begin{array}{l}\text { - To investigate teachers' and students' } \\
\text { attitude towards the use of vocabulary } \\
\text { notebooks, and its effectiveness on } \\
\text { students' vocabulary acquisition } \\
\text { - To explore the extent to which the use of } \\
\text { vocabulary notebooks support learner } \\
\text { autonomy }\end{array}$ & $\begin{array}{l}60 \text { students + their } \\
\text { teachers (no not } \\
\text { specified) }\end{array}$ & $\begin{array}{l}\text { Experimental study } \\
\text { 1. Pre-and post vocabulary tests } \\
\text { 2. Students' compositions } \\
\text { 3. Interviews }\end{array}$ & $\begin{array}{l}\text { 1. Students and teachers had positive attitudes towards the integration of } \\
\text { vocabulary notebooks in their courses; } \\
\text { 2. Students in the treatment group had higher vocabulary acquisition. } \\
\text { Thus, the vocabulary notebooks were able to enhance students' } \\
\text { vocabulary acquisition; } \\
\text { 3. It was not evident that the use of vocabulary notebooks would } \\
\text { facilitate students' development of autonomy. }\end{array}$ \\
\hline 73 & Wei (2009) & $\begin{array}{l}\text { China } \\
\text { (Tertiary) }\end{array}$ & $\begin{array}{l}\text { Language } \\
\text { (English) }\end{array}$ & $\begin{array}{l}\text { To explore roles the teachers should play } \\
\text { when teaching in e-learning contexts }\end{array}$ & 172 students & $\begin{array}{l}\text { 1. Questionnaire } \\
\text { 2. Interviews }\end{array}$ & $\begin{array}{l}\text { 1. Students were enthusiastic in engaging in E-learning and in directing } \\
\text { their own learning, but their anxiety of technology prevented them from } \\
\text { truly engage in this mode of learning. } \\
\text { 2. Students realized the importance of learning strategies, and expected }\end{array}$ \\
\hline
\end{tabular}




\begin{tabular}{|c|c|c|c|c|c|c|c|}
\hline & & & & & & & $\begin{array}{l}\text { that knowledge about learning strategies were provided to them by the } \\
\text { teachers. } \\
\text { 3. Teachers did not provide enough guidance about learning English and } \\
\text { learning strategies to students. This made students become doubtful and } \\
\text { less confident in directing their own learning }\end{array}$ \\
\hline 74 & Zhe (2009) & $\begin{array}{l}\text { China \& EU } \\
\text { (Secondary } \\
\text { level) }\end{array}$ & $\begin{array}{l}\text { Language } \\
\text { (English) }\end{array}$ & $\begin{array}{l}\text { To examine the differences in the } \\
\text { awareness of learner autonomy between } \\
\text { western and Chinese teachers }\end{array}$ & 166 teachers & Survey by questionnaire & $\begin{array}{l}\text { 1. Teachers from western countries were highly aware of leaner } \\
\text { autonomy and perceived students as 'equal agent' (p.9). Their classes } \\
\text { were organized in ways that facilitated the development of learner } \\
\text { autonomy; } \\
\text { 2. Most of Chinese participants regarded learner autonomy as not } \\
\text { appropriate for the eastern environment, and saw many constraints in its } \\
\text { implementation. }\end{array}$ \\
\hline 75 & $\begin{array}{l}\text { Zhou, Ma \& } \\
\text { Deci (2009) }\end{array}$ & $\begin{array}{l}\text { China } \\
\text { (Elementar } \\
\text { y level) }\end{array}$ & $\begin{array}{l}\text { English \& } \\
\text { Math }\end{array}$ & $\begin{array}{l}\text { To investigate whether or not there was a } \\
\text { difference in terms of autonomy and } \\
\text { motivation of Chinese students and western } \\
\text { students. Two studies under one research } \\
\text { Study 1: To find out whether or not Chinese } \\
\text { students' type of motivation had a relation } \\
\text { with their perceptions of their competence, } \\
\text { choice and interest } \\
\text { Study 2: To examine the relations between } \\
\text { students' perception of teachers' auton omy } \\
\text { support and their motivation, interest and } \\
\text { perceived choice and competence }\end{array}$ & $\begin{array}{l}\text { Study 1: } 195 \text { students } \\
\text { Study 2: } 48 \text { students } \\
\text { from Study } 1\end{array}$ & $\begin{array}{l}\text { Study } 1 \\
\text { 1. Autonomous and controlled motivation } \\
\text { questionnaire } \\
\text { 2. Self-perceived classroom adjustment } \\
\text { inventory } \\
\text { Study } 2 \\
\text { 1. Autonomous motivation and classroom } \\
\text { adjustment scale } \\
\text { 2. Perceptions of autonomy support from } \\
\text { teachers questionnaire }\end{array}$ & $\begin{array}{l}\text { Study } 1 \\
\text { 1. Autonomous motivation had a positive correlation with students' } \\
\text { perception of competence and choices, and their interest, while } \\
\text { controlled motivation had a negative correlation with these variables; } \\
\text { 2. This suggested that autonomous motivation was also important for } \\
\text { Chinese students in their learning perception } \\
\text { Study } 2 \\
\text { 1. Teachers' autonomy-supportive behaviors had a positive correlation } \\
\text { with students' motivation and perceived competence and choice; } \\
\text { 2. The findings suggested that the experience learning style conducive to } \\
\text { the exercise of autonomy could result in positive learning consequences. }\end{array}$ \\
\hline 76 & $\begin{array}{l}\text { Abar \& Loken } \\
\text { (2010) }\end{array}$ & $\begin{array}{l}\text { USA. } \\
\text { (Secondary } \\
\text { level) }\end{array}$ & & $\begin{array}{l}\text { To investigate the extent to which pre- } \\
\text { college students were engaged in self- } \\
\text { regulated learning (SRL) }\end{array}$ & 205 students & Survey & $\begin{array}{l}\text { Students were categorized into three groups according to their level of } \\
\text { self-regulated learning: } \\
\text { 1) High SRL (the smallest group with } 15 \% \text { of students): They reported } \\
\text { appropriate regulated learning behaviors and avoided behaviors not } \\
\text { supportive to learning achievement; } \\
\text { 2) Low SRL ( } 37 \% \text { of students): Students in this group had perceptions } \\
\text { and behaviors that were not supportive to academic achievement; } \\
\text { 3) Average (the largest group with } 48 \% \text { of students) }\end{array}$ \\
\hline 77 & $\begin{array}{l}\text { Alexiou \& } \\
\text { Paraskeva } \\
(2010)\end{array}$ & $\begin{array}{l}\text { Greece } \\
\text { (Tertiary) }\end{array}$ & $\begin{array}{l}\text { Computer } \\
\text { science }\end{array}$ & $\begin{array}{l}\text { To examine the extent to which e-portfolio } \\
\text { could support self-regulated learning }\end{array}$ & 41 students & $\begin{array}{l}\text { Experimental design } \\
\text { 1. Pre questionnaire } \\
\text { 2. Rubrics of self-assessment }\end{array}$ & $\begin{array}{l}\text { 1. Students had positive attitudes towards keeping the e-portfolio. Their } \\
\text { self-regulated learning and reflective skills were enhanced through } \\
\text { creating and managing their portfolios; } \\
\text { 2. It becomes a scaffold for students to actively engage in their own } \\
\text { learning. }\end{array}$ \\
\hline 78 & $\begin{array}{l}\text { Bhattacharya, } \\
\text { \& Chauhan } \\
\text { (2010) }\end{array}$ & $\begin{array}{l}\text { India } \\
\text { (Tertiary) }\end{array}$ & $\begin{array}{l}\text { Language } \\
\text { (English) }\end{array}$ & $\begin{array}{l}\text { To investigate the use of blogs in fostering } \\
\text { learner autonomy }\end{array}$ & 35 students & $\begin{array}{l}\text { 1. Analysis of students' reflective reports } \\
\text { 2. Follow-up interview }\end{array}$ & $\begin{array}{l}\text { Blogs could foster learner autonomy as it made students more aware of } \\
\text { their own learning. Plus, students were engaged in making their own } \\
\text { decisions and managing things on their own. }\end{array}$ \\
\hline 79 & Bullock (2010) & $\begin{array}{l}\text { Ukraine } \\
\text { (Informal } \\
\text { education: } \\
\text { British } \\
\text { Council) }\end{array}$ & $\begin{array}{l}\text { Subject not } \\
\text { specified }\end{array}$ & $\begin{array}{l}\text { - To investigate teacher attitudes, beliefs } \\
\text { and behaviors related to learner self- } \\
\text { assessment } \\
\text { - To explore the relationships between their } \\
\text { attitudes, beliefs and practices }\end{array}$ & 10 teachers & $\begin{array}{l}\text { 1. Attitude Questionnaire } \\
\text { 2. Follow-up open-ended interview }\end{array}$ & $\begin{array}{l}\text { 1. Teachers had positive attitudes towards learner self-assessment. They } \\
\text { regarded it as a way to support learner autonomy; } \\
\text { 2. However, in practice the implementation of self-assessment were } \\
\text { restricted and tied to formal assessments; } \\
\text { 3. Factors that obstruct the practices included teachers' perceived lack of } \\
\text { the resources, time constraints and perceptions of students' attitudes. }\end{array}$ \\
\hline 80 & Büyükduman & Turkey & Language & - To investigate students' perception and & 60 students & Survey by questionnaire & 1. The majority of the students believed that keeping LP benefited their \\
\hline
\end{tabular}


\&Şirin (2010) $\quad$ (Tertiary) $\quad$ (English) $\quad$ benefits of keeping Learning Portfolio (LP)

\begin{tabular}{llllll}
\hline 81 & $\begin{array}{l}\text { Drexler } \\
(2010)\end{array}$ & $\begin{array}{l}\text { USA. } \\
\text { (Secondary } \\
\text { level) }\end{array}$ & Not specified & $\begin{array}{l}\text { To investigate the effect of Networked } \\
\text { Student Model on students' development of } \\
\text { learner autonomy }\end{array}$ & 15 students \\
& & &
\end{tabular}

1. Teacher lesson plans, unit plan, research

field notes, assessment rubrics \& student

2. Students' blogs \& final essays
English learning and made them realize that it was they who were responsible for the learning process;

2. By keeping LP, students were engaged in searching for their own knowledge and recognized weaknesses and strengths. This supported the development of their autonomy.

1. Students took more control of the process and were responsible in making decisions related to the content of their own learning

2. The majority of students were comfortable with taking more control of the learning process; however, they still had some difficulties with using technology due to little exposure to technology in their previous learning experience;

3. Teachers' perception of using technology in teaching had an impact on the effectiveness of the implementation of such a learning model.

1. Students who were taught via computer-based materials exhibited higher scores in self-regulated learning strategies than those learnt with print-based materials;

2. Students exercised more autonomy when learning with computer.

$\begin{array}{lll}\begin{array}{l}\text { Moenikia } \\ (2010)\end{array} & \text { (Tertiary) } & \begin{array}{l}\text { regulated learning strategies between } \\ \text { students learning in computer-based an } \\ \text { printed-based environments }\end{array}\end{array}$

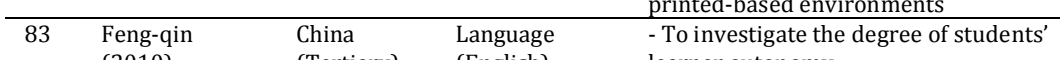

learner autonomy

- To explore factors influencing students autonomous learning in the self-access

(2010) (Tertiary) (English)

center

$84 \quad$ Lo (2010)

Taiwan

Language

- To investigate the extent to which

reflective portfolio supported students to

be autonomous in their learning

233 students

2. Interviews

1. Students had an intermediate level of learner autonomy;

2. Students did not know much about learning strategies. This became a

major constraint for their autonomy;
3. Most of students were motivated for the exam. Their purpose of

learning then became just to pass the exams.

101 students $+1 \quad 1$. Pre-course questionnaire

2. Post-course evaluation

1. These students did not have experience in keeping learning portfolio and did not know much about being an autonomous learner. Thus, they stiled relied a lot on the teachers;

2. Time constraint became the biggest challenge for teacher in giving eedback and advice on students' portfolios,

. Portslio helped rase sternes of their gnition. However, their critical derately enhanced.

did not change. Thus, the intervention viors: this was due to a brief

nature of this intervention.

increase in teachers' or not there was an increase in teachers autonomy-supp
behaviors after receiving a training

An experimental intervention design

1. Behavioral assessment

program

\begin{tabular}{cllllll}
\hline 86 & $\begin{array}{l}\text { Vandiver \& } \\
\text { Walsh (2010) }\end{array}$ & $\begin{array}{l}\text { USA. } \\
\text { (Tertiary) }\end{array}$ & $\begin{array}{l}\text { Research } \\
\text { methodology } \\
\text { course }\end{array}$ & $\begin{array}{l}\text { To assess students' level of autonomy after } \\
\text { doing their own research in the course }\end{array}$ & 67 students & Pre-and post-testes \\
\hline 87 & $\begin{array}{l}\text { Varol \& Yilmaz } \\
\text { (2010) }\end{array}$ & $\begin{array}{l}\text { Turkey } \\
\text { (Primary } \\
\text { level) }\end{array}$ & $\begin{array}{l}\text { Language } \\
\text { (English) }\end{array}$ & $\begin{array}{l}\text { To examine the differences between male } \\
\text { and female students' autonomous learning } \\
\text { activities of }\end{array}$ & $\begin{array}{l}80 \text { students + 1 } \\
\text { teacher }\end{array}$ & $\begin{array}{l}\text { A Likert-scale questionnaire } \\
\text { An interview with a teacher }\end{array}$ \\
\hline
\end{tabular}

Students felt more positive towards learning about research

method ology;

2. Students believed that by doing this research project, they became more active and relied more on themselves.

1. Female students did more autonomous learning activities both outside and inside class;

2. Female students were more willing to take responsibilities and played more active role in learning process i.e. in making decisions, taking initiatives to learning both outside and inside class. 


\section{Studies conducted in Thai settings}

\begin{tabular}{|c|c|c|c|c|c|c|c|}
\hline No. & Study & Setting & $\begin{array}{l}\text { Fields/ } \\
\text { Subjects }\end{array}$ & Aim/Question & $\begin{array}{l}\text { Participants } \\
\text { /Sources of data }\end{array}$ & Methodology/Instruments & Findings / Implications \\
\hline 88 & $\begin{array}{l}\text { Thongmon } \\
\text { (1998) }\end{array}$ & $\begin{array}{l}\text { Thailand } \\
\text { (Elementar } \\
\text { y) }\end{array}$ & $\begin{array}{l}\text { Not specified } \\
\text { (non } \\
\text { language) }\end{array}$ & $\begin{array}{l}\text { To compare characteristics related to self- } \\
\text { directed learning of researcher teachers } \\
\text { and non-researcher teachers; }\end{array}$ & 126 teachers & $\begin{array}{l}\text { Mixed-method approach: } \\
\text { 1. Quantitative survey } \\
\text { 2. Qualitative multiple-cases studies }\end{array}$ & $\begin{array}{l}\text { 1. Researcher teachers displayed higher readiness for self-directed } \\
\text { learning. Both researcher teachers and non researcher teachers } \\
\text { displayed the lowest scores in their creative thinking skill; } \\
\text { 2. Researcher teachers had willingness to learn, rely on themselves, are } \\
\text { organized but flexible, and realize the importance of regular self- } \\
\text { evaluation; } \\
\text { 3. It is likely that researcher teachers will manage their class or use } \\
\text { techniques more inclined to self-directed learning style. }\end{array}$ \\
\hline 89 & $\begin{array}{l}\text { Anantasate } \\
(2001)\end{array}$ & $\begin{array}{l}\text { Thailand } \\
\text { (Tertiary) }\end{array}$ & Language & $\begin{array}{l}\text { To develop a teaching/learning process that } \\
\text { promote learner autonomy }\end{array}$ & $\begin{array}{l}20 \text { lecturers + } \\
\text { students }\end{array}$ & $\begin{array}{l}\text { 1. Students' self evaluation, learning records \& } \\
\text { feeling records } \\
\text { 2. Participant and non-participant } \\
\text { observations } \\
\text { 3. Students' work } \\
\text { 4. Formal and informal interview } \\
\text { 5. Group discussion } \\
\text { 6. Interviews with lecturers }\end{array}$ & $\begin{array}{l}\text { 1. The teaching/learning process conducive the promotion of learner } \\
\text { autonomy should make learners aware of their roles in learning and view } \\
\text { their peer as learning partners; and should help learners have positive } \\
\text { attitudes towards themselves, their peers, their teachers and their } \\
\text { learning; } \\
\text { 2. Learners who have high autonomy were confident to use English and } \\
\text { would used English in other activities in addition to English classroom; } \\
\text { 3. Passion for learning, personal interest and preference, positive attitude } \\
\text { towards general as well as language learning, good language background, } \\
\text { strong self-discipline, and time management skills were essential in the } \\
\text { development of learner autonomy. }\end{array}$ \\
\hline$\overline{90}$ & $\begin{array}{l}\text { Charupan, } \\
\text { Soranastaporn, } \\
\text { \& } \\
\text { Suwatttananan } \\
\text { d, }\end{array}$ & $\begin{array}{l}\text { Thailand } \\
\text { (Tertiary) }\end{array}$ & Language & $\begin{array}{l}\text { To examine teachers' use of the Internet in } \\
\text { their English courses }\end{array}$ & 120 teachers & A survey by questionnaire & $\begin{array}{l}\text { 1. Majority of the participants acknowledged the benefit of using the } \\
\text { Internet in their teaching, with E-mail being used most; } \\
\text { 2. For those who were not interested, they revealed some negative } \\
\text { attitudes towards the use of the Internet in their teaching such as it was } \\
\text { too complex; they were too old or afraid to losing positions, textbooks } \\
\text { were the best for their teaching, etc. }\end{array}$ \\
\hline$\overline{91}$ & $\begin{array}{l}\text { Chinprahut } \\
\text { (2001) }\end{array}$ & $\begin{array}{l}\text { Thailand } \\
\text { (Elementary) }\end{array}$ & $\begin{array}{l}\text { Not specified } \\
\text { (non- } \\
\text { language) }\end{array}$ & $\begin{array}{l}\text { - To study the conceptual framework used } \\
\text { for assessing self-directed learning of } \\
\text { elementary school students when doing } \\
\text { project activities } \\
\text { - To develop a data collection technique and } \\
\text { an instrument for assessing students' self- } \\
\text { directed learning when doing project } \\
\text { activities }\end{array}$ & $\begin{array}{l}417 \text { students }+ \\
\text { teachers (number not } \\
\text { specified) }\end{array}$ & $\begin{array}{l}\text { 1. "My learning log" } \\
\text { 2. Teacher questionnaire } \\
\text { 3. Student questionnaire }\end{array}$ & $\begin{array}{l}\text { 1. The conceptual framework teachers used in assessing students' self- } \\
\text { directed learning included diagnosing needs, defining objectives, } \\
\text { designing a learning plan, conducting the learning, self-evaluating, } \\
\text { improving and appreciating the outcome; } \\
\text { 2. The technique developed for collecting data was the journal writing } \\
\text { and the instrument for assessing students' self-directed learning was "My } \\
\text { learning log" (The old instrument for measuring students' self-directed } \\
\text { learning was rating-scale questionnaire). }\end{array}$ \\
\hline 92 & $\begin{array}{l}\text { Kriwattanapong } \\
\text { (2001) }\end{array}$ & $\begin{array}{l}\text { Thailand } \\
\text { (Non- } \\
\text { formal } \\
\text { education/ } \\
\text { vocational } \\
\text { certificate) }\end{array}$ & $\begin{array}{l}\text { Not specified } \\
\text { (non- } \\
\text { language) }\end{array}$ & $\begin{array}{l}\text { To investigate non-formal education } \\
\text { students' readiness for self-directed } \\
\text { learning }\end{array}$ & 327 students & 2 sets of questionnaire & $\begin{array}{l}\text { 1. Generally, this group of non-formal education students was ready for } \\
\text { self-directed learning. However, these students lacked creative thinking } \\
\text { skills; } \\
\text { 2. Students should be provided with opportunities to improve their } \\
\text { thinking skills, particularly to think critically, to analyze \& synthesize, } \\
\text { and to express their own ideas. }\end{array}$ \\
\hline
\end{tabular}




\begin{tabular}{|c|c|c|c|c|c|c|c|}
\hline 93 & $\begin{array}{l}\text { Kongchan } \\
(2002)\end{array}$ & $\begin{array}{l}\text { Thailand } \\
\text { (Tertiary) }\end{array}$ & Language & $\begin{array}{l}\text { To demonstrate how to make consultations } \\
\text { with students effective }\end{array}$ & Students & $\begin{array}{l}\text { 1. Learner Profile } \\
\text { 2. Questionnaire }\end{array}$ & $\begin{array}{l}\text { 1. Studetns preferred the consultation which was based on the learner } \\
\text { profile. It was a way for reflecting and self-assessing, resulting in the } \\
\text { improvement in their English competency; } \\
\text { 2. Training in time management is needed for students; } \\
\text { 3. Learner profiles enable the teacher to conduct consultation effectively. }\end{array}$ \\
\hline 94 & $\begin{array}{l}\text { Wiriyakarun } \\
(2002)\end{array}$ & $\begin{array}{l}\text { Thailand } \\
\text { (Tertiary) }\end{array}$ & Language & $\begin{array}{l}\text { - To explore students' perceptions of the } \\
\text { effectiveness of learning through self-access } \\
\text { - To find out whether this learning mode } \\
\text { can help improve their English proficiency }\end{array}$ & 24 students & $\begin{array}{l}\text { 1. Attitude Questionnaires for Self-directed } \\
\text { Learning } \\
\text { 2. Interview \& face-to-face consultation }\end{array}$ & $\begin{array}{l}\text { 1. Students were not effective self-directed learners; } \\
\text { 2. Students can be more self-directed if they are encouraged to adopt a } \\
\text { more active and independent role in learning; } \\
\text { 3. Not only more training package for students but also formal training } \\
\text { for teachers in facilitating independent learning. }\end{array}$ \\
\hline 95 & $\begin{array}{l}\text { Teeraputon } \\
\text { (2003) }\end{array}$ & $\begin{array}{l}\text { Thailand } \\
\text { (Tertiary) }\end{array}$ & $\begin{array}{l}\text { Internet for } \\
\text { Education }\end{array}$ & $\begin{array}{l}\text {-To develop a self-directed learning scheme } \\
\text { on computer network } \\
\text { - To examine whether the use of the scheme } \\
\text { effect academic achievement }\end{array}$ & 34 Students & $\begin{array}{l}\text { One-Group Pretest-Posttest design } \\
\text { 1. Learning plan } \\
\text { 2. Self-regulated learning measurement \& } \\
\text { evaluation forms } \\
\text { 3. Learning-record book } \\
\text { 4. Pretest \& posttest }\end{array}$ & $\begin{array}{l}\text { 1. The self-regulated learning scheme that use on computer courses } \\
\text { consisted of } 17 \text { steps: } \\
\text { 1) lesson orientation; } 2 \text { )self-assessment for computer network learning; } \\
\text { 3) pre-testing; 4) students receiving pretest feedback; 5)set a learning } \\
\text { goal; 6) set a learning plan; 7) planning rewards \& punishment; 8) } \\
\text { designing learning environment; 9) studying from www.; } 10 \text { ) doing } \\
\text { activities on network; 11) recording assignment; } 12 \text { ) doing assignment; } \\
\text { 13) drafting a report; 14) asking questions with the instructor via } \\
\text { network; 15) reviewing the lesson; 16)posttest; and 17) giving rewards } \\
\text { or punishments according to the plan } \\
\text { 2. Students' academic achievement improved after applying self- } \\
\text { regulated learning strategy in their learning; } \\
\text { 3. Students were satisfied with the idea of allowing them to direct their } \\
\text { own learning (use of self-directed learning scheme). }\end{array}$ \\
\hline 96 & $\begin{array}{l}\text { Vanijdee } \\
(2003)\end{array}$ & $\begin{array}{l}\text { Thailand } \\
\text { (Open } \\
\text { education) }\end{array}$ & $\begin{array}{l}\text { Language } \\
\text { (English) }\end{array}$ & $\begin{array}{l}\text { To examine learner autonomy of Thai } \\
\text { distance students }\end{array}$ & 391 distance students & $\begin{array}{l}\text { 1. Questionnaire } \\
\text { 2. ThinkAloud protocols } \\
\text { 3. Interviews }\end{array}$ & $\begin{array}{l}\text { 1. These students could be categorized into main two groups according to } \\
\text { their degrees of learner autonomy: self-sufficient \& dynamic students; } \\
\text { 2. Self-sufficient students were able to handle their learning with the } \\
\text { assistance of self-instructional materials and their goal was to pass the } \\
\text { exam or to satisfy the curriculum requirements. In contrast, dynamic } \\
\text { students were able to extend their learning using a more variety of } \\
\text { materials and to learn on their own in a wider context. }\end{array}$ \\
\hline 97 & $\begin{array}{l}\text { Wiriyakarun } \\
(2003)\end{array}$ & $\begin{array}{l}\text { Thailand } \\
\text { (Tertiary) }\end{array}$ & $\begin{array}{l}\text { Language } \\
\text { (English) }\end{array}$ & $\begin{array}{l}\text { To examine students' attitudes and feelings } \\
\text { towards teacher-made materials based on } \\
\text { task-based approach }\end{array}$ & $\begin{array}{l}\text { Students (no.not } \\
\text { specified) }\end{array}$ & Post-course students' journals & $\begin{array}{l}\text { 1.Students show highly positive attitude towards the materials used, and } \\
\text { become more motivated and active learners as the task-based approach } \\
\text { enable them to direct their own learning and give more freedom in } \\
\text { choosing what and how to learn } \\
\text { 2. What needed to promote learner autonomy were } \\
\text { - more training for both teachers and learners; } \\
\text { - well-prepared and well-chosen materials; } \\
\text { - supports and understanding from institutions \& parents }\end{array}$ \\
\hline 98 & $\begin{array}{l}\text { Yamkate \& } \\
\text { Uantrai } \\
\text { (2003) }\end{array}$ & $\begin{array}{l}\text { Thailand } \\
\text { (Secondary ) }\end{array}$ & Language & $\begin{array}{l}\text { To examine secondary school students' } \\
\text { Internet use }\end{array}$ & $\begin{array}{l}5 \text { students from M.2 \& } \\
\text { 4students from M.5 }\end{array}$ & $\begin{array}{l}\text { 1. Questionnaire } \\
\text { 2. Semi-structured interview }\end{array}$ & $\begin{array}{l}\text { 1.Students need support from the teacher to enable them to exploit the } \\
\text { Internet as effectively as possible } \\
\text { 2. Both psychological preparation and methodological support in terms } \\
\text { of techniques should be provided for students }\end{array}$ \\
\hline 99 & Kiddee (2004) & $\begin{array}{l}\text { Thailand } \\
\text { (High } \\
\text { school) }\end{array}$ & Not specified & $\begin{array}{l}\text { To develop the evaluation model of student- } \\
\text { centered learning management }\end{array}$ & $\begin{array}{l}31 \text { teachers }+310 \\
\text { students' parents }+ \\
930 \text { students }\end{array}$ & $\begin{array}{l}\text { 1. Evaluation forms } \\
\text { 2. Attitude scales } \\
\text { 3. Interviews }\end{array}$ & $\begin{array}{l}\text { 1. The indicators of students-centered learning management consisted of } \\
\text { 1) learning environment; 2) learning preparation; 3) learning process; } \\
\text { and 4) learning output; }\end{array}$ \\
\hline
\end{tabular}




\begin{tabular}{|c|c|c|c|c|c|c|c|}
\hline & & & & & & & $\begin{array}{l}\text { participation, and learners habits; 4)Learning output: Evaluation and } \\
\text { expectation in learners }\end{array}$ \\
\hline 100 & $\begin{array}{l}\text { Na ranong, } \\
\text { Neancharoensu } \\
\text { k, Boonsom, \& } \\
\text { Siriratanawit } \\
(2004)\end{array}$ & $\begin{array}{l}\text { Thailand } \\
\text { (Junior } \\
\text { high school } \\
\text { \& Tertiary) }\end{array}$ & Language & $\begin{array}{l}\text { To study teachers' and students' use of } \\
\text { computer in Japanese teaching-learning } \\
\text { process }\end{array}$ & $\begin{array}{l}90 \text { teachers }+251 \\
\text { students }\end{array}$ & Three surveys & $\begin{array}{l}\text { 1. Electronic materials were not widely used by the teachers, due to the } \\
\text { limited availability of facilities and equipment in each university; } \\
\text { 2. More than } 60 \% \text { of the students used The number of the students using } \\
\text { these materials may increase if there are more in variety and content; } \\
\text { 3. The teachers perceived that electronic materials helped students to be } \\
\text { more autonomous in their learning. }\end{array}$ \\
\hline 101 & Saman (2004) & $\begin{array}{l}\text { Thailand } \\
\text { (Primary, } \\
\text { secondary } \\
\text { \& high } \\
\text { school) }\end{array}$ & $\begin{array}{l}\text { Science, Math, } \\
\text { Thai, English } \\
\text { and Social } \\
\text { Science }\end{array}$ & $\begin{array}{l}\text { To develop a scheme for enhancing } \\
\text { teachers' self-directed learning ability }\end{array}$ & 9 teachers & $\begin{array}{l}\text { A multi-case study } \\
\text { 1. Evaluation forms } \\
\text { 2. Attitudes questionnaire } \\
\text { 3. Interview } \\
\text { 4. Class observation }\end{array}$ & $\begin{array}{l}\text { The enhancement of teachers' self-directed learning ability consisted of } 7 \\
\text { steps,: } \\
\text { 1) Preparing the teachers: by explaining about the scheme, its goals and } \\
\text { principles, and building a friendly atmosphere } \\
\text { 2) Helping teachers to identify and analyze the problems; } \\
\text { 3) Building awareness and motivation in self-directed learning; } \\
\text { 4) Analyzing their own needs; } \\
\text { 5) Supporting and motivating teachers to follow the scheme; } \\
\text { 6) Coaching, observing and proving continuous support and help; } \\
\text { 7) Assessing and giving feedback }\end{array}$ \\
\hline 102 & $\begin{array}{l}\text { Srimavin \& } \\
\text { Darasawang } \\
(2004)\end{array}$ & $\begin{array}{l}\text { Thailand } \\
\text { (Tertiary; } \\
\text { Postgrad) }\end{array}$ & $\begin{array}{l}\text { Resource } \\
\text { Based } \\
\text { Learning } \\
\text { (RBL) }\end{array}$ & $\begin{array}{l}\text { To investigate whether or not self- } \\
\text { assessment ability can be developed } \\
\text { through journal writing }\end{array}$ & 4 students & Students' journals & $\begin{array}{l}\text { 1. The students were not able to use journal writing to set their goals; } \\
\text { they use it simply as a means to answer the questions given; } \\
\text { 2. Their lack of deep reflection and self-assessment ability displayed in } \\
\text { their journals was due to the restrictions of the guided questions and the } \\
\text { lack of reaction from the tutor. }\end{array}$ \\
\hline 103 & $\begin{array}{l}\text { Wanpen \& } \\
\text { Fisher (2004) }\end{array}$ & $\begin{array}{l}\text { Thailand } \\
\text { (Tertiary) }\end{array}$ & Computer & $\begin{array}{l}\text { To investigate constructivist learning } \\
\text { environments in a computer classroom }\end{array}$ & 710 students & $\begin{array}{l}\text { 1. Pre-and Post questionnaire } \\
\text { 2. Student journals }\end{array}$ & $\begin{array}{l}\text { 1. Students believed there was a positive change in their constructivist } \\
\text { learning environment ; } \\
\text { 2. After the intervention students were more likely to learn with fun and } \\
\text { help friends in doing assignments. }\end{array}$ \\
\hline 104 & $\begin{array}{l}\text { Holme \& } \\
\text { Chalauisaeng } \\
\text { (2006) }\end{array}$ & $\begin{array}{l}\text { Thailand } \\
\text { (Tertiary) }\end{array}$ & $\begin{array}{l}\text { Language } \\
\text { (English) }\end{array}$ & $\begin{array}{l}\text { To investigate effects of "Participatory } \\
\text { Appraisal" (PA) on students' learning and } \\
\text { attitudes (a set of techniques of need } \\
\text { analysis) }\end{array}$ & Students & $\begin{array}{l}\text { Case study } \\
\text { 1. Participant observation } \\
\text { 2. Semi-structured interview } \\
\text { 3. Pre- and post-questionnaire }\end{array}$ & $\begin{array}{l}\text { 1. Students had more positive attitudes towards learning and more } \\
\text { motivated to learn; } \\
\text { 2. By analyzing their own need, students set their learning targets and } \\
\text { realized that it was they who had to make decision about their own } \\
\text { learning. Thus, with PA students became more self-directed to improve } \\
\text { their own reading. }\end{array}$ \\
\hline 105 & $\begin{array}{l}\text { Hongsa-ngiam } \\
\text { (2006) }\end{array}$ & $\begin{array}{l}\text { Thailand } \\
\text { (Tertiary) }\end{array}$ & Physics & $\begin{array}{l}\text { - To examine Thai lecturers' beliefs about } \\
\text { teaching and learning physics, and their } \\
\text { actual teaching practices } \\
\text { - To examine Thai students' beliefs, goals } \\
\text { and motivation for studying physics }\end{array}$ & $\begin{array}{l}89 \text { lecturers + } 147 \\
\text { students }\end{array}$ & $\begin{array}{l}\text { Mixed-method approach } \\
\text { 1. Survey by questionnaire } \\
\text { 2. Lecturers questionnaire } \\
\text { 3. Student questionnaires } \\
\text { 4. Cases studies (four cases: four lecturers and } \\
\text { 20 students) }\end{array}$ & $\begin{array}{l}\text { 1. The lecturers reported that they believed in student-centeredness and } \\
\text { constructivism, but in their actual practices, they tended to play roles of } \\
\text { knowledge transmitter; } \\
\text { 2. In laboratory sessions, students were to verify what had been taught, } \\
\text { rather than to construct their own knowledge. } \\
\text { 3. Students thought that physics class was boring because of its }\end{array}$ \\
\hline
\end{tabular}




\begin{tabular}{|c|c|c|c|c|c|c|c|}
\hline & & & & & & $\begin{array}{l}\text { - Classroom observations, } \\
\text { - Lecturers and students interviews } \\
\text { - Document analysis }\end{array}$ & $\begin{array}{l}\text { traditional way of teaching. They preferred to played more roles in their } \\
\text { learning and suggested the use of student-centered approach in the class. } \\
\text { 3. Students had extrinsic motivations in learning phy sics: to get good } \\
\text { grades and to pass the examination }\end{array}$ \\
\hline 106 & $\begin{array}{l}\text { Nonkukhetkho } \\
\text { ng, Baldauf } \\
\text { Richard \& } \\
\text { Moni (2006) }\end{array}$ & $\begin{array}{l}\text { Thailand } \\
\text { (Secondary ) }\end{array}$ & $\begin{array}{l}\text { Language } \\
\text { (English) }\end{array}$ & $\begin{array}{l}\text { To examine teachers' perceptions \& } \\
\text { implementation of learner centredness }\end{array}$ & 5 teachers & $\begin{array}{l}\text { Case study } \\
\text { - Interviews } \\
\text { - Classroom observations } \\
\text { - Questionnaire }\end{array}$ & $\begin{array}{l}\text { 1.Teachers were not confident in applying the learner-centred approach, } \\
\text { due to the lack of a clear understanding of its theory and principles; } \\
\text { 2. This new approach has been mandated top-down. Support for teachers } \\
\text { is not sufficient. }\end{array}$ \\
\hline 107 & $\begin{array}{l}\text { Nuntrakune, } \\
\text { Nason , \& } \\
\text { Kidman } \\
(2006)\end{array}$ & $\begin{array}{l}\text { Thailand } \\
\text { (Primary) }\end{array}$ & Mathematics & $\begin{array}{l}\text { To investigate how teachers perceived the } \\
\text { implementation of cooperative learning in } \\
\text { their classes }\end{array}$ & 2 teachers & $\begin{array}{l}\text { Action research } \\
\text { - Pre- and post-interviews } \\
\text { - Class Observations }\end{array}$ & $\begin{array}{l}\text { 1. Both teachers perceived the benefits and gained clearer } \\
\text { understandings of cooperative learning; } \\
\text { 2. However, the teacher who was less experience was not confident in } \\
\text { implementing cooperative learning in her class. } \\
\text { 3. The intensive program offered seemed inadequate for the novice } \\
\text { teacher. }\end{array}$ \\
\hline 108 & $\begin{array}{l}\text { Sirithongthaw } \\
\text { orn, Krairit, } \\
\text { Dimmitt, \& } \\
\text { Paul (2006) }\end{array}$ & $\begin{array}{l}\text { Thailand } \\
\text { (Tertiary) }\end{array}$ & $\begin{array}{l}\text { Subject not } \\
\text { specified }\end{array}$ & $\begin{array}{l}\text { To examine how universities in Thailand } \\
\text { have implemented e-learning; }\end{array}$ & 4 universities & $\begin{array}{l}\text { Cases studies } \\
\text { 1.Interview } \\
\text { 2.Observations }\end{array}$ & $\begin{array}{l}\text { 1. The implementation of e-learning was influenced by factors related to } \\
\text { organization, instructor and Internet environment. Among these, } \\
\text { organization factors were perceived as playing the most critical role; } \\
\text { 2. In order for the success of EL implementation, there must be a } \\
\text { collaboration from university administrators and instructors, which can } \\
\text { be done through a clear policy and support for resources and training. }\end{array}$ \\
\hline 109 & $\begin{array}{l}\text { Darasawang, } \\
\text { Singhasiri, \& } \\
\text { Keyuravong } \\
(2007)\end{array}$ & $\begin{array}{l}\text { Thailand } \\
\text { (Secondary) }\end{array}$ & Language & $\begin{array}{l}\text { To explore what specific problems teachers } \\
\text { and students face in making the best use of } \\
\text { SEARs (Students English Access Rooms) }\end{array}$ & -4 teachers + students & $\begin{array}{l}\text { Mixed Approach } \\
\text { 1. Interview } \\
\text { 2. Observation } \\
\text { 3. Examination of materials } \\
\text { 4. Questionnaires }\end{array}$ & $\begin{array}{l}\text { 1. Factors limit the effective implementation of SEARs:a) Lack of genuine } \\
\text { support; b)Teachers' workload; and c) Teachers' lack of real } \\
\text { understanding of the principles of learner autonomy; } \\
\text { 2. Teachers were confused about their roles: in class the teacher acted as } \\
\text { assessors, but when in SEAR they were to be guide, facilitator and } \\
\text { counselor (conflict in roles). }\end{array}$ \\
\hline 110 & $\begin{array}{l}\text { Intaraprasert } \\
(2007)\end{array}$ & $\begin{array}{l}\text { Thailand } \\
\text { (Tertiary) }\end{array}$ & Language & $\begin{array}{l}\text { - To examine the frequency that students } \\
\text { are engaged in out-of-class/independent } \\
\text { strategies in their English learning; } \\
\text { - To investigate the relationship between } \\
\text { that frequency and these variables: their } \\
\text { perceptions of their language ability, gender } \\
\text { and study field }\end{array}$ & 488 students & Questionnaire & $\begin{array}{l}\text { 1. Four strategies which were employed more frequently are surfing the } \\
\text { Internet, listening to English songs, watching English-speaking films, and } \\
\text { listening to English songs or cassette tapes of English conversations; } \\
\text { 2. Four strategies which were employed less frequently are using a } \\
\text { computer program, listening to a radio program in English, going to a } \\
\text { language school for general English and going to a language school for } \\
\text { speaking skills; } \\
\text { 3. There was a strong relationship between students' perceived language } \\
\text { ability and their frequency of out-of-class strategy. That is, students who } \\
\text { perceived themselves as having high ability in English reported higher } \\
\text { frequency of strategy use than those who perceived themselves as having } \\
\text { low ability; }\end{array}$ \\
\hline 111 & $\begin{array}{l}\text { Israsena } \\
(2007)\end{array}$ & $\begin{array}{l}\text { Thailand } \\
\text { (Early } \\
\text { childhood) }\end{array}$ & $\begin{array}{l}\text { Subject not } \\
\text { specified }\end{array}$ & $\begin{array}{l}\text { To investigate beliefs and practices related } \\
\text { to learner-centeredness of Thai early } \\
\text { childhood teachers }\end{array}$ & 93 teachers & Survey & $\begin{array}{l}\text { 1. Thai teachers highly valued learner centeredness. However, their } \\
\text { actual practices did not truly engage students in active learning. } \\
\text { 2. Teachers had little knowledge about how to implement learner- } \\
\text { centeredness in their actual classroom. }\end{array}$ \\
\hline 112 & $\begin{array}{l}\text { Poonruksa } \\
\text { (2007) }\end{array}$ & $\begin{array}{l}\text { Thailand } \\
\text { (Tertiary) }\end{array}$ & $\begin{array}{l}\text { Nursing } \\
\text { Sciences }\end{array}$ & $\begin{array}{l}\text { To examine students' opinions toward the } \\
\text { integration of student-centered principle in } \\
\text { their field trip }\end{array}$ & 8 students & $\begin{array}{l}\text { Classroom action research } \\
\text { 1. Focus group interview } \\
\text { 2. Field trip report (recorded by teachers) }\end{array}$ & $\begin{array}{l}\text { 1. Students gained sophisticated knowledge from real experiences, team- } \\
\text { work skills, cohesiveness, good attitudes towards peers, and leadership; } \\
\text { 2. The success of the integration of student-centeredness depends largely }\end{array}$ \\
\hline
\end{tabular}


3. Observation from participants' presentation

\begin{tabular}{|c|c|c|c|c|c|c|c|}
\hline & & & & & & . & $\begin{array}{l}\text { and have a clear understanding of its principles. } \\
\text { and on steacning, }\end{array}$ \\
\hline 113 & $\begin{array}{l}\text { Rumpagaporn } \\
\text { \& Darmawan } \\
\text { (2007) }\end{array}$ & $\begin{array}{l}\text { Thailand } \\
\text { (Primary \& } \\
\text { Secondary } \\
\text { levels) }\end{array}$ & $\begin{array}{l}\text { Not specific to } \\
\text { any particular } \\
\text { field }\end{array}$ & $\begin{array}{l}\text { To determine the extent to which the model } \\
\text { ICT schools had classroom learning } \\
\text { environments conducive to students' } \\
\text { critical thinking skills }\end{array}$ & 13 model ICT schools & $\begin{array}{l}\text { 1. Questionnaire } \\
\text { 2. Interview survey } \\
\text { 3. Classroom observations }\end{array}$ & $\begin{array}{l}\text { 1. Students' critical thinking skills could be promoted in ICT-integrated } \\
\text { classroom; } \\
\text { 2. The success of ICT integration into classroom learning depends largely } \\
\text { on teachers' roles and school man agement. Teachers need to change } \\
\text { roles from delivering information to guides and facilitators of learning. }\end{array}$ \\
\hline 114 & $\begin{array}{l}\text { Hongsranagon } \\
\text { et al., (2008) }\end{array}$ & $\begin{array}{l}\text { Thailand } \\
\text { (Tertiary; } \\
\text { Postgrad) }\end{array}$ & Nursing & $\begin{array}{l}\text { - To categorize learners according to the } \\
\text { level of their autonomy } \\
\text { - To study experiences of learners in the } \\
\text { distance program offered by Chulalongkorn } \\
\text { University }\end{array}$ & 45 students & $\begin{array}{l}\text { 1. Self-directed Learning Readiness Scale } \\
\text { (SDLRS) } \\
\text { 2. Focus group discussion }\end{array}$ & $\begin{array}{l}\text { 1. The participants did not have a clear understanding of distance } \\
\text { learning, as they equated the distance learning program they were taking } \\
\text { with Open University in Thailand; } \\
\text { 2. The participants chose the distance program because it suits their } \\
\text { work \& financial status, and the participants were still employed. }\end{array}$ \\
\hline 115 & $\begin{array}{l}\text { Rukthong } \\
\text { (2008) }\end{array}$ & $\begin{array}{l}\text { Thailand } \\
\text { (Tertiary) }\end{array}$ & $\begin{array}{l}\text { Language } \\
\text { (English) }\end{array}$ & $\begin{array}{l}\text { To gauge students' readiness to learn } \\
\text { English autonomously }\end{array}$ & 174 students & $\begin{array}{l}\text { 1. Two sets of questionnaires } \\
\text { 2. A self report } \\
\text { 3. Interview }\end{array}$ & $\begin{array}{l}\text { 1. The participants' beliefs about teacher roles suggested that the } \\
\text { majority of them still relied a lot on their teachers; } \\
\text { 2. The participants viewed themselves as not adequately competent in } \\
\text { English and lacked of knowledge about learning strategies. They rarely } \\
\text { used metacognitive strategies; } \\
\text { 3. They were willing to learn autonomously but not confident in their } \\
\text { capability to do so. }\end{array}$ \\
\hline 116 & $\begin{array}{l}\text { Sojisirikul \& } \\
\text { Intratat (2008) }\end{array}$ & $\begin{array}{l}\text { Thailand } \\
\text { (Tertiary) }\end{array}$ & $\begin{array}{l}\text { Language } \\
\text { (English) }\end{array}$ & $\begin{array}{l}\text { - To investigate students' attitudes and } \\
\text { confidence after taking the course delivered } \\
\text { in autonomous learning style } \\
\text { - To find out students' opinion towards } \\
\text { teachers' consultation }\end{array}$ & 248 students & Questionnaire & $\begin{array}{l}\text { 1. All students were confident in their ability to learn autonomously; } \\
\text { 2. Students found consultations with lecturers highly helpful when } \\
\text { learning autonomously; } \\
\text { 3. Consultations about grammar was regarded the most helpful when } \\
\text { students were to take charge of their own learning. }\end{array}$ \\
\hline 117 & $\begin{array}{l}\text { Wisaijorn \& } \\
\text { Tremayne } \\
(2008)\end{array}$ & $\begin{array}{l}\text { Thailand } \\
\text { (Tertiary) }\end{array}$ & $\begin{array}{l}\text { Language } \\
\text { (English) }\end{array}$ & $\begin{array}{l}\text { To investigate Thai students' attitudes } \\
\text { towards learner autonomy and self- } \\
\text { directed learning methods }\end{array}$ & 691 students & Questionnaire & $\begin{array}{l}\text { 1. Students displayed positive attitudes towards learner autonomy and } \\
\text { self-directed learning methods; } \\
\text { 2. Students were dissatisfied with traditional classrooms and expressed a } \\
\text { strong desire to be exposed in different ways of learning. }\end{array}$ \\
\hline 118 & $\begin{array}{l}\text { Chantarasombat } \\
(2009)\end{array}$ & $\begin{array}{l}\text { Thailand } \\
\text { (Tertiary: } \\
\text { Postgrad) }\end{array}$ & $\begin{array}{l}\text { Education } \\
\text { Management }\end{array}$ & $\begin{array}{l}\text { To examine the management of action } \\
\text { learning process, which is focused on } \\
\text { student-centeredness }\end{array}$ & 148 students & $\begin{array}{l}\text { 1. Course's Supplementary documents } \\
\text { 2. Test result } \\
\text { 3. After Action Record form } \\
\text { 4. Questionnaire }\end{array}$ & $\begin{array}{l}\text { 1. Students were highly satisfied with the course. The satisfaction results } \\
\text { from the student-centered approach ; familiarity with the course' } \\
\text { content; teachers' factors such as their temperament, good intention, } \\
\text { pedagogical style; } \\
\text { 2. For the action learning where student-centeredness as a key to be } \\
\text { effective, teachers need to study how to manage this process in order to } \\
\text { have a thorough understanding of all steps to be taken. }\end{array}$ \\
\hline 119 & $\begin{array}{l}\text { James } \\
\text { (2009) }\end{array}$ & $\begin{array}{l}\text { Thailand } \\
\text { (Tertiary) }\end{array}$ & $\begin{array}{l}\text { Subject area } \\
\text { not specified }\end{array}$ & $\begin{array}{l}\text { To explore students' experience of m- } \\
\text { Learning at a university in Bangkok }\end{array}$ & Students) & Focus group interview & $\begin{array}{l}\text { 1. Students preferred media that they could use to work with their } \\
\text { friends; } \\
\text { 2. Technological constraints might prevent students from } \\
\text { engaging in m-learning. If these constraints are minimized, } \\
\text { m-learning may become more widely used. }\end{array}$ \\
\hline 120 & $\begin{array}{l}\text { Maneekhao \& } \\
\text { Tepsuriwong } \\
\text { (2009) }\end{array}$ & $\begin{array}{l}\text { Thailand } \\
\text { (Tertiary) }\end{array}$ & $\begin{array}{l}\text { Language } \\
\text { (English) }\end{array}$ & $\begin{array}{l}\text { To examine students' opinion on the use of } \\
\text { ELLIS program in their English class }\end{array}$ & 140 students & Questionnaire & $\begin{array}{l}\text { 1. Though ELLIS contained features that facilitated the development of } \\
\text { learner autonomy, its successful implementation still depended on } \\
\text { sufficient training for students, guidance and teachers' support; } \\
\text { 2. Most of the students were extrinsically motivated to use the ELLIS, as } \\
\text { they wanted good grade and were required by the course's instructor. }\end{array}$ \\
\hline
\end{tabular}




\begin{tabular}{|c|c|c|c|c|c|c|c|}
\hline 121 & $\begin{array}{l}\text { Klunklin, } \\
\text { Viseskul, } \\
\text { Sripusanapan, } \\
\text { \& Turale } \\
(2010)\end{array}$ & $\begin{array}{l}\text { Thailand } \\
\text { (Tertiary) }\end{array}$ & $\begin{array}{l}\text { Nursing } \\
\text { education }\end{array}$ & $\begin{array}{l}\text { - To examine the extent to which nursing } \\
\text { students at CMU (Chiang Mai University) } \\
\text { were ready for self-directed learning } \\
\text { - To explore the differences in self-directed } \\
\text { learning among students from different } \\
\text { years of education }\end{array}$ & 272 students & $\begin{array}{l}\text { Survey } \\
\text { 1. Demographic data questionnaire } \\
\text { 2. Guglielmino's Self Directed Learning } \\
\text { Readiness Scale (SDLRS) }\end{array}$ & 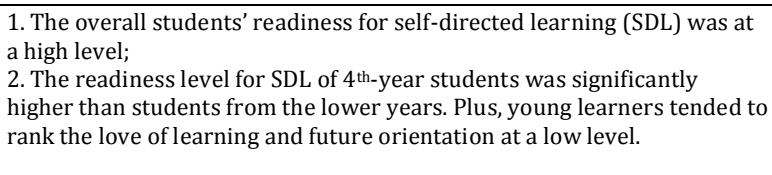 \\
\hline 122 & $\begin{array}{l}\text { Sanprasert } \\
(2010)\end{array}$ & $\begin{array}{l}\text { Thailand } \\
\text { (Tertiary) }\end{array}$ & $\begin{array}{l}\text { Language } \\
\text { (English) }\end{array}$ & $\begin{array}{l}\text { - To investigate the extent to which a } \\
\text { blended learning (BL)situation is able to } \\
\text { change students' learning habits and their } \\
\text { perception of learning in relation to } \\
\text { autonomous learning } \\
\text { (a blended learning situation in this study } \\
\text { was referred to learning in which a course } \\
\text { management system was integrated into a } \\
\text { traditional face-to-face classroom) }\end{array}$ & 100 students & $\begin{array}{l}\text { Mixed-method approach } \\
\text { 1. Quantitative questionnaire survey } \\
\text { 2. Qualitative examination of students' journals }\end{array}$ & $\begin{array}{l}\text { 1. BL was able to promote autonomous learning skills, as students in the } \\
\text { experimental group became more independent and confident, and took } \\
\text { more control of their learning; } \\
\text { 2. Though there were changes in students' learning practices and } \\
\text { perception of their own roles as learners, there was no change in ways } \\
\text { they perceived their teachers, that is teachers were stilled viewed as } \\
\text { playing the central role in their learning }\end{array}$ \\
\hline
\end{tabular}




\section{Appendix B: Letter Requesting Permission from Deans}

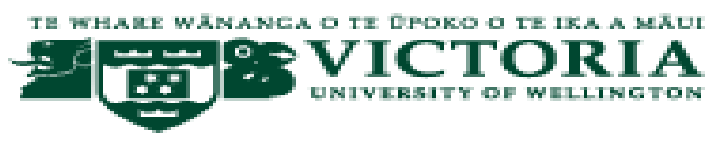

วันที่ ธันวาคม พ.ศ. 2552

เรื่อง ขออนุญาตแจกแบบสอบถามแก่อาจารย์เพื่อเป็นข้อมูลการทำวิจัย

เรียน

ด้วยข้าพเจ้านางสาวปิยวรรณ รุ่งวรพงศ์ อาจารย์ประจำภาควิชาภาษาต่างประเทศ

คณะพาณิชยศาสตร์และการจัดการ มหาวิทยาลัยสงขลานครินทร์ วิทยาเขตตรัง ปัจจุบันกำลังศึกษาต่อระดับปริญูญาเอก ใน

\section{School of Educational Psychology and Pedagogy, Faculty of Education ณ}

Victoria University of Wellington มีความประสงค์ เก็บข้อมูล เพื่องานวิจัยชื่อ Learner

Autonomy in Thailand Tertiary Education: Perspectives and Practices

ซึ่งเป็นงานวิจัยระดับปริญญาเอก ของข้าพเจ้า โดยงานวิจัยชิ้นนี้มุ่งเน้นศึกษาเรื่องการสนับสนุน Learner

Autonomy ในการเรียนการสอนภาษาต่างประเทศใน การศึกษาระดับอุดมศึกษาของประเทศไทย

โดยวัดว่ามีการสนับสนุน ให้ผู้เรียนมี Autonomy มากน้อยเพียง ใดและมีกลวิธีหรือ แนวการสอน

หรือดำเนินกิจกรรมในการเรียนการสอนอย่างไร ที่จะเอื้อให้ผู้เรียนมี Autonomy การวิจัยจะเก็บข้อมูลโดย

แบบสอบถาม โดยกลุ่มเป้าหมายคืออาจารย์ชาวไทย

ที่สอนภาษาต่างประเทศในมหาวิทยาลัยต่างๆ

ในการนี้ข้าพเจ้าจึงเรียนมาเพื่อขอความอนุเคราะห์จากท่านได้ไปรดพิจารณาอนุญาตให้ข้าพเจ้าดำเนินการแจก แบบสอบถามให้แก่อาจารย์ชาวไทยซึ่งสอนภาษาต่างประเทศในคณะ/สถาบันของท่าน ข้อมูลต่างๆในแบบสอบถาม รวมถึงในการตีพิมพ์ผลการวิจัยทั้งในวิทยานิพนธ์หรือวารสารวิชาการต่างๆจะไม่มีการระบุตัวผู้ตอบและสถานศึกษาที่ผู้ตอบสั งกัดอยู่ โครงการวิจัยนี้ได้รับการตรวจสอบและอนุญาตโดย Victoria University Faculty of Education Ethics Committee (Application: RM16870)

หากท่านมีข้อสงสัยใดๆเกี่ยวกับโครงการวิจัยหรือตัวข้าพเจ้าท่านสามารถสอบถามข้อมูลเพิ่มเติมได้ทั้งจากตัวข้าพเจ้า หรือจากอาจารย์ที่ปรึกษาของข้าพเจ้า 


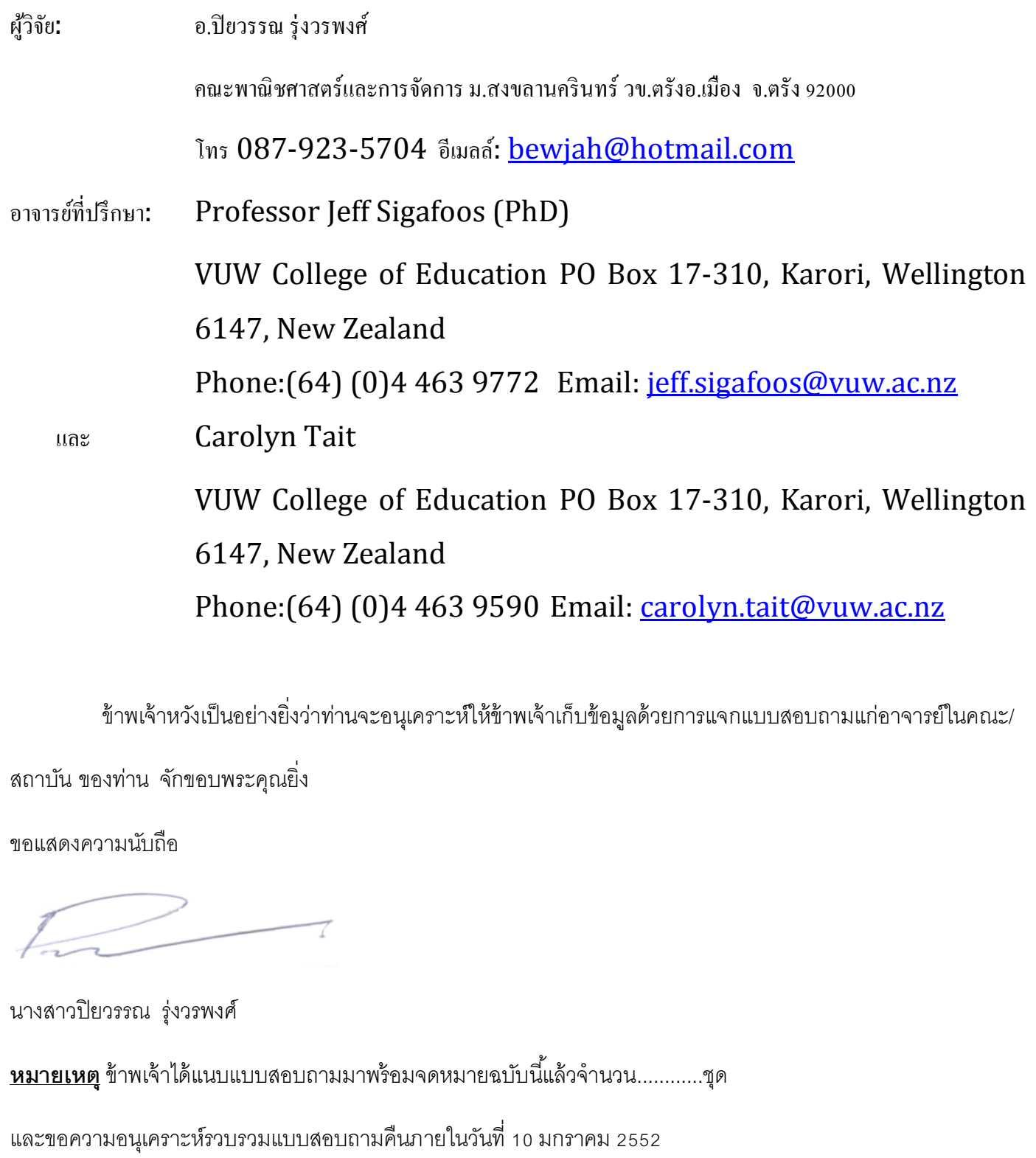

นางสาวปิยวรรณ รุ่งวรพงศ์

หมายเหตุ ข้าพเจ้าได้แนบแบบสอบถามมาพร้อมจดหมายฉบับนี้แล้วจำนวน............ศุด

และขอความอนุเคราะห์รวบรวมแบบสอบถามคืนภายในวันที่ 10 มกราคม 2552 
Appendix C: Questionnaire by Cotterall (1999)

WHAT IS IMPORTANT TO YOU IN LANGUAGE LEARNING?

PART ONE

Below is a list of beliefs that people have about language learning.

Please show how much you agree or disagree with those beliefs by circling the number which matches your answer.

Strongly Agree Agree Undecided Disagree Strongly Disagree

$\begin{array}{lllll}1 & 2 & 3 & 4 & 5\end{array}$

$\begin{array}{lllllllllll}1 & & 1 & \text { I believe that the role of the } & 1 & 1 & 1 & 2 & 1 & 1 & 5\end{array}$ teacher is to tell me what to do.

$\begin{array}{lllllllllll}2 & 2 & \text { I believe I know how to find } & 2 & 1 & 2 & 2 & 2 & 3 & 5\end{array}$ my own ways of practising.

$\begin{array}{lllllllllll}4 & 3 & \text { I am confident about finding } & 3 & 1 & 3 & 2 & 3 & & 5 & 5\end{array}$ my own ways of practising.

$\begin{array}{llllllllllll}6 & 4 & \text { I } \text { am willing to find my own } & 4 & 1 & 4 & 2 & 4 & 7 & 5\end{array}$ ways of practising if I get help.

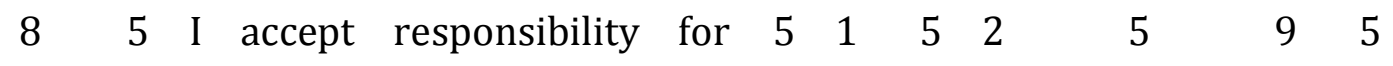
finding my own ways of practising.

$\begin{array}{llllllllll}1 & 6 & \text { I believe that the role of the } & 6 & 1 & 6 & 2 & 6 & 11 & 5\end{array}$ teacher is to help me learn effectively.

$\begin{array}{lllllllllllllll}1 & 7 & \text { I } & \text { believe } & \text { that } & \text { I } & \text { can } & 7 & 1 & 7 & 2 & & 7 & 13 & 5\end{array}$ communicate in English without knowing the rules.

$\begin{array}{lllllllllll}1 & & 8 & \text { I believe that all people learn } & 8 & 1 & 8 & 2 & 8 & 15 & 5\end{array}$ languages in the same way.

$\begin{array}{lllllllllll}1 & 9 & \text { I believe I know how to check } & 9 & 1 & 9 & 2 & 9 & 17 & 5\end{array}$ my work for mistakes. 
$1 \quad 10$ I am confident about checking $\quad \begin{array}{lllllll}10 & 1 & 10 & 2 & 10 & 19 & 5\end{array}$ my work for mistakes.

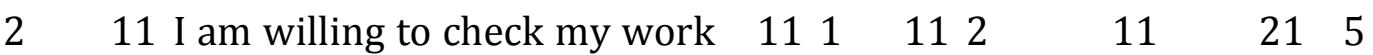
for mistakes.

$\begin{array}{lllllll}6 \mathrm{~d} & \text { I accept responsibility for checking } & 1 & 2 & 3 & 4 & 5\end{array}$ my work for mistakes.

1 I believe that the role of

$\begin{array}{llllll}1 & 2 & 1 & 3 & 1 & 1\end{array}$
the teacher is to tell me what progress I am making.

For this question tick the box (Yes or No)

Do you believe you have the ability to learn a language successfully?
Yes
$\square$ No

For this question place a cross on the line in the place which shows how confident you are about your answer to the question

How confident are you that you have the ability to learn a language successfully?

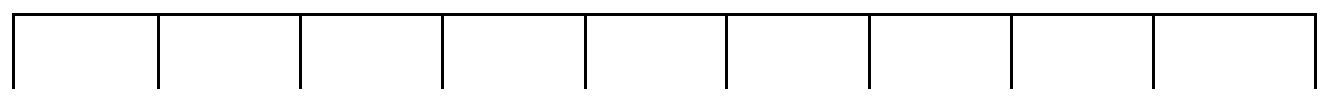

Not at all confident

Extremely confident 
Please show how much you agree or disagree with the beliefs below by circling the number which matches your answer.

$\begin{array}{lllll}\begin{array}{l}\text { Strongly } \\ \text { Agree }\end{array} & \text { Agree } & \text { Undecided } & \text { Disagree } & \begin{array}{l}\text { Strongly } \\ \text { Disagree }\end{array} \\ 1 & & 3 & 4 & 5\end{array}$

11 I believe I know how to

$\begin{array}{lllll}1 & 1 & 1 & 4 & 5\end{array}$ explain what I need English for.

2

I am confident about explaining what I need English for.

2 I am willing to explain what I need English for if I get help.

4

3 I accept responsibility for explaining what I need English for. at language learning. knows best how well I am learning. identify my strengths and weaknesses as a language learner. identifying my strengths and weaknesses as a language learner. 
strengths and weaknesses

as a language learner if I get help.

12 I accept responsibility for identifying

d my strengths and weaknesses as a language learner.

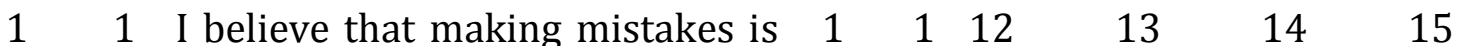
harmful in language learning.

\section{For this question tick the box (Yes or No)}

Do you believe you have the ability to write accurately in English?

Yes

$\square$ No

For this question place a cross on the line in the place which shows how confident you are about your answer to the question

How confident are you that you have the ability to write accurately in English?

Not at all confident

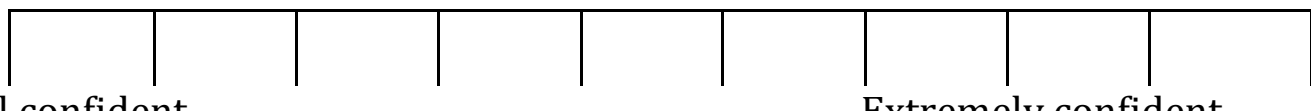

Extremely confident

Please show to what extent you agree or disagree with the beliefs below by circling the number which matches your answer.

$\begin{array}{lllll}\begin{array}{l}\text { Strongly } \\ \text { Agree }\end{array} & \text { Agree } & \text { Undecided } & \text { Disagree } & \begin{array}{l}\text { Strongly } \\ \text { Disagree }\end{array} \\ 1 & & 3 & & 5\end{array}$

$\begin{array}{lllllll}1 & 1 \text { I believe that the role of the teacher } & 11 & 12 & 13 & 14 & 5\end{array}$ is to say what my difficulties are.

2a $\quad$ 2I believe I know how to ask for help $\begin{array}{llllll}21 & 22 & 23 & 24 & 5\end{array}$ when I need it. 
$\begin{array}{lllllll}31 & 3 \text { I am confident about asking for help } & 31 & 32 & 33 & 34 & 5\end{array}$

$6 \mathrm{~b} \quad$ when I need it.

$\begin{array}{lllllll}41 & 4 \mathrm{I} \text { am willing to ask for help when I } & 41 & 42 & 43 & 44 & 5\end{array}$

6c need it.

$\begin{array}{lllllll}51 & 5 \text { I accept responsibility for asking for } & 51 & 52 & 53 & 54 & 5\end{array}$

6d help when I need it.

$\begin{array}{lllllll}6 & 6 \mathrm{I} \text { believe it is possible to learn a } & 61 & 62 & 63 & 64 & 5\end{array}$ language in a short time.

$\begin{array}{llllllll}\text { 7a } & \text { 7I believe I know how to set my own } & 71 & 72 & 73 & 74 & 5\end{array}$ learning goals.

$\begin{array}{lllllllll}81 & \text { 8I am confident about setting my } & 81 & 82 & 83 & 84 & 5\end{array}$

$8 \mathrm{~b}$ own learning goals.

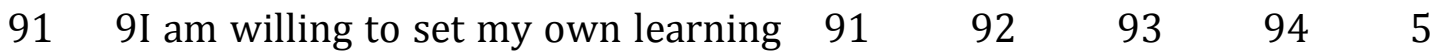

8c goals if I get help.

$\begin{array}{lllllll}18 & \text { I accept responsibility for setting my } & 1 & 2 & 3 & 4 & 5\end{array}$

d own learning goals.

\section{For this question tick the box (Yes or No)}

1a Do you believe you have the ability to get the score you are trying for in your next English test?

Yes

$\square$ No

For this question place a cross on the line in the place which shows how confident you are about your answer to the question

19b How confident are you that you have the ability to get the score you are trying for in your next English test?

Not at all confident

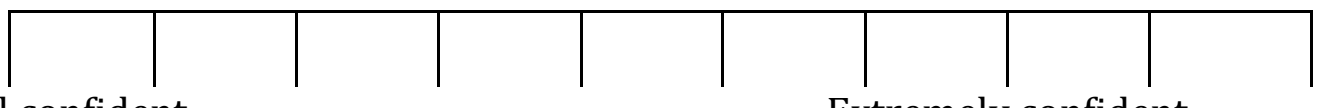

Extremely confident 
Please show to what extent you agree or disagree with the beliefs below by circling the number which matches your answer.

$\begin{array}{lllll}\begin{array}{l}\text { Strongly } \\ \text { Agree }\end{array} & \text { Agree } & \text { Undecided } & \text { Disagree } & \begin{array}{l}\text { Strongly } \\ \text { Disagree }\end{array} \\ 1 & & & & 5\end{array}$

$\begin{array}{lllllll}\text { 1a } 1 \text { I believe I know how to plan my } & 11 & 12 & 13 & 14 & 5\end{array}$ learning.

$\begin{array}{lllllll}22 & \text { 2I am confident about planning my } & 21 & 22 & 23 & 24 & 5\end{array}$

$0 \mathrm{~b}$ learning.

$\begin{array}{lllllll}32 & 3 \mathrm{I} \text { am willing to plan my learning if I } & 31 & 32 & 33 & 34 & 5\end{array}$

0c get help.

$\begin{array}{llllllll}42 & \text { 4I accept responsibility for planning } & 41 & 42 & 43 & 44 & 5\end{array}$

od my learning.

$\begin{array}{lllllllll}5 & 5 \mathrm{I} \\ \end{array}$ evaluated by others is scary.

$\begin{array}{lllllll}6 & 6 \mathrm{I} \text { believe that the role of the teacher } & 61 & 62 & 63 & 64 & 5\end{array}$ is to create opportunities for me to practise.

$\begin{array}{llllllll}7 & 7 \mathrm{I} & \text { believe that language learning } & 71 & 72 & 73 & 74 & 5\end{array}$ takes a long time.

$\begin{array}{lllllll}8 & \text { 8I believe that the role of the teacher } & 81 & 82 & 83 & 84 & 5\end{array}$ is to decide how long I spend on activities.

$\begin{array}{lllllllll}9 & 9 \mathrm{I} \text { believe that I need to know } & 91 & 92 & 93 & 94 & 5\end{array}$ language rules before I can communicate in English.

$\begin{array}{lllllll}10 & 10 \mathrm{I} \text { believe that I am above average } & 101 & 102 & 103 & 104 & 5\end{array}$ at language learning. 
$\begin{array}{llllllll}11 & 11 \mathrm{I} & \text { believe that different people } & 111 & 112 & 113 & 114 & 15\end{array}$ learn languages in different ways.

\section{For this question tick the box (Yes or No)}

Do you believe you know how to find an effective way to learn English?

Yes

$\square$ No

For this question place a cross on the line in a place which shows how confident you are about your answer to the question

28b How confident are you that you know how to find an effective way to learn English?

Not at all confident

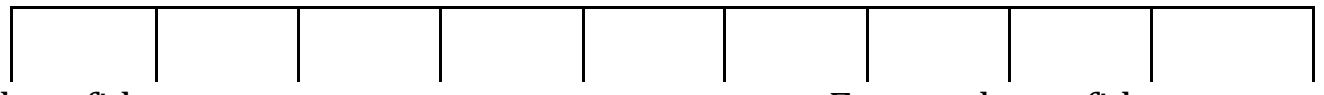

Extremely confident

Please show to what extent you agree or disagree with the beliefs below by circling the number which matches your answer.

$\begin{array}{lllll}\begin{array}{l}\text { Strongly } \\ \text { Agree }\end{array} & \text { Agree } & \text { Undecided } & \text { Disagree } & \begin{array}{l}\text { Strongly } \\ \text { Disagree }\end{array} \\ 1 & 2 & 3 & 4 & 5\end{array}$

$\begin{array}{lllllll}1 & 1 \text { I believe that the role of the teacher } & 11 & 12 & 13 & 14 & 5\end{array}$

is to explain why we are doing an

activity.

$\begin{array}{lllllll}2 & \text { 2I believe that making mistakes is a } & 21 & 22 & 23 & 24 & 5\end{array}$ natural part of language learning.

$\begin{array}{lllllllll}3 & 3 \mathrm{I} & \text { believe that having my work } & 31 & 32 & 33 & 34 & 5\end{array}$

evaluated by others is helpful.

$\begin{array}{lllllll}4 & \text { 4I believe that the role of the teacher } & 41 & 42 & 43 & 44 & 5\end{array}$

is to set my learning goals.

$\begin{array}{lllllll}5 & 5 \text { I believe that the role of the teacher } & 51 & 52 & 53 & 54 & 5\end{array}$ is to give me regular tests. 

am learning.

$\begin{array}{lllllll}7 & \text { 7I believe that the role of the teacher } & 71 & 72 & 73 & 74 & 5\end{array}$ is to offer help to me.

$\begin{array}{llllllllll}\text { 8a } & \text { 8I believe that I know how to } 81 & 82 & 83 & 84 & 5\end{array}$ measure my language learning progress.

$\begin{array}{lllllll}93 & 9 \text { I am confident about measuring my } & 91 & 92 & 93 & 94 & 5\end{array}$

6b language learning progress.

$\begin{array}{lllllllll}103 & 10 \mathrm{I} & \mathrm{am} & \text { willing to measure my } & 101 & 102 & 103 & 104 & 5\end{array}$

6c language learning progress if I get help.

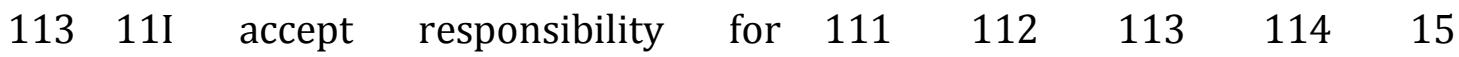

6d measuring my language learning progress.

\section{PART TWO}

Please rank the three beliefs under each heading according to how important each belief is to you. Write number (1) in the box next to the belief which is most important to you; write number (2) in the box next to the belief which is next most important and write number (3) in the box next to the belief which is least important to you.

\section{Feedback}

I believe feedback on my language learning that I give myself helps me most.

I believe feedback on my language learning from the teacher helps me most.

I believe feedback on my language learning from other people helps me most. 


\section{Opportunities to use the language}

I believe that opportunities to use the language should be provided by my classmates.

I believe that I should find my own opportunities to use the language.

$\square \quad$ I believe that opportunities to use the language should be provided by the teacher.

\section{Tactics}

I believe I can find for myself the best ways to learn a language.

I believe my classmates can show me the best ways to learn a language.

I believe the teacher can teach me the best ways to learn a language.

\section{Teacher}

I believe the teacher should be an expert at teaching language.

I believe the teacher should be an expert at learning languages.

I believe the teacher should be an expert at showing students how to learn.

\section{Effort}

I believe my language learning success depends on what I do outside the classroom.

$\square \quad$ I believe my language learning success depends on what I do in the classroom.

$\square \quad$ I believe my language learning success depends on what my classmates do in the classroom.

I believe my language learning success depends on what the teacher does in the classroom.

Now rank the following beliefs according to how important each is to you. Write number (1) in the box beside the belief which is most 
important to you; write number (2) in the box beside the belief which is next most important and so on until you have used up all the numbers (1-5).

Feedback plays an important role in successful language learning

Opportunities to use the language play an important role in successful language learning

Practice plays an important role in successful language learning.

The language teacher plays an important role in successful language learning.

$\square \quad$ My own effort plays an important role in successful language learning.

\section{PART THREE}

What kind of learner are you? The sentences below describe three types of learner. Which type describes you best? Please write number (1) in the box next to the group which describes you best; write number (2) in the box next to the group which describes you next best, and write number (3) in the box next to the group which describes you least.

Learners who like to learn with other people.

Learners who like to learn with a teacher.

Learners who like to decide for themselves how and what they learn.

Now draw three circles of different sizes to show the relationship between the three types of people mentioned above. The circles can be separate from each other or they can touch. Label your diagram clearly. THERE IS NO RIGHT ANSWER. 


\section{PART FOUR}

A friend of yours has just written to you to say that he/she plans to start learning English at a language school in Australia next year. Write him/her a short letter giving some advice about how he/she should use the language school and other opportunities to learn English as effectively as possible.

\section{Wellington}

November 14, 1994

Dear 


\section{Appendix D: Survey Questionnaire}

The questionnaire contains two parts and 56 items. Please answer every question. Indicate your answer to each question by filling in the information or marking the responses that matches best your own experiences.

\section{Part 1: Demographic information}

Please indicate your answer to each question by filling in the information or marking $(\checkmark)$ the responses that matches best your own experiences.

1. What is your gender?

$\bigcirc$ Male $\quad$ Female

2. How old are you?
Under 30
31-39
40-49
50 up

3. What is the highest level of education you completed? (Mark one)

$\bigcirc$ Bachelor's degree $\quad$ Master's degree

$\bigcirc$ Doctoral degree $\quad \bigcirc$ Other: (please specify)

4. What did you study in your bachelor degree?

$\bigcirc$ Arts

$\bigcirc$ Education

$\bigcirc$ Humanities

$\bigcirc$ Other: (please specify)

5. Where did you complete your bachelor degree?

$\bigcirc$ In Thailand $\quad \bigcirc$ Overseas

6. How many years have you been in teaching profession?
1-5
6-10
11-15
○ $16-20$
$\bigcirc 21$ up

7. Where are you teaching at the moment? (Mark only where you work full time)

$\bigcirc$ In a government university/institution

$\bigcirc$ In a private university/institution

$\bigcirc$ Other: (please specify)

8. Which of the following choice best describe where you are teaching?

$\bigcirc$ In Bangkok and its vicinities $\bigcirc$ In a city $\bigcirc$ In a small town 
9. What faculty/department are you in?
$\bigcirc$ Arts
$\bigcirc$ Education
$\bigcirc$ Language center/institute
$\bigcirc$ Humanities and Social Sciences
$\bigcirc$ Other: (please specify)

10. What language(s) do you teach? (Mark all that apply)
$\bigcirc$ English
Spanish
$\bigcirc$ Germany
OJapanese
$\bigcirc$ Korean
$\bigcirc$ Chinese
$\bigcirc$ Other: (please specify)

\section{Professional information}

The statements below include examples of beliefs, confidence and practice in classroom. They concern the strategies-related dimensions of learning as well as assessment and feedback. Please circle the extent to which you as a language lecturer agree or disagree with each of the following statement.

$$
\begin{array}{ll}
1 & =\text { strongly disagree } \\
2 & =\text { disagree } \\
3 & =\text { neutral } \\
4 & =\text { agree } \\
5 & =\text { strongly agree }
\end{array}
$$

11. I believe that students should know how to find their own ways of practising their language skills.

12. I believe students need to set their own goals for learning another language.

13. I give my students opportunities to measure their language learning progress.

14. I am confident that my students are able to evaluate their own work.

15. In my class, the length of time for an activity is decided by students.

16. I am confident that my students can identify the purpose of doing activities. 
17. I believe that the length of time for an activity should be decided by students.

18. I am confident that my students can set their own goals for learning another language.

$\begin{array}{lllll}1 & 2 & 3 & 4 & 5\end{array}$

19. I allow my students to learn from their own mistakes.

$\begin{array}{lllll}1 & 2 & 3 & 4 & 5\end{array}$

20. I am confident that my students know how to identify their strengths and weaknesses as a $\begin{array}{llllll}1 & 2 & 3 & 4 & 5\end{array}$ language learner.

21. I believe that test results should be viewed as a way for students to monitor their own learning

$\begin{array}{lllll}1 & 2 & 3 & 4 & 5\end{array}$

22. I am confident that my students can effectively use learning strategies in their language learning.

$\begin{array}{lllll}1 & 2 & 3 & 4 & 5\end{array}$

23. I believe that successful language learning is an inborn ability.

24. I am confident that my students are able to find out their own effective ways of practising their language $\begin{array}{lllll}1 & 2 & 3 & 4 & 5\end{array}$ skills

25. I am confident that my students are able to plan their learning.

$\begin{array}{lllll}1 & 2 & 3 & 4 & 5\end{array}$

26. I am confident that my students can make appropriate choices to fit their learning needs.

$\begin{array}{lllll}1 & 2 & 3 & 4 & 5\end{array}$

27. I give my students opportunities to find out their own ways of practicing their language skills.

$\begin{array}{lllll}1 & 2 & 3 & 4 & 5\end{array}$

28. I believe that students should know how to identify their strengths and weaknesses as a language $\begin{array}{llllll}1 & 2 & 3 & 4 & 5\end{array}$ learner.

29. I believe that students should evaluate their own work.

$\begin{array}{lllll}1 & 2 & 3 & 4 & 5\end{array}$

30. I encourage my students to identify their strengths and weaknesses as a language learner. 
31. I provide opportunities for my students to select from a variety of learning activities.

$\begin{array}{lllll}1 & 2 & 3 & 4 & 5\end{array}$

32. I believe that training about learning strategies is really helpful for students.

$\begin{array}{lllll}1 & 2 & 3 & 4 & 5\end{array}$

33. I believe that students should know how to plan their learning.

34. I allow my students to set their own goals for learning another language.

$\begin{array}{lllll}1 & 2 & 3 & 4 & 5\end{array}$

$\begin{array}{lllll}1 & 2 & 3 & 4 & 5\end{array}$

35. I am confident my students are able to use test results to monitor their own learning.

36. I give opportunities for students to use test results to make decisions about their learning.

$\begin{array}{lllll}1 & 2 & 3 & 4 & 5\end{array}$

$\begin{array}{lllll}1 & 2 & 3 & 4 & 5\end{array}$

37. I am confident that my students are able to effectively measure their language learning progress.

$\begin{array}{lllll}1 & 2 & 3 & 4 & 5\end{array}$

38. I give my students opportunities to evaluate their own work.

$\begin{array}{lllll}1 & 2 & 3 & 4 & 5\end{array}$

39. I am confident that my students are able to effectively decide how much they need to spend on $\begin{array}{lllll}1 & 2 & 3 & 4 & 5\end{array}$ an activity.

40. I believe that teachers should provide a choice of activities for students.

$\begin{array}{lllll}1 & 2 & 3 & 4 & 5\end{array}$

41. I give my students opportunities to use their own learning strategies in their language learning.

$\begin{array}{lllll}1 & 2 & 3 & 4 & 5\end{array}$

42. I am confident that my students can learn from their own mistakes.

$\begin{array}{lllll}1 & 2 & 3 & 4 & 5\end{array}$

43. I believe students should check their own work for the mistakes

$\begin{array}{lllll}1 & 2 & 3 & 4 & 5\end{array}$

44. I give my students opportunities to plan their learning.

$\begin{array}{lllll}1 & 2 & 3 & 4 & 5\end{array}$

45. I believe that students should know how to measure their language learning progress.

$\begin{array}{lllll}1 & 2 & 3 & 4 & 5\end{array}$ 
46. I am confident that my students can check their work for mistakes

47. I give my students opportunities to understand the purpose of doing activities.

$\begin{array}{lllll}1 & 2 & 3 & 4 & 5\end{array}$

48. I believe that students can learn from their own mistakes.

$\begin{array}{lllll}1 & 2 & 3 & 4 & 5\end{array}$

49. I believe that students should identify the purpose of doing activities.

$\begin{array}{lllll}1 & 2 & 3 & 4 & 5\end{array}$

50. I believe that students need to know language grammar before they can communicate in that $\begin{array}{rrrrr}1 & 2 & 3 & 4 & 5\end{array}$ language.

51. I believe that different people learn language in different ways.

$\begin{array}{lllll}1 & 2 & 3 & 4 & 5\end{array}$

52. I give opportunities for my students to check their work for mistakes

$\begin{array}{lllll}1 & 2 & 3 & 4 & 5\end{array}$

53. I believe that making mistake is a natural part in language learning

The questions below explore your daily practice and experience in relation to your teaching. Please answer questions by ticking the box(s) or filling in the information.

54. At the outset of your courses, do you do any of the following activities? (Mark all that apply)

O Yes, I ...

Train students about learning strategies

Give students orientation about the course

O Hold a workshop for students about how to learn

Find out what students expect from the course (by questionnaire, interview, dialogue etc.) 
Find out students' attitudes or beliefs related to language learning (by questionnaire, interview, dialogue etc.)

Analyze students' needs (by questionnaire, interview, dialogue etc.)

Other: (please specify)

O No, I do not do any of the above activities.

55. Apart from quizzes, tests, formal mid-term and final examination, how often do you encourage your students to assess themselves in relation to their language learning?

56. What outside-class activity do you most encourage students to do in order to practice their language? (List one activity) 


\title{
Appendix E: Information Sheet and Consent Form for Survey
}

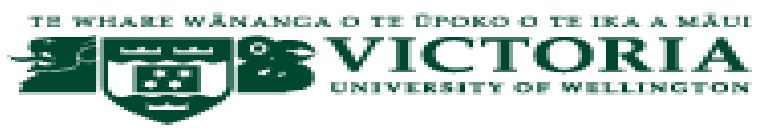

\section{Victoria University of Wellington, New Zealand \\ School of Educational Psychology and Pedagogy, Faculty of Education}

\author{
Information sheet for lecturer participation in a survey of \\ "Learner Autonomy in Thailand Tertiary Education: Perspectives and \\ Practices" \\ Researcher: Piyawan Rungwaraphong
}

Dear Sir or Madam,

My name is Piyawan Rungwaraphong and I am a PhD student in School of Educational Psychology and Pedagogy, Faculty of Education, Victoria University of Wellington, New Zealand. I am writing to invite you to participate in research by answering a questionnaire.

My research project is entitled "Learner Autonomy in Thailand Tertiary Education: Perspectives and Practices". It is specially focused on the promotion of learner autonomy in university language learning. The research aims to identify the extent to which learner autonomy is promoted and what strategies are employed in that promotion. It is expected to provide insight and a guiding framework for lecturers, university administrators, and educational planners when taking any decisions related to the implementation of learner autonomy.

The questionnaire is being circulated to Thai lecturers of language in universities in Bangkok and the south of Thailand. It should take about 20 minutes to complete. Please be assured that all the information you provide will be kept strictly confidential and you and your university will not be identified in any publications resulting from the research. Access to the data is restricted to my supervisors and myself.

Participation in the research is entirely voluntary and you have the right to withdraw from the research at any stage. If you consent to participate in the research project, please return the attached consent form and completed questionnaire in the enclosed pre-paid enveloped. It would be greatly appreciated if you could complete and return the questionnaire within two weeks. If you would like a summary off the questionnaire findings, please indicate this by circling YES on the consent form.

This application has been approved by the Victoria University College of Education Ethics Committee: Application RM16870. If you have any 
questions about my research, please do not hesitate to contact me or my supervisors.

Researcher: Ms.Piyawan Rungwaraphong

72 Moo 2 Tambol Tamiram

Meung District, Phattalung province Thailand 93000

Phone: 087-923-5704

Email:

piyawan.rungwaraphong@vuw.ac.nz, bewkjah@hotmail.com

Supervisors: Professor Jeff Sigafoos (PhD)

VUW College of Education PO Box 17-310,

Karori, Wellington 6147, New Zealand

Phone:(64) (0)4 4639772

Email jeff.sigafoos@vuw.ac.nz

Carolyn Tait

VUW College of Education PO Box 17-310,

Karori, Wellington 6147, New Zealand

Phone:(64) (0)4 4639590

Email: carolyn.tait@vuw.ac.nz

Thank you for your consideration,

Yours sincerely,

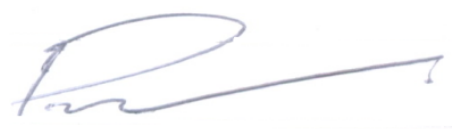

Piyawan Rungwaraphong 


\section{Consent form for lecturer participation in the survey of "Learner Autonomy in Thailand Tertiary Education: Perspectives and Practices"}

Consent form (please tick $\checkmark$ all that apply)

$\square$ I have read the information sheet relating to the purpose and nature of this research project. I have understood this information.

I understand that participation in this study will have no effect on my career.

$\square$ I understand that I may ask any questions about the study at any time during participation.

I agree to participate in this study under the conditions set out in the information sheet.

$\square$ I understand that records of any data from me will be kept confidential and that my identity will not be revealed.

$\square$ I understand that my participation is voluntary and I have the right to withdraw from the research project at any time during participation.

$\square$ I understand that data collection for the survey will finish by January 2010 and all questionnaires will be destroyed 5 years after the conclusion of the research.

Full Name

I wish to receive for feedback from this project by being sent a summary of the research. This will not be available until 2012.

Yes

$\square$ No

Email address

Signature

Date 


\title{
Appendix F: Information Sheet and Consent Form for Cases studies
}

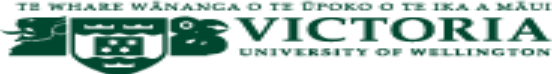 \\ Victoria University of Wellington, New Zealand \\ School of Educational Psychology and Pedagogy, Faculty of Education \\ Information sheet for lecturer participation in a case study of \\ "Learner Autonomy in Thailand Tertiary Education: Perspectives and \\ Practices"
}

Researcher: Piyawan Rungwaraphong

Dear Sir or Madam,

My name is Piyawan Rungwaraphong and I am a PhD student in School of Educational Psychology and Pedagogy, Faculty of Education, Victoria University of Wellington, New Zealand. I am writing to invite you to in a case study of the research.

Before doing the PhD, I was a lecturer of English at Faculty of Commerce and Management, Prince of Songkla University, Trang Campus. The research aims to provide insight and a guiding framework for lecturers, university administrators, and educational planners when taking any decisions related to the implementation of learner autonomy.

The case study phase of the research will involve document analysis, one interview, two classroom observations and two follow-up discussions. The duration of the case study will be approximately two months. The information collected will be strictly confidential with no identifying information used in any publication resulting from the research, including the thesis itself and scholarly journal. Transcriptions of data from the interview and classroom interactions will be returned to you for checking and all interviews notes, observations fieldnotes, transcriptions, records and similar materials will be destroyed 5 years after the conclusion of the research. Participation in the research is entirely voluntary and you have the right to withdraw from the research at any stage.

If you consent to participate in this case study, please return the attached consent form in the enclosed pre-paid enveloped. If you would like a summary off the questionnaire findings, please indicate this by circling YES on the consent form. For further information or any questions about my research, please do not hesitate to contact me or my supervisors. 
Researcher: Ms.Piyawan Rungwaraphong

72 Moo 2 Tambol Tamiram

Meung District, Phattalung province Thailand 93000

Phone: 087-923-5704

Email:

piyawan.rungwaraphong@vuw.ac.nz, bewjah@hotmail.com

Supervisors: Professor Jeff Sigafoos (PhD)

VUW College of Education PO Box 17-310,

Karori, Wellington 6147, New Zealand

Phone:(64) (0)4 4639772

Email jeff.sigafoos@vuw.ac.nz

Carolyn Tait

VUW College of Education PO Box 17-310,

Karori, Wellington 6147, New Zealand

Phone:(64) (0)4 4639590

Email: carolyn.tait@vuw.ac.nz

Thank you for your consideration,

Yours sincerely,

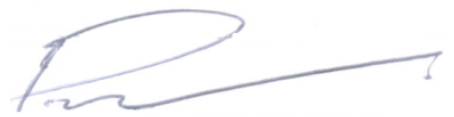

Piyawan Rungwaraphong 


\section{Consent form for lecturer participation in a case study of "Learner Autonomy in Thailand Tertiary Education: Perspectives and Practices"}
Consent form (please tick $\checkmark$ all that apply)
The researcher has discussed the purpose and nature of this research project. I have understood this information.
$\square$ I understand that participation in this study will have no effect on my career.
$\square$ I understand that I may ask any questions about the study at any time during participation.
I agree to participate in this phase of the study under the conditions set out in the information sheet.
$\square$ I understand that the transcriptions of data from the interview and classroom interactions will be returned to me for checking.
$\square$ I understand that all interviews notes, observations fieldnotes, transcriptions, records and similar materials will be kept secure and destroyed 5 years after the conclusion of the research
I understand that records of any data from me will be kept confidential and that my identity will not be revealed.
$\square$ I understand that my participation is voluntary and I have the right to withdraw from the research project at any time during participation.

Full Name

I wish to receive for feedback from this project by being sent a summary of the research. This will not be available until 2012: $\quad \square$ Yes

\section{No}

Email address

Signature

Date 


\section{Appendix G: Interview Protocol}

\section{Interview Protocol \\ Section 1 Past educational experience}

1. How did you see the role of teachers when you were learning a foreign language?

2. When you were a student, were you encouraged from teachers to learn autonomously? In what way?

3. Do you think classroom activities in those days supported you to learn on your own?

4. What were facilities provided in schools that help support students' language learning?

\section{Section 2 Current students}

1. How do you describe your relationship with students?

2. How would you describe your students?

3. When you implement some innovations in your classroom, how do they respond?

4. In what way do your students meet your expectation?

\section{Section 3 Workplace}

1. How much freedom do you have to teach in your preferred style?

2. Describe the teaching style expected from your university.

3. How is your workload at the moment?

4. Apart from teaching, what are other responsibilities that you have to do?

5. How do you regard your duties in additional to teaching?

6. How does your university support your teaching?

7. Are there any supports that you want from your university in relation to language learning and teaching?

8. How does your university support learner autonomy?

\section{Section 4 Thai society, culture and educational system}

1. How do social and cultural contexts affect your teaching profession?

2. How do educational and social contexts in Thailand help or hinder the development of learner autonomy?

3. How do social and cultural contexts limit or facilitate your freedom in teaching?

4. Give example of social and contexts that affect your freedom in teaching. 


\section{Appendix H: Observation Fieldnote}

\section{Observation Field note}

Case:

Course name:

Location:

No. of students registered:

Actual presence:

Begin time:

End time:

Frame: physical setting, activities, teacher-student interaction (pattern, frequency, and direction), and decision-making patterns

Time

Activities/Events

Reflective note:

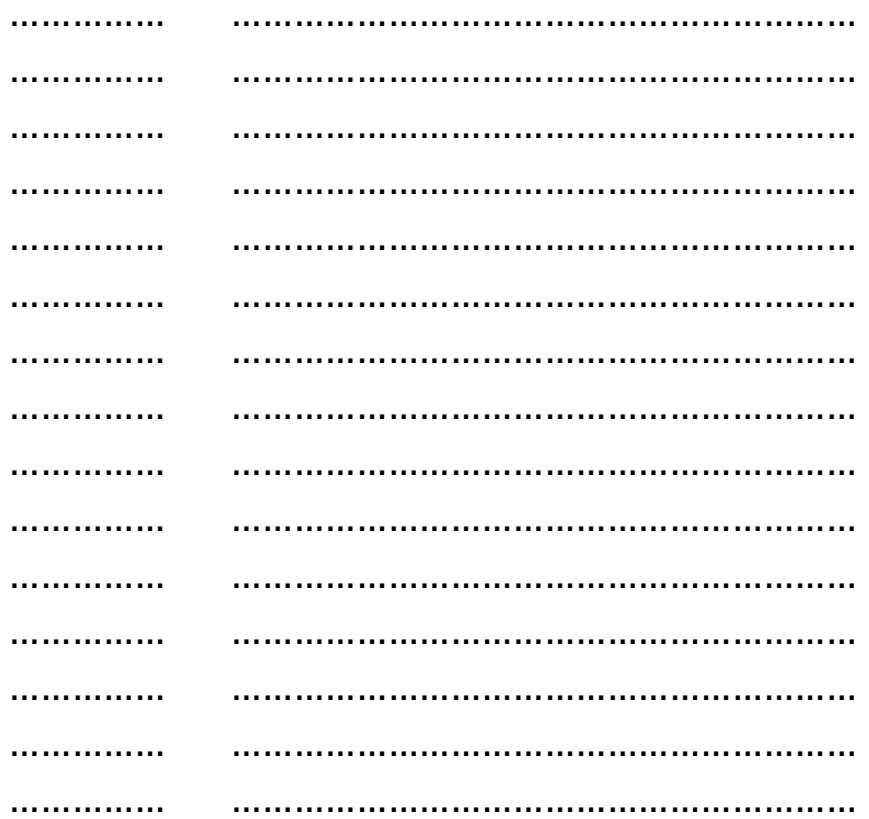

\section{Researcher's comment:}




\section{Appendix I: Document Analysis Worksheet}

1. Participant name:

2. Type of document(Check one):

$\square$ Course syllabus

Textbook

$\square$ Course book

$\square$ Supplementary worksheets

$\square$ Exam paper

$\square$ Book

Quiz/test paper

$\square$ Others

3. Courses name:

4. Designer of the materials (Check one):

$\square$ Commercial

$\square$ The participant

$\square$ The participant and other lecturers

$\square$ Other lecturers

$\square$ Others

5. Number of pages

6. Appearance (colour, thin/thick, colour cover etc.)

7. Content/activities:

8. Note: 